Reactivity of oxygen ions in mixed oxides in dehydrogenation of propane 
Doctoral supervisory committee:

Prof. dr. ir. L. Lefferts, promoter

Dr. I.V. Babich, referent

Dr. H.J.M Bouwmeester

Prof. dr. G. Mul

Prof. dr. ir. A. Nijmeijer

Prof. dr. ir. E.J.M. Hensen

Prof. dr. E. Bordes-Richard
Universiteit Twente

Universiteit Twente

Universiteit Twente

Universiteit Twente

Universiteit Twente

Technische Universiteit Eindhoven

Université de Lille

Cover illustration:

On the front page, scheme of distorted perovskite crystal structure $\left(\mathrm{K}_{2} \mathrm{NiF}_{4}\right.$-type $)$ and picture of Alps mountains. On the back page, view of the city of Turin.

Cover design by S. D. Crapanzano, Ž. Kotanjac and B. Geerdink,

Catalytic Processes and Material (CPM), University of Twente, The Netherlands

Publisher:

Gildeprint, Enschede, The Netherlands

Copyright $@ 2010$ by S. Crapanzano

All rights reserved. No part of this book may be reproduced or transmitted in any form, or by any means, including, but not limited to electronic, mechanical, photocopying, recording, or otherwise, without the prior permission of the author.

ISBN 90-365-3038-5 


\title{
REACTIVITY OF OXYGEN IONS IN MIXED OXIDES IN DEHYDROGENATION OF PROPANE
}

\author{
DISSERTATION \\ to obtain \\ the doctoral degree at the University of Twente, \\ on the authority of the rector magnificus, \\ prof. dr. H. Brinksma, \\ on account of the decision of the graduation committee, \\ to be publicly defended on \\ Friday May $28^{\text {th }}, 2010$ at 13:15
}

by

Salvatore Davide Crapanzano

born on June $28^{\text {th }}, 1977$

in Turin (Italy) 
This manuscript is approved by the promoter:

Prof. dr. ir. L. Lefferts

and the referent:

Dr. ir. I.V. Babich 
"Happiness only real when shared"

Christopher "Supertramp" McCandless 



\section{Content}

1 Introduction 1

$1.1 \quad$ Introduction ................................................... 3

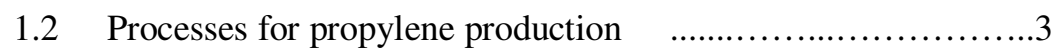

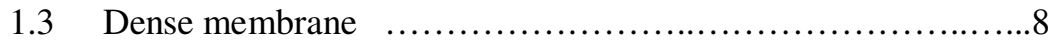

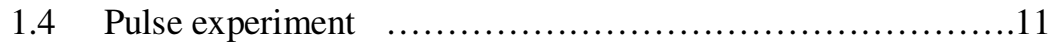

References.......................................................

2 Experimental details 15

$2.1 \quad$ Introduction ............................................ 17

2.2 Materials ................................................... 17

2.3 Catalyst preparation …................................17

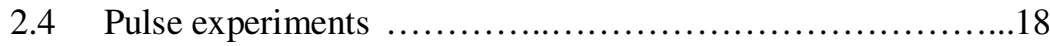

2.5 Catalytic membrane experiments …..........................21

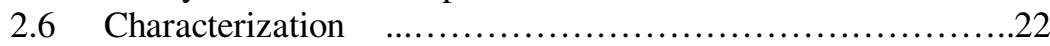

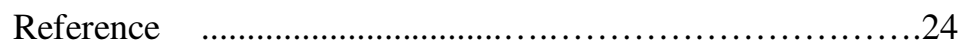

3 Selection of mixed conducting oxides for selective oxidation of propane with dense membranes $\quad 25$

3.1 Introduction ...................................................

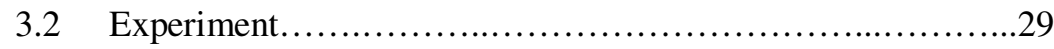

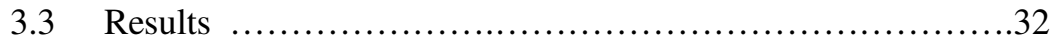

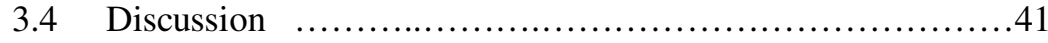

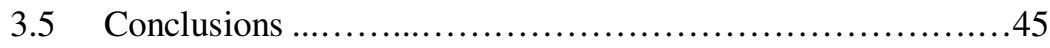

References.....................................................

4 Effect of $\mathrm{V}$ in $\mathrm{La}_{2} \mathrm{Ni}_{\mathrm{x}} \mathrm{V}_{1-\mathrm{x}} \mathrm{O}_{4+\delta}$ on selective oxidative dehydrogenation of propane $\quad 49$

4.1 Introduction..................................................

4.2 Experimental.......................................................

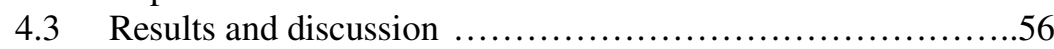

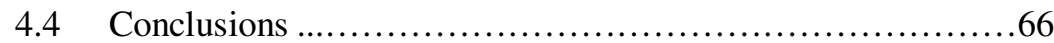

References................................................ 67

5 The effect of $\mathrm{V}$ in $\mathrm{La}_{2} \mathrm{Ni}_{1-\mathrm{x}} \mathrm{V}_{\mathrm{x}} \mathrm{O}_{4+1.5 \mathrm{x}+\delta}$ on selective oxidative dehydrogenation of propane: stabilization of lattice oxygen

$5.1 \quad$ Introduction....................................................

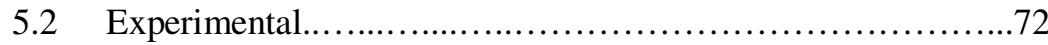

5.3 Results ................................................ 


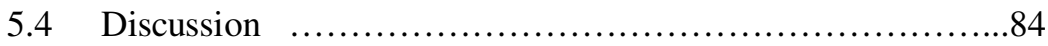

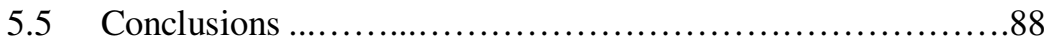

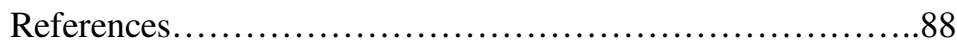

6 The influence of over-stoichiometry in

$\mathrm{La}_{2} \mathrm{Ni}_{0.9} \mathrm{~V}_{0.1} \mathrm{O}_{4.15+\delta}$ on selective oxidative dehydrogenation of propane $\quad 91$

$6.1 \quad$ Introduction ................................................... 93

6.2 Experimental............................................ 96

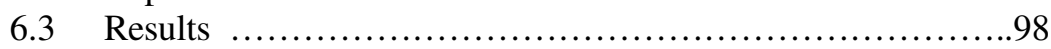

6.4 Discussion ................................................

6.5 Conclusions .............................................. 106

References........................................... 107

7 Selective oxidative dehydrogenation of propane over dense membrane 109

$7.1 \quad$ Introduction ..............................................111

7.2 Experimental............................................ 112

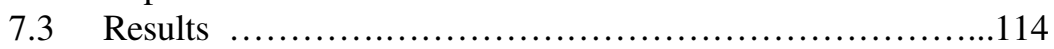

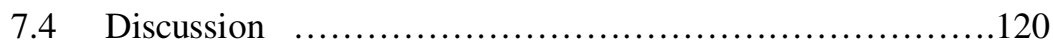

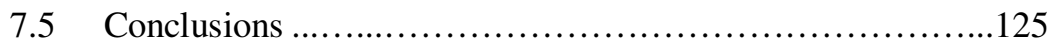

References.........................................126

8 Conclusions and recommendations 129

8.1 Conclusions ..............................................131

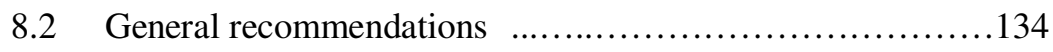

$\begin{array}{ll}\text { Summary } & 137\end{array}$

Samenvatting 141

$\begin{array}{ll}\text { Riassunto } & 145\end{array}$

$\begin{array}{ll}\text { Publications } & 149\end{array}$

Acknowledgements and ringraziamenti 151 


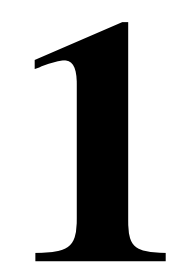

\section{Introduction}

As the demand to propylene is increasing in the last years, new catalytic processes have been study for "on purpose" production of propylene. This is the case of oxidative dehydrogenation of propane which is an attractive process as it does not suffer from thermodynamic limitation and it allows relatively low temperature of reaction, therefore limiting the amount of coke deposition on the catalyst. This introductive chapter will give an overview of the processes currently available for the propylene production, together with a brief description of oxidative dehydrogenation of propane. Additionally, a short discussion of the application of dense membrane as oxygen supplier for the oxidative dehydrogenation of propane will be provided, together with the description of pulse experiment as tool to investigate the variation of the catalytic performance at different oxidation degree. 



\subsection{Introduction}

The total amount of ethylene and propylene consumed in 2005 was 107 and 67 Mton, respectively and the demand of these light olefins is expected to increase in the future because they are a crucial intermediate for many industrial processes [1, 2]. Light olefins are produced mostly in thermal and catalytic crackers using naphtha or, now in increasing extent, using LPG, i.e ethane/propane/butane [3 - 5]. In the case of propylene, a relatively small amount is also produced by catalytic non-oxidative dehydrogenation.

The primary source of propylene is steam cracking in which ethylene is mainly produced and propylene is obtained as side-product. Varying the process condition and feedstock composition, the ratio between ethylene and propylene can be tailored between 1:0.4 to 1:0.75. Considering that the demand of propylene is increasing more than the demand for ethylene, new technology is nowadays required for "on-purpose" production of propylene. For this reason, propane dehydrogenation was widely investigated and it is currently industrially applied. This process is feasible exclusively in location where low cost feedstock is available as it suffers from thermodynamic limitation, high operating temperature and expensive heat exchange operation, which make the overall costs of the process high.

In the next section more detailed description of the above mentioned processes is given based on literature review [6-10].

\subsection{Processes for propylene production}

The processes which are mainly applied in industry for production of propylene can be classified in three groups:

1 - Thermal cracking

2 - Catalytic cracking

3 - Catalytic dehydrogenation.

\subsubsection{Thermal cracking}

The majority of current production of olefins derives from thermal cracking of various petroleum hydrocarbons. The process is commonly called pyrolysis or steam cracking and the main product is ethylene. Propylene, together with limited 
amount of higher olefins, is produced as side-products. The feedstock, mostly naphtha or LPG, together with steam, are heated up in a first cracker reactor at the incipient temperature of $500-680{ }^{\circ} \mathrm{C}$, depending on the feedstock. Secondly, the products of the primary cracking are heated up to $750-875{ }^{\circ} \mathrm{C}$ for $0.1-0.5 \mathrm{~s}$. In this way, smaller molecules as ethylene, propylene and diolefins are obtained. The fact that no catalyst is used in this process is a benefit for the overall cost of the process but, on the other hand, relatively low yield of propylene is usually obtained (lower than $15 \%$ ).

\subsubsection{Catalytic cracking}

Fluid catalytic cracking of heavy oil produces mainly branched alkanes and aromatics which are used as additives for gasoline to increase the octane number, crucial to reduce the chance of spontaneous ignition. Additionally, propylene and ethylene are formed but exclusively as by-products. In this process the catalyst which behaves like a fluid, is mixed with feed and steam and is introduced at the bottom of the riser reactor. During the reaction with hydrocarbon vapours, the catalyst is deactivated because of carbon deposition and needs to be regenerated. Therefore, after being separated from the products in the stripper unit, the catalyst is sent to the fluid bed regenerator in which air is used to combust coke and to generate heat, used for endothermic cracking of hydrocarbons. Subsequently, the catalyst is reintroduced in the reactor and the cracking of hydrocarbons takes place again. This cyclic procedure of reaction - regeneration of the catalyst is repeated continuously. Currently, the most used catalysts are crystalline aluminosilicates (zeolites) but also silica - aluminates were widely used. Catalyst is required to be robust against attrition because it is exposed to high friction during the process.

Recently, petrochemical companies such as Mobil (MOI), Kellog Brown \& Root (SUPERFLEX) and Lurgi (PROPYLUR) achieved to produce propylene as main product (propylene to ethylene ratio of about 2:1), via catalytic cracking of olefinic steams (C4-C5) [11].

\subsubsection{Catalytic dehydrogenation}

Catalytic dehydrogenation of propane (Eq. 1.1) was specifically designed for "onpurpose" production of propylene as, for most of the previously mentioned processes, propylene was only a side-product. This process is based on an endothermic equilibrium reaction (eq. 1.1) which is generally carried out using 
chromia - alumina catalyst. Recently also platinum and modified platinum catalysts have been used successfully.

$\mathrm{C}_{3} \mathrm{H}_{8} \leftrightarrows \mathrm{C}_{3} \mathrm{H}_{6}+\mathrm{H}_{2} \quad \Delta \mathrm{H}=+156 \mathrm{KJ} / \mathrm{mol}$

Eq. 1.1

This process is highly selective but the relatively high temperature used is causing formation of coke, decreasing the yield to olefins and deactivating the catalyst. For this reason, the catalyst needs to be regenerated every 10-100 min by oxidation.

The most important dehydrogenation processes which are industrially used are: CATOFIN from ABB Lummus, OLEFEX from UOP, Fluidized Bed Dehydrogenation (FDB) from Snamprogetti and Steam Active Reforming (STAR) from Phillips Petroleum. The essential differences between these processes are the choice of the catalyst (mainly supported $\mathrm{Cr}$, $\mathrm{Pt}$ and more noble metals), temperature of operation (from 480 to $705{ }^{\circ} \mathrm{C}$ ), pressure (from 1.1 to 8 bars), reactor type (adiabatic or isothermal), number of reactors (from 1 to 8 ) and duration of the cycle (from 25 min to continuous).

\subsubsection{Catalytic oxidative dehydrogenation}

An attractive alternative for propylene production, not yet implemented at industrial scale, is catalytic oxidative dehydrogenation (ODH) of propane [12], as illustrated in eq. 1.2.

$\mathrm{C}_{3} \mathrm{H}_{8}+\mathrm{O}_{2} \leftrightarrows \mathrm{C}_{3} \mathrm{H}_{6}+\mathrm{H}_{2} \mathrm{O}$

$\Delta \mathrm{H}=-86 \mathrm{KJ} / \mathrm{mol}$

Eq. 1.2

The high quantity of heat generated by water formation turns the overall ODH of propane into an exothermic reaction, overcoming the thermodynamic limitation. Additionally, the relatively low process temperature as well as the presence of $\mathrm{O}_{2}$ is beneficial to reduce the formation of coke which was one of the major disadvantages in catalytic dehydrogenation. Several different catalysts were investigated for this reaction, including supported noble metals, redox catalyst and non-redox catalyst [13].

Supported noble metals (Pd, Pt, Rh) are generally known as nonselective for alkane oxidation but by tuning properly the ratio between oxygen and hydrocarbon, this limitation could be overcome. Moreover, the usage of thin film layer of the catalytically active metal allows operation at very short residence time in the order 
of milliseconds, which (i) decreases the chance of further oxidation of products and (ii) reduces the deactivation of catalyst due to coke, consequently enhancing the selectivity [13].

Non redox catalyst based on alkali earth oxide (mainly $\mathrm{MgO}$ and $\mathrm{CaO}$ ), doped with alkali metal ions, are reported in literature to be promising in the ODH of ethane to ethylene (best yield $=30 \%$ ) but lower selectivity were achieved in ODH of propane to propylene. In this case, the selectivity to propylene is limited by the fact that ethylene is produced as major compound, as observed for steam cracking. Although the debate is still open, it is accepted that this is a gas phase reaction initiated by alkyl-radical formed on the surface of the catalyst. Therefore, the main challenge for this oxidative route is to decrease the consecutive reaction of formed desired product (propylene, in this case) to lower hydrocarbons and $\mathrm{CO}_{\mathrm{x}}$, increasing the selectivity towards propylene [13 - 15].

Redox catalysts mainly based on vanadium and molybdenum, were widely used in selective oxidation catalysis because of the possibility of reducing the catalyst via reaction with propane and the immediate re-oxidation to initial state by oxygen present in the feed, according to Mars - Van Krevelen mechanism [16 - 18]. Limitation of this approach is that deep oxidation of highly reactive olefins to $\mathrm{CO}_{\mathrm{x}}$ can also take place. In fact, oxygen ions adsorbed on the catalyst and propylradicals present in gas phase can further react with products, drastically decreasing the selectivity to olefins $[19,20]$.

Many alternative oxidative agents were investigated (i.e. $\mathrm{N}_{2} \mathrm{O}, \mathrm{H}_{2} \mathrm{O}_{2}$ and $\mathrm{CO}_{2}$ ) to accomplish less severe oxidative conditions, aiming at increasing the yield. Interesting results were achieved in laboratory scale for process like ammoxidation of propane to acrylonitrile, oxidation of ethylbenzene to styrene, oxidation of styrene to benzaldehyde and oxidation of propane to propylene but the scale up to industrial level was not achieved yet [21 - 26].

A different approach to improve the selectivity was to use solid oxide as oxidant instead of molecular oxygen in the feed. This was the case, e.g., for phthalic anhydride production from o-xylene, using $\mathrm{VO}_{\mathrm{x}} / \mathrm{TiO}_{2}$ catalyst as well as maleic anhydride production from n-butane over VPO catalyst [27 - 30]. Obviously, the oxide will be reduced when exposed to the hydrocarbons and a regeneration step is needed. This is industrially effectuated by either moving bed technology or by switching between exposure to alkane and oxygen, respectively, reducing the overall efficiency of process [31].

An alternative innovative approach is the application of oxygen-ion permeable dense membrane as catalyst for oxidative dehydrogenation of alkanes, which allows a continuous process still using solid oxide as oxidant [32 - 35]. The operation of this continuous process is schematically represented in fig. 1.1. 


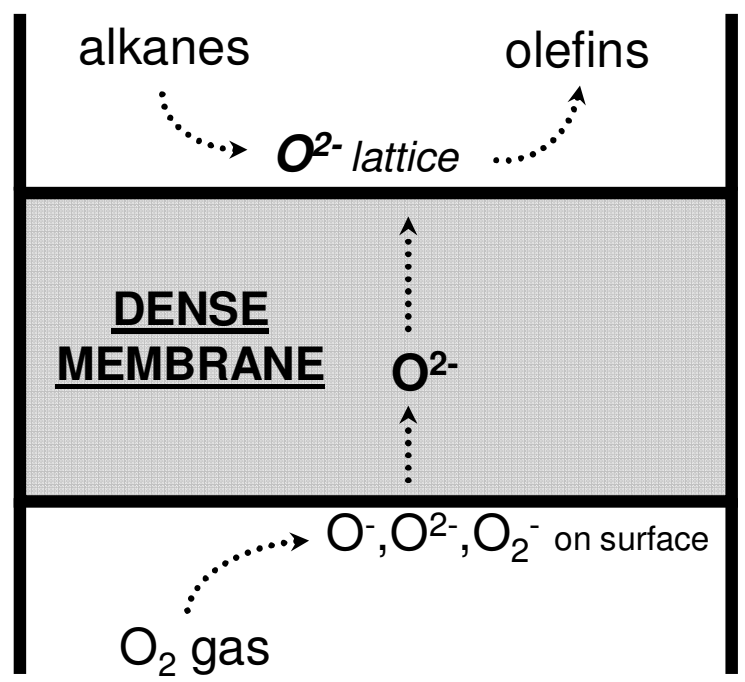

Fig. 1.1: Schematic representation of application of dense membrane in selective oxidation of alkanes.

The membrane is exposed on one side to hydrocarbon and, on the other side, to molecular oxygen, generating oxygen ions such as $\mathrm{O}^{-}, \mathrm{O}^{2-}$ and $\mathrm{O}_{2}^{-}$which are adsorbed on the surface of the membrane. Among these oxygen species, $\mathrm{O}^{2-}$ ions exclusively can permeate through the mixed conducting dense membrane while unselective species such as $\mathrm{O}^{-}$and $\mathrm{O}_{2}^{-}$, responsible for $\mathrm{CO}_{\mathrm{x}}$ formation, do not permeate to the reaction side. When arriving at the other side of the membrane, $\mathrm{O}^{2-}$ lattice ions are converted and removed by reaction with the alkane. By matching the oxygen permeability rate with the rate of conversion, recombination of oxygen ions at alkane side can be prevented, avoiding the detrimental formation of $\mathrm{O}_{2}$ molecular oxygen. Consequently, oxygen and alkane are strictly separated at two side of membrane and conversion of alkane can proceed via oxygen lattice ions exclusively. Olefin products are not exposed to $\mathrm{O}_{2}, \mathrm{O}_{2}^{-}$and $\mathrm{O}^{-}$, limiting deep oxidation and formation of possibly explosive mixtures of alkanes and $\mathrm{O}_{2}$ is prevented. Additional benefit of this approach is that by tuning the composition of the membrane, the reactivity of oxygen ions can be modified, providing an additional degree of freedom to improve selectivity.

This thesis is dedicated to materials suitable for dense membrane application and a more detailed description is given in the next paragraph. 


\subsection{Dense membrane}

The development of inorganic membranes started in the beginning of the 1980`s with membranes which were used for enrichment of $U^{235}$ [36]. In the following 10 years, the development of industrial ultra- and micro filtration (pore-diameter range 2 - $50 \mathrm{~nm}$ and > $50 \mathrm{~nm}$, respectively) started and nowadays several type of inorganic membranes are available, from macroporous to dense membranes which will be the object of interest of this thesis.

Table 1.1: Types and applications of inorganic membranes.

\begin{tabular}{|c|c|c|c|c|}
\hline Terminology & $\begin{array}{l}\text { Pore- } \\
\text { diameter } \\
(\mathrm{nm})\end{array}$ & $\begin{array}{l}\text { Type of } \\
\text { operation }\end{array}$ & Industry & Remark \\
\hline Macropores & $>50$ & Microfiltration & $\begin{array}{l}\text { - Beverage } \\
\text { - Pharmaceutical } \\
\text { - Textile }\end{array}$ & $\begin{array}{l}\text { - Good resistance } \\
\text { to cleaning in } \\
\text { alkaline media } \\
\text { - } \begin{array}{l}\text { High temperature } \\
\text { resistance }\end{array} \\
\end{array}$ \\
\hline Mesopores & $2-50$ & Ultrafiltration & $\begin{array}{l}\text { - Beverage } \\
\text { - Pharmaceutical } \\
\text { - Textile }\end{array}$ & $\begin{array}{l}\text { Good resistance } \\
\text { to cleaning in } \\
\text { alkaline media } \\
\text { - } \begin{array}{l}\text { High temperature } \\
\text { resistance }\end{array} \\
\end{array}$ \\
\hline \multirow[b]{2}{*}{ Micropores } & \multirow[b]{2}{*}{$<2$} & Nanofiltration & $\begin{array}{ll}\text { - } & \text { Water } \\
\text { - } & \text { Food } \\
\text { - } & \text { Textile } \\
\text { - } & \text { Paper } \\
\end{array}$ & $\begin{array}{l}\text { High active } \\
\text { surface area } \\
\text { - } \begin{array}{l}\text { Low net driving } \\
\text { pressure }\end{array}\end{array}$ \\
\hline & & Gas separation & $\begin{array}{l}\text { - Petrochemical } \\
\text { industry }\end{array}$ & $\begin{array}{l}\text { - High } \\
\text { temperatures } \\
\text { - High selectivity } \\
\text { and permeability } \\
\text { for } \mathrm{H}_{2}, \mathrm{CO}_{2} \text { and } \\
\mathrm{CO}\end{array}$ \\
\hline \multirow[t]{2}{*}{$\begin{array}{l}\text { Dense } \\
\text { Membrane }\end{array}$} & \multirow[t]{2}{*}{ none } & \multirow[t]{2}{*}{$\begin{array}{l}\text { Catalytic } \\
\text { reaction }\end{array}$} & $\begin{array}{l}\text { - Petrochemical } \\
\text { industry }\end{array}$ & 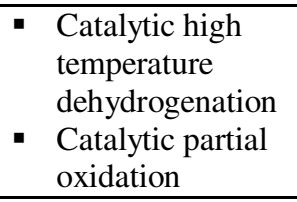 \\
\hline & & & $\begin{array}{l}\text { Refining } \\
\text { industry }\end{array}$ & $\begin{array}{l}\text { - Catalytic removal } \\
\text { of } \mathrm{NO}_{\mathrm{x}} \text { and } \mathrm{SO}_{\mathrm{x}}\end{array}$ \\
\hline
\end{tabular}


Few characteristic on inorganic membranes are resumed in table 1.1 [36 - 38].

Dense membranes are defined as membranes without any porosity and which are impervious of most molecular gas but permeable to only specific compounds. An example of dense, non ceramic membrane is a thin palladium foil [39] which is permeable to $\mathrm{H}$-atoms. The $\mathrm{H}_{2}$ molecule, reacting with the membrane surface, splits in two $\mathrm{H}$-atoms which can hence permeate through the thin palladium foil. In this thesis we will focus on oxygen-ion conducting membranes, in which only oxygen ions can permeate through the membrane.

The driving force for overall oxygen transport is the differential oxygen partial pressure applied across the membrane. As the membrane is dense and gas tight, direct passage of oxygen molecules is prevented and only oxygen ions migrate selectively through the membrane. Dissociation and ionization of oxygen occurs at the membrane surface at the high-pressure side (oxidation side) where electrons and vacancies play a crucial role, as described in eq. 1.3 [40]:

$1 / 2 \mathrm{O}_{2}+\mathrm{V}_{\mathrm{o}} \ddot{\bullet}^{\prime}+2 \mathrm{e}^{\prime} \leftrightarrows \mathrm{O}_{\mathrm{o}}{ }^{\mathrm{x}}$

where $\mathrm{O}_{2}$ stands for gaseous molecular oxygen, $\mathrm{V}_{\mathrm{o}}{ }^{\bullet}$ stands for an oxygen ion vacancy, $\mathrm{e}^{\mathrm{e}}$ stands for an electron and $\mathrm{O}_{\mathrm{o}}{ }^{\mathrm{x}}$ stands for an oxygen ion absorbed in a vacancy position.

As the ions are formed, permeation through the membrane can be theoretically calculated according to the Wagner equation (eq. 1.4) reported below:

$$
\mathrm{J}_{\mathrm{O}_{2}}=-\frac{\mathrm{RT}}{16 \mathrm{~F}^{2} \mathrm{~L}} \int_{\ln \mathrm{p}_{\mathrm{O}_{2}}}^{\ln \mathrm{p}_{\mathrm{O}_{2}}} \frac{\sigma_{\mathrm{e}} \sigma_{\mathrm{i}}}{\sigma_{\mathrm{e}}+\sigma_{\mathrm{i}}} \mathrm{d} \ln \mathrm{p}_{\mathrm{O}_{2}}
$$

where $\mathrm{J}_{\mathrm{O} 2}$ stands for the oxygen flux, $\mathrm{R}$ is the gas constant, $\mathrm{T}$ is the temperature, $\mathrm{F}$ stands for the Faraday constant, L represents the membrane thickness, p' $\mathrm{O}_{2}$ and p" $\mathrm{O} 2$ are the high and the low oxygen partial pressures and $\sigma_{\mathrm{e}}$ and $\sigma_{\mathrm{i}}$ stand for the electronic and ionic conductivities.

Upon arrival at the low-pressure side (reaction side) the individual oxygen ions are recombined to form oxygen molecules, which are released in the permeate stream, as described in eq. 1.5:

$2 \mathrm{O}_{\mathrm{o}}{ }^{\mathrm{x}} \leftrightarrows \mathrm{O}_{2}+2 \mathrm{~V}_{\mathrm{o}}{ }^{\bullet \bullet}+4 \mathrm{e}^{\prime}$ 
Oxygen transport in dense membranes is only possible if both oxygen ions and electrons can be transported through the bulk of the material, avoiding charge accumulation across the membrane. A scheme of oxygen permeation due to oxygen partial pressure gradient through a mixed conducting membrane is given in fig. 1.1.

High $\mathrm{pO}_{2}$

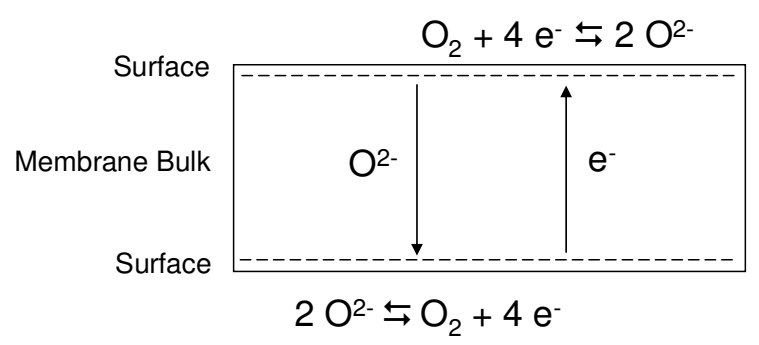

Low $\mathrm{pO}_{2}$

Fig. 1.2: Scheme of oxygen permeation through a mixed conducting membrane.

As it can be seen in fig. 1.2 the overall permeation process consists of three steps: 1) oxygen dissociation at high $\mathrm{pO}_{2}$ side, 2) oxygen ions permeation through the membrane 3) oxygen recombination at low $\mathrm{pO}_{2}$ side. As previously described, using the membrane as a catalytic dense membrane reactor (CDMR) flushing propane in the low $\mathrm{pO}_{2}$ side, the oxygen recombination does not take place as the hydrocarbons react with $\mathrm{O}^{2-}$ lattice ions, avoiding the detrimental formation of $\mathrm{O}_{2}$ and, hopefully, $\mathrm{O}_{2}{ }^{-}$and $\mathrm{O}^{-}$. This mechanism, which involves oxidation of hydrocarbons via oxygen ions from the catalyst and subsequent simultaneous reoxidation of catalyst, is equivalent to the Mars - Van Krevelen mechanism, as illustrated in eq. 1.6 and 1.7, being that in this case the two steps of the mechanism are spatially separated by the dense membrane.

$\mathrm{HC}+\mathrm{MO}_{\mathrm{x}} \rightarrow \mathrm{HCO}+\mathrm{MO}_{\mathrm{x}-1}$

Eq. 1.6

$\mathrm{MO}_{\mathrm{x}-1}+1 / 2 \mathrm{O}_{2} \rightarrow \mathrm{MO}_{\mathrm{x}}$

Eq. 1.7

where $\mathrm{HC}$ stands for hydrocarbon and $\mathrm{MO}_{\mathrm{x}}$ stands for oxide based membrane. In the case of CDMR, reoxidation of catalyst surface occurs via permeation of oxygen ions through the membrane instead of conventional co-feed of oxygen and 
hydrocarbon. By matching the oxygen permeability rate with the rate of hydrocarbon conversion, continuous membrane operation is in principle feasible In this thesis, catalytic activity of materials suitable for CDMR operation will be investigated using propane pulse experiments. Therefore only the first part of the Mars - Van Krevelen cycle (eq. 1.6) will be thoroughly studied. Additional details about the pulse experiments are given in the next section.

\subsection{Pulse experiment}

Pulse experiments are widely used to investigate the mechanism and reaction pathways of heterogeneous catalyzed reactions. The performance of the catalyst can be investigated by repetitive injection of a small amount of reactant $\left(10^{17}-10^{19}\right.$ molecules per pulse) and studying the amount of products formed, by means of mass spectrometry. Pulse experiment can also be used to test the stability of the catalyst during several reaction cycles [41], investigating e.g. the gradual deactivation of catalyst due to coke deposition [42]. Pulse experiment can be used to titrate the active sites of the catalyst, described for $\mathrm{Li} / \mathrm{MgO}$ [43], pulsing small amounts of propane ( $30 \mu \mathrm{l}$ per pulse), gradually consuming the oxygen active sites; the titration of active sites was accomplished by subsequently pulsing with oxygen. Similarly, in this study the effect of the oxidation state of the catalyst, i.e. the oxygen content, on both reactivity of propane as well as the product slate, was studied by gradually removing oxygen, i.e. reducing the catalyst, by providing small propane pulses. By pulsing propane exclusively, lattice oxygen in the catalyst was the only oxidant present for the oxidative dehydrogenation, ruling out the presence of adsorbed oxygen species on the surface $\left(\mathrm{O}_{2}^{-}, \mathrm{O}_{2}^{2-}\right.$ and $\left.\mathrm{O}^{-}\right)$as well as gas phase oxygen $\left(\mathrm{O}_{2}\right)$, as discussed earlier. Subsequently, the regeneration of materials and quantification of consumed oxygen ions were achieved by pulsing oxygen. Moreover, monitoring the possible formation of $\mathrm{CO}_{\mathrm{x}}$ during $\mathrm{O}_{2}$ pulsing, allowed detection of coke deposition. Experiments were performed at atmospheric pressure, using $\sim 10^{17}$ molecules per pulse with a tubular reactor with $1 \mathrm{~mm}$ internal radius.

A more sophisticated pulse technique is the temporal analysis of products (TAP) which was widely used to investigate mechanistic, transport and kinetic parameters to reveal information about individual steps in catalytic processes [44]. Conventional parameters for this technique are (i) low pressure (20-200 Pa), (ii) low concentration of reactant ( $10^{15}$ molecules), equal to $0.1-1 \%$ of the total amount of active sites in the catalyst, (iii) time resolution of milliseconds, (iv) size of the isothermal reactor in the order of $\mu \mathrm{m}$ [45]. In this case the shape and the size of resulting peaks of e.g. reaction products including intermediate products are determined, providing information about chemical composition, rate of formation and desorption of these species. Detailed results were obtained about kinetic 
parameters for several reactions including catalytic cracking, diffusion in zeolites, $\mathrm{NO}_{\mathrm{x}}$ and $\mathrm{SO}_{\mathrm{x}}$ removal, syngas production and selective catalytic reduction of $\mathrm{NO}_{\mathrm{x}}$ $[45,46]$.

Please note that the pulse experiment used in this work are essentially very similar to TAP experiments as (i) the propane pulses are relatively small as compared to the amount of active site in the catalyst and (ii) significant contribution of gas phase reaction can be excluded thanks to adequate design of the equipment. However, in our case, the peak shape is likely to be affected by mass transfer limitation, as conventional pulse experiments operate mainly under condition with diffusion according to Fick's law whereas TAP experiments operate under conditions ensuring Knudsen type of diffusion. Anyhow, this is not a limitation for our goal, focusing on the reactivity of oxides as function of the oxidation degree, based on peak sizes exclusively.

The experimental procedure, the set-up and the evaluation of data are described in detail in chapter 2.

\section{References}

[1] M. Eramo, Oil \& Gas Journal 103 (2005) 52-60

[2] J. F. Brazdil, Top. Catal., 38 (2006) 289-294

[3] Z.B. Ouyang, Z.C. Guo, N. Duan, Q, Qiao, Energy Conversion and Management 48 (2007) 2439-2446

[4] R.S. Deng, F. Wei, Y. Jin, Q.H. Zhang, Y. Jin, Chemical Engeneering \& Technology 25 (2002) 711-716

[5] M. Walther, Oil \& Gas Journal 101 (2003) 52-54

[6] Ullmann's Encyclopedia of Industrial Chemistry, Sixth ed. Wiley-VCH, Weinheim, 2002

[7] Kirk-Othmer Encyclopedia of Chemical Technology, online ed. Wiley-VCH, Weinheim 2002

[8] M.M. Bhasin, J.H. McCain, B.V. Bora, T. Imai, P.R. Pujado, Appl. Catal. A 221 (2001) 397-419

[9] L. Leveles, PhD Thesis, 2002, University of Twente (NL)

[10] Ž. Kotanjac, PhD Thesis, 2009, University of Twente (NL)

[11] Q. Shao, P.Wang, H. Tian, R. Yao, Y. Sun, J. Long, Catal. Today 147S (2009) S347-S351

[12] F. Cavani, N. Ballarini and A. Cericola, Cat. Today 127 (2007) 113-131

[13] F. Cavani, F. Trifiro', Catal. Today 51 (1999) 561-580

[14] F. Cavani, F. Trifiro', Catal. Today 24 (1995) 307-313

[15] C. Trionfetti, I.V. Babich, K. Seshan, L. Lefferts, Langmuir 24 (2008) 8220-

8228

[16] D.L. Stern, R.K. Grasselli, J. of Catal. 167 (1997) 550-559 
[17] F. Arena, F. Frusteri, A. Parmeliana, Catal. Letters 60 (1999) 59-63

[18] N. Ballarini, F. Cavani, C. Cortelli, C. Giunchi, P. Nobili, F. Trifiro', R.

Catani, U. Cornaro, Catal. Today 78 (2003) 353-364

[19] E. V. Kondratenko and M. Y. Sinev, Appl. Catal. A: Gen. 325 (2007) 353-361

[20] M. Y. Sinev, V. S. Arutyunov and A. Romanets, Adv. Chem. Eng. 32 (2007)

$167-258$

[21] J. Perez-Ramirez, N. Blangenois, P. Ruiz, Catal. Lett. 104 (2005) 163

[22] J. R. Monnier, Appl. Catal. A 221 (2001) 73

[23] M. G. Clerici, G. Bellussi, U. Romano, J. Catal. 129 (1991) 159

[24] J. Hu, K. Li, W. Li, F. Ma, Y. Guo, Appl. Catal. A 364 (2009) 211

[25] V. Cortes Corberan, Catal. Today 99 (2005) 33

[26] K.N. Rao, B.M. Reddy, B. Abhishek, Y.H. Seo, N. Jiang, S. Park, Appl. Catal. B 91 (2009) 649

[27] G. C. Bond, J. Catal. 116 (1989) 531

[28] F. Cavani, N. Ballarini, S. Luciani, Top. Catal. 52 (2009) 935

[29] Y. Zhang-Lin, M. Forissier, J. C. Vedrine, J. C. Volta, J. Catal. 145 (1994) 267

[30] E. V. Cheburakova, A. Zazighalov, Kinet. Catal. 49 (2008) 552

[31] R.M. Contractor, H.E. Bergna, H.S. Horowitz, C.M. Blackstone, B. Malone,

C.C. Torardi, B. Griffeths, U. Chowdhry, A.W. Sleight, Catal. Today 1 (1987) 49

[32] S. Miachon, J. A. Dalmon, Topics in Catal. 29 (2004) 59-65

[33] L. Olivier, S. Haag, C. Mirodatos, A. C van Veen Catal. Today 142 (2009) 34-

41

[34] A. Loftberg, H. Bodet, C. Pirovano, M. C. Steil, R. N. Vannier, E. Bordes-

Richard, Topics in Catal 38 (2006) 169-179

[35] C. M. O'Neill, E. E. Wolf, Ind. Eng. Chem. Res. 45 (2006) 2697-2706

[36] J. M. Hofman-Zuter, PhD Thesis, 1995, University of Twente (NL)

[37] DOW chemicals, on-line web site

[38] Koch membranes, on-line web site

[39] E. Brinkman, PhD Thesis, 1994, University of Twente (NL)

[40] Gellings P.J., Bouwmeester H.J.M., The CRC handbook of Solid State

Electrochemistry, pag. 512

[41] N. Kraikul, P. Rangsunvigit, S. Kulprathipanja, Chem. Eng. J. 131 (2007) 145153

[42] M. Hoang, K. C. Pratt, J. Mathews, United States Patent 5759946 (1998)

[43] C. Trionfetti, S. Crapanzano, I.V. Babich, K. Seshan, L. Lefferts, Catal. Today 145 (2009) 19-26

[44] J. T. Gleaves, G. S. Yablonskii, P. Phanawadee, Y. Schuurman, Appl. Catal. A 160 (1997) 55-88

[45] R. J. Berger, F. Kapteijn, J. A. Moulijn, G. B. Marin, J. De Wilde, M. Olea, D. Chen, A. Holmen, L. Lietti, E. Tronconi, Y. Schuurman, Appl. Catal. A 342 (2008) 3-28

[46] A. C. van Veen, D. Farrusseng, M. Rebeilleau, T. Decamp, A. Holzwarth, Y. Schuurman, C. Mirodatos, J. of Catal. 216 (2003) 135-143 



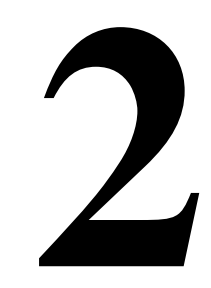

\section{Experimental details}

In this chapter the details of material used, catalyst preparation methods, the experimental procedures and the characterization techniques are given. 



\subsection{Introduction}

In this chapter the details of material used, catalyst preparation methods, the experimental procedures and the characterization techniques are given.

\subsection{Materials}

Five different catalysts have been prepared: $\mathrm{La}_{2} \mathrm{NiO}_{4+\delta}(\mathrm{LN}), \mathrm{La}_{2} \mathrm{Ni}_{0.95} \mathrm{~V}_{0.05} \mathrm{O}_{4.07+\delta}$ (LNV-05) $\mathrm{La}_{2} \mathrm{Ni}_{0.9} \mathrm{~V}_{0.1} \mathrm{O}_{4.15+\delta}$ (LNV-10), $\mathrm{PrBaCO}_{2} \mathrm{O}_{5+\delta}(\mathrm{PBC}), \mathrm{Ba}_{0.5} \mathrm{Sr}_{0.5} \mathrm{Co}_{0.8} \mathrm{Fe}_{0.2} \mathrm{O}_{3-}$ $\delta$ (BSCF). The following materials have been used to prepare the catalysts: $\mathrm{La}\left(\mathrm{NO}_{3}\right)_{3} * 6 \mathrm{H}_{2} \mathrm{O}$ (Merck), $\mathrm{Ni}\left(\mathrm{NO}_{3}\right)_{2} * 6 \mathrm{H}_{2} \mathrm{O}$ (Merck) and $\mathrm{V}_{2} \mathrm{O}_{5}$ (Merck), $\operatorname{Pr}\left(\mathrm{NO}_{3}\right)_{3} * 6 \mathrm{H}_{2} \mathrm{O}$ (Alfa Aesar), $\quad \mathrm{Ba}\left(\mathrm{NO}_{3}\right)_{2} \quad$ (Merck), $\mathrm{Sr}\left(\mathrm{NO}_{3}\right)_{2} \quad$ (Merck), $\mathrm{Co}\left(\mathrm{NO}_{3}\right)_{2} * 6 \mathrm{H}_{2} \mathrm{O}$ (Sigma-Aldrich), $\mathrm{Fe}\left(\mathrm{NO}_{3}\right)_{3} * 9 \mathrm{H}_{2} \mathrm{O}$ (Merck), EDTA (Fluka), $\mathrm{NH}_{4} \mathrm{OH}$ (Sigma-Aldrich, 50\% vv), $\mathrm{HNO}_{3}$ (Merck, $65 \%$ vv), $\left(\mathrm{CH}_{3}\right)_{2} \mathrm{CO}$ (Assink Chemie). All the nitrates and oxides used for catalysts preparation had a purity level higher than $99 \%$.

Additionally, the following materials have been used during the experiments: quartz (Merck), helium (Praxair, 5.0), argon (Praxair, 5.0) propane (Praxair, 3.5), oxygen (Praxair 5.0), $10 \%$ oxygen diluted in helium (Praxair) and $4 \%$ hydrogen diluted in argon (Praxair). Gases were used without further purification.

\subsection{Catalyst preparation}

The catalysts were prepared via sol-gel method using EDTA as chelating agent [1]. A stoichiometric amount of appropriate metal- hydrated nitrates and an excess of EDTA and $\mathrm{NH}_{4} \mathrm{OH}$ solutions were added and the obtained solutions were heated for 2 hours under stirring. After drying at $230^{\circ} \mathrm{C}$, foam-type materials were formed and pyrolysis took place after spontaneous ignition. The resulting solid mixed metal oxides were milled and calcined in air, slowly increasing temperature $\left(1^{\circ} \mathrm{C} / \mathrm{min}\right)$ up to $900-1050{ }^{\circ} \mathrm{C}$ (see table 1) to obtain single phase materials. The resulting materials were ball milled in acetone for $5 \mathrm{~h}$ and dried at $80{ }^{\circ} \mathrm{C}$. The powdered materials were sieved and particles sized between 0.1 and $0.3 \mathrm{~mm}$ were used for all experiments. The materials thus prepared are identified with the suffix "LT" in the chapter 3 exclusively, indicating the relatively low calcination temperature.

Membranes were produced using the powders after the ball milling procedure. The powders were isostatically pressed at 4000 bar and sintered at appropriate 
temperatures $\left(1100{ }^{\circ} \mathrm{C}, 1200{ }^{\circ} \mathrm{C}, 1370\right.$ and $1400{ }^{\circ} \mathrm{C}$ for BSCF, PBC, LNV-10 and $\mathrm{LN}$, respectively) in air for $10 \mathrm{~h}$. Bulk density of obtained membranes was $>95 \%$. The materials thus prepared are indicated with the suffix "HT", indicating the relative high sintering temperatures used to fabricate dense membrane materials. Please note that the suffix LT and HT are used in the chapter 3 exclusively; in the rest of the thesis all experiments were done with LT materials except for steadystate catalytic experiments and permeability tests in chapter 6 which were performed on HT materials without specifying any suffix.

\subsection{Pulse experiment}

\subsubsection{Experimental Procedure}

Pulse experiments were carried out in a fixed-bed reactor (quartz tube, length 400 $\mathrm{mm}$, internal diameter $2 \mathrm{~mm}$ ) at $550{ }^{\circ} \mathrm{C}$. About $35 \mathrm{mg}$ of catalyst were packed between two quartz-wool plugs (length approximately $10 \mathrm{~mm}$ each). The remaining volume of the reactor was filled with quartz particles, in order to reduce the void space and minimize gas phase reaction. Before each titration test, the catalysts were pre-treated in $10 \% \mathrm{O}_{2}$ in $\mathrm{He}$ flow $\left(20 \mathrm{ml} / \mathrm{min}, 30 \mathrm{~min}\right.$.) at $720{ }^{\circ} \mathrm{C}$ in order to remove any trace of water or inorganic compounds physisorbed on surface and to keep the catalyst oxygen level as high as possible. The samples were cooled down to the reaction temperature under the same atmosphere whereafter the gas flow was changed to $\mathrm{He}(3 \mathrm{ml} / \mathrm{min})$.

After flowing pure $\mathrm{He}$ for $15 \mathrm{~min}$, pulses of $300 \mu \mathrm{l}$ at atmospheric pressure containing $10 \% \mathrm{C}_{3} \mathrm{H}_{8}$ in $\mathrm{He}$ were introduced, whereas pulses of a $10 \%$ mixture of $\mathrm{O}_{2}$ in $\mathrm{He}$ were used to re-oxidize the catalyst, after exposure to $\mathrm{C}_{3} \mathrm{H}_{8}$ pulses. In all experiments, the regeneration process was confirmed by subsequent propane pulses (not shown here), resulting in identical product distributions as compared to results obtained with fresh material.

The product distributions were monitored by sampling on-line with a heated capillary to a quadrupole mass spectrometer (Pfeiffer AG Balzers, OmniStar) equipped with Channeltron and Faraday detectors (2-200 amu). 


\subsubsection{Set-up}

The experimental set-up is schematically represented in fig. 2.1.

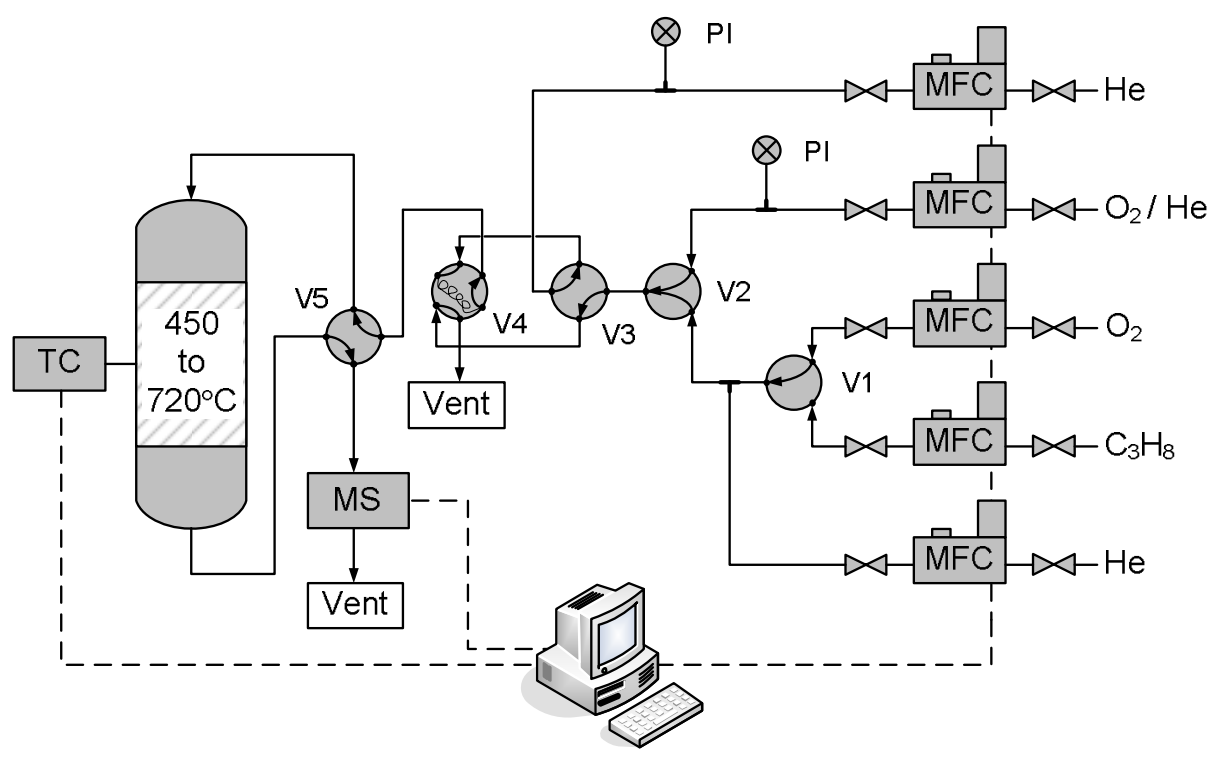

Fig. 2.1: The experimental set-up used for pulse experiments.

The gas flows were regulated by five mass flow controllers (Brooks, MFC in fig 2.1) and the He line on top left-hand side of fig. 2 was used as carrier gas line while the other four lines were used to vary the composition of the feed in pulse experiment. The pressure inside both parts of the system was monitored by two pressure indicators (Druck, PI in fig. 2.1). Two manually actuated valves (Valco, $\mathrm{V} 1$ and $\mathrm{V} 2$ in fig. 2) were included to vary the concentration of mixture of $\mathrm{O}_{2}, \mathrm{C}_{3} \mathrm{H}_{8}$ and $\mathrm{He}$ within the explosion limit as (i) the $\mathrm{O}_{2} / \mathrm{He}$ mixture contains $10 \% \mathrm{O}_{2}$ (second MFC from the top in fig. 2) and (ii) pure $\mathrm{C}_{3} \mathrm{H}_{8}$ and $\mathrm{O}_{2}$ could not be mixed because of V1. One electrically actuated " 4 ports -2 ways" valve (Valco, V3 in fig. 2 ) is used to invert the carrier and the feed line, allowing to switch between pulse mode operation to steady state mode operation. A second electrically actuated " 6 ports - 2 ways" valve (Valco, V4 in fig.2) is used to pulse the feed which is stored in a 300 $\mu l$ loop, represented by the coil in the middle of V4 in fig 2.1. In this way an identical amount of gas is sent at each pulse. Additionally a manually actuated bypass valve (Valco, V5 in fig. 2) was included to by-pass the reactor, in order to check the composition of the pulsed feed prior each experiment. The reactor oven, which was operating at temperature between 450 and $720{ }^{\circ} \mathrm{C}$, was regulated by a 
Eurotherm thermal controller (TC in fig 2.1). The downstream lines were heated with thermally controlled heating wires (Eurotherm) to avoid water condensation and the product mixture was analyzed with the quadrupole Pfeiffer Mass Spectrometer, described in section 2.4.1 (MS in fig. 2.1). The MFC, the MS and the TC were operated via a personal computer.

\subsubsection{Evaluation of data}

Prior to each experiment, the fragment pattern of diluted propane and diluted oxygen were recorded and compared with the fragment pattern of the product gas mixture to qualitatively identify the product distribution. Water, propane, oxygen and carbon dioxide were identified monitoring $\mathrm{m} / \mathrm{z}=18,29,32$ and 44 , respectively, since no other possible products show additional significant contribution to those $\mathrm{m} / \mathrm{z}$ signals. To determine presence of methane, ethane, ethylene and propylene, two or three $\mathrm{m} / \mathrm{z}$ signals were monitored for each compound. Because of the similarity in fragmentation patterns and the consequent contribution of several products to the same $\mathrm{m} / \mathrm{z}$ signal (cross-contamination effect), matrix-type calculation was performed. In this way, formation of $\mathrm{CO}$ was also determined via $\mathrm{m} / \mathrm{z}=28$, although many compounds as propane, ethylene and carbon dioxide contribute to $\mathrm{m} / \mathrm{z}=28$. These additional contributions were taken into account and subtracted from $\mathrm{m} / \mathrm{z}=28$. This procedure never resulted in any significant detection of $\mathrm{CO}$, although the presence of small amounts cannot be excluded. Attempt to determine production of $\mathrm{H}_{2}$ was done by calibrating the MS and by following $\mathrm{m} / \mathrm{z}=2$ but unfortunately negative intensity of that signal was obtained (signal below the MS detection limit) which made the detection of $\mathrm{H}_{2}$ unreliable. This procedure allows quantitative determination of propane and oxygen conversion only, with an experimental error of about $5 \%$.

As the formation of products could not be quantified, only semi-quantitative comparison of selectivity patterns, called "apparent selectivity", will be reported. The apparent selectivity is based on the integrated area of peaks of the corresponding $\mathrm{m} / \mathrm{z}$ signals of each compound $v s$ time on stream, divided by total integrated areas of all carbon containing products (e.g. for methane: $\mathrm{A}\left(\mathrm{m}_{\mathrm{Z}} \mathrm{Z}_{\mathrm{CH}}\right)$ / $\left.\mathrm{A}\left(\mathrm{m}_{/} \mathrm{Z}_{\mathrm{CH} 4}\right)+\mathrm{A}\left(\mathrm{m}_{/} \mathrm{Z}_{\mathrm{C} 2 \mathrm{H} 6}\right)+\mathrm{A}\left(\mathrm{m}_{\mathrm{Z}} \mathrm{Z}_{\mathrm{C} 2 \mathrm{H} 4}\right)+\mathrm{A}\left(\mathrm{m}_{/} \mathrm{Z}_{\mathrm{C} 3 \mathrm{H} 6}\right)+\mathrm{A}\left(\mathrm{m}_{/} \mathrm{Z}_{\mathrm{CO}}\right)+\mathrm{A}\left(\mathrm{m}_{\mathrm{Z}} \mathrm{Z}_{\mathrm{CO} 2}\right)\right)$. In case of methane, ethane, ethylene and propylene, which were monitored using two or three $\mathrm{m} / \mathrm{z}$ signals, only the most intense signal was included in the figures.

The possible contribution of gas-phase reaction was checked by pulsing propane in the reactor filled with quartz particles only. The conversion of propane was below the detection limit and therefore we can exclude significant gas phase reaction during the pulse tests. 


\subsection{Catalytic membrane experiments}

Catalytic tests on membrane employing steady-state propane flow were done to investigate the performance of different materials in oxidative dehydrogenation of propane. The catalytic tests were performed in a modified vertical high-temperature gas permeation system schematically illustrated in fig. 2.2.

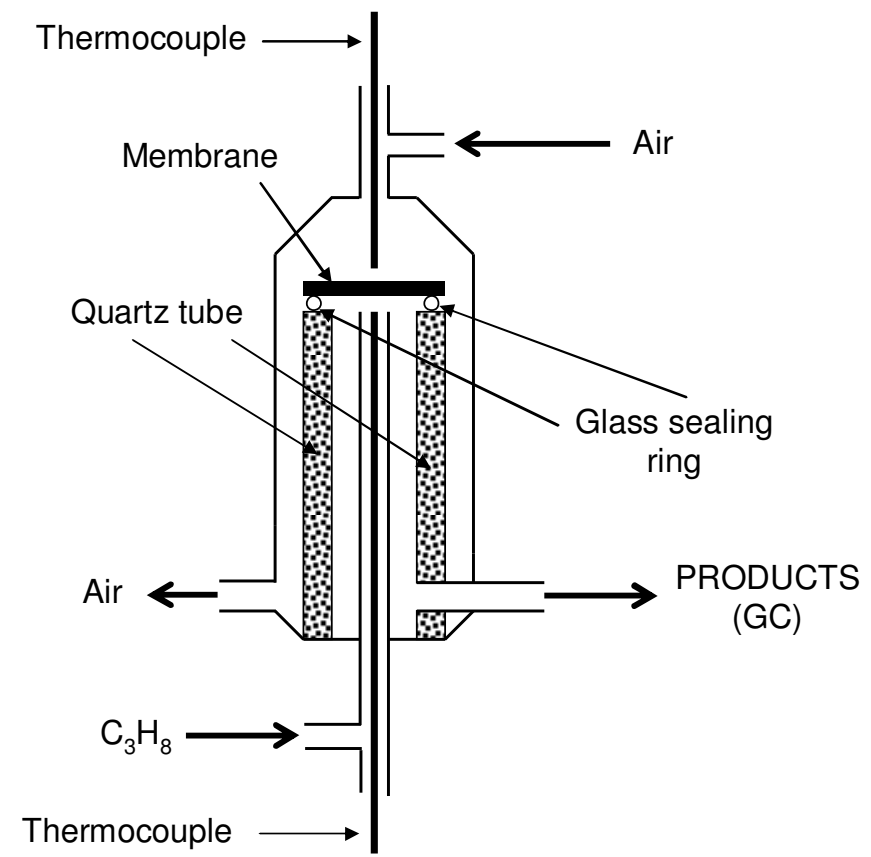

Fig. 2.2: Schematic representation of experimental set-up for permeability measurement and catalytic test of disk dense membrane reactor.

A ceramic glass ring was used as binding agent to seal $1 \mathrm{~mm}$ tick membrane disk with radius of $8 \mathrm{~mm}$ on a dense quartz tube. The temperature of the membrane was controlled on both sides by means of two thermocouples. Catalytic studies were performed between 550 and $650{ }^{\circ} \mathrm{C}$. On the oxygen side of the membrane, constant flow of $100 \mathrm{ml} / \mathrm{min}$ of technical air was employed while on the reaction side 10 $\mathrm{ml} / \mathrm{min}$ of $10 \% \mathrm{C}_{3} \mathrm{H}_{8}$ in $\mathrm{He}$ was used. A CP-4900 micro gas chromatograph equipped with Poraplot $\mathrm{Q}$ and 5Asil columns was connected to the outlet of reaction side.

The product distribution was considered after $14 \mathrm{~h}$ flowing propane over membranes, and the selectivities were calculated based on carbon containing 
products only $\left(\mathrm{CO}, \mathrm{CO}_{2}, \mathrm{C}_{3} \mathrm{H}_{6}, \mathrm{C}_{2} \mathrm{H}_{6}, \mathrm{C}_{2} \mathrm{H}_{4}\right.$ and $\left.\mathrm{CH}_{4}\right)$. The $\mathrm{C}_{3} \mathrm{H}_{8}$ conversion in gas phase was measured replacing the membrane with an inert quartz disk (blank experiment).

\subsection{Characterization}

\subsubsection{Elemental analysis}

The chemical composition of samples were determined with X-ray fluorescence (XRF) using Philips (Panalytical) PW 1480 equipment. The stoichiometric amount of oxygen was estimated assuming specific oxidation state for each metal present in each sample.

\subsubsection{Surface area}

Nitrogen adsorption measurements were carried out at $-196{ }^{\circ} \mathrm{C}$ with a Micromeritics Tristar system. Prior the adsorption measurements the samples were degassed at $300{ }^{\circ} \mathrm{C}$ and $10^{-3} \mathrm{~Pa}$ for $24 \mathrm{~h}$. The specific surface areas were calculated according to the Brunauer-Emmet-Teller (BET) method.

\subsubsection{XRD}

The crystal structure of the materials was determined in air with powder X-ray diffraction (XRD) using a Philips PW2050 (X'Pert-APD) diffractometer with $\mathrm{Cu}$ $\mathrm{K}_{\alpha}$ radiation $(\lambda=0.15406 \mathrm{~nm})$. Data were collected varying $2 \theta$ between 5 and $75^{\circ}$ with a step size of $0.005^{\circ}$ and a step time of $1 \mathrm{~s}$.

The XRD patterns of reduced sample were obtained after in-situ reduction in $\mathrm{H}_{2}$ in a high temperature chamber (Anton Paar HTK16). The temperature was increased up to $500{ }^{\circ} \mathrm{C}$ and $750{ }^{\circ} \mathrm{C}$ respectively, in $4 \% \mathrm{H}_{2} / \mathrm{Ar}$ atmosphere and kept at those specific temperatures for $1 \mathrm{~h}$. Subsequently, the samples were cooled down to room temperature under the same atmosphere and the XRD pattern was measured. 


\subsubsection{TPR}

Temperature programmed reduction experiments in $\mathrm{H}_{2}\left(\mathrm{H}_{2}\right.$-TPR) of the samples were carried out with a home-built set-up, equipped with a TCD detector. First, 40 $\mathrm{mg}$ of sample mixed with $40 \mathrm{mg}$ quartz particles were placed in a reactor with a 4 $\mathrm{mm}$ inner diameter and heated in a flow of $5 \% \mathrm{O}_{2}$ in $\mathrm{He}$ up to $500{ }^{\circ} \mathrm{C}\left(10{ }^{\circ} \mathrm{C} / \mathrm{min}\right)$ and kept at $500{ }^{\circ} \mathrm{C}$ for $1 \mathrm{~h}$. Then the sample was cooled down to room temperature in the same atmosphere. At room temperature the flow was changed to pure He for 30 min. and whereafter to $5 \% \mathrm{H}_{2}$ in Ar and TPR was carried out with a heating rate of $5{ }^{\circ} \mathrm{C} / \mathrm{min}$ up to $900{ }^{\circ} \mathrm{C}$. The TCD was calibrated via reduction of $\mathrm{NiO}$.

Temperature programmed reduction in $\mathrm{C}_{3} \mathrm{H}_{8}\left(\mathrm{C}_{3} \mathrm{H}_{8}\right.$-TPR) of the samples were carried out in the equipment described above, employing a quadrupole mass spectrometer as analyzer (Pfeiffer AG Balzers, OmniStar, equipped with Channeltron and Faraday detectors) to follow the consumption of propane. Preparation of the reactor and the pre-treatment procedure were identical to the $\mathrm{H}_{2^{-}}$ TPR experiment; at room temperature the flow was changed to $3 \% \mathrm{C}_{3} \mathrm{H}_{8}$ in $\mathrm{Ar}$ and TPR was carried out with a heating rate of $10{ }^{\circ} \mathrm{C} / \mathrm{min}$ up to $900^{\circ} \mathrm{C}$.

\subsubsection{TPD}

Carbon dioxide temperature programmed desorption (TPD) from spent BSCF catalyst was measured using the same equipment used for pulse experiment (described above) by sampling on-line to a quadrupole mass spectrometer, monitoring $\mathrm{m} / \mathrm{z}=44$. After the propane pulse experiment and subsequent regeneration with $\mathrm{O}_{2}$ pulses at $550{ }^{\circ} \mathrm{C}$, the spent catalyst was cooled down to room temperature in $10 \% \mathrm{O}_{2}$ in $\mathrm{He}$ flow. Subsequently, the catalyst was flushed for $1 \mathrm{~h}$ in $3 \mathrm{ml} / \mathrm{min}$ flow of $\mathrm{He}$ at room temperature and then the TPD was performed by heating the sample up to $970{ }^{\circ} \mathrm{C}$ at heating rate of $20^{\circ} \mathrm{C} / \mathrm{min}$.

\subsubsection{TGA}

Thermal gravimetric analyses (TGA) were carried out using a Mettler-Toledo TGASDTA 851 unit. The sample (around $55 \mathrm{mg}$ ) was placed in a TGA cup and kept at $140{ }^{\circ} \mathrm{C}$ for $8 \mathrm{~h}$ to remove $\mathrm{H}_{2} \mathrm{O}$ and any organic volatile compound adsorbed on the surface. Then the catalyst was heated up to $550{ }^{\circ} \mathrm{C}$ and, subsequently, up to $650{ }^{\circ} \mathrm{C}$, with rate of $10{ }^{\circ} \mathrm{C} / \mathrm{min}$ in Ar flow of $40 \mathrm{ml} / \mathrm{min}$. Experimental results were 
corrected for the buoyancy effect using a cup filled with quartz particles with similar volume to the catalyst volume.

\subsubsection{Oxygen permeability}

Oxygen permeability experiments were conducted using the equipment described above (fig. 2.2) but $100 \mathrm{ml} / \mathrm{min}$ flow of high purity $\mathrm{He}\left(\mathrm{O}_{2}<2 \mathrm{ppm}\right)$ was used instead of $10 \% \mathrm{C}_{3} \mathrm{H}_{8}$ in He. Thus the He was used as sweep gas to carry permeated oxygen to the analyzer. The oxygen permeability was calculated based on (i) the amount of molecular oxygen present on the sweep side, (ii) the sweep gas flow rate and (iii) the membrane thickness. Nitrogen leakage through pores or cracks due to sealing problems was monitored and never detected.

\section{Reference}

[1] R.H.E. van Doorn, H. Kruidhof, A. Nijmeijer, L. Winnubst and A.J. Burggraaf, J. Mater. Chem., 1998, 8(9), 2109-2112 


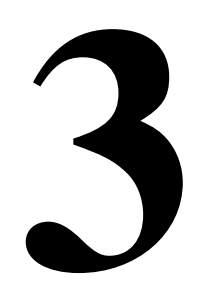

\section{Selection of mixed conducting oxides for selective oxidation of propane with dense membranes}

In this study, propane pulse experiments at $550{ }^{\circ} \mathrm{C}$ are used as a method to select suitable oxides for operation of catalytic dense membrane reactor (CDMR) for selective oxidation of propane. $\mathrm{Ba}_{0.5} \mathrm{Sr}_{0.5} \mathrm{Co}_{0.8} \mathrm{Fe}_{0.2} \mathrm{O}_{3-\delta}(\mathrm{BSCF}), \mathrm{La}_{2} \mathrm{NiO}_{4+\delta}(\mathrm{LN})$ and $\mathrm{PrBaCO}_{2} \mathrm{O}_{5+\delta}(\mathrm{PBC})$ powders were used as model catalysts to explore the catalytic properties of membrane surfaces in terms of activity and selectivity. Furthermore, as propane pulses induce variation of the oxidation degree by slowly reducing the oxide, crucial information on the effect of variation of the oxygen content (i.e. the oxidation degree) in the samples on reactivity and selectivity is obtained. It will be shown that $\mathrm{LN}$ is the most promising material for membrane application, provided that it is operated in the optimal window of reduction degree, to ensure high selectivity towards $\mathrm{C}_{3} \mathrm{H}_{6}$. Contrary, $\mathrm{PBC}$ and $\mathrm{BSCF}$ are not suitable for CDMR. In fact, $\mathrm{PBC}$ showed low selectivity to $\mathrm{C}_{3} \mathrm{H}_{6}$ due to significant formation of $\mathrm{CO}_{2}$, independently of the oxidation degree of the material and BSCF appears to adsorb $\mathrm{CO}_{2}$ by forming carbonates, which might be detrimental for long term operation. However, pulse experiments revealed the remarkable stability of BSCF catalyst towards $\mathrm{CO}_{2}$. Despite the presence of carbonate, the material preserved the ability to act as an oxygen source for propane and can be completely regenerated via oxidation. Additionally, the onset temperature in TPR appears to correlate well with the reactivity of lattice oxygen ions with propane, for the three materials studied. 



\subsection{Introduction}

The demand for propylene is continuously growing and it is expected to rise to 80 million tonnes in 2010 worldwide [1-3]. Nowadays the main industrial routes for propylene production are endothermic reactions such as steam cracking [4], fluid catalytic cracking [5] and catalytic dehydrogenation which is the most promising for alkenes production. The main drawbacks are that catalytic dehydrogenation is equilibrium limited and it suffers from catalyst deactivation due to coke deposition [6]. This problem can be avoided by oxidative dehydrogenation (ODH) of propane where gaseous oxygen containing compounds (i.e. $\mathrm{O}_{2}, \mathrm{~N}_{2} \mathrm{O}$ and $\mathrm{CO}_{2}$ ) are employed as oxidant, turning the process to exothermic and reducing the coke deposition [7]. On the other hand, further oxidation of propylene to $\mathrm{CO}_{2}$ can also occur because of consecutive oxidation of propylene, which is more reactive than propane $[8,9]$. One way to overcome this issue is to employ metal oxide lattice oxygen as oxidant, limiting the extent of deep oxidation by tuning the reactivity of these lattice oxygen ions. In this chapter, mixed metal oxides suitable for catalytic dense membrane reactor (CDMR) will be investigated as oxidant for oxidative dehydrogenation of propane. The dense membrane is exposed on one side to propane (reaction side) and, on the other side, to molecular oxygen (regeneration side), separating the two gases. As the membrane at the reaction side will get depleted in oxygen due to reaction with the alkane, membrane regeneration is required. This occurs via ionic permeation of $\mathrm{O}^{2-}$ ions through the mixed conducting dense membrane, which are generated at the regeneration side interface. By matching the oxygen diffusion rate with the rate of conversion, oxygen recombination at the alkane side can be prevented and alkane oxidation can, in principle, proceed via oxygen lattice ions exclusively.

In this chapter, propane pulse experiments are used as method to select different oxides for operation of CDMR, based on propane conversion and product distribution. In fact, pulsing with propane in absence of oxygen is mimicking the interaction between membrane lattice oxygen and propane at the reaction side of the membrane. The pulse experiment can therefore be regarded as a model experiment for selection of suitable membrane materials. Furthermore, as propane pulses induce variation of the oxidation degree by slowly reducing the oxide, pulse experiments can also provide crucial information on the effect of variation of the oxygen content (i.e. the oxidation degree) in the samples on reactivity and selectivity.

Three mixed metal oxides have been selected to shown the applicability of pulse experiment: $\mathrm{Ba}_{0.5} \mathrm{Sr}_{0.5} \mathrm{Co}_{0.8} \mathrm{Fe}_{0.2} \mathrm{O}_{3-\delta}$ (BSCF), $\mathrm{La}_{2} \mathrm{NiO}_{4+\delta}$ (LN) and $\mathrm{PrBaCo}_{2} \mathrm{O}_{5+\delta}$ (PBC). These materials have been selected because of clear differences in ion permeability $[10,11]$ and lattice oxygen reactivity $[12,13]$, despite their similar perovskite-like structures as discussed below. The influence of those parameters on 
the catalytic reactivity and selectivity of the materials will be investigated in this chapter.

BSCF possesses pure perovskite structure, indicated as $\mathrm{ABO}_{3}$, consisting of a cubic arrangement of corner-sharing $\mathrm{BO}_{6}$ octahedra, where $\mathrm{B}$ is a transition metal cation. The A-site ions, located in interstitial position between the $\mathrm{BO}_{6}$ octahedra, are usually occupied by an alkali, alkali earth or rare earth ion [14], as shown in Fig. 3.1a. Due to the redox nature of B-site ions ( $\mathrm{Co}$ or $\mathrm{Fe}$ ), the catalyst can easily change composition, resulting in structural defects as vacancies at oxygen-ion lattice positions, like in many redox compounds [15-17]. The oxygen understoichiometry due to the formation of vacancies is represented by $\delta$ in the nominal composition of the material.

a)

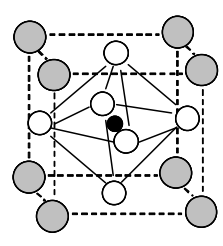

b)

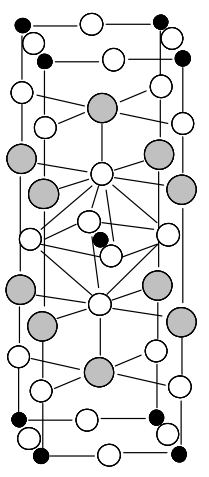

$\mathrm{Ba}, \mathrm{Sr}$

- $\mathrm{Co}, \mathrm{Fe}$

$\bigcirc \mathrm{O}$ $\bigcirc \mathrm{La}$

- $\mathrm{Ni}$

O 0 c)

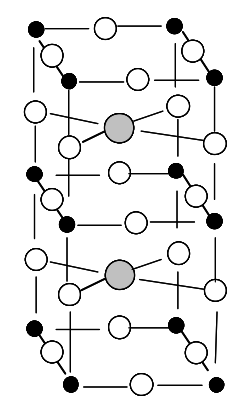

$\mathrm{Pr}, \mathrm{Ba}$

- Co

○ $\mathrm{O}$

Fig. 3.1: Schematic representation of unit cells of perovskite (a), $\mathrm{K}_{2} \mathrm{NiF}_{4}$-type (b) and pseudo-brookite (c) structures.

When varying the ratio metal-A: metal-B to $2: 1$, the perovskite structure is modified towards the $\mathrm{K}_{2} \mathrm{NiF}_{4}$-type structure (fig. 3.1b), generally indicated as $\mathrm{A}_{2} \mathrm{BO}_{4}$. This is the case for $\mathrm{LN}\left(\mathrm{La}_{2} \mathrm{NiO}_{4}\right)$ catalyst which presents a double layer arrangement: $\mathrm{Ni}$, octahedrally coordinated, is present in the perovskite layer and $\mathrm{La}$, tetragonally coordinated, is present in a layer with a rock-salt structure [18]. Due to the specific crystallographic arrangement of this oxide and the redox properties of $\mathrm{Ni}$, the catalyst possesses two types of structural defects: vacancies and interstitial 
oxygen, which is over-stoichiometric oxygen, located in between the perovskite layer and rock-salt layer (not shown in fig. 3.1b) [19]. In this case the $\delta$ value in the nominal composition of the material represents the balance of both under- and overstoichiometric oxygen, due to vacancies and interstitial oxygen, respectively. Interstitial oxygen usually dominates as $0<\delta<0.2$. The two types of oxygen present in LN possess different reactivity due to the different crystallographic position [20], as discussed in details in chapter 4. A third family of perovskiterelated structure is the pseudo-brookite structure which is generally indicated as $\mathrm{AA}^{\prime} \mathrm{B}_{2} \mathrm{O}_{5}$ where $\mathrm{A}$ is a tri- or tetra-valent lanthanide ion and $\mathrm{A}^{\prime}$ is a divalent alkaliearth metal. This is the case of $\mathrm{PBC}$ (fig. 3.1c) and the related layered structure is generated by stacking sequence ... $\left|\mathrm{A}^{\prime} \mathrm{O}\right| \mathrm{BO}_{2}\left|\mathrm{AO}_{\mathrm{x}}\right| \mathrm{BO}_{2} \mid \ldots$, similar to the structure of cuprate superconductor [21]. In this case, due to redox nature of both $\mathrm{A}^{\prime}-(\mathrm{Pr})$ and B- (Co) site ions, the catalyst possesses vacancies $[22,23]$. In this case, the $\delta$ value can vary from 0 to 1 according to the amount of vacancies in PBC, which directly influences the Co oxidation states $\left(\delta=0\right.$ when Co oxidation states are $50 \% \mathrm{Co}^{2+}$ and $50 \% \mathrm{Co}^{3+} ; \delta=1$ when Co oxidation states are $50 \% \mathrm{Co}^{3+}$ and $50 \% \mathrm{Co}^{4+}$ ) [22].

It was shown that the oxygen content in redox materials can change by varying the experimental conditions (oxygen partial pressure and temperature, i.e. [24]), affecting the oxygen reactivity [20]. In this chapter the oxidation degree of the materials is decreased by pulsing propane and the resulting variation in the product distributions are investigated. Additionally, oxygen reactivity in $\mathrm{H}_{2}$-TPR and ionic permeabilities of the three samples were also considered as parameters for understanding the catalyst performances in pulse experiments.

\subsection{Experimental}

\subsubsection{Catalyst preparation}

$\mathrm{PrBaCo}_{2} \mathrm{O}_{5+\delta}$ (PBC), $\mathrm{Ba}_{0.5} \mathrm{Sr}_{0.5} \mathrm{Co}_{0.8} \mathrm{Fe}_{0.2} \mathrm{O}_{3-\delta}$ (BSCF) and $\mathrm{La}_{2} \mathrm{NiO}_{4+\delta}$ (LN) catalysts were prepared via sol-gel method using EDTA as chelating agent [25]. A stoichiometric amount of appropriate metal- hydrated nitrates (Merck), EDTA and $\mathrm{NH}_{4} \mathrm{OH}$ solutions were added and the obtained solutions were heated for 2 hours under stirring. After drying at $230{ }^{\circ} \mathrm{C}$, foam-type materials were formed and pyrolysis took place after spontaneous ignition. The resulting solid mixed metal oxides were milled and calcined in air, slowly increasing temperature $\left(1^{\circ} \mathrm{C} / \mathrm{min}\right)$ up to 900 - $1050{ }^{\circ} \mathrm{C}$ (see table 3.1) to obtain single phase materials. The resulting materials were ball milled in acetone for $5 \mathrm{~h}$ and dried at $80{ }^{\circ} \mathrm{C}$. The powdered materials were sieved and particles size of $0.1-0.3 \mathrm{~mm}$ were used for all 
experiments. The materials thus prepared will be called PBC-LT, BSCF-LT and LN-LT, indicating the relative low calcination temperatures employed.

To fabricate membranes, after the ball milling procedure, the powders were isostatically pressed at $4000 \mathrm{bar}$ and sintered at appropriate temperatures $\left(1200{ }^{\circ} \mathrm{C}\right.$, $1100{ }^{\circ} \mathrm{C}$ and $1400{ }^{\circ} \mathrm{C}$ for $\mathrm{PBC}, \mathrm{BSCF}$ and $\mathrm{LN}$, respectively) in air for $10 \mathrm{~h}$, obtaining bulk density $>95 \%$. The materials thus prepared will be called PBC-HT, BSCF-HT and LN-HT, indicating the relative high sintering temperatures used to fabricate dense membrane materials.

\subsubsection{Characterization}

Nitrogen adsorption measurements were carried out at $-196{ }^{\circ} \mathrm{C}$ with a Micromeritics Tristar system. Prior the adsorption measurements the samples were degassed at $300{ }^{\circ} \mathrm{C}$ and $10^{-3} \mathrm{~Pa}$ for $24 \mathrm{~h}$. The specific surface areas were calculated according to the Brunauer-Emmet-Teller (BET) method.

The crystal structure of the materials was determined in air with powder X-ray diffraction (XRD) using a Philips PW2050 (X'Pert-APD) diffractometer with $\mathrm{Cu}$ $\mathrm{K}_{\alpha}$ radiation $(\lambda=0.15406 \mathrm{~nm})$. Data were collected varying $2 \theta$ between 20 and $75^{\circ}$ with a step size of $0.005^{\circ}$ and a step time of $1 \mathrm{~s}$.

Temperature programmed reduction (TPR) was carried out with a home-built setup, equipped with a TCD detector. First, $40 \mathrm{mg}$ of sample mixed with $40 \mathrm{mg}$ quartz particles were placed in a $4 \mathrm{~mm}$ inner diameter reactor, heated up to $500{ }^{\circ} \mathrm{C}(10$ ${ }^{\circ} \mathrm{C} / \mathrm{min}$ ), kept at $500{ }^{\circ} \mathrm{C}$ for $1 \mathrm{~h}$ in a $20 \mathrm{ml} / \mathrm{min}$ flow of $5 \% \mathrm{O}_{2}$ in $\mathrm{He}$ and then the sample was cooled down to room temperature in the same atmosphere. At room temperature the flow was changed, after flushing with inert, to $5 \% \mathrm{H}_{2}$ in $\mathrm{Ar}$ and the TPR was carried out at $5{ }^{\circ} \mathrm{C} / \mathrm{min}$ up to $750{ }^{\circ} \mathrm{C}$. The TCD was calibrated via reduction of $\mathrm{NiO}$.

Carbon dioxide temperature programmed desorption (TPD) from spent BSCF catalyst was measured using a fixed-bed reactor (described in the section 2.4) measuring the composition of the outgoing gas mixture on-line and continuously with a quadrupole mass spectrometer (Pfeiffer AG Balzers, OmniStar) equipped with Channeltron and Faraday detectors (2-200 amu). The $\mathrm{CO}_{2}$ content was measured by monitoring $\mathrm{m} / \mathrm{z}=44$. After completion of the propane pulse experiment and subsequent regeneration with $\mathrm{O}_{2}$ pulses at $550{ }^{\circ} \mathrm{C}$, the spent catalyst was cooled down to room temperature in $10 \% \mathrm{O}_{2}$ in He flow. Subsequently, the catalyst was flushed for $1 \mathrm{~h}$ in $3 \mathrm{ml} / \mathrm{min}$ flow of $\mathrm{He}$ at room temperature whereafter the TPD was performed by heating the sample up to $970{ }^{\circ} \mathrm{C}$ at heating rate of 20 ${ }^{\circ} \mathrm{C} / \mathrm{min}$. The MS was calibrated for $\mathrm{CO}_{2}$ by performing decomposition of a known amount of $\mathrm{CaCO}_{3}$. 
The oxygen permeability experiments were performed in a vertical hightemperature gas permeation system. A ceramic glass ring was used as binding agent to seal $1 \mathrm{~mm}$ thick membrane disk on a dense quartz tube. Permeation studies were performed between 525 and $650{ }^{\circ} \mathrm{C}$. On the oxygen side of the membrane, constant flow of $100 \mathrm{ml} / \mathrm{min}$ of technical air was employed while on the sweep side 100 $\mathrm{ml} / \mathrm{min}$ of high purity $\mathrm{He}\left(\mathrm{O}_{2}<2 \mathrm{ppm}\right)$ was used. A CP-4900 micro gas chromatograph equipped with Poraplot $\mathrm{Q}$ and 5Asil columns was connected to the outlet of sweep side. The oxygen permeability was calculated based on (i) the amount of molecular oxygen present on the sweep side, (ii) the sweep gas flow rate and (iii) the membrane thickness. Nitrogen was never detected in the sweep gas, demonstrating that leakage of $\mathrm{N}_{2}$ or $\mathrm{O}_{2}$ through pores or cracks never occurred.

\subsubsection{Pulse experiment}

Pulse experiments were carried out in a fix-bed reactor (quartz tube, length 400 $\mathrm{mm}$, internal diameter $2 \mathrm{~mm})$ at $550{ }^{\circ} \mathrm{C}$. The catalyst particles $(\sim 35 \mathrm{mg})$ were sieved (particle size $0.1-0.3 \mathrm{~mm}$ ) and packed between two quartz-wool plugs (length approximately $10 \mathrm{~mm}$ each). The remaining volume of the reactor was filled up with quartz particles, in order to reduce the void space and minimize gas phase reactions. Before each titration test, the catalysts were pre-treated in $10 \%$ of $\mathrm{O}_{2}$ in He flow $\left(20 \mathrm{ml} / \mathrm{min}, 30 \mathrm{~min}\right.$.) at $720{ }^{\circ} \mathrm{C}$ in order to remove any trace of water or inorganic compounds physisorbed on the surface and in order to keep the catalyst oxygen level as high as possible. The samples were cooled down to reaction temperature under the same atmosphere, and afterwards the gas flow was changed to $\mathrm{He}(3 \mathrm{ml} / \mathrm{min})$. After flowing pure $\mathrm{He}$ for $15 \mathrm{~min}$, pulses of $300 \mu \mathrm{l}$ at atmospheric pressure containing $10 \% \mathrm{C}_{3} \mathrm{H}_{8}$ in He were introduced. After pulsing with propane is completed, the catalyst is re-oxidize by pulsing with $10 \% \mathrm{O}_{2}$ in He. In all experiments, the regeneration process was confirmed by subsequent propane pulses (not shown here), resulting in identical product distributions as compared to experiments with fresh material.

Product distributions were monitored by sampling on-line to a quadrupole mass spectrometer (Pfeiffer AG Balzers, OmniStar) equipped with Channeltron and Faraday detectors (2-200 amu). Prior to each experiment, the fragmentation patterns of fresh propane and fresh oxygen were recorded allowing quantitative determinations of propane and oxygen with an experimental error of about 5\%. Water, propane and oxygen were identified by monitoring $\mathrm{m} / \mathrm{z}=18,29$ and 32 , respectively, since no other products contributed significantly to these $\mathrm{m} / \mathrm{z}$ signals. The concentrations of methane, ethane, ethylene, propylene, carbon mono- and dioxide were calculated semi-quantitatively with a matrix calculation in order to 
account for cross-contamination effects; quantitative calibration for these compounds was not available.

Apparent selectivities were calculated based on the integrated area of peaks of the corresponding $\mathrm{m} / \mathrm{z}$ signals of each compound divided by total integrated areas of the peaks of all carbon containing products (e.g. for methane: $\mathrm{A}\left(\mathrm{m}_{/} \mathrm{Z}_{\mathrm{CH} 4}\right) / \mathrm{A}\left(\mathrm{m}_{/} \mathrm{z}_{\mathrm{CH} 4}\right)$ $\left.+\mathrm{A}\left(\mathrm{m}_{/} \mathrm{z}_{\mathrm{C} 2 \mathrm{H} 6}\right)+\mathrm{A}\left(\mathrm{m}_{/} \mathrm{z}_{\mathrm{C} 2 \mathrm{H} 4}\right)+\mathrm{A}\left(\mathrm{m}_{/} \mathrm{z}_{\mathrm{C} 3 \mathrm{H} 6}\right)+\mathrm{A}\left(\mathrm{m}_{/} \mathrm{z}_{\mathrm{CO}}\right)+\mathrm{A}\left(\mathrm{m}_{/} \mathrm{z}_{\mathrm{CO} 2}\right)\right)$. The conversion of propane was below the detection limit when pulsing propane to the reactor filled with quartz particles exclusively and therefore we exclude gas phase contribution during the pulse tests. The amount of oxygen removed from the fresh catalyst during propane pulsing was quantified with help of back-titration with $\mathrm{O}_{2}$.

\subsection{Results}

\subsubsection{Characterization}

The investigated materials showed similar, relatively small BET surface areas as reported in Table 3.1. It is important to stress that the surface areas of LT-samples exposed during the pulse experiments are similarly low and thus the diffusion distance between surface and bulk of the oxides is similar. Slightly higher surface area $\left(9.3 \mathrm{~m}^{2} / \mathrm{g}\right)$ was reported by Liu et al. [26], probably due to the lower calcination temperature used $\left(800^{\circ} \mathrm{C}\right)$.

Table 3.1: Surface areas and calcination temperature of the three investigated materials.

\begin{tabular}{|ccc|}
\hline Catalyst & $\begin{array}{c}\text { Calcination } \\
\text { Temperature }\left({ }^{\circ} \mathrm{C}\right)\end{array}$ & $\begin{array}{c}\text { Surface } \\
\text { Area }\left(\mathrm{m}^{2} / \mathrm{g}\right)\end{array}$ \\
\hline PBC-LT & 900 & 1.0 \\
\hline PBC-HT & 1200 & 0.5 \\
\hline BSCF-LT & 950 & 1.6 \\
\hline BSCF-HT & 1100 & n.d. ${ }^{(\mathrm{a})}$ \\
\hline LN-LT & 1050 & 2.5 \\
\hline LN-HT & 1400 & 0.4 \\
\hline
\end{tabular}

a) Not determined 
The XRD patterns of LT-samples (fig. 3.1a, 3.2a and 3.3a) demonstrated good cristallinity of the catalysts and all peaks could be assigned to either single perovskite (BSCF) or perovskite like-structure (PBC and LN) [27-30]. Calcination at high temperature resulted in very similar XRD patterns for LN and BSCF, the only difference being that high temperature calcination results in narrower, better resolved and more intense peaks due to crystal growth (fig. 3.2b and 3.3b). High temperature calcination of PBC (fig. 3.1b) resulted in the presence of additional peaks $(2 \theta=32.8,47.8,53.6,58.8$ and 68.8 , indicated with arrows in fig. 3.1b) as compared to PBC-LT, indicating the formation of an orthorhombic phase [31]. It should be noted that the asymmetry of the peaks in the diffractogram of PBC-LT indicates that the same phase is also present in PBC-LT, be it at much lower concentration.

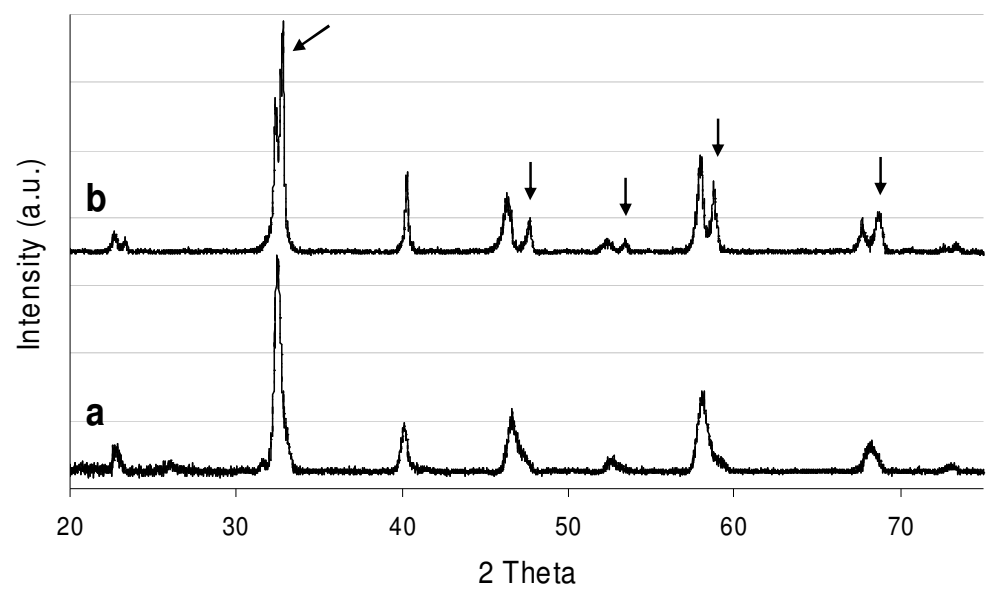

Fig 3.1: XRD spectrum of PBC sintered at $900{ }^{\circ} \mathrm{C}\left(\right.$ a) and sintered at $1200{ }^{\circ} \mathrm{C}(\mathrm{b})$. 


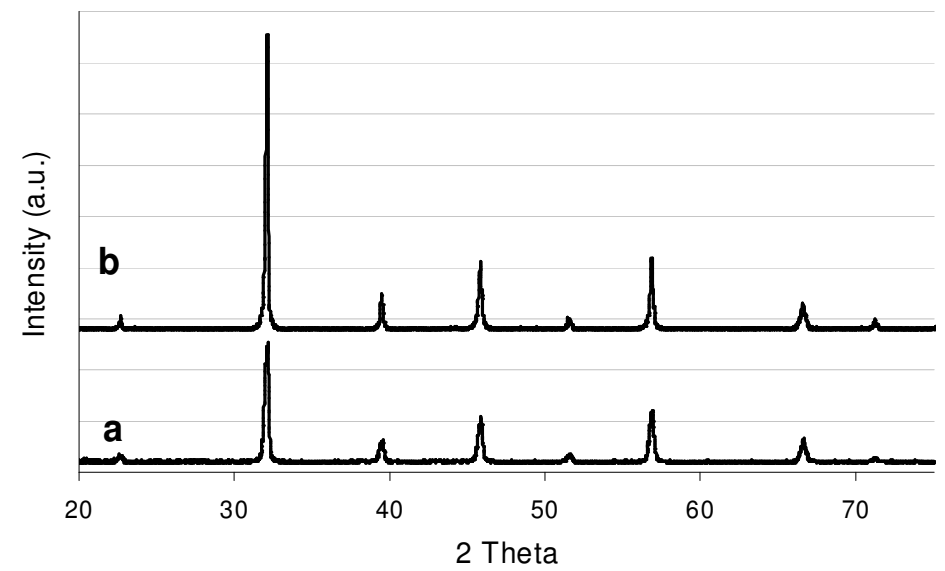

Fig 3.2: XRD spectrum of BSCF sintered at $950{ }^{\circ} \mathrm{C}\left(\right.$ a) and sintered at $1100{ }^{\circ} \mathrm{C}(\mathrm{b})$.

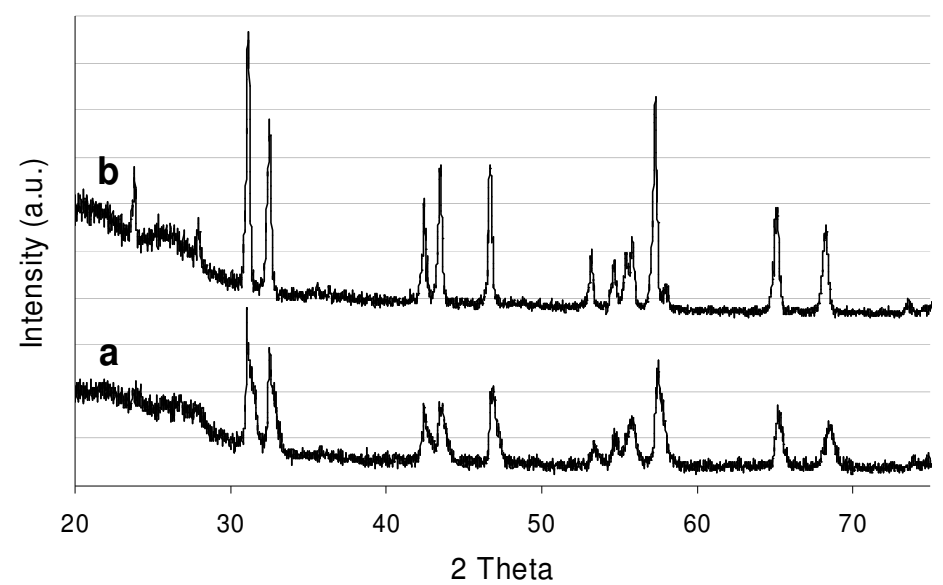

Fig 3.3: XRD spectrum of $L N$ sintered at $1050{ }^{\circ} \mathrm{C}\left(\right.$ a) and sintered at $1400{ }^{\circ} \mathrm{C}(\mathrm{b})$.

Oxygen permeation increased with temperature for all three samples, as illustrated in fig. 3.4. The oxygen permeation values for BSCF in the range $0.93<1000 / \mathrm{T}<$ 1.027 were reported in literature by Wang et al. [10] and a linear extrapolation to lower temperatures will be used for comparison with LN and PBC. The permeability of the three material differs a few orders of magnitude in the order $\mathrm{BSCF}>\mathrm{PBC}>\mathrm{LN}$. 


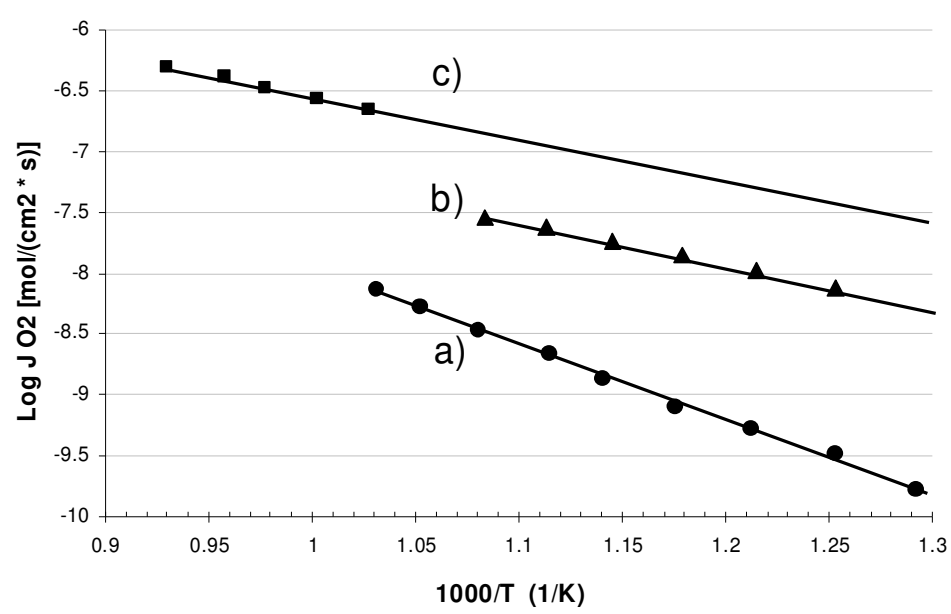

Fig. 3.4: Arrhenius plot of oxygen permeation fluxes through $L N(a), P B C(b)$ and $B S C F(c)$ membranes. BSCF data taken from [10].

TPR profiles of the three samples are shown in fig. 3.5. Two distinctive reduction steps are visible at $\sim 300{ }^{\circ} \mathrm{C}$ and $650{ }^{\circ} \mathrm{C}$ for $\mathrm{LN}$, typical for $\mathrm{K}_{2} \mathrm{NiF}_{4}$-type of materials [32]. The two peaks were assigned to reduction of $\mathrm{Ni}^{3+}$ to $\mathrm{Ni}^{2+}$ and $\mathrm{Ni}^{2+}$ to Ni metal, respectively [33], as discussed in detail in chapter 4 [20]. In case of PBC, three reduction steps were observed at 220,350 and $450{ }^{\circ} \mathrm{C}$ which have not been assigned in literature. Note that the small peak at $220{ }^{\circ} \mathrm{C}$ is only visible in the enlarged insert of fig. 3.5. We suggest that these reduction steps are related to stepwise reductions of $\mathrm{Co}^{4+}$ to $\mathrm{Co}$ metal, inspired by the reduction temperatures of $\mathrm{CoO}_{2}[34,35]$ occurring in multiple steps $\left(\mathrm{CoO}_{2} \rightarrow \mathrm{CoO}(\mathrm{OH}) \rightarrow \mathrm{Co}_{3} \mathrm{O}_{4} \rightarrow \mathrm{CoO} \rightarrow\right.$ Co metal). As the first peak at $220^{\circ} \mathrm{C}$ is much smaller than the subsequent peaks, it is clear that the metal ion responsible for this reduction peak $\left(\right.$ e.g. $\left.\mathrm{Co}^{4+}\right)$ is present at low concentration. Reduction of BSCF showed three reduction steps at 350, 420 and $480{ }^{\circ} \mathrm{C}$. In literature, these were related to reduction of $\mathrm{Co}^{4+}$ and $\mathrm{Fe}^{4+}$, which are stable oxidation states in perovskite materials, to lower oxidation states [12, 36 - 38]. Comparing the TPR profiles of $\mathrm{BSCF}$ and bulk $\mathrm{CoFe}_{2} \mathrm{O}_{4}$ [39] we suggest that the peak at $350{ }^{\circ} \mathrm{C}$ is related to the reduction of $\mathrm{Fe}^{4+}$ to $\mathrm{Fe}_{3} \mathrm{O}_{4}$ while the two peaks at higher temperature are related to stepwise reduction of $\mathrm{Co}^{4+}$ to $\mathrm{Co}^{0}$. The amount of oxygen removed from BSCF during TPR is $6.8 \mathrm{mmol} / \mathrm{g}$, which agrees surprisingly well with the amount of oxygen removed, assuming reduction of $\mathrm{Fe}_{2} \mathrm{O}_{3}$ and $\mathrm{Co}_{2} \mathrm{O}_{3}$ completely to $\mathrm{Co}$ and $\mathrm{Fe}$ metal. However, it is known that BSCF contains $\mathrm{Fe}^{4+}$ and $\mathrm{Co}^{4+}$, and therefore the TPR experiment apparently results in a mixture of Co and $\mathrm{Fe}$ in both metallic and $2+$ states. 
Considering the onset temperatures of the first reduction steps for the three catalyst, which is highlighted in the insert in fig. 3.5, initial removal of oxygen is more facile in the order $\mathrm{PBC}>\mathrm{LN}>\mathrm{BSCF}$.

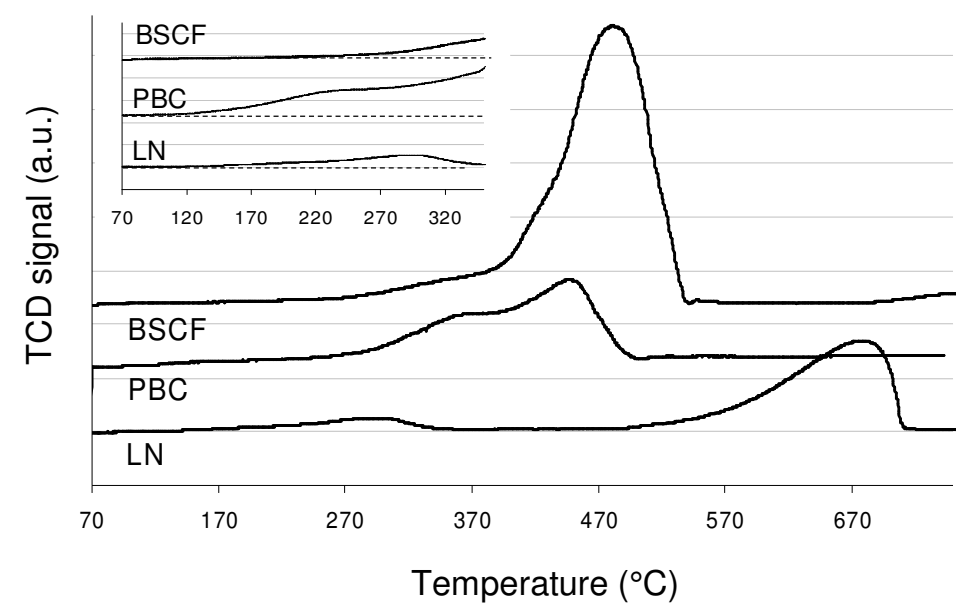

Fig. 3.5: Temperature programmed reduction in $\mathrm{H}_{2}$ of fresh $L N, P B C$ and $B S C F$. The insert is an enlargement of the same figure.

\subsubsection{Pulse experiments}

The propane conversion over $\mathrm{PBC}, \mathrm{LN}$ and $\mathrm{BSCF}$ during pulse experiments at 550 ${ }^{\circ} \mathrm{C}$ (fig. 3.6) showed higher activity for $\mathrm{PBC}$ catalyst (fig. 3.6a) compared to the other materials, during the first six pulses. BSCF (fig. 3.6c) showed a slightly higher activity than LN (fig. 3.6b), except for the first pulse. The conversion for all three materials decreased with the number of pulses to around 5\% and only in case of LN a sudden increase in the conversion up to $50 \%$, was observed after the fourteenth pulse. Please note that the pulse experiment on $\mathrm{LN}$ at $550{ }^{\circ} \mathrm{C}$ is discussed in detail in chapter 4 and the main results are reported here in order to allow comparison with the results on $\mathrm{BSCF}$ and $\mathrm{PBC}$. 


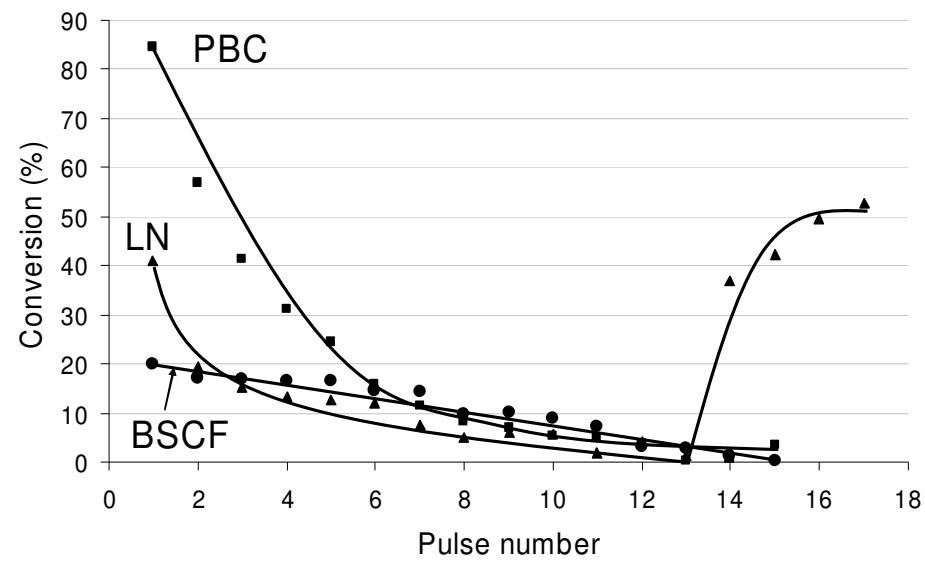

Fig. 3.6: Propane conversion profile during pulse tests at $550{ }^{\circ} \mathrm{C}$ on $L N, P B C$ and $B S C F$.

The product distribution during pulsing over freshly oxidized PBC (fig. 3.7) shows $\mathrm{CO}_{2}$ and $\mathrm{H}_{2} \mathrm{O}$ as the main products, while production of propylene was low throughout the experiment. $\mathrm{CO}_{2}$ formation decreased with the number of pulses while ethylene, propylene and methane formation increased (fig. 3.7).

After the titration test, the catalyst was regenerated by pulsing oxygen (fig. 3.7, right hand side) and formation of $\mathrm{CO}_{2}$ was observed, testifying that carbon was deposited on the catalyst surface. The $\mathrm{O}_{2}$ level reached a plateau value after eight pulses, equal to blank $\mathrm{O}_{2}$ pulses, indicating complete regeneration of the samples. It is remarkable that $\mathrm{CO}_{2}$ was not detected during the first two oxygen pulses, and we suggest that the catalyst is partly re-oxidized first, before carbon combustion started. The total amount of atomic oxygen consumed during regeneration, employed to both re-oxidize the catalyst and to combust coke, was $0.350 \mathrm{mmol} / \mathrm{g}$. 


\section{Chapter 3}
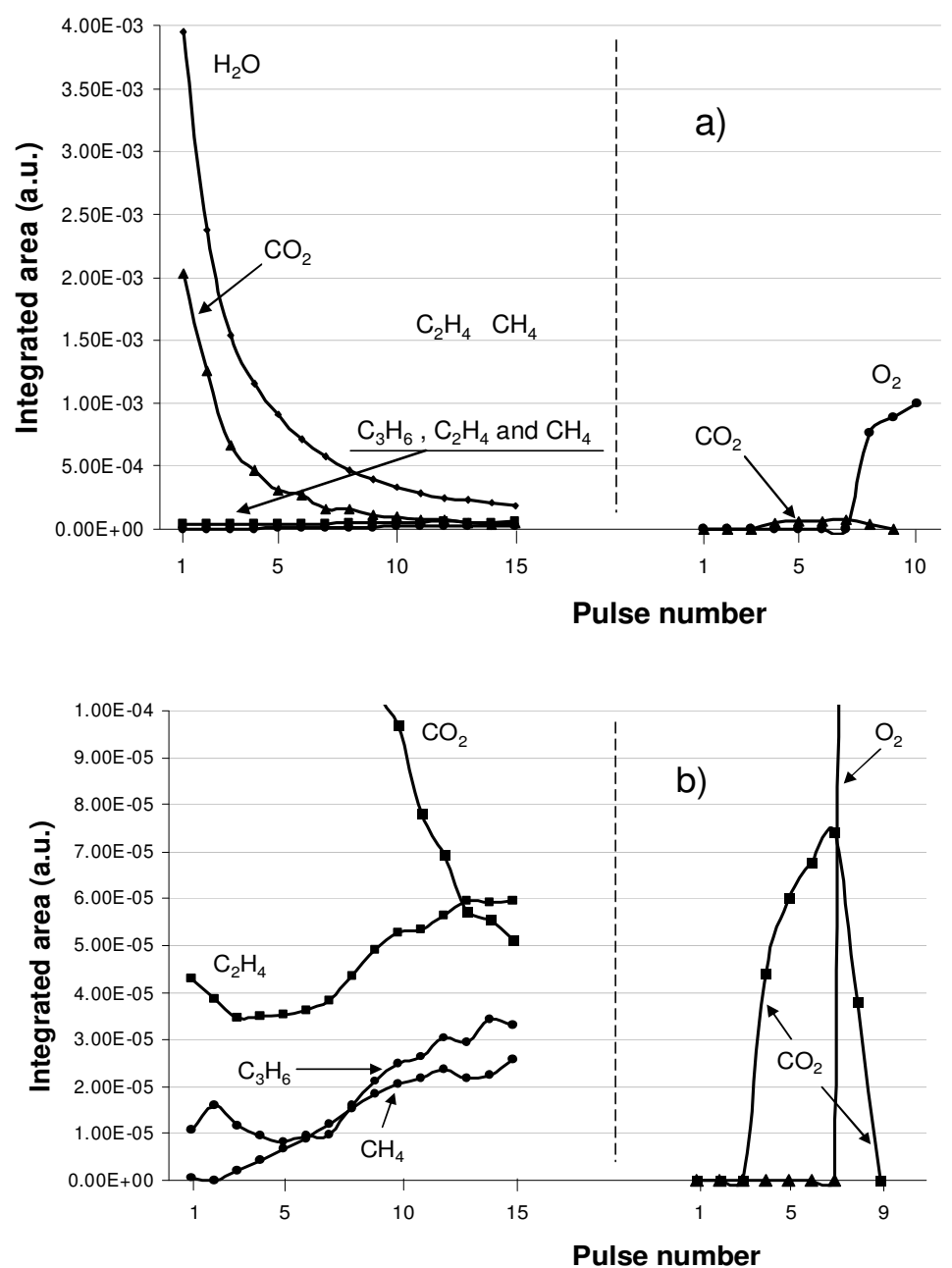

Fig. 3.7: Products distribution during the titration test on $P B C$ at $550^{\circ} \mathrm{C}$ (a, left hand side) and regeneration profile of the catalyst by $\mathrm{O}_{2}$ pulse ( $a$, right hand side). Zoom in of fig. 3.7a (b). 
As it will be discussed in details in chapter 4 and 5, in the case of $\mathrm{LN}$ at $550{ }^{\circ} \mathrm{C}$ (fig. 3.8 ), the active sites for activating propane changed from over-stoichiometric oxygen, responsible for formation of $\mathrm{CO}_{2}, \mathrm{CH}_{4}, \mathrm{C}_{2} \mathrm{H}_{4}, \mathrm{C}_{3} \mathrm{H}_{6}$ and $\mathrm{H}_{2} \mathrm{O}$, to lattice oxygen and $\mathrm{Ni}$ metal, responsible for formation of $\mathrm{CO}, \mathrm{CH}_{4}$ and carbonaceous species [20, 40, 41]. It will be also reported that carbon deposition occurs exclusively after the eleventh propane pulse [40].

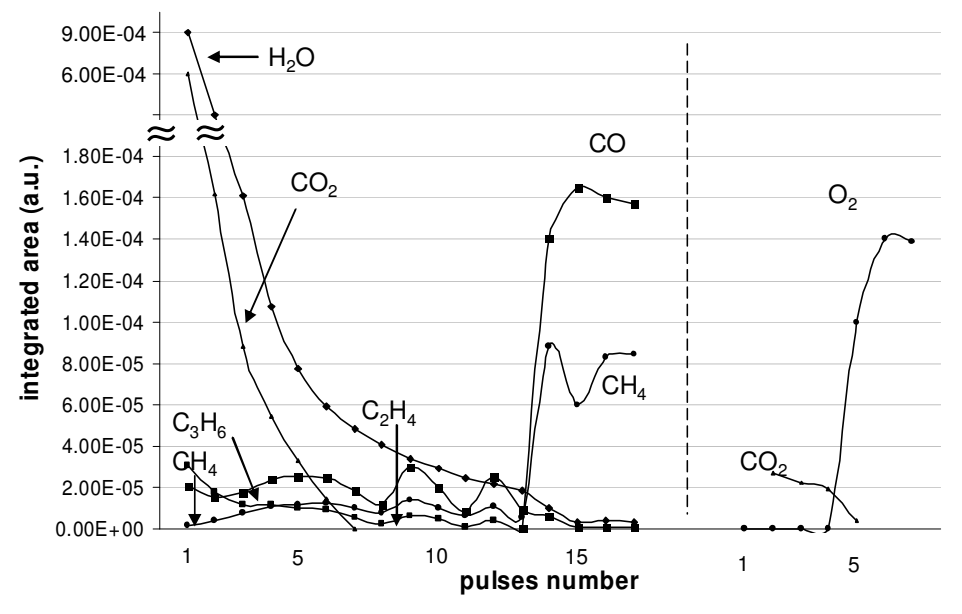

Fig. 3.8: Products distribution during the titration test on $L N$ at $550^{\circ} \mathrm{C}$ (left hand side) and regeneration profile of the catalyst by $\mathrm{O}_{2}$ pulse (right hand side) [20].

The product distribution during pulse experiment over freshly oxidized BSCF at $550{ }^{\circ} \mathrm{C}$ (fig. 3.9) showed $\mathrm{H}_{2} \mathrm{O}$ as main product while $\mathrm{CO}_{2}$ was formed as the minor compound. Significant formation of ethylene and propylene was also observed. Continuing pulsing, the $\mathrm{CO}_{2}$ formation decreased below the MS detection limit, while olefins were constantly produced. Also the formation of $\mathrm{CH}_{4}$ was constant for all pulses throughout the experiment.

Interestingly, no $\mathrm{CO}_{2}$ was detected during the regeneration after propane pulses, testifying that no carbon was deposited on the catalyst surface. The total amount of atomic oxygen consumed to regenerate the catalyst was $0.160 \mathrm{mmol} / \mathrm{g}$. 


\section{Chapter 3}

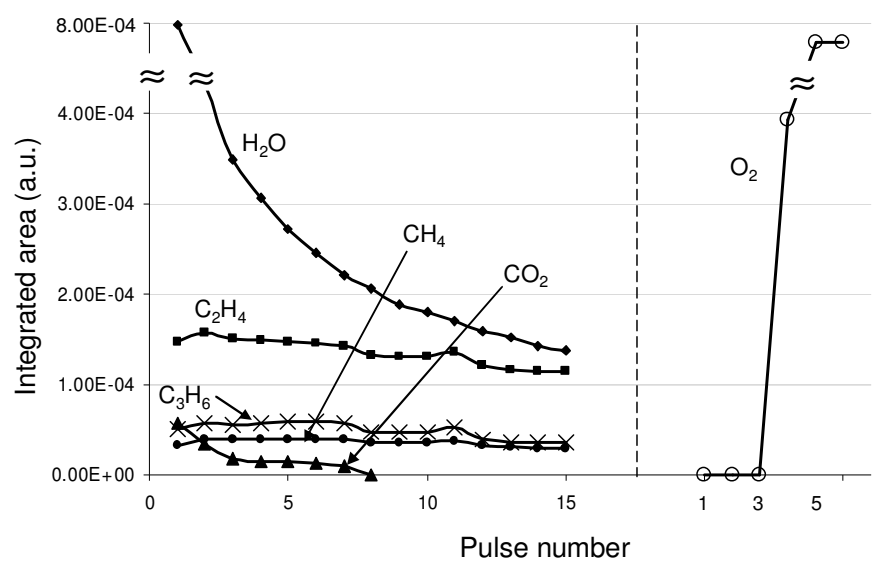

Fig. 3.9: Products distribution during the titration test on $B S C F$ at $550^{\circ} \mathrm{C}$ (left hand side) and regeneration profile of the catalyst by $\mathrm{O}_{2}$ pulse (right hand side).

After the regeneration with oxygen pulses, the BSCF catalyst was cooled down to room temperature in oxygen and TPD analysis was performed in He. Desorption of $\mathrm{CO}_{2}$ was detected starting at around $600{ }^{\circ} \mathrm{C}$ and reaching a maximum at $860^{\circ} \mathrm{C}$, as shown in fig. 3.10. The amount of $\mathrm{CO}_{2}$ desorbed during the TPD was $5.0 * 10^{-5}$ mol. It is suggested that this peak is mainly due to decomposition of $\mathrm{Ba}$ and $\mathrm{Sr}$ carbonates, based on similar observation in literature [37, 42 - 45]. This also agrees with the fact that decomposition of $\mathrm{Ba}_{\mathrm{x}} \mathrm{Sr}_{1-\mathrm{x}} \mathrm{CO}_{3}$ is reported to occur between 700 and $900{ }^{\circ} \mathrm{C}$ [46]. However, we cannot exclude that $\mathrm{CO}_{2}$ desorption contributes to the signal in fig. 3.10 at lower temperatures [45].

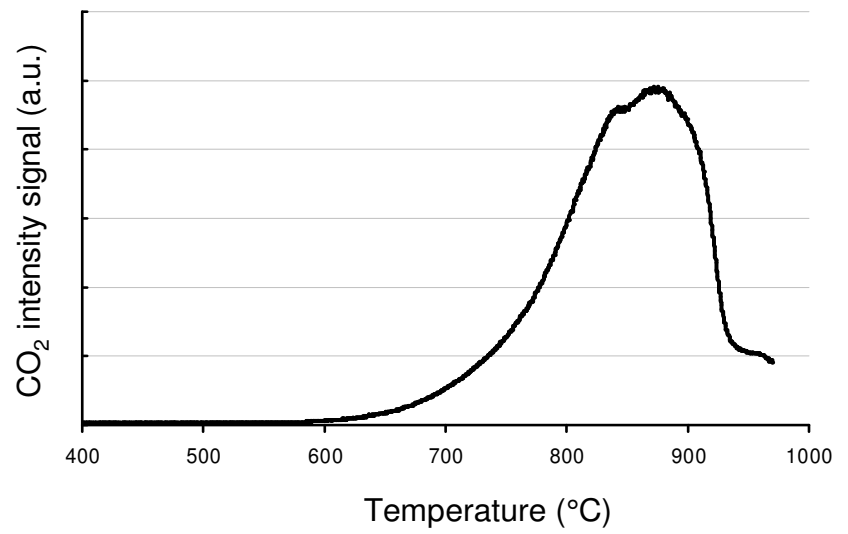

Fig. 3.10: $\mathrm{CO}_{2}-\mathrm{TPD}$ profile of spent $\mathrm{BSCF}$ after propane pulse experiment at $550{ }^{\circ} \mathrm{C}$. 


\subsection{Discussion}

The materials showed different reactivity during the first propane pulse, resulting in 85,40 and $20 \%$ conversion of propane for PBC, $\mathrm{LN}$ and BSCF, respectively. This result is in line with the onset temperatures of the three materials in TPR, showing a first reduction step at 220,300 and $350{ }^{\circ} \mathrm{C}$ for PBC, LN and BSCF, respectively (fig. 3.5). The fact that the amount of oxygen removed during the pulse experiment at $550{ }^{\circ} \mathrm{C}$ is a small fraction of the amount of oxygen that can be removed during TPR (less than $10 \%$ in all cases) confirms that the onset reduction temperatures is the preferred indicator of oxygen reactivity during the pulse experiment, rather than the temperature of the maximum of the TPR peak. Additionally, we suggest that the decreasing propane conversion with the pulse number for all three catalysts is due to decreasing reactivity of remaining oxygen species, due to the removal of oxygen, similar to what will be reported for $\mathrm{LN}$ in chapter 4 [20].

Product distributions at different catalyst reduction degree are also relevant for the applicability of materials as catalytic dense membranes. $\mathrm{CO}_{2}$ was the main carboncontaining product over $\mathrm{PBC}$ and $\mathrm{LN}$ initially, while pulsing propane over BSCF resulted in formation of mainly $\mathrm{C}_{2} \mathrm{H}_{4}$ (fig 3.11).

Continuing pulsing, thus decreasing the catalyst oxidation degree, PBC showed $\mathrm{CO}_{2}$ as the main product as well as significant carbon deposition throughout the experiment (fig 3.7b), resulting in low selectivity to propylene. Therefore, $\mathrm{PBC}$ is considered not suitable for selective oxidation of propane at $550{ }^{\circ} \mathrm{C}$ due to the too high reactivity of oxygen ions, resulting in mainly deep oxidation. Better selectivity might be achievable by decreasing the reaction temperature. On the other hand, also the permeability decreases with temperature (fig. 3.4) [21], lowering the permeation rates which would be unfavorable for CDMR application. More investigation would be needed to clarify this.

In the case of $\mathrm{LN}$, the $\mathrm{CO}_{2}$ formation rapidly decreased and a window of oxidation degrees with promising selectivity to propylene of $60 \%$ was observed, between pulse number 7 and 13 (fig. 3.11). This is the window in which the surface of LN exposed to propane should be operated as CDMR, in order to achieve high selectivity to propylene. In fact, further reduction of $\mathrm{LN}$ would cause the reduction of $\mathrm{Ni}^{2+}$ to $\mathrm{Ni}$ metal, changing the product distribution drastically to $\mathrm{CO}, \mathrm{CH}_{4}$ and carbon, as discussed in detail in chapter 5 [40] and in literature [41, 47].

Contrary, BSCF showed stable apparent selectivities to propylene and ethylene, evidencing constant rates for propane dehydrogenation and cracking (fig 3.11c). Interestingly, $\mathrm{CO}_{2}$ was detected in very low extent during the first six pulses and could not be detected at all in next pulses, whereas coke deposition was not observed. However, a significant release of $\mathrm{CO}_{2}\left(5.0 * 10^{-5} \mathrm{~mol}\right)$ was detected in the temperature range between 600 and $900{ }^{\circ} \mathrm{C}$ when performing a TPD experiment on spent BSCF catalyst (fig. 3.10), suggesting that most of the formed $\mathrm{CO}_{2}$ was adsorbed on the surface of the catalyst during the pulse experiment. 
Chapter 3
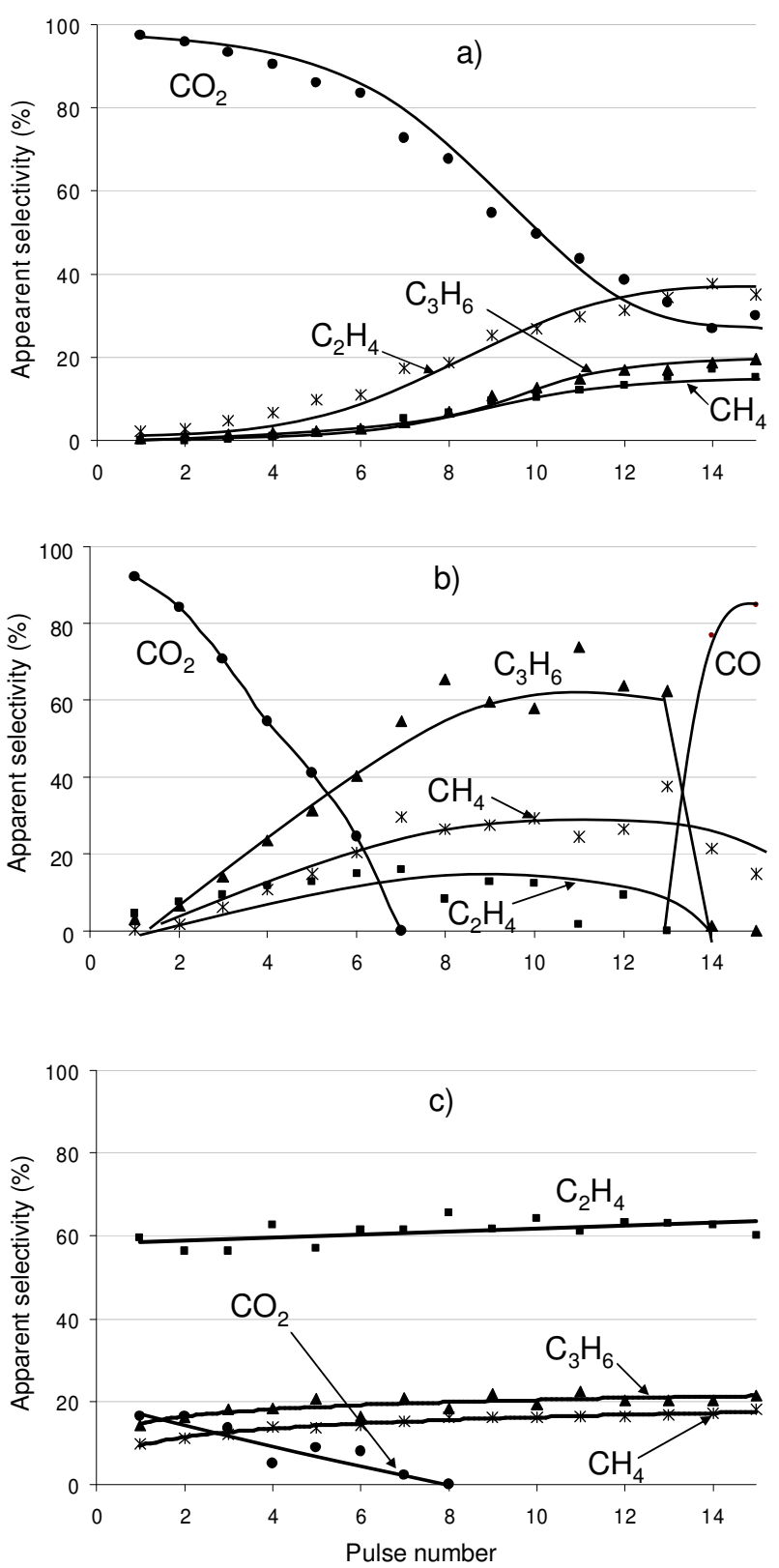

Fig. 3.11: Apparent selectivities of $\mathrm{C}_{3} \mathrm{H}_{6}, \mathrm{C}_{2} \mathrm{H}_{4}, \mathrm{CH}_{4}, \mathrm{CO}_{2}$ and $\mathrm{CO}$ during pulse experiments at $550{ }^{\circ} \mathrm{C}$ over $P B C(a), L N(b)$ and $B S C F(c)$. 
Therefore, the amount of $\mathrm{CO}_{2}$ formed based on $\mathrm{MS}$ analysis is strongly underestimated, misleading the apparent selectivities reported in fig. $3.11 \mathrm{c}$. Moreover, the $\mathrm{CO}_{2}$ detected during TPD contains an order of magnitude more carbon than the amount of carbon contained in the propane fed during pulsing, suggesting that the material adsorbed $\mathrm{CO}_{2}$ during storage in air. However, regeneration of BSCF by pulsing with $\mathrm{O}_{2}$ at $550{ }^{\circ} \mathrm{C}$ was remarkably successful, as the reactivity is completely recovered to the level of fresh catalyst (fig. 3.6 and 3.9). Apparently, the variation in the concentration of carbonate and/or adsorbed $\mathrm{CO}_{2}$ on the catalyst is not influencing the reactivity of BSCF with propane. Decreasing reactivity during propane pulsing is therefore due to the removal of oxygen from the oxide, and not due to carbonate formation. Apparently, formation of carbonate does not affect accessibility or reactivity of oxygen ions in $\mathrm{BSCF}$, which is remarkable because formation of carbonate layers, containing $\mathrm{SrCO}_{3}, \mathrm{BaCO}_{3}$ and $\mathrm{Sr}_{\mathrm{x}} \mathrm{Ba}_{1-\mathrm{x}} \mathrm{CO}_{3}$ on BSCF is reported in literature [37, $42-45]$. Our result shows that catalyst deactivation via formation of a carbonate layer is not taking place under our conditions and that BSCF retains its redox properties. It was reported that oxygen permeation through Ba- and Sr-based perovskite membrane deteriorated by 30-50 $\%$ over a time period of about $100 \mathrm{~h}$, which was assigned to carbonate formation [42 - 44]. Therefore, we suggest that BSCF is probably not a good choice for CDMR as the long term formation of carbonate will probably affect the activity as well as the integrity of the material. Unfortunately, this conclusion cannot ne drawn based on pulse experiment alone because the uncertainty in the amount of $\mathrm{CO}_{2}$ formed.

The apparent selectivities of $\mathrm{PBC}$ and $\mathrm{LN}$ are compared at different conversion levels, as illustrated in fig. 3.12. At $5 \%$ conversion level, $\mathrm{PBC}$ showed $\mathrm{CO}_{2}$ as the main product while $\mathrm{LN}$ gives $\mathrm{C}_{3} \mathrm{H}_{6}$ and $\mathrm{CH}_{4}$ as major compounds, without significant formation of $\mathrm{CO}_{2}$. Increasing the level of conversion induces increasing apparent selectivity to $\mathrm{CO}_{2}$ for both $\mathrm{LN}$ and $\mathrm{PBC}$, whereas $\mathrm{CO}_{2}$ formation on $\mathrm{LN}$ is always lower as compared to PBC. Clearly, higher selectivity observed with LN is not due to differences in the conversion level, which occurs frequently because of the well known problem of consecutive conversion of propylene to $\mathrm{CO}_{\mathrm{x}}$.

Therefore, we can conclude that the superior performance of LN over BSCF is due to differences in the reactivity of lattice oxygen in these oxides.

Finally, it should be mentioned that the pulse experiments were performed over powdered materials (LT-samples in table 3.1), which were calcined at lower temperature than dense membrane (HT-samples in table 3.1). The XRD of both LTand HT- samples confirmed that the structures of LT and HT samples are identical. Therefore, it is reasonable to extend the conclusions based on experiments performed with material calcined at low temperature (between 900 and $1050{ }^{\circ} \mathrm{C}$ ) to selection of membrane materials, necessarily synthesized via calcination at higher temperature (between 1100 and $1400{ }^{\circ} \mathrm{C}$ ). 
Chapter 3
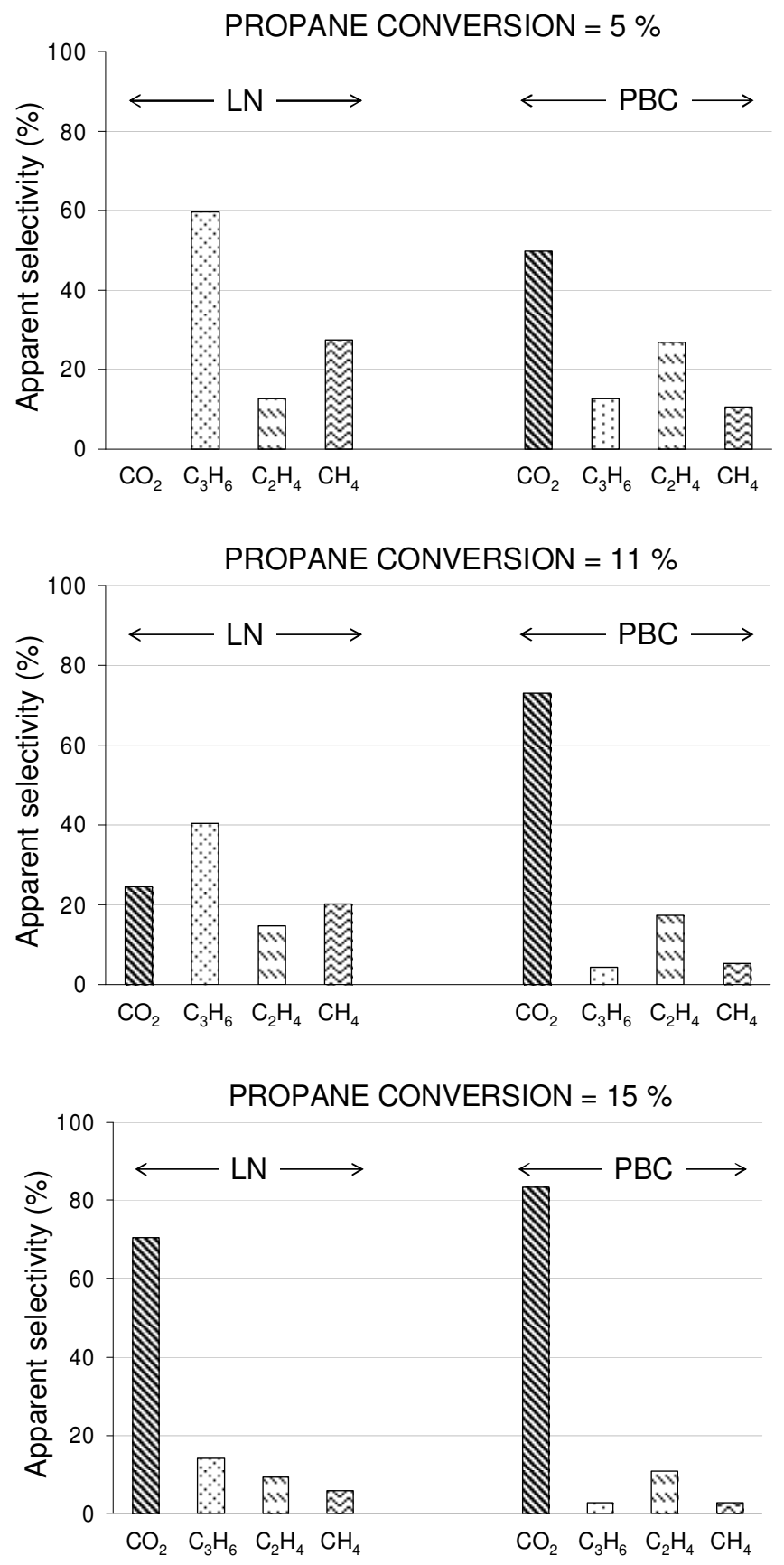

Fig. 3.12: Apparent selectivities to $\mathrm{C}_{3} \mathrm{H}_{6}, \mathrm{C}_{2} \mathrm{H}_{4}, \mathrm{CH}_{4}$ and $\mathrm{CO}_{2}$ at different conversion level during pulse experiments at $550{ }^{\circ} \mathrm{C}$ over $L N$ and $P B C$. 


\subsection{Conclusions}

It was shown in this chapter that pulse experiments can be used as method to select materials for operation of catalytic dense membrane reactors for selective oxidation of propane, providing that $\mathrm{CO}_{2}$ formed is not adsorbed on the surface of the catalyst. Pulse experiments reveal the intrinsic activity and selectivity of lattice oxygen-ions in the mixed oxides. $\mathrm{LN}$ is the most promising material for membrane application, provided that it is operated in the right window of reduction degree, to ensure high selectivity towards $\mathrm{C}_{3} \mathrm{H}_{6}$. According to the pulse experiments $\mathrm{PBC}$ is not suitable, showing low selectivity to $\mathrm{C}_{3} \mathrm{H}_{6}$ due to significant formation of $\mathrm{CO}_{2}$, independent of the oxidation degree of the material. BSCF appears to adsorb $\mathrm{CO}_{2}$ by forming carbonates. Therefore, pulse experiments fail to give reliable data on selectivity of BSCF in propane pulse experiments. However, pulse experiments revealed the remarkable stability of BSCF catalyst towards $\mathrm{CO}_{2}$. Despite the presence of carbonate, the material preserved the ability to act as an oxygen source for propane and can be completely regenerated via oxidation. Additionally, the reactivity with propane of lattice oxygen ions in the three materials clearly correlates with the onset temperature in TPR.

\section{Acknowledgements}

The author would like to thank Ing. C. Song for oxygen permeability tests, Dr. H.J.M Bouwmeester and Dr. C. Trionfetti for inspiring discussions related to this chapter. We thank the ASPECT programme of ACTS/NWO, The Netherlands for financial support (project number 053.62.004).

\section{References}

[1] J. Plotkin and E. Glatzer, Eur. Chem. News, 82 (2005) 20

[2] N. Alperowicz, Chem. Week, 169 (2007) 27

[3] N. Alperowicz, Chem. Week, 168 (2006) 17

[4] C. Sumner, PTC/US2004/038213

[5] R. K. Grasselli, D. L. Stern and J. G. Tsikoyiannis, Appl. Catal. A: Gen., 189 (1999) $1-8$

[6] T.A. Nijhuis, S.J. Tinnemans, T. Visser and B.M. Weckhuysen, Chem. Eng. Sci., 59 (2004) 5487

[7] F. Cavani, N. Ballarini and A. Cericola, Cat. Today 127 (2007) 113-131 
[8] A. Dinse, S. Khennache, B. Frank, C. Hess, R. Herbert, S. Wrabetz, R. Schlogl, R. Schomacker, J. of Molecular Catal. A 307 (2009) 43-50

[9] F. Ivars, B. Solsona, S. Hernandez, J.M. Lopez Nieto, Catal. Today, in press

[10] H. Wang, W.S. Yang, Y. Cong, X. Zhu, Y.S. Lin, J. Memb. Science 224 (2003) $107-115$

[11] A.L. Shaula, E.N. Naumovich, A.P. Viskup, V.V. Pankov, A.V. Kovalevsky, V.V. Kharton, Solid State Ionics 180 (2009) 812-816

[12] W,L. Chu, J.H. Tong, W.S. Yang, L. W. Lin, Chinese Chemical Letters 12 (2001) 975-978

[13] C. Guo, J. Zhang, X. Zhang, React. Kinet. Catal. Lett., 95 (2008) 89-97

[14] Gellings P.J., Bouwmeester H.J.M., The CRC handbook of Solid State Electrochemistry, pag. 512

[15] R. Merkle and J. Maier, Top. Catal., 38 (2006) 141-145

[16] J. C. Conesa, Catal. Today, 143 (2009) 315-325

[17] C. Trionfetti, I. V. Babich, K. Seshan and L. Lefferts, Top. Catal., 39 (2006) 191-197

[18] M. Hucker, K. Chung, M. Chand, T. Vogt, J.M. Tranquada, D.J. Buttrey, Phys. Rev. B 70 (2004) 064105

[19] L. Minervini, R. W. Grimes, J. A. Kilner and K. E. Sickafus, J. Mat. Chem., 10 (2000) 2349-2354

[20] S. Crapanzano, I.V. Babich and L. Lefferts, Appl. Catal A, in press

[21] G. Kim, S. Wang, A.J. Jacobson, L. Reimus, P. Brodersen, C.A. Mims, J. Mater. Chem. 17 (2007) 2500-2505

[22] C. Frontera, A. Caneiro, A.E. Carrillo, J. Oro-Sole, J.L. Garcia-Munoz, Chem. Mater. 17 (2005) 5439-5445

[23] A. Maignan, C. Martin, D. Pelloquin, N. Nguyen, B. Raveau, J. Solid State Chem. 142 (1999) 247-260

[24] V. Cherepanov, T. Aksenova, E. Kiselev, L. Gavrilova, Solid State Sciences 10 (2008) 438-443

[25] R.H.E. van Doorn, H. Kruidhof, A. Nijmeijer, L. Winnubst and A.J. Burggraaf, J. Mater. Chem., 1998, 8(9), 2109-2112

[26] B.S. Liu and C.T. Au, Appl. Catal. A: Gen. 244 (2003) 181-195

[27] M. Rebeilleau-Dassonneville, S. Rosini, A.C. van Veen, D. Farrusseng, C. Mirodatos, Cat. Today 104 (2205) 131-137

[28] I.A. Leonidov, M.V. Patrakeev, E.B. Mitberg, O.N. Leonidova, V.L. Kozhevnikov, Inorg. Mat. 42 (2006) 196-201

[29] D. Perez-Coll, A. Aguadero, M.J. Escudero, L. Daza, J. Power Sources 192 (2009) 2-13

[30] S.M de Lima, M.A. Pena, J.L.G. Fierro, J.M. Assaf, Catal. Lett. 124 (2008) 195-203

[31] X. Yang, L. Luo, H. Zhong, Appl. Catal. A 272 (2004) 299-303

[32] G. S. Gallego, F. Mondragon, J. Barrault, J.M. Tatibouet and C. BatiotDupeyrat, Appl. Catal. A: Gen. 311 (2006) 164-171 
[33] B. Zhao, R. Wang, W. Yao, X. Yang and B. Zhou, Catal. Lett. 132 (2009) 4149

[34] H.K. Lin, H.C. Chiu, H.C. Tsai, S.H. Chien, C.H. Wang, Catal. Letters 88 (2003) 169-174

[35] S. Nuori, T. Amran, Rasayan J. Chem. 2 (2009) 543-554

[36] Z. Shao, G. Xiong, J. Tong, H. Dong, W. Yang, Separation and Purification Technology 25 (2001) 419-429

[37] L. Ge, W. Zhou, R. Ran, S. Liu, Z. Shao, W. Jin, N. Xu, J. Membr. Science 306 (2007) 318-328

[38] Q. Zhu, T. Jin, Y. Wang, Solid state ionics 177 (2006) 1199-1204

[39] Q. Yang, H. Choi, S. R. Al-Abed, D. D. Dionysiou, Appl. Catal. B 88 (2009) 462-469

[40] S. Crapanzano, I.V. Babich and L. Lefferts, submitted to Appl. Catal. A

[41] K.P. De Jong, J.W. Geus, Catal. Rev. Sci. Eng., 42 (2000) 481-510

[42] M.F. Carolan, P.N. Dyer, J.M. LaBar Sr., R.M. Thorogood, US Patent, 5, 261, 932 (1993)

[43] M.F. Carolan, P.N. Dyer, S.M. Fine, J.M. LaBar Sr., R.M. Thorogood, US Patent, 5, 269, 822 (1993)

[44] M.F. Carolan, P.N. Dyer, J.M. LaBar Sr., R.M. Thorogood, US Patent, 5, 240, 473 (1993)

[45] A. Yan, V. Maragou, A. Arico, M. Cheng, P. Tsiakaras, Appl. Catal B 76 (2007) 320-327

[46] J.M. Criado, M.J. Dianez, M. Macias, Thermochimica Acta 171 (1990) 229238

[47] G. Sierra Gallego, F. Mondragon, J.M. Tatibouet, J. Barrault, C. BatiotDupeyrat, Catal. Today 133 (2008) 200-209 



\section{Effect of $\mathrm{V}$ in $\mathrm{La}_{2} \mathrm{Ni}_{\mathrm{x}} \mathrm{V}_{1-\mathrm{x}} \mathrm{O}_{4+\delta}$ on Selective Oxidative Dehydrogenation of Propane}

In this chapter, non-stoichiometric redox compounds such as $\mathrm{La}_{2} \mathrm{NiO}_{4+\delta}$, $\mathrm{La}_{2} \mathrm{Ni}_{0.95} \mathrm{~V}_{0.05} \mathrm{O}_{4.07+\delta}$ and $\mathrm{La}_{2} \mathrm{Ni}_{0.9} \mathrm{~V}_{0.1} \mathrm{O}_{4.15+\delta}$ have been tested as oxidants in selective oxidation of propane, in order to judge the suitability of these materials for a densemembrane reactor for selective propane oxidation. Reducibility of the samples has been investigated using temperature programmed reduction in $\mathrm{H}_{2} / \mathrm{Ar}$ flow. The catalysts' activity and selectivity at $550{ }^{\circ} \mathrm{C}$ have been investigated employing sequential pulses of diluted propane over the oxides.

Pulsing with propane induces step-by-step reduction of the oxide; consequently, the activity of remaining oxygen decreases with the number of pulses, affecting the products distribution. It is observed that at $550{ }^{\circ} \mathrm{C}$ on oxidized catalysts $\mathrm{CO}_{2}$ and $\mathrm{H}_{2} \mathrm{O}$ are the main products and the selectivity towards propylene is very low. At a certain reduction level, obtained after pulse 8 in our experiments, the production of $\mathrm{CO}_{2}$ stopped without changing the amount of $\mathrm{C}_{3} \mathrm{H}_{6}$ produced. At this stage, also $\mathrm{CH}_{4}$ and $\mathrm{C}_{2} \mathrm{H}_{4}$ are being formed. V-doped catalysts have shown a constant level of $\mathrm{C}_{3} \mathrm{H}_{6}$ production within a broad window of oxidation degree, while the performance of $\mathrm{La}_{2} \mathrm{NiO}_{4+\delta}$, catalyst deteriorated drastically after just a few pulses. $\mathrm{CO}, \mathrm{CH}_{4}$ and coke deposits are formed with $\mathrm{La}_{2} \mathrm{NiO}_{4+\delta}$, caused by the formation of metallic Ni. Vanadium is able to prevent this phenomenon, thus drastically broadening the window of selective oxidation of propane. 



\subsection{Introduction}

Selective oxidation of propane to light olefins is an important research subject since the demand of such olefins is growing. In the last few decades many catalytic systems have been investigated for this reaction including alkali salts [1], metal molybdates [2] and metal vanadates [3]. Promising performance of $\mathrm{V} / \mathrm{MgO}$ was reported, showing $60 \%$ selectivity to olefins at $15 \%$ propane conversion employing co-feed of gaseous $\mathrm{C}_{3} \mathrm{H}_{8}$ and $\mathrm{O}_{2}[4,5]$. The major challenge in selective catalytic oxidation of alkanes is the fact that the desired products are more reactive than the alkane reactant, causing domination of total combustion especially at high conversion level.

One effective way to minimize deep oxidation is to avoid the direct contact between products and reactants such as molecular gaseous oxygen. This approach can be used in a moving bed reactor [6] or in a catalytic dense membrane reactor (CDMR) [7]. In the last case, the membrane, as physical separator between products and oxygen, defines two separate compartments, where reaction and regeneration occurs respectively. In case of oxidative dehydrogenation of propane, the reactive side of the membrane is depleted in oxygen. Regeneration of the membrane surface at reaction side occurs via ionic permeation $\left(\mathrm{O}^{2-}\right.$ and/or $\left.\mathrm{O}^{-}\right)$through the membrane body, originated from oxidation of the membrane with molecular oxygen at the regeneration side. At the same time, to counter-balance the permeation of oxygen ions through the membrane body, migration of electrons in opposite direction occurs. Comparable ionic and electronic permeability rates are required to avoid charge accumulation, slowing down the diffusion of oxygen ions. If the reactivity of the surface oxygen and oxygen permeability are matched, continuous operation of the membrane reactor with high selectivity to olefins can be achieved. This would require tuning of the material composition, temperature as well as concentrations of propane and oxygen.

Suitable materials for this purpose are redox mixed metal oxides with a well organized structure, able to provide oxygen ions for oxidation reactions (Mars - Van Krevelen mechanism). Therefore materials such as perovskite and related compounds have been extensively studied for oxidative dehydrogenation of alkanes in CDMR mode. The ideal perovskite structure, indicated as $\mathrm{ABO}_{3}$, consists on a cubic arrangement of corner-sharing $\mathrm{BO}_{6}$ octahedra, where $\mathrm{B}$ is a transition metal cation. The A-site ions, located in interstitial position between the $\mathrm{BO}_{6}$ octahedra, are usually occupied by an alkali, alkali earth or rare earth ion [8], as shown in Fig. 4.1 for $\mathrm{LaNiO}_{3}$. 


\section{Chapter 4}

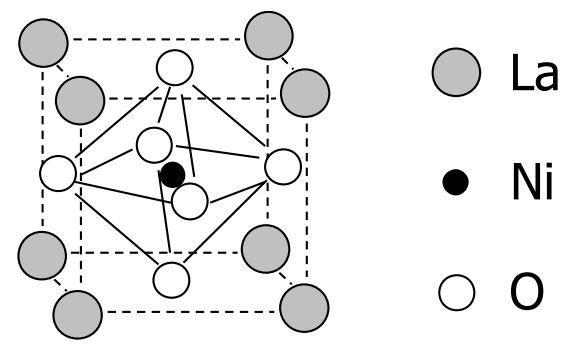

Fig. 4.1: Schematic representation of perovskite structure.

These materials allow easy red-ox transformations due to the presence of redox metals $(\mathrm{V}, \mathrm{Ni}, \mathrm{Mo}, \mathrm{Bi}, \mathrm{Fe})$. Synthesis conditions, like calcination temperature, partial pressure of oxygen, heating and cooling rate, affect the structure as well as the amount of oxygen in the samples, and consequently the amount of vacant sites. In the case of $\mathrm{LaNiO}_{3}$, it was shown that under oxidative atmosphere the perovskite structure is stable up to $850{ }^{\circ} \mathrm{C}[9,10]$. Exceeding that temperature, the material reversibly decomposes to $\mathrm{NiO}$ and $\mathrm{La}_{2} \mathrm{NiO}_{4}$, which shows a modified perovskite structure called $\mathrm{K}_{2} \mathrm{NiF}_{4}$-type structure. In the case of $\mathrm{K}_{2} \mathrm{NiF}_{4}$ structure, the material possesses a double layer structure: $\mathrm{Ni}$, octahedrally coordinated, is present in the perovskite layer and La, tetragonally coordinated, is present in a rock-salt layer, as shown in fig. 4.2.

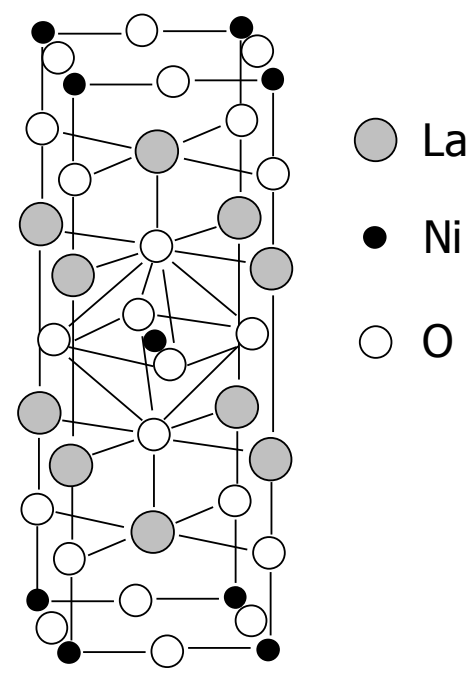

Fig. 4.2: Schematic representation of $\mathrm{K}_{2} \mathrm{NiF}_{4}$ structure for $\mathrm{La}_{2} \mathrm{NiO}_{4}$. 
Such changes in crystallographic structure obviously influence the thermodynamic activity of oxygen ions in the oxide. In fact, the re-arrangement of the material in the double layer structure enables the formation of "interstitial oxygen" in the interlayer position. This can bring about oxygen over-stoichiometry. As a result, $\mathrm{K}_{2} \mathrm{NiF}_{4}$ structure materials have one extra crystallographic type of oxygen ions which might have different thermodynamic activity as compared to strongly bonded lattice oxygen ions. The material is conventionally represented as $\mathrm{La}_{2} \mathrm{NiO}_{4+\delta}$, where $\delta$ corresponds to the amount of over-stoichiometric interstitial oxygen; $\mathrm{Ni}^{2+}$ is partially oxidized to $\mathrm{Ni}^{3+}$ in order to compensate for the extra negative charge [1113].

In addition, the chemical and physical properties of $\mathrm{K}_{2} \mathrm{NiF}_{4}$-type materials can be modified by adding dopants [14]. Structural distortion and variation of activity of oxygen species depend on ionic radius and valency of the dopant [15]. It was reported [16] that structural stability of $\mathrm{Eu}_{2} \mathrm{NiO}_{4}$ can be increased by adding $\mathrm{Sr}$ as dopant. Substitution of $\mathrm{Ni}^{2+}$ with $\mathrm{V}^{5+}$ in $\mathrm{La}_{2} \mathrm{NiO}_{4}$ brings extra positive charge to the material, which must be compensated with additional oxygen ions in interstitial positions or in oxygen vacant sites. To the best of our knowledge, the influence of addition of $\mathrm{V}$ on the reactivity of $\mathrm{O}^{2-}$ ions with propane was not addressed in the literature.

Reactivity of oxygen species can be elucidated from propane pulse experiments. Strictly speaking these are not catalytic experiments; nevertheless, we are using the term catalysts for brevity reasons. During the propane pulses the catalyst provides oxygen ion species to the reaction, increasing the reduction level of the materials with the number of pulses. Oxygen is not present in the gas phase, in contrast to classical co-feed catalytic test with propane and oxygen, and regeneration of the surface sites does not occur during the propane pulses, except for $\mathrm{O}^{2-}$ delivery from the bulk of the oxide. The consequent depletion of oxygen active species implies changes in the reactivity of the remaining oxygen species in the catalyst. In this way the influence of the reactivity of the oxygen species on conversion and selectivity can be determined. In addition, reaction pathways which involve gas phase oxygen and adsorbed oxygen are avoided.

In this chapter the variation of propane conversion and selectivity to olefins as a function of the reduction degree of $\mathrm{La}_{2} \mathrm{Ni}_{\mathrm{x}} \mathrm{V}_{1-\mathrm{x}} \mathrm{O}_{4+\delta}$ catalysts is reported. The role of $\mathrm{V}$ in enhancing the selectivity towards propylene is discussed. 


\subsection{Experimental}

\subsubsection{Catalyst preparation}

$\mathrm{La}_{2} \mathrm{NiO}_{4+\delta}(\mathrm{LN}), \mathrm{La}_{2} \mathrm{Ni}_{0.95} \mathrm{~V}_{0.05} \mathrm{O}_{4.07+\delta}(\mathrm{LNV}-05)$ and $\mathrm{La}_{2} \mathrm{Ni}_{0.9} \mathrm{~V}_{0.1} \mathrm{O}_{4.15+\delta}$ (LNV-10) were prepared via sol-gel method using EDTA as chelating agent [17]. The appropriate amount of $\mathrm{V}_{2} \mathrm{O}_{5}$ (Merck) was dissolved in diluted $\mathrm{HNO}_{3}$ (Merck) at 80 ${ }^{\circ} \mathrm{C}$ under stirring for $1 \mathrm{~h}$. A stoichiometric amount of $\mathrm{La}\left(\mathrm{NO}_{3}\right)_{3} * 6 \mathrm{H}_{2} \mathrm{O}$ (Merck), $\mathrm{Ni}\left(\mathrm{NO}_{3}\right)_{2} * 6 \mathrm{H}_{2} \mathrm{O}$ (Merck), EDTA and $\mathrm{NH}_{4} \mathrm{OH}$ solutions were added and the obtained solution was heated for 2 hours under stirring. After drying at $230{ }^{\circ} \mathrm{C}$, foam-type material was formed and pyrolysis took place after spontaneous ignition. The resulting solid mixed metal oxides were milled and calcined in air, slowly increasing temperature $\left(1{ }^{\circ} \mathrm{C} / \mathrm{min}\right)$ up to $1050{ }^{\circ} \mathrm{C}$. The resulting materials were finally ball milled in acetone for $5 \mathrm{~h}$ and dried at $80{ }^{\circ} \mathrm{C}$. The materials were sieved and particles size of $0.1-0.3 \mathrm{~mm}$ was used for all experiments.

\subsubsection{Characterization}

The chemical composition of samples were determined by X-ray fluorescence (XRF) using Philips (Panalytical) PW 1480 equipment.

Nitrogen adsorption measurements were carried out at $-196{ }^{\circ} \mathrm{C}$ with a Micromeritics Tristar system. Prior the adsorption measurements the samples were degassed at $300{ }^{\circ} \mathrm{C}$ and $10^{-3} \mathrm{~Pa}$ for $24 \mathrm{~h}$. The specific surface areas were calculated according to the Brunauer-Emmet-Teller (BET) method.

The crystal structure of the materials was determined in air with powder X-ray diffraction (XRD) using a Philips PW2050 (X'Pert-APD) diffractometer with $\mathrm{Cu}$ $\mathrm{K}_{\alpha}$ radiation $(\lambda=0.15406 \mathrm{~nm})$. Data were collected varying $2 \theta$ between 5 and $75^{\circ}$ with a step size of $0.005^{\circ}$ and a step time of $1 \mathrm{~s}$.

Temperature programmed reduction (TPR) of the samples was carried out with a home-built set-up, equipped with a TCD detector. First, $40 \mathrm{mg}$ of sample mixed with $40 \mathrm{mg}$ quartz particles were placed in a reactor with a $4 \mathrm{~mm}$ inner diameter and heated in a flow of $5 \% \mathrm{O}_{2}$ in $\mathrm{He}$ up to $500{ }^{\circ} \mathrm{C}\left(10{ }^{\circ} \mathrm{C} / \mathrm{min}\right)$ and kept at $500{ }^{\circ} \mathrm{C}$ for $1 \mathrm{~h}$. Then the sample was cooled down to room temperature in the same atmosphere. At room temperature the flow was changed to $5 \% \mathrm{H}_{2}$ in $\mathrm{Ar}$ and TPR was carried out with a heating rate of $5{ }^{\circ} \mathrm{C} / \mathrm{min}$ up to $980{ }^{\circ} \mathrm{C}$. The TCD was calibrated via reduction of $\mathrm{NiO}$. 


\subsubsection{Pulse experiments}

Pulse experiments were carried out in a fixed-bed reactor (quartz tube, length 400 $\mathrm{mm}$, internal diameter $2 \mathrm{~mm}$ ) at $550{ }^{\circ} \mathrm{C}$. About $35 \mathrm{mg}$ of catalyst were packed between two quartz-wool plugs (length approximately $10 \mathrm{~mm}$ each). The remaining volume of the reactor was filled with quartz particles, in order to reduce the void space and minimize gas phase reaction. Before each titration test, the catalysts have been pretreated in $10 \%$ of $\mathrm{O}_{2}$ in $\mathrm{He}$ flow $\left(20 \mathrm{ml} / \mathrm{min}, 30 \mathrm{~min}\right.$.) at $720{ }^{\circ} \mathrm{C}$ in order to remove any trace of water or inorganic compounds physisorbed on surface and keep the catalyst oxygen level as high as possible. The samples were cooled down to reaction temperature under the same atmosphere and gas flow was changed to $\mathrm{He}$ (3 $\mathrm{ml} / \mathrm{min}$ ).

After flowing pure $\mathrm{He}$ for $15 \mathrm{~min}$, pulses of $300 \mu \mathrm{l}$ at atmospheric pressure containing $10 \% \mathrm{C}_{3} \mathrm{H}_{8}$ in $\mathrm{He}$ were introduced and pulses of a $10 \%$ mixture of $\mathrm{O}_{2}$ in $\mathrm{He}$ were used to re-oxidize the catalyst, after exposure to $\mathrm{C}_{3} \mathrm{H}_{8}$ pulses. In all experiments, the regeneration process was confirmed by subsequent propane pulses (not shown here) which always resulted in identical products distribution as compared to fresh material.

The products distributions were monitored by sampling on-line with a heated capillary to a quadrupole mass spectrometer (Pfeiffer AG Balzers, OmniStar) equipped with Channeltron and Faraday detectors (2-200 amu). Prior to each experiment, the fragment pattern of diluted propane and diluted oxygen were recorded and compared with the fragment pattern of products gas mixture to qualitatively identify the product distribution. Water, propane, oxygen and carbon dioxide were identified monitoring $\mathrm{m} / \mathrm{z}=18,29,32$ and 44 , respectively, since no other possible products show additional significant contribution to those $\mathrm{m} / \mathrm{z}$ signals. To determine presence of methane, ethane, ethylene and propylene, two or three $\mathrm{m} / \mathrm{z}$ signals were monitored for each compound. Because of the similarity in fragmentation patterns and the consequent contribution of several products to the same $\mathrm{m} / \mathrm{z}$ signal (cross-contamination effect), matrix-type calculation was performed. In this way, formation of $\mathrm{CO}$ was also determined $v i a \mathrm{~m} / \mathrm{z}=28$, although many compounds as propane, ethylene and carbon dioxide contribute to $\mathrm{m} / \mathrm{z}=28$. These additional contributions were taken into account and subtracted from $\mathrm{m} / \mathrm{z}=28$, resulting in no significant detection of $\mathrm{CO}$ but small amount cannot be excluded. Attempt to determine production of $\mathrm{H}_{2}$ was done by following $\mathrm{m} / \mathrm{z}=$ 2 but unfortunately negative intensity of that signal was obtained (signal below the MS detection limit) which made the detection of $\mathrm{H}_{2}$ unreliable. This procedure allows quantitative determination of propane and oxygen conversion only, with an experimental error of about $5 \%$.

As the formation of products could not be quantified, only semi-quantitative comparison of selectivity patterns, called "apparent selectivity", will be reported. The apparent selectivity is based on the integrated area of peaks of the 
corresponding $\mathrm{m} / \mathrm{z}$ signals of each compound $v s$ time on stream, divided by total integrated areas of all carbon containing products (e.g. for methane: $A\left(m_{/} \mathrm{Z}_{\mathrm{CH} 4}\right)$ / $\left.\mathrm{A}\left(\mathrm{m}_{/} \mathrm{z}_{\mathrm{CH} 4}\right)+\mathrm{A}\left(\mathrm{m}_{/} \mathrm{z}_{\mathrm{C} 2 \mathrm{H} 6}\right)+\mathrm{A}\left(\mathrm{m}_{/} \mathrm{z}_{\mathrm{C} 2 \mathrm{H} 4}\right)+\mathrm{A}\left(\mathrm{m}_{/} \mathrm{z}_{\mathrm{C} 3 \mathrm{H} 6}\right)+\mathrm{A}\left(\mathrm{m}_{/} \mathrm{z}_{\mathrm{CO}}\right)+\mathrm{A}\left(\mathrm{m}_{/} \mathrm{z}_{\mathrm{CO} 2}\right)\right)$. In case of methane, ethane, ethylene and propylene, which were monitored using two or three $\mathrm{m} / \mathrm{z}$ signals, only the most intense signal was included in the figures.

The possible contribution of gas-phase reaction was checked by pulsing propane in the reactor filled with quartz particles only. The conversion of propane was below the detection limit and therefore we can exclude gas phase initiation during the pulse tests.

\subsection{Results and Discussion}

\subsubsection{Catalyst characterization}

\subsubsection{Chemical composition and surface area (BET and XRF analysis)}

The stoichiometric ratio of metals in the catalyst, measured with XRF analysis, is presented in Table 4.1 together with surface area values, according to $\mathrm{N}_{2}$ physisorption. The observed compositions are in a good agreement with the compositions expected based on the preparation procedures. Assuming specific oxidation state for each metal $\left(\mathrm{La}^{3+}\right.$ and $\mathrm{Ni}^{2+}$ for $\mathrm{LN}$ and $\mathrm{La}^{3+}, 90 \%$ of $\mathrm{Ni}^{2+}+10 \%$ of $\mathrm{Ni}^{3+}$ and $\mathrm{V}^{5+}$ for LNV10) the stoichiometric amount of oxygen can be calculated. The materials have similar, relatively small BET surface areas. This is important for our study because it implies that the diffusion distance between surface and bulk of the oxides is similar. Moreover, the surface areas exposed during the pulse experiments are equivalent. Liu et al. [18] reported a slightly higher value of 9.3 $\mathrm{m}^{2} / \mathrm{g}$ for LN, which is probably due to the lower sintering temperature used in that study $\left(800^{\circ} \mathrm{C}\right)$.

Table 4.1: Stoichiometric ratio of metals and surface areas of investigated samples.

\begin{tabular}{|ccccc|}
\hline \multirow{2}{*}{ Catalyst } & \multicolumn{3}{c}{ Stoichiometric ratio (XRF) } & Surface area \\
\cline { 2 - 4 } & $\mathrm{La}$ & $\mathrm{Ni}$ & $\mathrm{V}$ & $\mathrm{m}^{2} / \mathrm{g}$ \\
\hline LN & 2.0 & 1.01 & - & $2.3 \pm 0.2$ \\
\hline LNV-05 & 2.0 & 0.96 & 0.05 & $2.0 \pm 0.2$ \\
\hline LNV-10 & 2.0 & 0.90 & 0.10 & $2.0 \pm 0.2$ \\
\hline
\end{tabular}


The X-ray diffraction patterns obtained for LN and LNV-10 are shown in Fig. 4.3.

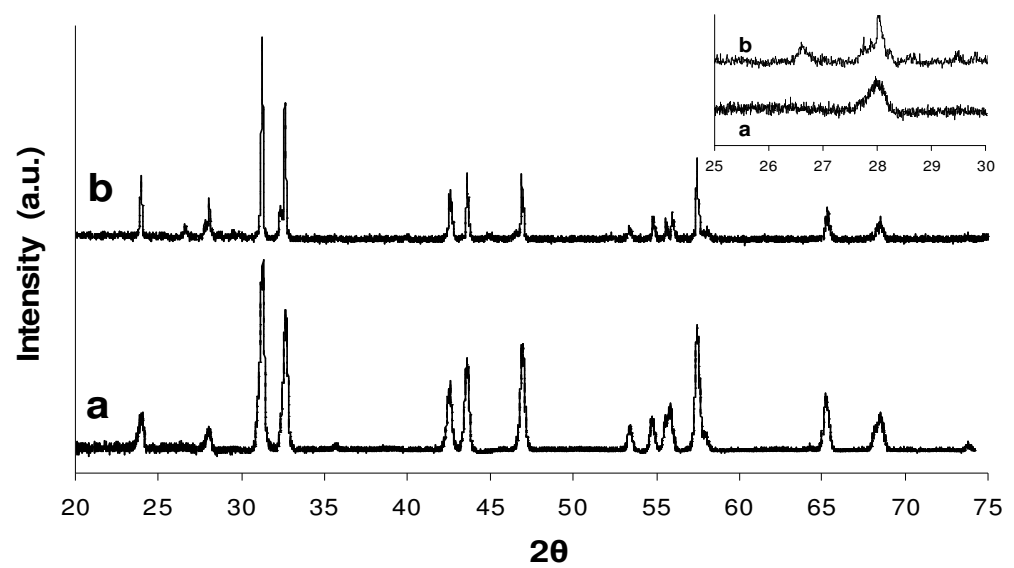

Fig. 4.3: XRD patterns of fresh $L N($ a) and fresh $L N V-10(b)$. XRD pattern in the range $27<2 \theta<31$ is shown in the insert.

Both LN and LNV10 samples are clearly crystalline and all peaks (except one) were assigned to single $\mathrm{K}_{2} \mathrm{NiF}_{4}$ tetragonal structure typical for this type of materials [19, 20]. The main difference between the two spectra is the change in relative intensity of the main peaks at $2 \theta=31.4$ and 32.7. These results are very similar to the effect of $\mathrm{Cu}$ addition to $\mathrm{LN}$ [21]: the $\mathrm{K}_{2} \mathrm{NiF}_{4}$ structure is retained and the ratio of intensities of the main peaks varies. The reason for the latter observation is not known.

An extra peak at $2 \theta=26.6$ was observed in the case of LNV-10 (see Fig. 4.3, insert). Based on XRD-database [ICDD 2006], this peak cannot be assigned to any of the individual- or mixed oxides possibly present (oxides of $\mathrm{La}, \mathrm{V}$ and $\mathrm{Ni}$ ) as well as metallic Ni. The assignment of this peak remains unknown at this time. It should be mentioned that no contaminants were detected on XRF analysis and only a very small peak related to $\mathrm{Mg}$ was present on XPS (not shown here). However, the extra peak at $2 \theta=26.6$ cannot be assigned to $\mathrm{Mg}$, based on XRD-database. 


\subsubsection{Temperature Programmed reduction (TPR)}

The TPR profiles of LN, LNV-05 and LNV-10 are shown in figure 4.4.

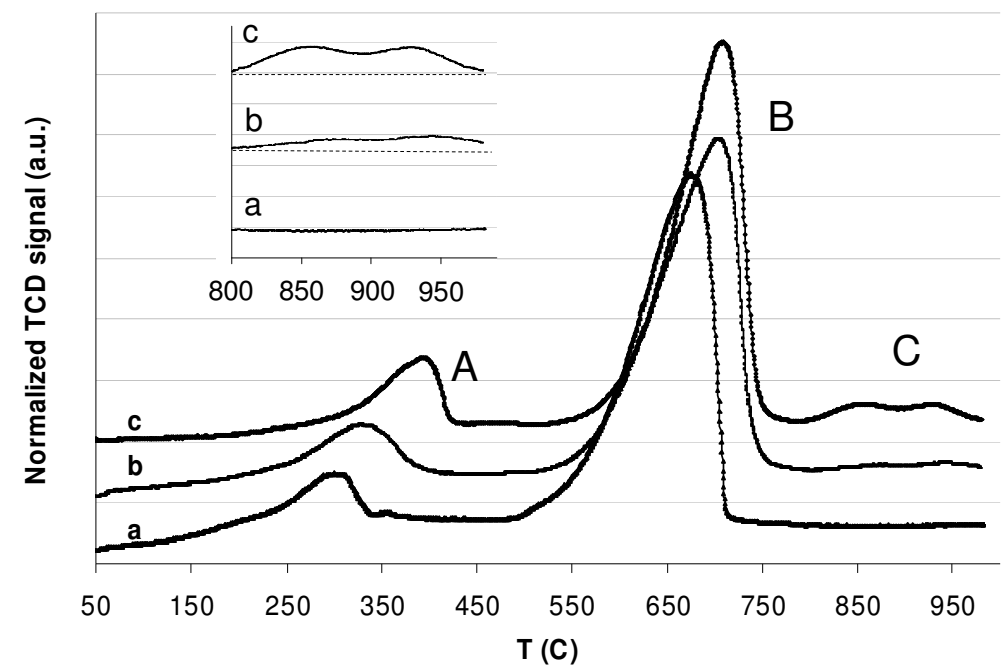

Fig. 4.4: Temperature programmed reduction on three fresh samples: $L N(a), L N V-05$ (b) and $\mathrm{LNV}-10$ (c) in $\mathrm{H}_{2}\left(\mathrm{ramp} 50-980^{\circ} \mathrm{C}\right)$. In the inset, TPR profiles at high temperature are highlighted.

Two distinctive reduction steps are visible at $\sim 300{ }^{\circ} \mathrm{C}$ and $650{ }^{\circ} \mathrm{C}$ for all samples, typical for $\mathrm{K}_{2} \mathrm{NiF}_{4}$-type of materials. The measured patterns are similar to what has been reported in literature for $\mathrm{La}_{2} \mathrm{NiO}_{4+\delta}[18,19,22]$. In addition, $\mathrm{V}$-doped samples show the presence of a small reduction peak in the temperature interval between 850 and $980{ }^{\circ} \mathrm{C}$ (see insert in figure 4.4). As the area of the high temperature peak (peak C in Fig 4.4) is proportionally increasing (from 0.09 to $0.20 \mathrm{mmol} / \mathrm{g}$ ) with the $\mathrm{V}$ loading (5\% vs 10\%), this peak is related to reduction of $\mathrm{V}$ present in the sample. Based on typical reduction profiles for bulk $\mathrm{V}_{2} \mathrm{O}_{5}$ in literature [23, 24], this peak is assigned to reduction of $\mathrm{V}^{4+}$ to $\mathrm{V}^{3+}$.

Table 4.2 presents a quantitative evaluation of the TPR profiles shown in Fig. 4.4. The first reduction step (peaks A in Fig. 4.4) of LN corresponds to removal of 0.37 mmol O per gram (see Table 4.2). Saez Puche et al. [25] assigned the low temperature reduction of $\mathrm{La}_{2} \mathrm{NiO}_{4+\delta}$ to removal of over-stoichiometric oxygen, related to the presence of $\mathrm{Ni}^{3+}$, based on electron diffraction patterns and TGA analysis. Therefore, we also assign the low temperature peak in TPR to removal of over-stoichiometric oxygen and reduction of $\mathrm{Ni}^{3+}$ to $\mathrm{Ni}^{2+}$. Consequently, the initial composition of the material (at room temperature) is $\mathrm{La}_{2} \mathrm{NiO}_{4.15}$. This is in good 
agreement with results of Bassat et al. [26], who reported comparable composition $\left(\mathrm{La}_{2} \mathrm{NiO}_{4.16}\right)$ based on TGA data under identical reductive atmosphere.

The amount of atomic oxygen removed from the LN sample during the reduction around $650{ }^{\circ} \mathrm{C}$ (see Table 4.2), as calculated based on the amount of molecular $\mathrm{H}_{2}$ consumed, was $2.5 \mathrm{mmol} / \mathrm{g}$, which is in a good agreement with complete reduction of $\mathrm{Ni}^{2+}$ to $\mathrm{Ni}^{0}$. After this reduction step, the final composition of the material is $\mathrm{Ni}^{0}$ $+\mathrm{La}_{2} \mathrm{O}_{3}$, in full agreement with literature [22] and confirmed with XRD measurements (not shown). No further reduction at temperatures higher than $750{ }^{\circ} \mathrm{C}$ was observed for $\mathrm{La}_{2} \mathrm{NiO}_{4+\delta}$.

Addition of $\mathrm{V}$ causes the low temperature reduction peak to shift to higher temperature as compared to $\mathrm{LN}$ (Fig. 4.4, $b$ and $c$ ). The onset and offset temperature of the first peak was shifted up by $30{ }^{\circ} \mathrm{C}$ and by $60{ }^{\circ} \mathrm{C}$ for the LNV- 05 and LNV10 , respectively (Table 4.2 ).

It has been reported $[27,28]$ that the insertion of $\mathrm{Sr}$ as dopant in a $\mathrm{K}_{2} \mathrm{NiF}_{4}$ type oxide $\left(\mathrm{Pr}_{2} \mathrm{CoO}_{4}\right.$ and $\left.\mathrm{Eu}_{2} \mathrm{NiO}_{4}\right)$ affects the reduction profile of the materials, in agreement with our observation.

The fact that the low temperature reduction peak is shifted to higher temperature with increase in $\mathrm{V}$ loading is additional evidence that the low temperature peak is related to over-stoichiometric oxygen. If this peak would have been due to reduction of amorphous $\mathrm{NiO}$, as proposed in literature [22, 29], no shift in temperature would be expected, because it is not reasonable to assume that the reducibility of a separate amorphous $\mathrm{NiO}$ phase would be influenced by the presence of vanadium.

Table 4.2: Quantification of removed oxygen during TPR on investigated samples and relative onset and offset temperatures of the TPR peaks.

\begin{tabular}{|c|c|c|c|c|c|c|c|c|c|}
\hline \multirow[b]{2}{*}{ Catalyst } & \multicolumn{3}{|c|}{ Peak A } & \multicolumn{3}{|c|}{ Peak B } & \multicolumn{3}{|c|}{ Peak C } \\
\hline & $\begin{array}{l}\text { Onset } \\
\mathrm{T} \\
\left({ }^{\circ} \mathrm{C}\right) \\
\end{array}$ & $\begin{array}{l}\text { Offset } \\
\mathrm{T} \\
\left({ }^{\circ} \mathrm{C}\right) \\
\end{array}$ & $\begin{array}{c}\text { Removed } \\
\text { Oxygen } \\
(\mathrm{mmol} / \mathrm{g})\end{array}$ & $\begin{array}{c}\text { Onset } \\
\mathrm{T} \\
\left({ }^{\circ} \mathrm{C}\right) \\
\end{array}$ & $\begin{array}{c}\text { Offset } \\
\mathrm{T} \\
\left({ }^{\circ} \mathrm{C}\right) \\
\end{array}$ & $\begin{array}{c}\text { Removed } \\
\text { Oxygen } \\
(\mathrm{mmol} / \mathrm{g})\end{array}$ & $\begin{array}{c}\text { Onset } \\
\mathrm{T} \\
\left({ }^{\circ} \mathrm{C}\right) \\
\end{array}$ & $\begin{array}{c}\text { Offset } \\
\mathrm{T} \\
\left({ }^{\circ} \mathrm{C}\right) \\
\end{array}$ & $\begin{array}{c}\text { Removed } \\
\text { Oxygen } \\
(\mathrm{mmol} / \mathrm{g})\end{array}$ \\
\hline LN & $\begin{array}{r}132 \\
\pm 10\end{array}$ & $\begin{array}{l}379 \\
\pm 20\end{array}$ & $\begin{array}{c}0.37 \\
\pm 0.02\end{array}$ & $\begin{array}{l}498 \\
\pm 20\end{array}$ & $\begin{array}{r}725 \\
\pm 15\end{array}$ & $\begin{array}{l}2.50 \\
\pm 0.1\end{array}$ & - & - & - \\
\hline LNV-05 & $\begin{array}{r}165 \\
\pm 15 \\
\end{array}$ & $\begin{array}{r}410 \\
\pm 20 \\
\end{array}$ & $\begin{array}{c}0.40 \\
\pm 0.02\end{array}$ & $\begin{array}{l}525 \\
\pm 20 \\
\end{array}$ & $\begin{array}{r}765 \\
\pm 15 \\
\end{array}$ & $\begin{array}{l}2.47 \\
\pm 0.1 \\
\end{array}$ & $\begin{array}{r}790 \\
\pm 20 \\
\end{array}$ & $\begin{array}{c}\text { Until } \\
\text { end }\end{array}$ & $\begin{array}{c}0.09 \\
\pm 0.01\end{array}$ \\
\hline LNV-10 & $\begin{array}{l}207 \\
\pm 20\end{array}$ & $\begin{array}{l}436 \\
\pm 20\end{array}$ & $\begin{array}{c}0.42 \\
\pm 0.02\end{array}$ & $\begin{array}{l}545 \\
\pm 20\end{array}$ & $\begin{array}{r}775 \\
\pm 15\end{array}$ & $\begin{array}{l}2.42 \\
\pm 0.1\end{array}$ & $\begin{array}{l}800 \\
\pm 15\end{array}$ & $\begin{array}{l}\text { Until } \\
\text { end }\end{array}$ & $\begin{array}{c}0.20 \\
\pm 0.01\end{array}$ \\
\hline
\end{tabular}

The presence of $\mathrm{V}$ also stabilizes the mixed oxide regarding reduction to $\mathrm{Ni}^{0}$ (reduction peak B in Fig. 4.4) whereas the onset temperature is slightly shifted to higher value. Surprisingly, experimentally observed amounts of oxygen removed for LNV-05 and LNV-10 (2.47 and $2.42 \mathrm{mmol} / \mathrm{g}$, respectively - B peak, Table 4.2) are higher than theoretical values assuming complete reduction of $\mathrm{Ni}^{2+}$, which 
would result in 2.37 and $2.25 \mathrm{mmol} / \mathrm{g}$, respectively. This difference may be caused by an additional contribution due to the reduction of $\mathrm{V}\left(\mathrm{V}^{5+}\right.$ to $\left.\mathrm{V}^{4+}\right)$, which was reported to occur at $650-700{ }^{\circ} \mathrm{C}$ for bulk $\mathrm{V}_{2} \mathrm{O}_{5}[23,24]$.

\subsubsection{Pulse experiments}

\subsubsection{LN}

The propane conversion over $\mathrm{LN}$ during pulse experiments at $550{ }^{\circ} \mathrm{C}$ is shown in Fig. 4.5. The conversion gradually decreased during the first 13 pulses of propane from $40 \%$ at the first pulse to below 5\% from the eighth pulse onwards, which is due to consumption of oxygen in the oxide. The conversion suddenly increased to $\sim 50 \%$ when continuing pulsing with propane.

The product distribution when pulsing propane over $\mathrm{La}_{2} \mathrm{NiO}_{4+\delta}$ at $550{ }^{\circ} \mathrm{C}$, as well as the re-oxidation of the catalyst by pulsing $\mathrm{O}_{2}$, are shown in Fig. 4.6. $\mathrm{CO}_{2}$ and $\mathrm{H}_{2} \mathrm{O}$ are observed as main products when pulsing propane over freshly oxidized material, indicating deep oxidation with oxygen provided by $\mathrm{La}_{2} \mathrm{NiO}_{4+\delta}$ (Eq. 4.1).

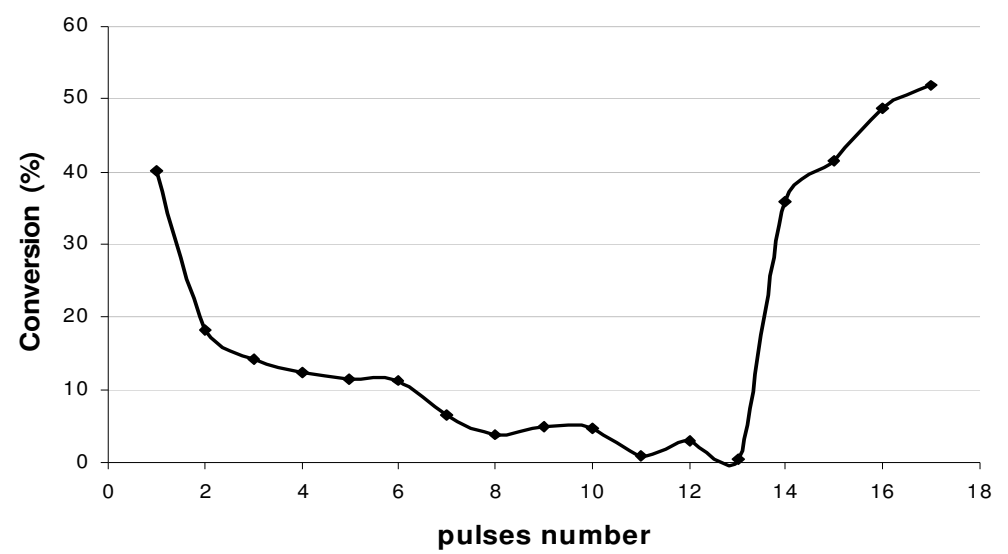

Fig. 4.5: Propane conversion profile during the titration test on $\mathrm{La}_{2} \mathrm{NiO}_{4+\delta}$ at $550^{\circ} \mathrm{C}$. 


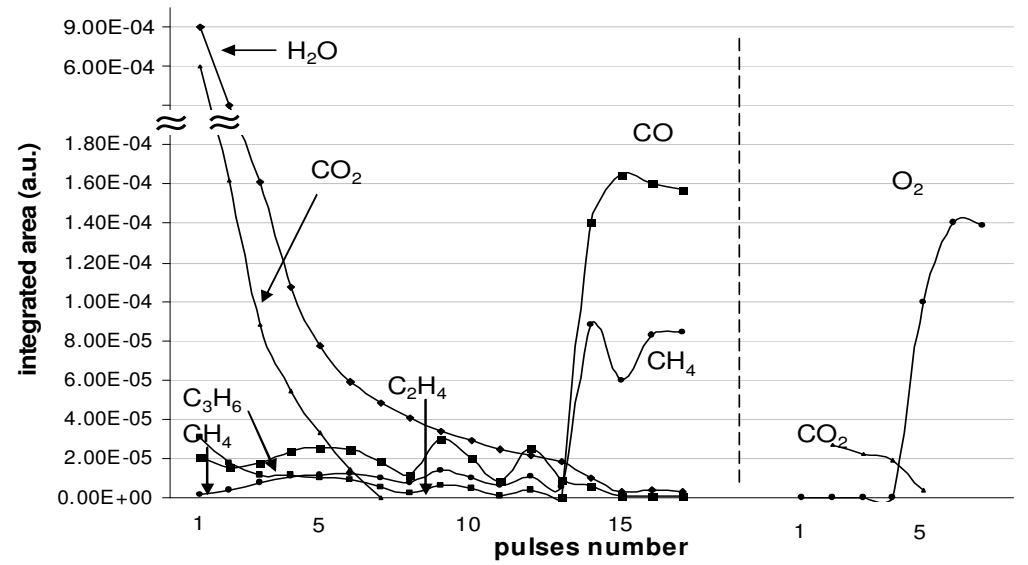

Fig. 4.6: Products distribution during the titration test on $\mathrm{La}_{2} \mathrm{NiO}_{4+\delta}$ at $550^{\circ} \mathrm{C}$ (left hand side) and regeneration profile of the catalyst by $\mathrm{O}_{2}$ pulse (right hand side).

$\mathrm{C}_{3} \mathrm{H}_{8}+10 \mathrm{O}_{\text {CAT. }} \rightarrow 3 \mathrm{CO}_{2}+4 \mathrm{H}_{2} \mathrm{O}$

where $\mathrm{O}_{\text {CAT. }}$ indicates the oxygen released from the catalyst.

The products mixture contains also $\mathrm{CH}_{4}, \mathrm{C}_{2} \mathrm{H}_{4}$ and $\mathrm{C}_{3} \mathrm{H}_{6}$, demonstrating that both cracking as well as dehydrogenation reactions contribute (Eq. 4.2, 4.3 and 4.4).

$\mathrm{C}_{3} \mathrm{H}_{8}+\mathrm{O}_{\text {CAT. }} \rightarrow \mathrm{CH}_{4}+\mathrm{C}_{2} \mathrm{H}_{4}+\mathrm{O}_{\text {CAT. }}$

$\mathrm{C}_{3} \mathrm{H}_{8}+\mathrm{O}_{\text {CAT. }} \rightarrow \mathrm{C}_{3} \mathrm{H}_{6}+\mathrm{H}_{2}+\mathrm{O}_{\text {СAT. }}$

$\mathrm{C}_{3} \mathrm{H}_{8}+\mathrm{O}_{\text {CAT. }} \rightarrow \mathrm{C}_{3} \mathrm{H}_{6}+\mathrm{H}_{2} \mathrm{O}$

The formation of $\mathrm{C}_{3} \mathrm{H}_{6}$ may be explained by selective dehydrogenation of propane with formation of $\mathrm{H}_{2}$ (Eq. 4.3) or by oxidative dehydrogenation of propane, forming water (Eq. 4.4). Probably oxidative dehydrogenation contributes since $\mathrm{H}_{2} \mathrm{O}$ was always detected; however we cannot rule out formation of $\mathrm{H}_{2} \mathrm{O}$ via oxidation of $\mathrm{H}_{2}$. The contribution of dehydrogenation remains unclear since $\mathrm{H}_{2}$ could not be monitored. It should be mentioned that the formed $\mathrm{C}_{3} \mathrm{H}_{6}$ might be further converted to deep oxidation products since at the reaction temperature used $\left(550{ }^{\circ} \mathrm{C}\right)$ olefins possess higher reactivity in oxidation reaction than paraffins [30]. 


\section{Chapter 4}

The $\mathrm{CO}_{2}$ production diminished rapidly with the number of pulses (Fig. 4.6) and decreased below the detection limit after $7^{\text {th }}$ pulse, while formation of propylene was approximately constant, thus increasing the selectivity towards propylene.

After pulse 12 the products distribution changed with a sudden increase in propane conversion. $\mathrm{No}_{3} \mathrm{H}_{6}, \mathrm{C}_{2} \mathrm{H}_{4}$ and $\mathrm{H}_{2} \mathrm{O}$ were observed at this stage, instead only $\mathrm{CO}$ and $\mathrm{CH}_{4}$ were observed. Additionally, coke was deposited on the catalyst surface, as will be discussed in more detail below. After the titration test, the catalyst was regenerated by pulsing oxygen (fig. 4.6, right hand side). The pulses 1-4 resulted in complete oxygen consumption and formation of $\mathrm{CO}_{2}$, testifying that carbon was deposited on catalyst surface. $\mathrm{O}_{2}$ level reached a plateau value, equal to blank $\mathrm{O}_{2}$ pulses, after pulse 6 , indicating complete regeneration of the samples. However, no $\mathrm{CO}_{2}$ was detected during regeneration by pulsing oxygen after exposing the sample to only 11 pulses of propane. Therefore, carbon deposition took place exclusively after the drastic change in selectivity and the sudden increase of propane conversion level. We suggest that at this moment $\mathrm{Ni}^{2+}$ starts to reduce to $\mathrm{Ni}$ metal, forming $\mathrm{CO}$ and $\mathrm{CH}_{4}$ according to equation 4.5 (overall equation); it is important to note that the ratio of intensities of $\mathrm{CO}$ and $\mathrm{CH}_{4}$ in figure 4.6 cannot be compared quantitatively. Ni metal is well known to easily form coke deposits as well as carbon nanofibers [31].

$\mathrm{La}_{2} \mathrm{NiO}_{4}+\mathrm{C}_{3} \mathrm{H}_{8} \rightarrow \mathrm{Ni}^{0}+\mathrm{CO}+2 \mathrm{CH}_{4}+\mathrm{La}_{2} \mathrm{O}_{3}$

The total amount of atomic oxygen consumed during regeneration, involving both catalyst reoxidation and carbon combustion, is $0.180 \mathrm{mmol} / \mathrm{g}$, while regeneration after only 11 pulses of propane consumed $0.140 \mathrm{mmol} / \mathrm{g}$ oxygen only. Therefore it is affirmed here that $0.14 \mathrm{mmol} / \mathrm{g}$ of oxygen was needed to reoxidize the catalyst and $0.04 \mathrm{mmol} / \mathrm{g}$ oxygen is consumed by carbon combustion, $\mathrm{CO}$ formation and reoxidation of $\mathrm{Ni}$ metal.

To conclude, propane conversion shifted from deep oxidation to reasonable selectivity towards olefins when varying the amount and consequently the reactivity of over-stoichiometric oxygen species. Further removing of oxygen causes initiation of another reaction pathway, forming $\mathrm{CO}, \mathrm{CH}_{4}$ and coke, which is probably due to $\mathrm{Ni}^{0}$ formation.

\subsubsection{LNV-05 and LNV-10}

Doping LN with vanadium does not affect drastically the conversion trend at the initial stage of the pulse experiment (Fig. 4.7), as compared to Fig. 4.5. The activity of the materials diminished with the number of pulses for all materials. Within the 
first 10 pulses $\mathrm{LN}$ showed higher propane conversion than V-doped LN, denoting the higher reactivity of oxygen ion species.

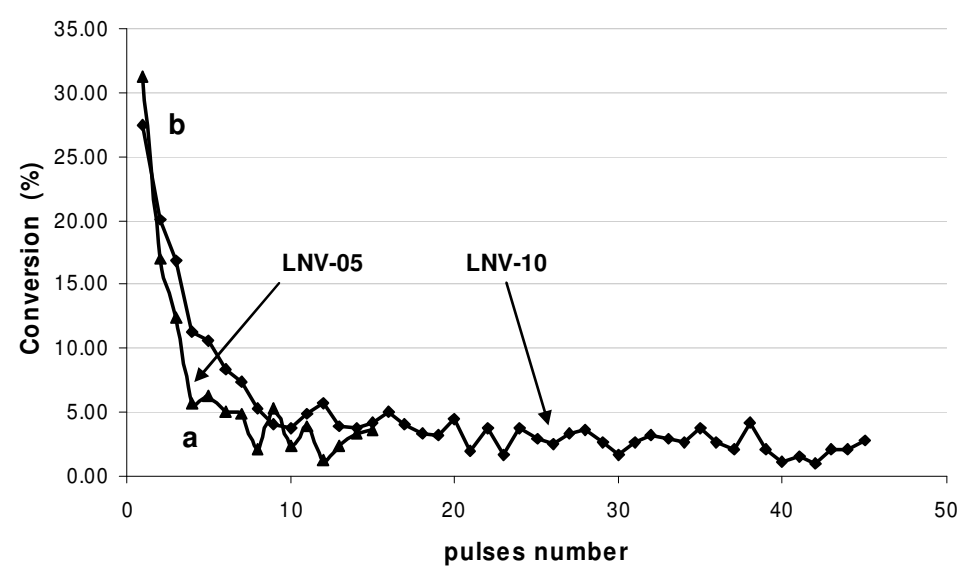

Fig. 4.7: Propane conversion profile during the titration test on $\mathrm{La}_{2} \mathrm{Ni}_{0.95} \mathrm{~V}_{0.05} \mathrm{O}_{4+\delta}(a)$ and $\mathrm{La}_{2} \mathrm{Ni}_{0.9} \mathrm{~V}_{0.1} \mathrm{O}_{4+\delta}\left(\right.$ b) at $550^{\circ} \mathrm{C}$.

Figures 4.8 and 4.9 show the product distributions during pulsing propane at $5500^{\circ} \mathrm{C}$ over LNV-05 and LNV-10, respectively, as well as the re-oxidation of the catalyst by pulsing $\mathrm{O}_{2}$. Initially, the product distribution was similar to un-doped $\mathrm{LN}$ catalyst: main products were $\mathrm{CO}_{2}$ and $\mathrm{H}_{2} \mathrm{O}$ (deep oxidation, Eq. 4.1). Similar to undoped catalyst, the catalyst was depleted in oxygen during pulsing propane, decreasing the catalyst oxidation degree as well as the propane conversion. Continuing pulsing, the V-doped catalysts showed a constant production of propylene (Eq. 4.3 and 4.4), probably due to the decrease of chemical potential of remaining oxygen in the slightly reduced catalyst. Also cracking products $\left(\mathrm{CH}_{4}\right.$ and $\mathrm{C}_{2} \mathrm{H}_{4}$ ) were constantly produced (Eq. 4.2). In the case of LNV-05 (up to 15 pulses of propane) and LNV-10 (up to 45 pulses of propane) no drastic increase in conversion and sudden change in product distribution were noticed when continuing pulsing, in contrast to LN. Stable performance was maintained in a much broader window of pulses as compared to LN. 


\section{Chapter 4}

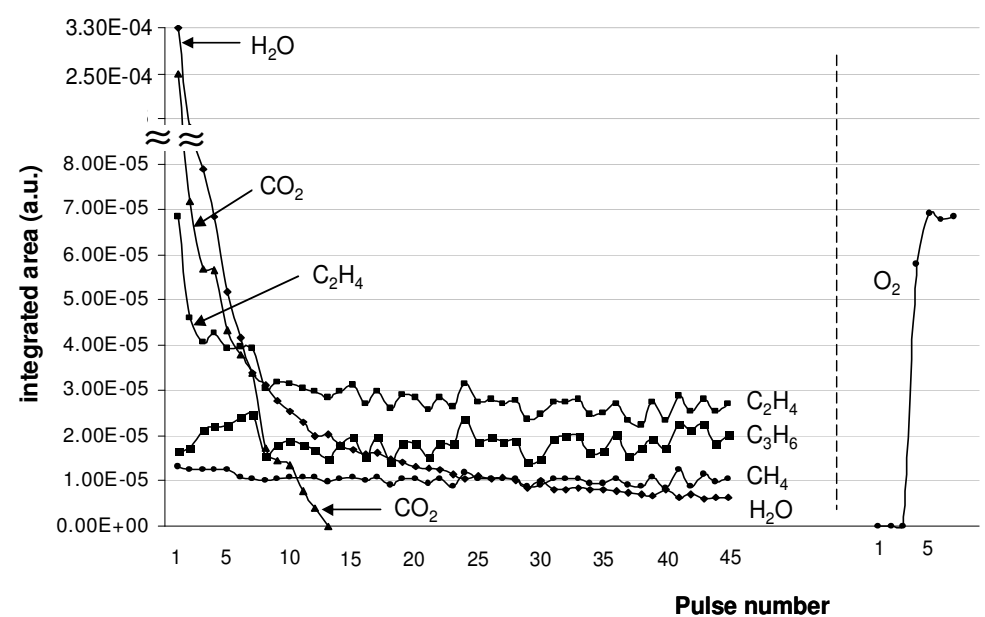

Fig. 4.8: Products distribution during titration test (45 pulses) of $\mathrm{La}_{2} \mathrm{Ni}_{0.9} \mathrm{~V}_{0.1} \mathrm{O}_{4+\delta}$ at $550{ }^{\circ} \mathrm{C}$ (left hand side) and regeneration profile of the catalyst by $\mathrm{O}_{2}$ pulse (right hand side).

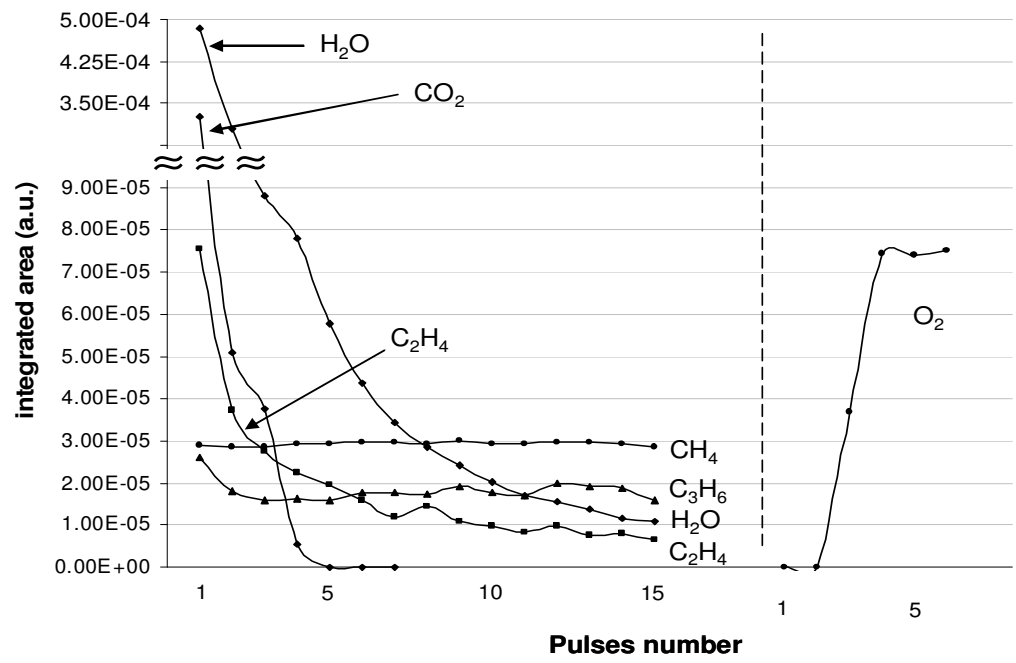

Fig. 4.9: Products distribution during titration test (15 pulses) of $\mathrm{La}_{2} \mathrm{Ni}_{0.95} \mathrm{~V}_{0.05} \mathrm{O}_{4+\delta}$ at $550{ }^{\circ} \mathrm{C}$ (left hand side) and regeneration profile of the catalyst by $\mathrm{O}_{2}$ pulse (right hand side). 
The amounts of oxygen consumed during the regeneration processes after comparable number of propane pulses (15 pulses for LNV-05 and LNV-10, 11 pulses for LN) were quantified: $0.106 \mathrm{mmol} / \mathrm{g}$ for LNV-10, $0.110 \mathrm{mmol} / \mathrm{g}$ for LNV-05 and $0.140 \mathrm{mmol} / \mathrm{g}$ for $\mathrm{LN}$, which is the highest value despite the lower number of pulses. These results reveal that less oxygen is removed during propane pulses with increasing V content, in agreement with the TPR result in Figure 4.4. The stabilizing effect of $\mathrm{V}$ therefore does not depend on the reducing agent used, hydrogen or propane.

The apparent selectivity of olefins is shown in Fig. 4.10. Unfortunately, the selectivity could not be calculated quantitatively since the product distribution was analyzed by MS without a full calibration. The apparent selectivity to olefin was lower than $40 \%$ during first three pulses for all three catalysts, due to mainly $\mathrm{CO}_{2}$ formation. It is clear that especially $\mathrm{LN}$ produced much $\mathrm{CO}_{2}$ initially, which in agreement with the observation that more oxygen is being removed from LN as compared to the $\mathrm{V}$-containing catalysts. Continuing pulsing propane and reducing the catalyst, V-doped LN showed an increase of apparent selectivity to olefin up to constant value $(80 \%)$ for around thirty pulses while it suddenly decreased below the detection limit for LN. LNV-05 also showed constant apparent selectivity to olefin within 15 pulses (not tested further). It is obvious that all three catalysts result in significant selectivity to olefins when operated at optimal reduction-degree. It is important to note that the propane conversion levels are comparable and low (typically 4\%) under these conditions for all three catalysts. Therefore, the small, though significant, differences in olefin selectivity between the three catalysts (LNV-10 $>\mathrm{LN}>\mathrm{LNV}-05)$ must be due to differences in the ratios between the rate of activation of propane versus the rate of activation of olefins for the three catalysts. Therefore we conclude that vanadium contributes on reducing the activity of oxygen species, reducing the amount of $\mathrm{CO}_{2}$ formed (comparison of Fig. 4.6 and 4.8 ), consequently reducing the amount of oxygen consumed, enhancing the selectivity towards olefins. $10 \% \mathrm{~V}$ as dopant in $\mathrm{LN}$ is required to achieve the highest yields to olefins.

Contrary to what observed for $\mathrm{LN}$, during the regeneration by pulsing oxygen (Fig. 4.8 and 4.9, right hand side) after the titration test, no $\mathrm{CO}_{2}$ formation was observed, denoting no carbon deposition during propane pulses. This observation confirms that the presence of $\mathrm{V}$ prevents formation of metallic $\mathrm{Ni}$ within the window of operation in this study. 


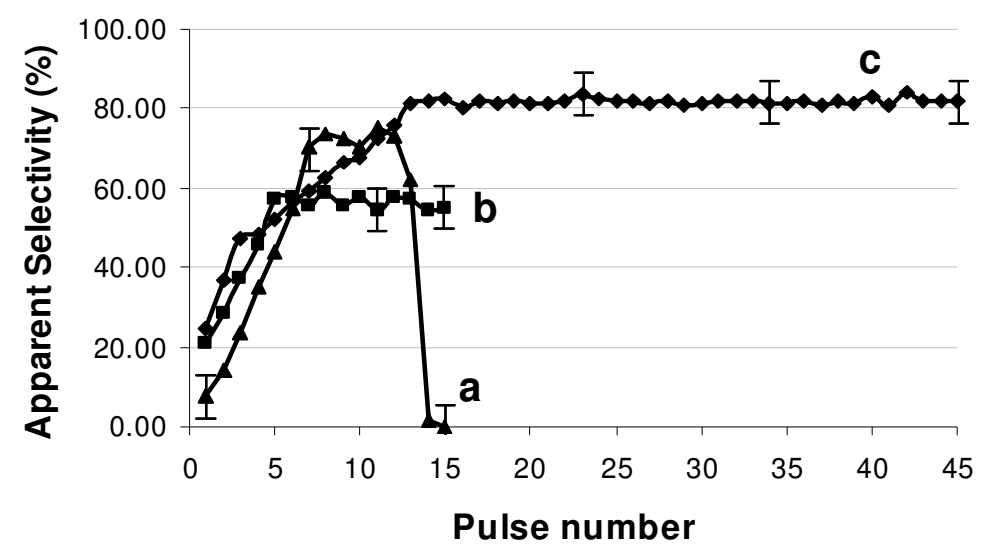

Fig. 4.10: Apparent olefins $\left(\mathrm{C}_{2} \mathrm{H}_{4}+\mathrm{C}_{3} \mathrm{H}_{6}\right)$ selectivity during titration test on $L N(a)$ $L N V-05(b)$ and LNV-10 (c). Only few error margin bars are shown in the figure as they are constant $( \pm 5 \%)$ for the three different samples.

\subsection{Conclusions}

It was shown that over the oxidized materials, too high activity of oxygen species was responsible for formation of deep oxidation products $\left(\mathrm{CO}_{2}\right.$ and $\left.\mathrm{H}_{2} \mathrm{O}\right)$ for both doped and un-doped materials. The scenario changed after partial removal of oxygen and consequent decrease of reactivity of the remaining oxygen species: $\mathrm{C}_{3} \mathrm{H}_{6}, \mathrm{C}_{2} \mathrm{H}_{4}, \mathrm{CH}_{4}$ and $\mathrm{H}_{2} \mathrm{O}$ were the only products detected with beneficial effect on selectivity to olefins.

The presence of vanadium as dopant in LN enhances the material stability towards reduction in $\mathrm{H}_{2}$. The stabilization of over-stoichiometric oxygen positively affected the products distribution in pulse experiment, as less $\mathrm{CO}_{2}$ was produced (and less oxygen consumed), over deep-oxidized catalyst. Also the stability of lattice oxygen, bonded to $\mathrm{Ni}$ atoms, was influenced by the dopant. It was shown that the presence of $\mathrm{V}$ delayed the release of lattice oxygen and the consequent formation on $\mathrm{Ni}^{0}$, responsible for drastic detrimental change in reaction patterns $\left(\mathrm{CO}, \mathrm{CH}_{4}\right.$ and coke as products). Therefore, the $\mathrm{V}$-doped catalyst showed much larger window (more than 30 propane pulses) in which the selectivity towards propylene was constant and promising, contrary to un-doped catalyst.

Slightly reduced V-doped LN is a promising material for selective oxidation of propane if a specific reduction level of the catalyst can be maintained during the process; e.g. by operating a Catalytic Dense Membrane Reactor with well balanced 
oxygen diffusion versus oxygen consumption at the propane side. LNV-10 is probably the best candidate as it showed the better selectivity towards propylene.

\section{Acknowledgements}

The author would like to thank Dr. B. L. Mojet and Dr. C. Trionfetti for inspiring discussions as well as precious help on writing this chapter. We thank ACTS/NWO, The Netherlands for financial support (project number 053.62.004).

\section{References}

[1] I.M. Dahl, K. Grande, K.J. Jens, E. Rytter, A. Slagtern, Appl. Catal. 77 (1991) 163-174

[2] C. Mazzocchia, C. Aboumard, D. Diagne, E. Temesti, J.M. Herrmann,G. Thomas, Catal. Lett. 10 (1991) 181-192

[3] A. Cherrak, R. Hubaut, Y. Barbaux, G. Mairesse, Catal. Lett. 15 (1992) 377-383

[4] R.H.H. Smits, K. Seshan, H. Leemreize, J.R.H. Ross, Catal. Today 16 (1993) 513-523

[5] M.C. Kung, H.H. Kung, J. Catal. 134 (1992) 668-677

[6] R.M. Contractor, H.E. Bergna, H.S. Horowitz, C.M. Blackstone, B. Malone, C.C. Torardi, B. Griffeths, U. Chowdhry, A.W. Sleight, Catal. Today 1 (1987) 4958

[7] S. Haag, A.C. van Veen, C. Mirodatos, Catal. Today 127 (2007) 157-164

[8] P.J. Gellings, H.J.M. Bouwmeester, The CRC handbook of Solid State Electrochemistry, first ed., P.J. Gellings and H.J.M. Bouwmeester, CRC Inc., 1997, pag. 520

[9] H. Fjellvag, O.H. Hansteen, B.G. Tilset, A. Olafsen, N. Sakai, H. Seim, Thermochim. Acta 256 (1995) 75-89

[10] R. Chiba, F. Yoshimura, Y. Sakurai, Solid State Ionics 124 (1999) 281-288

[11] E.V. Tsipis, E.N. Naumovich, A.L. Shaula, M.V. Patrakeev, J.C. Waerenborgh, V.V. Kharton, Solid State Ionics 179 (2008) 57-60

[12] L. Minervini, R.W. Grimes, J.A. Kilner, K.E. Sickafus, J. Mater. Chem. 10 (2000), 2349-2354

[13] C. Li, T. Hu, H. Zhang, Y. Chen, J. Jin, N. Yang, J. Membr. Sci. 226 (2003) 17

[14] E.V. Tsipis, E.A. Kiselev, V.A. Kolotygin, J.C. Waerenborgh, V.A. Cherepanov, V.V. Kharton, Solid State Ionics 179 (2008) 2170-2180 
[15] S. Miyoshi, T. Furuno, O. Sangoanruang, H. Matsumoto, T. Ishihara, J. Electrochem. Soc. 154 (2007) B57-B62

[16] L. Hui, C. Ping, G. Yuping, L. Yueqing, L. Guanglie, X. Yuanzhe, M. Futai, J. Solid State Chem. 141 (1998) 99-104

[17] R.H.E. van Doorn, H. Kruidhof, A. Nijmeijer, L. Winnubst, A.J. Burggraaf, J. Mater. Chem. 1998, 8(9), 2109-2112

[18] B.S. Liu, C.T. Au, Appl. Catal., A 244 (2003) 181-195

[19] B.S. Liu, C.T. Au, Catal. Lett. 85 (2003) 165-169

[20] D.E. Rice, D.J. Buttrey, J. Solid State Chem. 105 (1993) 197-210

[21] T.C. Vaimakis, Thermochim. Acta 206 (1002) 219-234

[22] G. S. Gallego, F. Mondragon, J. Barrault, J.M. Tatibouet, C. Batiot-Dupeyrat, Appl. Catal., A 311 (2006) 164-171

[23] M.M. Koranne, J.G. Goodwin, G. Marcelin, J. Catal. 148 (1994) 369-377

[24] H. Bosch, B.J. Kip, J.G. van Ommen, P.J. Gellings, J. Chem. Soc. Faraday Trans. 80 (1984) 2479

[25] R. Saez Puche, J.L. Rodriguez, F. Fernandez, Inorg. Chem. Acta 140 (1987) 151-153

[26] J.M. Bassat, P. Odier, J.P. Loup, J. Solid State Chem. 110 (1994) 124-135

[27] H. Zhong, X. Zeng, Kinet. Catal. 47 (2007) 423-429

[28] L. Hui, C. Ping, G. Yuping, L. Yueqing, L. Guanglie, X. Yuanzhe, M. Futai, J. Solid State Chem. 141 (1998) 99-104

[29] E. Ruckenstein, Y.H. Hu, J. Catal. 161 (1996) 55-61

[30] A. Lofberg, C. Pirovano, M.C. Steil, R.N. Vannier, E. Bordes-Richard, Catal. Today 112 (2006) 8-11

[31] K.P. De Jong, J.W. Geus, Catal. Rev. - Sci. Eng. 42 (2000) 481-510 


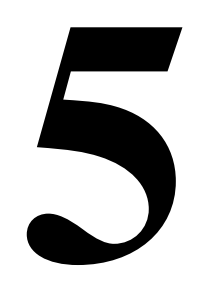

\section{The effect of $\mathrm{V}$ in $\mathrm{La}_{2} \mathrm{Ni}_{1-\mathrm{x}} \mathrm{V}_{\mathrm{x}} \mathrm{O}_{4+1.5 \mathrm{x}+\delta}$ on selective oxidative dehydrogenation of propane: stabilization of lattice oxygen}

In this chapter, the non-stoichiometric redox compounds $\mathrm{La}_{2} \mathrm{NiO}_{4+\delta}$ and $\mathrm{La}_{2} \mathrm{Ni}_{0.9} \mathrm{~V}_{0.1} \mathrm{O}_{4.15+\delta}$ have been tested as an oxidant in selective oxidation of propane in pulse experiments at temperatures between 450 and $650{ }^{\circ} \mathrm{C}$. The oxygen contents in the samples at different temperatures were calculated based on back titration with $\mathrm{O}_{2}$ pulses as well as on TGA analysis. In the case of $\mathrm{La}_{2} \mathrm{Ni}_{0.9} \mathrm{~V}_{0.1} \mathrm{O}_{4.15+\delta}$ overstoichiometric oxygen was the only active species, responsible for formation of $\mathrm{CO}_{2}, \mathrm{C}_{3} \mathrm{H}_{6}, \mathrm{C}_{2} \mathrm{H}_{4}$ and $\mathrm{CH}_{4}$ while pulsing propane at all investigated temperatures. Contrary, the reactive species in $\mathrm{La}_{2} \mathrm{NiO}_{4+\delta}$ changed from over-stoichiometric oxygen only at $450{ }^{\circ} \mathrm{C}$, to both over-stoichiometric and lattice oxygen at $550{ }^{\circ} \mathrm{C}$, to lattice oxygen only at $650{ }^{\circ} \mathrm{C}$. The activation of lattice oxygen and the consequent formation of $\mathrm{Ni}$ metal were detrimental for selectivity to propylene as formation of $\mathrm{CO}_{\mathrm{x}}, \mathrm{CH}_{4}$ and coke mainly occurred and no olefins were formed. 



\subsection{Introduction}

The demand for small olefins is growing in the last years. Propylene demand, for example, is expected to rise to 80 million tonnes in 2010 worldwide [1-3]. Nowadays the main industrial routes to propylene production are endothermic reactions such as steam cracking [4], fluid catalytic cracking and catalytic dehydrogenation [5]. Promising production of alkenes is achieved by catalytic dehydrogenation but this reaction is equilibrium limited and it suffers from catalyst deactivation due to coke deposition [6]. Oxidative dehydrogenation (ODH) employing molecular oxygen or oxygen containing compounds, i.e. $\mathrm{CO}_{2}$ and $\mathrm{N}_{2} \mathrm{O}$, as oxidant, can overcome these limitations [7, 8]. On the other hand, the possible presence of highly reactive propyl and oxygen radicals in gas phase in addition to adsorbed oxygen species on the catalyst surface can further oxidize the products to $\mathrm{CO}_{\mathrm{x}}$. In this chapter, to avoid the further oxidation of desirable products, suitable materials as catalytic dense membrane reactor (CDMR) will be investigated as oxygen ions supplier for oxidative dehydrogenation of propane. In CDMR, the membrane acts as physical separator between propane (reaction side) and molecular oxygen (regeneration side), limiting the deep oxidation. As the reaction side is depleted in oxygen due to reaction with the alkane, membrane regeneration is required. It occurs via ionic permeation of $\mathrm{O}^{2-}$ ions through the mixed conducting dense membrane, which are generated at regeneration side interface. By matching the conversion and oxygen permeation rates, oxygen recombination at the alkane side can be prevented and alkane oxidation may proceed via oxygen lattice ions exclusively.

In this chapter, the suitability of $\mathrm{La}_{2} \mathrm{NiO}_{4+\delta}$, for CDMR [9 - 11] will be investigated. As observed for many redox compounds [12-14], $\mathrm{La}_{2} \mathrm{NiO}_{4+\delta}$ contains structural defects, i.e. lacking oxygen ions in lattice position, conventionally called vacancies. Furthermore, due to the specific crystallographic arrangement, $\mathrm{La}_{2} \mathrm{NiO}_{4+\delta}$ can host over-stoichiometric oxygen as an additional type of defects (indicated with $\delta$ in the catalyst nominal composition). Thus, $\mathrm{La}_{2} \mathrm{NiO}_{4+\delta}$ contains two types of oxygen ions (lattice and interstitial) possessing different reactivity, as discussed in chapter 4 [15].

It is known that the permeability and the reactivity of oxygen ions can be modified by adding dopants to $\mathrm{La}_{2} \mathrm{NiO}_{4+\delta}$, [15-17]. Doping $\mathrm{La}_{2} \mathrm{NiO}_{4+\delta}$ with vanadium stabilizes over-stoichiometric oxygen, broadening the window of the level of reduction in which the catalyst is selective towards propylene at $550{ }^{\circ} \mathrm{C}$ [15]. In this chapter, the effect of temperature $\left(450-650{ }^{\circ} \mathrm{C}\right)$ will be investigated and the performances of $\mathrm{La}_{2} \mathrm{NiO}_{4+\delta}$ (LN) and $\mathrm{La}_{2} \mathrm{Ni}_{0.9} \mathrm{~V}_{0.1} \mathrm{O}_{4.15+\delta}$ (LNV-10) will be compared in propane pulse experiments. It will be shown that vanadium has a beneficial effect by stabilizing not only interstitial oxygen, as extensively discussed in chapters 4 and 6 [15-18] but also by stabilizing lattice oxygen, inhibiting the 
formation of $\mathrm{Ni}$ metal, which would be detrimental for selectivity towards propylene.

\subsection{Experimental}

\subsubsection{Catalyst preparation}

LN and LNV-10 were prepared via sol-gel method using EDTA as chelating agent [19]. The appropriate amount of $\mathrm{V}_{2} \mathrm{O}_{5}$ (Merck) was dissolved in diluted $\mathrm{HNO}_{3}$ (Merck) at $80{ }^{\circ} \mathrm{C}$ under stirring for $1 \mathrm{~h}$. A stoichiometric amount of $\mathrm{La}\left(\mathrm{NO}_{3}\right)_{3} * 6 \mathrm{H}_{2} \mathrm{O}$ (Merck), $\mathrm{Ni}\left(\mathrm{NO}_{3}\right)_{2} * 6 \mathrm{H}_{2} \mathrm{O}$ (Merck), EDTA and $\mathrm{NH}_{4} \mathrm{OH}$ solutions were added and the obtained solution was heated for 2 hours under stirring. After drying at $230{ }^{\circ} \mathrm{C}$, foam-type material was formed and pyrolysis took place after spontaneous ignition. The resulting solid mixed metal oxides was milled and calcined in air, slowly increasing temperature $\left(1{ }^{\circ} \mathrm{C} / \mathrm{min}\right)$ up to $1050{ }^{\circ} \mathrm{C}$. The resulting materials were finally ball milled in acetone for $5 \mathrm{~h}$ and dried at $80^{\circ} \mathrm{C}$. The materials were sieved and particles size of $0.1-0.3 \mathrm{~mm}$ was used for all experiments.

\subsubsection{Characterization}

Temperature programmed reduction in $\mathrm{H}_{2}\left(\mathrm{H}_{2}-\mathrm{TPR}\right)$ of the samples were carried out with a home-built set-up, equipped with a TCD detector. First, $40 \mathrm{mg}$ of sample mixed with $40 \mathrm{mg}$ quartz particles were placed in a reactor with a $4 \mathrm{~mm}$ inner diameter and heated in a flow of $5 \% \mathrm{O}_{2}$ in He up to $500{ }^{\circ} \mathrm{C}\left(10{ }^{\circ} \mathrm{C} / \mathrm{min}\right)$ and kept at $500{ }^{\circ} \mathrm{C}$ for $1 \mathrm{~h}$. Then the sample was cooled down to room temperature in the same atmosphere. At room temperature the flow was changed to $5 \% \mathrm{H}_{2}$ in $\mathrm{Ar}$ and TPR was carried out with a heating rate of $5{ }^{\circ} \mathrm{C} / \mathrm{min}$ up to $900{ }^{\circ} \mathrm{C}$. The TCD was calibrated via reduction of $\mathrm{NiO}$.

Temperature programmed reduction in $\mathrm{C}_{3} \mathrm{H}_{8}\left(\mathrm{C}_{3} \mathrm{H}_{8}\right.$-TPR $)$ of the samples were carried out in the equipment described above, employing quadrupole mass spectrometer as analyzer (Pfeiffer AG Balzers, OmniStar, equipped with Channeltron and Faraday detectors) to follow the consumption of propane. Preparation of reactor and pre-treatment were identical to the $\mathrm{H}_{2}$-TPR; at room temperature the flow was changed to $3 \% \mathrm{C}_{3} \mathrm{H}_{8}$ in $\mathrm{Ar}$ and TPR was carried out with a heating rate of $10^{\circ} \mathrm{C} / \mathrm{min}$ up to $900{ }^{\circ} \mathrm{C}$. 
Thermal gravimetric analyses (TGA) of both samples were carried out using a Mettler-Toledo TGA-SDTA 851 unit. The sample (around $55 \mathrm{mg}$ ) was placed in a TGA cup and kept at $140{ }^{\circ} \mathrm{C}$ for $8 \mathrm{~h}$ to remove $\mathrm{H}_{2} \mathrm{O}$ and any organic volatile compound adsorbed on the surface. Then the catalyst was heated up to $550{ }^{\circ} \mathrm{C}$ and, subsequently, up to $650{ }^{\circ} \mathrm{C}$, with rate of $10{ }^{\circ} \mathrm{C} / \mathrm{min}$ in Ar flow of $40 \mathrm{ml} / \mathrm{min}$. The weight loss was considered after $30 \mathrm{~min}$ of isothermal treatment at $550{ }^{\circ} \mathrm{C}$, mimicking the pre-treatment of pulse experiment. To check the sample stability, the compound was kept at $550{ }^{\circ} \mathrm{C}$ for $14 \mathrm{~h}$ and the weight loss was considered. Experimental results were corrected for the buoyancy effect using a cup filled with quartz particles with similar volume.

\subsubsection{Titration test}

Pulse experiments were carried out in a fix-bed reactor using a $400 \mathrm{~mm}$ long quartz tube with an internal diameter of $2 \mathrm{~mm}$, at temperatures between 450 and $650{ }^{\circ} \mathrm{C}$. About $40 \mathrm{mg}$ of catalyst particles were sieved with particle size of $0.1-0.3 \mathrm{~mm}$ and packed between two quartz-wool plugs which were approximately $10 \mathrm{~mm}$ long. The remaining volume of the reactor was filled up with quartz particles, in order to reduce the void space and minimize gas phase reactions. Before each titration test, the catalysts were pre-treated in $10 \%$ of $\mathrm{O}_{2}$ in $\mathrm{He}$ flow $(20 \mathrm{ml} / \mathrm{min}, 30 \mathrm{~min}$.) at 720 ${ }^{\circ} \mathrm{C}$ in order to remove any trace of water or inorganic compounds physisorbed on surface and keep the catalyst oxygen level as high as possible. The samples were cooled down to reaction temperature under the same atmosphere, where after the gas flow was changed to $\mathrm{He}(3 \mathrm{ml} / \mathrm{min})$. After flowing pure $\mathrm{He}$ for $30 \mathrm{~min}$, pulses of $300 \mu \mathrm{l}$ at atmospheric pressure containing $10 \% \mathrm{C}_{3} \mathrm{H}_{8}$ in $\mathrm{He}$ were introduced, whereas pulses containing $10 \% \mathrm{O}_{2}$ in $\mathrm{He}$ were used to re-oxidize the catalyst, after exposure to $\mathrm{C}_{3} \mathrm{H}_{8}$ pulses.

Product distributions were monitored by sampling on-line to a quadrupole mass spectrometer (Pfeiffer AG Balzers, OmniStar) equipped with Channeltron and Faraday detectors (2-200 amu). Prior to each experiment, the fragment pattern of fresh propane and fresh oxygen were recorder and compared with the fragmentation pattern of the produced gas mixture to qualitatively identify the products distribution. Water, propane, oxygen and carbon dioxide were identified monitoring $\mathrm{m} / \mathrm{z}=18,29,32$ and 44 , respectively, since no other products contribute to those $\mathrm{m} / \mathrm{z}$ signals significantly. The concentration of methane, ethane, ethylene, propylene and carbon monoxide were calculated semi-quantitatively with a matrix calculation in order to account for cross-contamination effect; calibration for these compounds was not available. This procedure allows quantitative determination of propane and oxygen conversion with an experimental error of about $5 \%$. 


\section{Chapter 5}

Apparent selectivities were calculated based on the integrated area of peaks of the corresponding $\mathrm{m} / \mathrm{z}$ signals of each compound divided by total integrated areas of the peaks of all carbon containing products (e.g. for methane: $\mathrm{A}\left(\mathrm{m}_{/} \mathrm{Z}_{\mathrm{CH} 4}\right) / \mathrm{A}\left(\mathrm{m}_{/} \mathrm{Z}_{\mathrm{CH} 4}\right)$ $\left.+\mathrm{A}\left(\mathrm{m}_{\mathrm{z}} \mathrm{Z}_{\mathrm{C} 2 \mathrm{H} 6}\right)+\mathrm{A}\left(\mathrm{m}_{/} \mathrm{z}_{\mathrm{C} 2 \mathrm{H} 4}\right)+\mathrm{A}\left(\mathrm{m}_{/} \mathrm{Z}_{\mathrm{C} 3 \mathrm{H} 6}\right)+\mathrm{A}\left(\mathrm{m}_{/} \mathrm{Z}_{\mathrm{CO}}\right)+\mathrm{A}\left(\mathrm{m}_{/} \mathrm{z}_{\mathrm{CO} 2}\right)\right)$. Obviously, water was not included in the calculation, despite the fact that water was always formed. The conversion of propane at $650{ }^{\circ} \mathrm{C}$ was below the detection limit when pulsing propane to the reactor filled with quartz particle exclusively and therefore we can exclude gas phase initiation during the pulse tests.

The amount of oxygen removed from the fresh catalyst during propane pulsing was quantified via of back-titration with $\mathrm{O}_{2}$.

\subsection{Results}

\subsection{1 $\mathrm{H}_{2}-$ and $\mathrm{C}_{3} \mathrm{H}_{8}-\mathrm{TPR}$}

Figure 5.1 shows the $\mathrm{H}_{2}$ - and $\mathrm{C}_{3} \mathrm{H}_{8^{-}}$temperature programmed reductions of fresh $\mathrm{LN}$ and LNV-10 and as the $\mathrm{H}_{2}$-TPR analysis was already presented in chapter 4 [15], only a brief summary of the results is provided here in order to compare with $\mathrm{C}_{3} \mathrm{H}_{8}$-TPR.

Two distinctive reduction steps are visible at $\sim 300{ }^{\circ} \mathrm{C}$ and $650{ }^{\circ} \mathrm{C}$ in $\mathrm{H}_{2}$-TPR for both samples, typical for $\mathrm{K}_{2} \mathrm{NiF}_{4}$-type of materials [15, 20-23]. In chapter 4, the low temperature peak was assigned to removal of over-stoichiometric oxygen (reduction of $\mathrm{Ni}^{3+}$ to $\mathrm{Ni}^{2+}$ ) while the high temperature reduction peak was assigned to removal of lattice oxygen bonded to $\mathrm{Ni}^{2+}$. Low temperature reduction $\left(\sim 300^{\circ} \mathrm{C}\right)$ corresponds to removal of $0.37 \pm 0.02$ and of $0.42 \pm 0.02 \mathrm{mmol}$ of oxygen per gram of catalyst for $\mathrm{LN}$ and LNV-10, respectively. The amount of oxygen removed at higher temperature $\left(600{ }^{\circ} \mathrm{C}\right)$ is similar for both samples and equal to $2.4 \pm 0.1 \mathrm{mmol} / \mathrm{g}$, which is in a good agreement with complete reduction of $\mathrm{Ni}^{2+}$ to $\mathrm{Ni}^{0}[15,20]$.

As shown in fig. 5.1a, addition of $\mathrm{V}$ causes the temperatures required for reduction of both interstitial and lattice oxygen to shift to higher temperatures, with about 80 and $45^{\circ} \mathrm{C}$, respectively.

In contrast to $\mathrm{H}_{2}$-TPR analysis, only the high temperature reduction step is observed in case of $\mathrm{C}_{3} \mathrm{H}_{8}$-TPR for both samples in the range between 520 and $650{ }^{\circ} \mathrm{C}$ for $\mathrm{LN}$ and between 570 and $620^{\circ} \mathrm{C}$ for LNV-10, as shown in Fig 5.1b. In the case of LN, the reduction step presents two peaks at 590 and $630{ }^{\circ} \mathrm{C}$. Additionally, consistent propane consumption is detected at temperature above $690{ }^{\circ} \mathrm{C}$ which is also observed in the blank experiment (Fig. 5.1b). Therefore, this is assigned to propane gas phase decomposition, as described in literature [24]. Surprisingly, no peak is 
observed between 200 and $500{ }^{\circ} \mathrm{C}$ in propane, in contrast to the observation in $\mathrm{H}_{2-}$ TPR (fig. 5.1a) which was attributed to over-stoichiometric oxygen. The reduction onset temperature in $\mathrm{C}_{3} \mathrm{H}_{8}$-TPR is about $20{ }^{\circ} \mathrm{C}$ higher as compared to $\mathrm{H}_{2}$-TPR, for both samples.
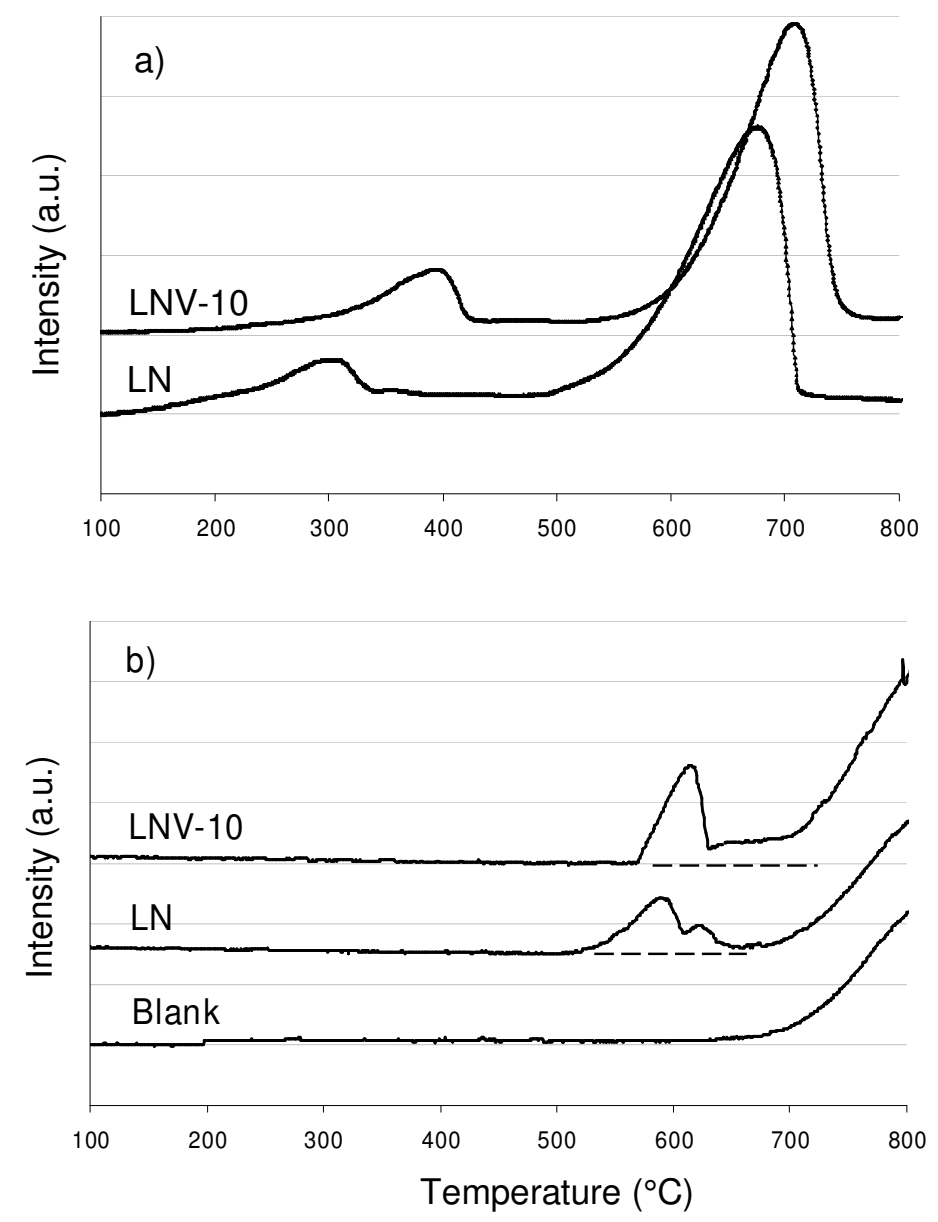

Fig. 5.1: $H_{2}(a)$ and $C_{3} H_{8}(b)$ temperature programmed reduction of $L N V-10$ and $L N$. The blank $\mathrm{C}_{3} \mathrm{H}_{8}$ TPR profile was obtained in an empty reactor (no catalyst). 
Table 5.1: Temperature range in which the reductions occur.

\begin{tabular}{|cccccc|}
\hline \multirow{2}{*}{ Catalyst } & \multirow{2}{*}{$\begin{array}{c}\text { Reductive } \\
\text { agent }\end{array}$} & \multicolumn{2}{c}{ First peak } & \multicolumn{2}{c|}{ Second peak } \\
\cline { 3 - 6 }$\left({ }^{\circ} \mathrm{C}\right)$ & $\begin{array}{c}\mathrm{T}_{\max } \\
\left({ }^{\circ} \mathrm{C}\right)\end{array}$ & $\begin{array}{c}\text { Onset } \mathrm{T} \\
\left({ }^{\circ} \mathrm{C}\right)\end{array}$ & $\begin{array}{c}\mathrm{T}_{\max } \\
\left({ }^{\circ} \mathrm{C}\right)\end{array}$ \\
\hline LN & $\mathrm{H}_{2}$ & $132 \pm 10$ & $300 \pm 20$ & $498 \pm 20$ & $680 \pm 15$ \\
\hline LNV-10 & $\mathrm{H}_{2}$ & $207 \pm 20$ & $390 \pm 20$ & $545 \pm 20$ & $720 \pm 15$ \\
\hline LN & $\mathrm{C}_{3} \mathrm{H}_{8}$ & & & $520 \pm 20$ & $595 \pm 20$ \\
\hline LNV-10 & $\mathrm{C}_{3} \mathrm{H}_{8}$ & & $570 \pm 20$ & $620 \pm 20$ \\
\hline
\end{tabular}

\subsubsection{TGA}

Thermal gravimetric analysis of fresh $\mathrm{LN}$ and LNV-10 up to $550{ }^{\circ} \mathrm{C}$ in inert atmosphere (fig. 5.2) showed continuous weight decrease which is associated to partial removal of over-stoichiometric oxygen, as discussed in chapter 6 and as reported in literature $[18,22]$. The relative weight losses (actual weight loss divided by the total initial weight) observed for the two samples after $30 \mathrm{~min}$ at $550{ }^{\circ} \mathrm{C}$ (conditions mimicking the pre-treatment prior the pulse test) are clearly different: 0.584 and $0.410 \%$ for $\mathrm{LN}$ and LNV-10, respectively. Additional relative weight losses of 0.009 and $0.017 \%$ for $\mathrm{LN}$ and LNV-10 respectively, were observed keeping the samples at $550{ }^{\circ} \mathrm{C}$ for $14 \mathrm{~h}$ (not shown in the figure). Increasing the temperature up to $650{ }^{\circ} \mathrm{C}$, both samples released additional oxygen, causing a relative weight loss of 0.062 and $0.046 \%$ for LN and LNV-10, respectively. 


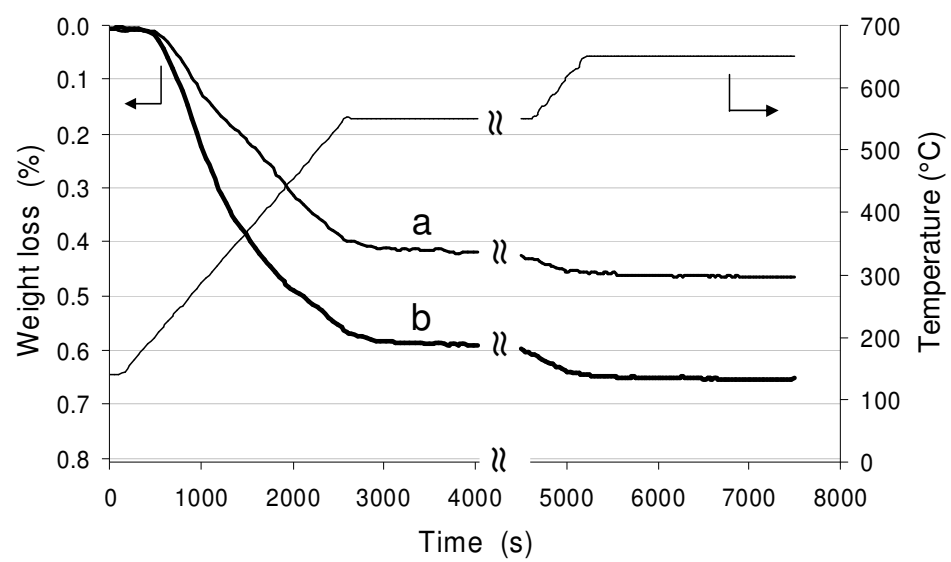

Fig. 5.2: Thermo-gravimetric analysis in pure Ar on $L N V-10(a)$ and on $L N(b)$ in the temperature range $140-550{ }^{\circ} \mathrm{C}$ and $550-650{ }^{\circ} \mathrm{C}$.

\subsubsection{Pulse experiments}

The propane conversion during pulse experiments over $\mathrm{LN}$ at $450{ }^{\circ} \mathrm{C}$ (fig. $5.3 \mathrm{a}$, curve a1) resulted in gradual decrease of conversion, reaching a value of $\sim 5 \%$ at the end of the test. The conversion at $550{ }^{\circ} \mathrm{C}$ was slightly higher at each pulse (fig. 5.3a, curve a2), showing a similar profile up to eleventh pulse, as previously presented in chapter 4 [15]. Continuing pulsing propane, the catalyst showed a drastic increase of conversion up to $50 \%$, contrary to what was observed at $450{ }^{\circ} \mathrm{C}$. At $650{ }^{\circ} \mathrm{C}$ the conversion profile was significantly different compared to lower temperatures (fig. 5.3a, curve a3): within the first five pulses the conversion increased from 70 to $100 \%$ and constant complete conversion was observed when continuing pulsing.

Contrary, LNV-10 (fig 5.3b) exhibited similar conversion profiles at all investigated temperatures, showing a gradual decrease in conversion, reaching a value of $\sim 5 \%$ at the end of the experiment, similar to the conversion profile over $\mathrm{LN}$ at $450{ }^{\circ} \mathrm{C}$. As expected, the conversion at the first pulse increased with increasing temperature. 

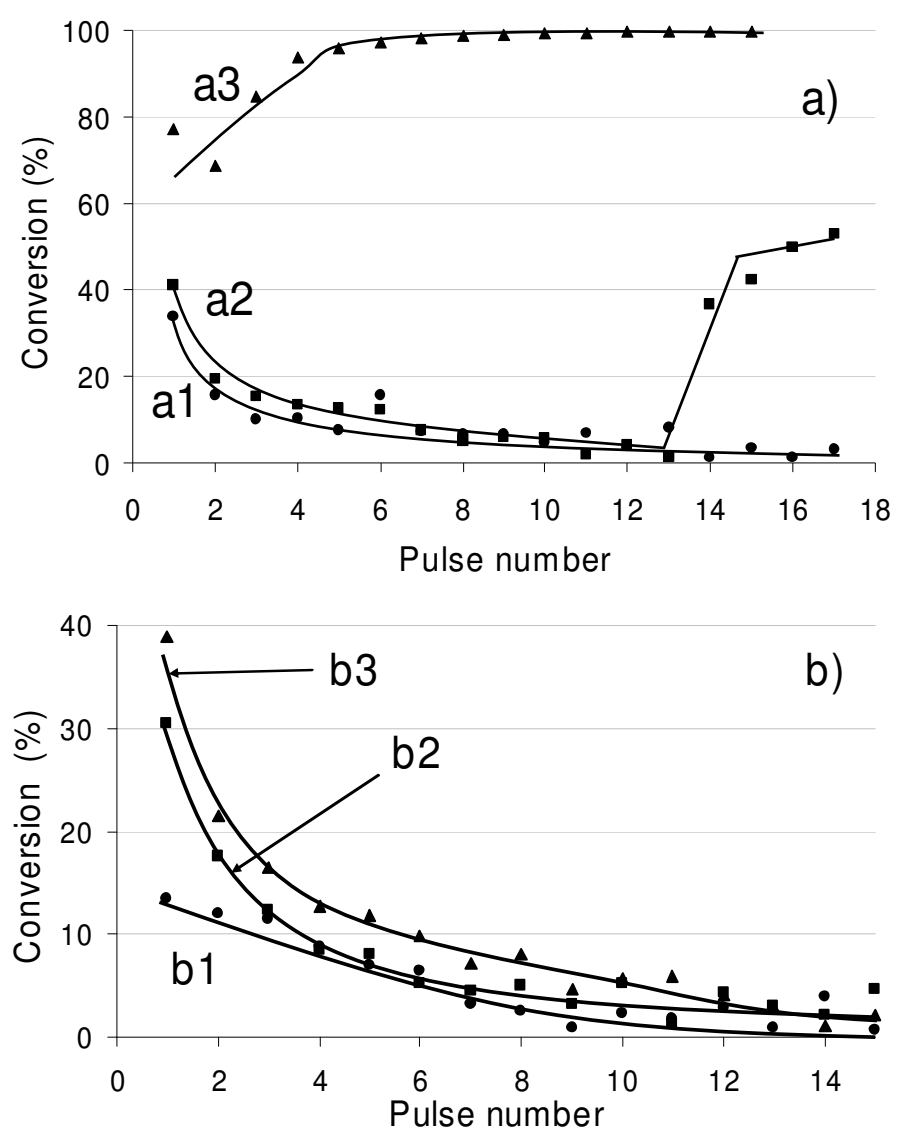

Fig. 5.3: Propane conversion profile during pulse tests on $L N($ a) and LNV-10 (b) at $450{ }^{\circ} \mathrm{C}$ (al and b1, •), $550{ }^{\circ} \mathrm{C}$ (a2 and b2, -) and $650{ }^{\circ} \mathrm{C}$ ( $a 3$ and b3, 4).

Fig. 5.4a shows that $\mathrm{CO}_{2}$ is main product during the first six propane pulses over $\mathrm{LN}$ at $450{ }^{\circ} \mathrm{C}$. The $\mathrm{CO}_{2}$ production rapidly decreased to a value lower than MS detection limit; consequently the selectivities to other products increased. From the tenth pulse onwards, $\mathrm{C}_{2} \mathrm{H}_{4}$ and $\mathrm{CH}_{4}$ were the main products and the relative apparent selectivities (AS) of both products were about 0.37. In this case the production of $\mathrm{C}_{3} \mathrm{H}_{6}$ was just slightly lower than $\mathrm{C}_{2} \mathrm{H}_{4}$ and $\mathrm{CH}_{4}\left(\mathrm{AS}_{\mathrm{C} 3 \mathrm{H} 6}=0.27\right)$. 

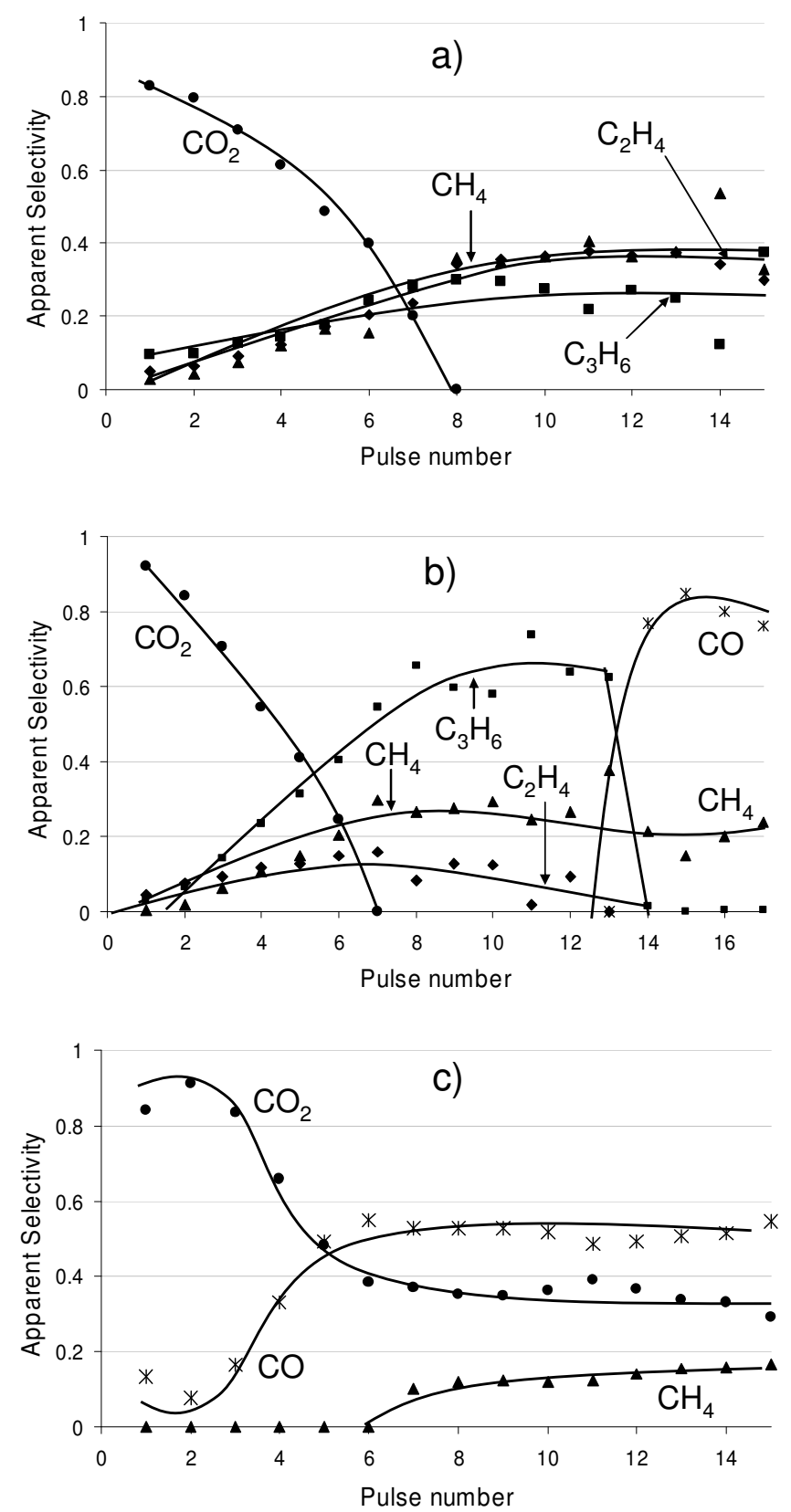

Fig. 5.4: Apparent selectivity to $\mathrm{CO}(*), \mathrm{CO}_{2}(\bullet), \mathrm{C}_{3} \mathrm{H}_{6}(\bullet), \mathrm{C}_{2} \mathrm{H}_{4}(\bullet)$ and $\mathrm{CH}_{4}(\bullet)$ during pulse experiment on $\mathrm{LN}$ at $450{ }^{\circ} \mathrm{C}(\mathrm{a}), 550{ }^{\circ} \mathrm{C}(\mathrm{b})$ and $650 \mathrm{C}(\mathrm{c})$. 


\section{Chapter 5}
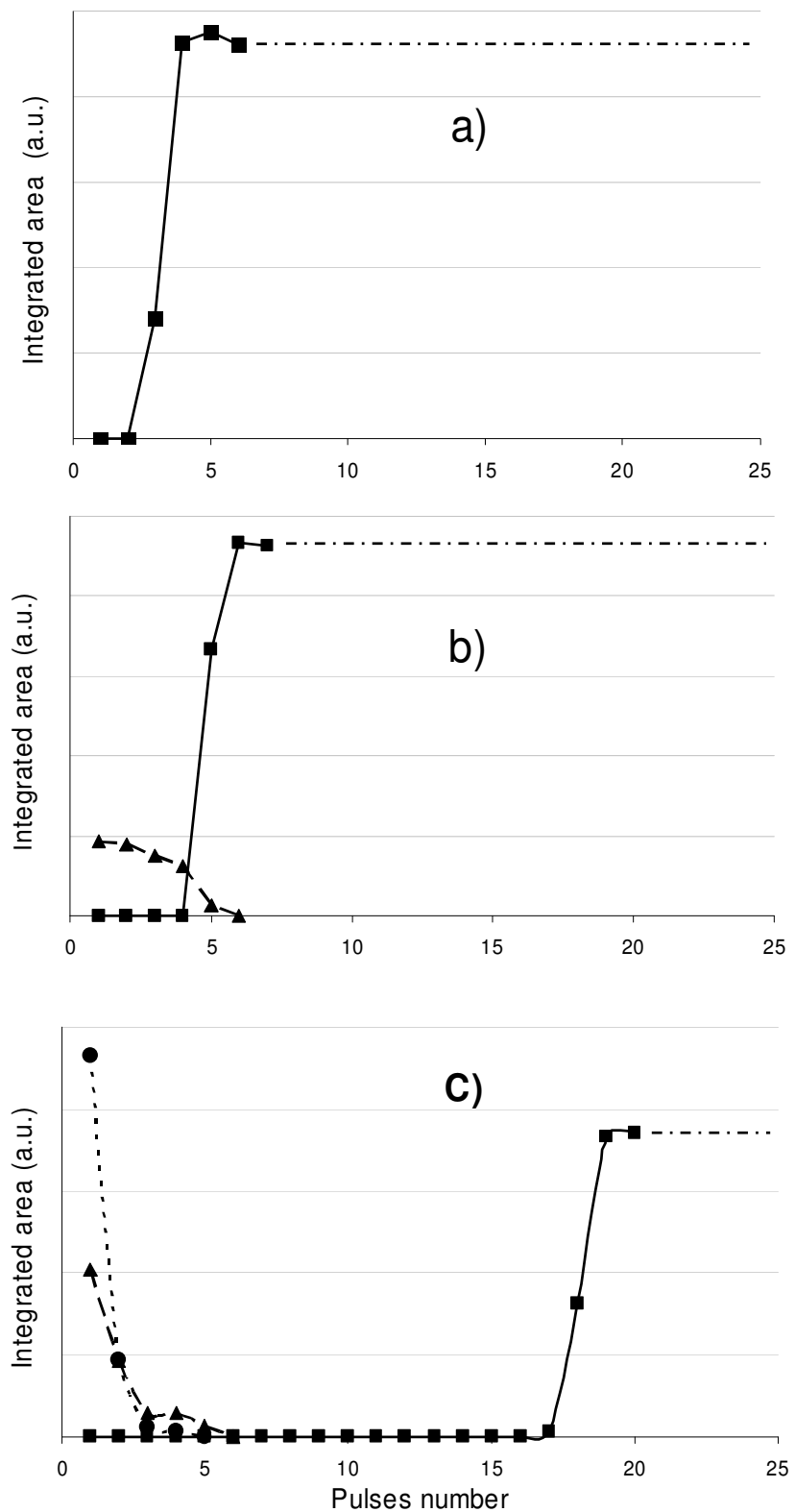

Fig. 5.5: Profile of oxygen pulses (solid lines, - ), formed $\mathrm{CO}$ (dotted line, •) and formed $\mathrm{CO}_{2}$ (dashed line, 4$)$ during regeneration process on $L N$ at $450($ a), 550 (b) and $650{ }^{\circ} \mathrm{C}(\mathrm{c})$. The dashed-dotted line represents the signal of blank oxygen pulses. 
When regenerating the catalyst by pulsing oxygen (fig. 5.5a), complete oxygen consumption was observed during the first two pulses at $450{ }^{\circ} \mathrm{C}$. The oxygen signal was constant after the fourth $\mathrm{O}_{2}$ pulse, indicating complete regeneration of the sample as the signal was equal to blank $\mathrm{O}_{2}$ pulses. No other products, i.e. $\mathrm{CO}_{\mathrm{x}}$, were detected during regeneration and the total amount of atomic oxygen consumed during regeneration was quantified as $0.101 \mathrm{mmol} / \mathrm{g}$.

Pulsing propane over $\mathrm{LN}$ at $550{ }^{\circ} \mathrm{C}$ (fig. 5.4b) resulted in similar trends in the product distribution during the first twelve pulses [15]. $\mathrm{CO}_{2}$ was the main product during the first five pulses and it rapidly decreased below the MS detection limit when continuing pulsing, while the apparent selectivities to olefins and methane increased. The apparent selectivities to $\mathrm{C}_{3} \mathrm{H}_{6}$ and $\mathrm{CH}_{4}$ were rather constant and $\mathrm{C}_{3} \mathrm{H}_{6}$ was the main product between the eighth and twelfth pulses. Contrary, the selectivity to $\mathrm{C}_{2} \mathrm{H}_{4}$ was significantly lower, decreasing with the number of pulses. After the twelfth pulse, the product distribution suddenly changed to $\mathrm{CO}$ and $\mathrm{CH}_{4}$ exclusively, as already discussed in chapter 4 [15].

During the subsequent catalyst regeneration at $550{ }^{\circ} \mathrm{C}, \mathrm{CO}_{2}$ was formed (fig. $5.5 \mathrm{~b}$, dashed line) testifying carbon deposition during the propane pulses [15]. After the seventh $\mathrm{O}_{2}$ pulse the catalyst was regenerated and the total amount of atomic oxygen consumed to both regenerate the catalyst and to combust coke was 0.180 $\mathrm{mmol} / \mathrm{g}$. In a separate experiment, the catalyst was regenerated after eleven propane pulses at $550{ }^{\circ} \mathrm{C}$ and no $\mathrm{CO}_{2}$ was formed, proving that carbon deposition did not take place and the total amount of atomic oxygen consumed was $0.140 \mathrm{mmol} / \mathrm{g}$ [15].

The product distribution drastically changed on $\mathrm{LN}$ when changing the temperature to $650{ }^{\circ} \mathrm{C}$ (fig. 5.4c). During the first five pulses, $\mathrm{CO}$ and $\mathrm{CO}_{2}$ were produced exclusively, showing opposite trends: apparent selectivity to $\mathrm{CO}$ increased while production of $\mathrm{CO}_{2}$ decreased.

After the sixth pulse the formation of both compounds stabilized and $\mathrm{CO}$ became the major product $\left(\mathrm{AS}_{\mathrm{CO}}=0.5\right)$. At this stage, also $\mathrm{CH}_{4}$ started to form but the apparent selectivity remained below 0.2 . Contrary to all other experiments, no olefins were produced during the entire experiment.

Regeneration of the catalyst via oxygen pulses resulted in releasing of $\mathrm{CO}$ and $\mathrm{CO}_{2}$, demonstrating that carbon deposition took place during the propane pulses at 650 ${ }^{\circ} \mathrm{C}$ (fig. 5.5c). During the first six pulses of oxygen, the $\mathrm{CO}_{\mathrm{x}}$ signal decreased below the MS detection limit and no compound was detected until the eighteenth pulse. Next, the oxygen signal became constant and equal to blank $\mathrm{O}_{2}$ pulses, indicating complete regeneration of the sample. The total amount of atomic oxygen consumed during regeneration, including both $\mathrm{LN}$ reoxidation and carbon combustion, was $0.610 \mathrm{mmol} / \mathrm{g}$.

When pulsing propane over LNV-10 at $450{ }^{\circ} \mathrm{C}$ (fig. 5.6a), formation of $\mathrm{C}_{3} \mathrm{H}_{6}, \mathrm{CO}_{2}$, $\mathrm{C}_{2} \mathrm{H}_{4}$ and $\mathrm{CH}_{4}$ was observed, similar to $\mathrm{LN}$, but at different apparent selectivities. 


\section{Chapter 5}
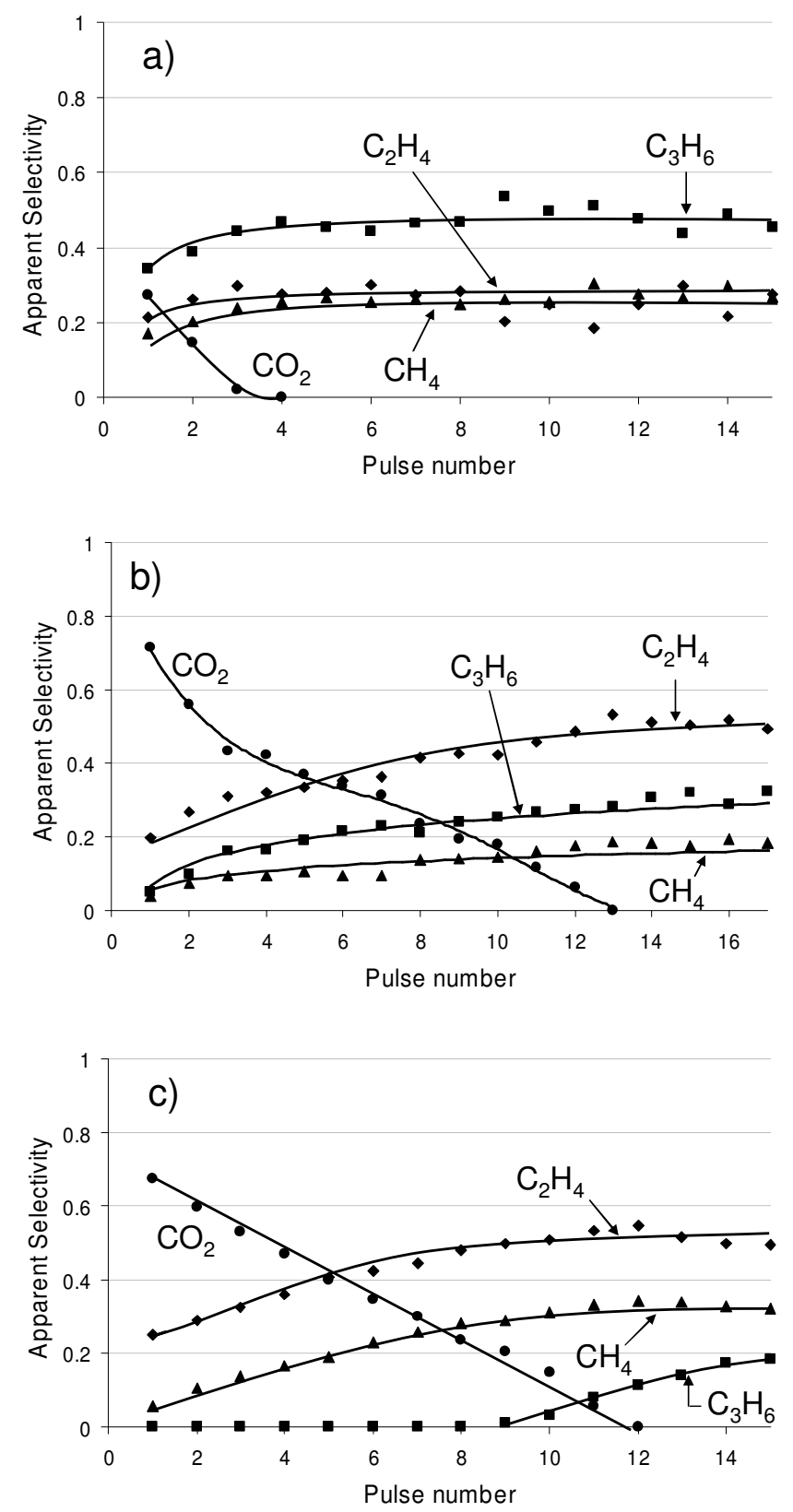

Fig. 5.6: Apparent selectivity to $\mathrm{CO}_{2}(\bullet), \mathrm{C}_{3} \mathrm{H}_{6}(\bullet), \mathrm{C}_{2} \mathrm{H}_{4}(\bullet)$ and $\mathrm{CH}_{4}(\bullet)$ during pulse experiment on LNV-10 at $450\left(\right.$ a), $550\left(\right.$ b) and $650{ }^{\circ} \mathrm{C}(\mathrm{c})$. 
Remarkably, $\mathrm{CO}_{2}$ was formed only for first two pulses in a very low amount. The apparent selectivity to $\mathrm{C}_{3} \mathrm{H}_{6}, \mathrm{C}_{2} \mathrm{H}_{4}$ and $\mathrm{CH}_{4}$ slightly increased during first three pulses and remained constant when continuing pulsing propane. $\mathrm{C}_{3} \mathrm{H}_{6}$ was the main product during the whole experiment, showing constant apparent selectivity $\mathrm{AS}_{\mathrm{C} 3 \mathrm{H} 6}$ $=0.50 . \mathrm{C}_{2} \mathrm{H}_{4}$ and $\mathrm{CH}_{4}$ showed comparable apparent selectivities throughout the experiment.

Testing the catalyst at $650{ }^{\circ} \mathrm{C}$ (fig. 5.6c) resulted in apparent selectivities similar to $450{ }^{\circ} \mathrm{C}$ as $\mathrm{CO}_{2}, \mathrm{C}_{2} \mathrm{H}_{4}, \mathrm{CH}_{4}$ and $\mathrm{C}_{3} \mathrm{H}_{6}$ were formed. In this case, $\mathrm{CO}_{2}$ was produced during eleven pulses and $\mathrm{C}_{3} \mathrm{H}_{6}$ was formed exclusively during the last six pulses, in a low amount $\left(\mathrm{AS}_{\mathrm{C} 3 \mathrm{H} 6}=0.2\right)$. The products observed at 450 and $650{ }^{\circ} \mathrm{C}$ are identical with previously reported observation at $550{ }^{\circ} \mathrm{C}$ on chapter 4 [15], although clear differences are observed when comparing the apparent selectivity to propylene, ethylene and methane.

After the titration tests, LNV-10 was regenerated by pulsing oxygen (fig. 5.7) and no $\mathrm{CO}_{\mathrm{x}}$ was detected at any investigated temperature, testifying the absence of carbon deposition. Complete regeneration of the sample was obtained at the end of each experiment, when the $\mathrm{O}_{2}$ level reached the plateau value equal to blank $\mathrm{O}_{2}$ pulses. Different amounts of oxygen were consumed by the catalyst after exposition to fifteen propane pulses at different temperatures: $0.048,0.105$ and $0.165 \mathrm{mmol} / \mathrm{g}$ at 450,550 and $650{ }^{\circ} \mathrm{C}$, respectively.

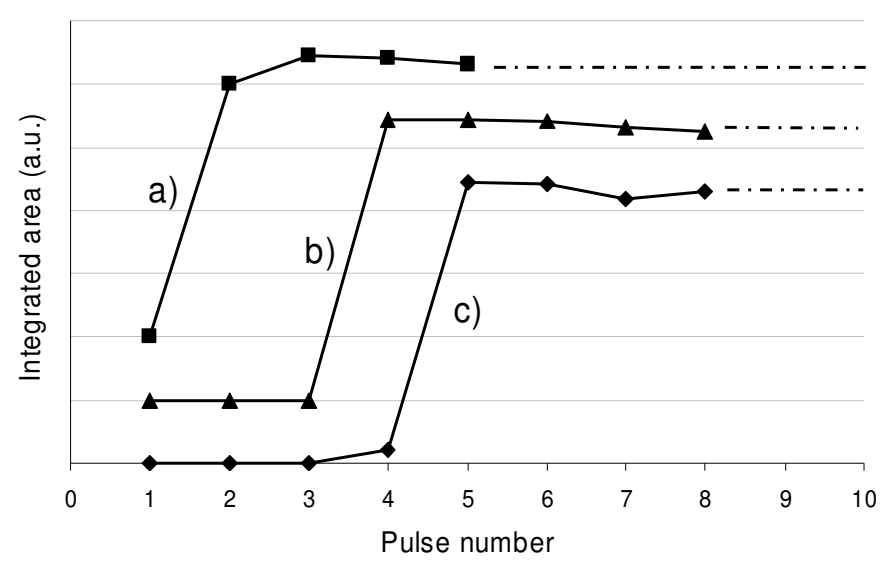

Fig. 5.7: Profile of oxygen pulses during regeneration process on LNV-10 at 450 (a), $550(b)$ and $650{ }^{\circ} \mathrm{C}(\mathrm{c})$. The dashed-dotted line represents the signal of blank oxygen pulses. 


\subsection{Discussion}

In chapter 4 [15] it was shown that pulsing propane over $\mathrm{LN}$ catalyst at $550{ }^{\circ} \mathrm{C}$ resulted in formation of $\mathrm{CO}_{2}, \mathrm{H}_{2} \mathrm{O}, \mathrm{C}_{3} \mathrm{H}_{6}, \mathrm{C}_{2} \mathrm{H}_{4}$ and $\mathrm{CH}_{4}$. The fact that oxygen containing species $\left(\mathrm{CO}_{2}\right.$ and $\left.\mathrm{H}_{2} \mathrm{O}\right)$ were formed demonstrates that the catalyst (i) is depleted in oxygen and (ii) has a crucial role in the reaction. Continuing pulsing propane, the reactivity of remaining oxygen ions in the catalyst decreased, increasing the selectivity towards propylene [15]. Therefore it is clear that the performance of the catalyst strongly depends on the amount of oxygen in the sample. Additionally, it was shown that over-stoichiometric oxygen is more reactive than lattice oxygen in $\mathrm{H}_{2}$ atmosphere as it was removed at lower temperature: $130{ }^{\circ} \mathrm{C}$ versus $500{ }^{\circ} \mathrm{C}$ for over-stoichiometric and lattice oxygen, respectively (fig. 5.1a and $[15,20]$ ).

In this chapter, the oxygen reactivity in $\mathrm{C}_{3} \mathrm{H}_{8}$ atmosphere was studied, showing a reduction step in the temperature range $520-650{ }^{\circ} \mathrm{C}$ (fig. 5.1b). This reduction step is attributed to removal of lattice oxygen bonded to Ni because of (i) the similar temperature range as compared to reduction of lattice oxygen in $\mathrm{H}_{2}$ atmosphere (fig. 5.1a and [15]) and (ii) the fact that in inert atmosphere the over-stoichiometric oxygen started to be removed at around $200{ }^{\circ} \mathrm{C}$ (fig. 5.2a) and, therefore, in $\mathrm{C}_{3} \mathrm{H}_{8}$ atmosphere the desorption of oxygen must take place at the same temperature, or possibly even lower temperature. We suggest that the removal of overstoichiometric oxygen was not detected in the $\mathrm{C}_{3} \mathrm{H}_{8}$-TPR because of the lower sensitivity of the analyzer used (MS) in this case than in $\mathrm{H}_{2}$-TPR (TCD). Additionally, considering the reduction in $\mathrm{H}_{2}$ and $\mathrm{C}_{3} \mathrm{H}_{8}$ atmospheres, described in eq. 5.1 and 5.2 respectively, it is clear that the amount of $\mathrm{C}_{3} \mathrm{H}_{8}$ required to remove over-stoichiometric oxygen is an order of magnitude smaller as compared to the amount of $\mathrm{H}_{2}$ consumed.

$\mathrm{H}_{2}+\mathrm{O} \rightarrow \mathrm{H}_{2} \mathrm{O}$

Eq. 5.1

$\mathrm{C}_{3} \mathrm{H}_{8}+10 \mathrm{O} \rightarrow 3 \mathrm{CO}_{2}+4 \mathrm{H}_{2} \mathrm{O}$

Eq. 5.2

We suggest that this reduction step at about $600{ }^{\circ} \mathrm{C}$ for $\mathrm{LN}$ contains two peaks because of the possible formation of active Ni metal particles, as reported in chapter 4 [15]. The formation of Ni metal can induce an additional reaction pathway for propane conversion to carbonaceous species [25], as further described below.

In order to establish the amount of oxygen in the catalyst at the beginning of each pulse experiment, the value of the over-stoichiometry $(\delta)$ of the material at 450,550 and $650{ }^{\circ} \mathrm{C}$ are calculated and reported in table 5.2. In chapter 4 the $\delta$ value at room temperature was calculated $(\delta=0.150)$ based on $\mathrm{H}_{2}$-TPR, as extensively described 
earlier [15]. The $\delta$ values reported in table 5.2 are calculated based on oxygen removed during Ar-TGA, described in fig 5.2 and in table 5.2. Immediately before pulsing propane, the catalyst was equilibrated in inert atmosphere for $30 \mathrm{~min}$ (see experimental), identical to the TGA analysis. Therefore, the calculated $\delta$ values after the TGA analysis are an appropriate measure for the $\delta$ values at the beginning of the propane pulse experiment.

Increasing the temperature to $450{ }^{\circ} \mathrm{C}$ in inert atmosphere, $\mathrm{LN}$ released a conspicuous amount of oxygen as $\delta$ decreased to 0.029 (table 5.2). The oxygen content of the materials at $450{ }^{\circ} \mathrm{C}$ was estimated based on the TGA results at 450 ${ }^{\circ} \mathrm{C}$ dynamically and therefore, the $\delta$ value might be even slightly lower. The overstoichiometric oxygen diminished drastically $(\delta=0.002)$ treating the sample in inert atmosphere at $550{ }^{\circ} \mathrm{C}$. At $650{ }^{\circ} \mathrm{C}$, the over-stoichiometric oxygen was completely removed, together with a small fraction of lattice oxygen $(\delta=-0.014)$ which also implies the formation of $\mathrm{Ni}$ metal, as mentioned in literature and as described in chapter 6 with in-situ XRD [18].

Table 5.2: Quantification of removed oxygen, relative over-stoichiometry ( $\delta$ values) and catalyst nominal compositions at 450,550 and $650{ }^{\circ} \mathrm{C}$, based on fig. 5.2.

\begin{tabular}{|cccccc|}
\hline Catalyst & $\begin{array}{c}\mathrm{T} \\
\left({ }^{\circ} \mathrm{C}\right)\end{array}$ & $\begin{array}{c}\text { Oxygen } \\
\text { removed } \\
(\mathrm{mg})\end{array}$ & $\begin{array}{c}\text { Oxygen } \\
\text { removed } \\
(\mathrm{mmol} / \mathrm{g})\end{array}$ & $\begin{array}{c}\text { Correspondent } \\
\delta \text { value }\end{array}$ & Catalyst composition \\
\hline LN & 450 & $0.274 \pm 0.002$ & $0.301 \pm 0.002$ & $0.029 \pm 0.005$ & $\mathrm{La}_{2} \mathrm{NiO}_{4.000+0.029}$ \\
\hline LNV-10 & 450 & $0.167 \pm 0.002$ & $0.188 \pm 0.002$ & $0.095 \pm 0.005$ & $\mathrm{La}_{2} \mathrm{Ni}_{0.9} \mathrm{~V}_{0.1} \mathrm{O}_{4.150+0.095}$ \\
\hline LN & 550 & $0.335 \pm 0.002$ & $0.367 \pm 0.002$ & $0.002 \pm 0.005$ & $\mathrm{La}_{2} \mathrm{NiO}_{4.000+0.002}$ \\
\hline LNV-10 & 550 & $0.240 \pm 0.002$ & $0.259 \pm 0.002$ & $0.066 \pm 0.005$ & $\mathrm{La}_{2} \mathrm{Ni}_{0.9} \mathrm{~V}_{0.1} \mathrm{O}_{4.150+0.066}$ \\
\hline LN & 650 & $0.370 \pm 0.002$ & $0.405 \pm 0.002$ & $-0.014 \pm 0.005$ & $\mathrm{La}_{2} \mathrm{Ni}_{0.986} \mathrm{O}_{3.986}+\mathrm{Ni}_{0.014}$ \\
\hline LNV-10 & 650 & $0.263 \pm 0.002$ & $0.285 \pm 0.002$ & $0.056 \pm 0.005$ & $\mathrm{La}_{2} \mathrm{Ni}_{0.9} \mathrm{~V}_{0.1} \mathrm{O}_{4.150+0.056}$ \\
\hline
\end{tabular}

Doping LN with vanadium stabilized both over-stoichiometric and lattice oxygen under all investigated conditions. In both $\mathrm{H}_{2}$ and $\mathrm{C}_{3} \mathrm{H}_{8}$-TPR (fig. 5.1) it was shown that the reduction steps of both interstitial and lattice oxygen were shifted towards higher temperatures when vanadium was present. Also under inert atmosphere stabilization was observed as the weight loss of LNV-10 was lower than in the case of $\mathrm{LN}$ at each investigated temperature in TGA (fig. 5.2 and table 5.1).

The product distributions during the pulse experiments at $450{ }^{\circ} \mathrm{C}$ was positively affected by stabilization of over-stoichiometric oxygen, as the selectivity to olefins was constantly high in the case on LNV-10 while $\mathrm{CO}_{2}$ was the main product at the beginning of the test, in the case of $\mathrm{LN}$.

In chapter 4 [15] we extensively discussed the performance of LN during pulse experiment at $550{ }^{\circ} \mathrm{C}$, stating that deep oxidation, cracking and dehydrogenation of 


\section{Chapter 5}

propane contribute to the product distribution at the beginning of the test. Continuing pulsing, carbon deposition and formation of $\mathrm{CO}$ and $\mathrm{CH}_{4}$ were observed due to the formation of $\mathrm{Ni}$ metal as active centre [15]. In this chapter the catalyst over-stoichiometry $(\delta)$ is quantified at the beginning of the experiment (table 5.2) as well as after eleven propane pulses. At the beginning of the test, the overstoichiometric oxygen was the active species responsible for deep oxidation, cracking and dehydrogenation reactions, similarly to what observed at $450{ }^{\circ} \mathrm{C}$ (fig. 5.4a), as $\delta=0.002$ (table 5.2). After the seventh propane pulse, the reactivity of oxygen species decreased and formation of $\mathrm{CO}_{2}$ was below the MS detection limit. Continuing pulsing, more oxygen was removed and the $\delta$ value decreased to $\delta=-$ 0.050 after eleven propane pulses, based on back-titration with $\mathrm{O}_{2}$, implying that catalyst contained $95 \%$ of $\mathrm{La}_{2} \mathrm{NiO}_{4}$ and $5 \%$ of $\mathrm{Ni}^{0} / \mathrm{La}_{2} \mathrm{O}_{3}$. We suggest that the amount of $\mathrm{Ni}^{0}$ was too low for crystallization of accessible $\mathrm{Ni}$ particles before the eleventh pulse, although the calculation of removed oxygen showed that $\mathrm{Ni}^{0}$ had already formed. Therefore, from the seventh to the eleventh pulse, $\mathrm{La}_{2} \mathrm{NiO}_{4}$ was responsible for cracking and dehydrogenation reactions exclusively. Continuing pulsing, $\mathrm{La}_{2} \mathrm{NiO}_{4}$ remained responsible for formation of $\mathrm{CH}_{4}$ and olefins; however the probable formation of $\mathrm{Ni}^{0}$ crystallites induced decomposition of olefins to carbonaceous species and hydrogen, as reported in literature [25], according to eq. 5.3:

$$
\mathrm{Ni}^{0}
$$

$\mathrm{C}_{3} \mathrm{H}_{6}+\mathrm{C}_{2} \mathrm{H}_{4} \rightarrow \mathrm{C}+\mathrm{H}_{2}$

Eq. 5.3

Additionally, the presence of highly reactive lattice oxygen species is responsible for the formation of $\mathrm{CO}$ via oxidation of carbonaceous species formed on $\mathrm{Ni}^{0}$ particles, as reported in literature for $\mathrm{Ni}^{0} / \mathrm{La}_{2} \mathrm{NiO}_{4}$ [26], according to eq. 5.4, forming additional $\mathrm{Ni}^{0}$ :

$\mathrm{La}_{2} \mathrm{NiO}_{4}+x \mathrm{C} \rightarrow \mathrm{x} \mathrm{CO}+\mathrm{x} \mathrm{Ni}^{0}+\mathrm{La}_{2} \mathrm{Ni}_{1-\mathrm{x}} \mathrm{O}_{4-\mathrm{x}}$

Apparently, the combustion of coke via lattice oxygen was not complete because of the relatively low temperature used here $\left(550^{\circ} \mathrm{C}\right)$ and therefore carbonaceous species were also detected during regeneration with oxygen pulses (fig. 5.5b). Furthermore, removal of lattice oxygen and consequent formation of Ni metal is expected when pulsing propane at $550{ }^{\circ} \mathrm{C}$, similar to observation in TPR (fig. 5.1b), exposing the sample to propane continuously. 
It was shown for LNV-10 (fig. 5.6b and 5.7b) that no carbon is deposited after 15 propane pulses at $550{ }^{\circ} \mathrm{C}$. This is because the $\delta$ value remained positive, varying from $\delta=0.066$ to $\delta=0.022$ (table 5.2) preventing the removal of lattice oxygen and thus the formation of Ni metal. This result agrees with pulse experiment reported in chapter $6[18]$ during which the $\delta$ value decreased to $\delta=0.008$ after forty-five propane pulses. Additionally, removal of lattice oxygen at $550{ }^{\circ} \mathrm{C}$ can be excluded as the TPR showed that this occurs exclusively above $570^{\circ} \mathrm{C}$ (fig $5.1 \mathrm{~b}$ ).

In the case of pulse experiment at $650^{\circ} \mathrm{C}$ over $\mathrm{LN}$, over-stoichiometric oxygen was completely removed during pre-treatment prior the pulse test and $\mathrm{Ni}$ metal was already present in the catalyst at the beginning of the experiment (table 5.2). Therefore, pulsing propane resulted in the formation of $\mathrm{CO}_{\mathrm{x}}$ and $\mathrm{CH}_{4}$ exclusively (fig. 5.4c), according to eq. 5.3, and more carbon was deposited on the surface (fig. $5.5 \mathrm{c})$. With the addition of vanadium as dopant, stabilizing the oxygen species, over-stoichiometric oxygen was still present in the catalyst $(\delta=0.056)$ at $650{ }^{\circ} \mathrm{C}$ and thus $\mathrm{CO}_{2}, \mathrm{C}_{3} \mathrm{H}_{6}, \mathrm{C}_{2} \mathrm{H}_{4}$ and $\mathrm{CH}_{4}$ are formed during pulsing propane. The catalyst over-stoichiometry after fifteen propane pulses was $\delta=0.001$, based on the amount of removed oxygen during the pulse experiment (fig. 5.7c). Therefore, also in this case over-stoichiometric oxygen was the exclusive active species during pulsing propane as $\delta$ remained positive. The exposure to propane in 15 pulses is apparently not sufficient to induce formation of Ni metal, like observed in TPR (fig. 5.1b) exposing the sample to propane continuously.

Selectivity towards $\mathrm{C}_{3} \mathrm{H}_{6}$ decreased stepwise with temperature when pulsing propane over LNV-10 and apparent selectivities of 48, 27 and $16( \pm 2) \%$ were observed at 450,550 and $650{ }^{\circ} \mathrm{C}$, respectively (fig 5.8a), as more $\mathrm{CO}_{2}$ was produced.

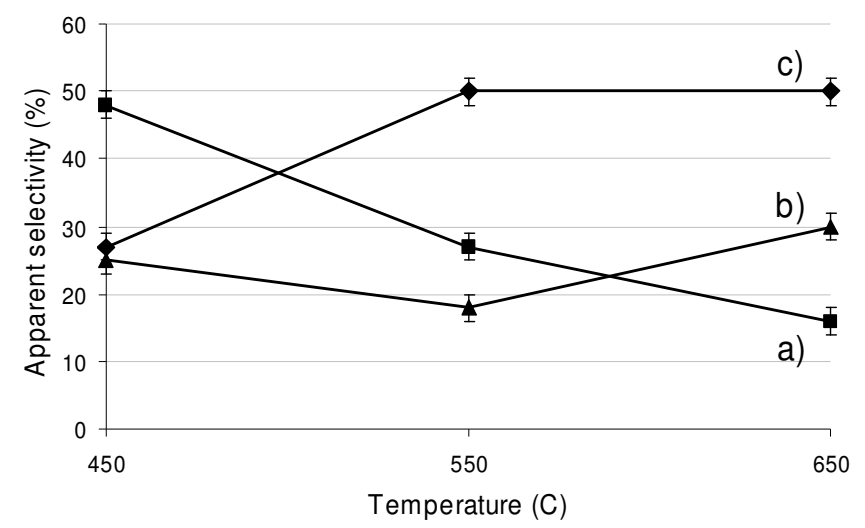

Fig. 5.8: Apparent selectivities to $\mathrm{C}_{3} \mathrm{H}_{6}(a,-), \mathrm{CH}_{4}(b, \boldsymbol{\Delta})$ and $\mathrm{C}_{2} \mathrm{H}_{4}(c, \bullet)$ over $L N V$ 10 at different temperatures. 
In contrast, the sum of ethylene and methane is increasing with temperature. This indicates that a parallel reaction pathway, cracking of propane, is increasingly contributing at higher temperature, which seems a reasonable proposition. Nevertheless, as the ratio between ethylene and methane is clearly not constant, it is clear that actual reaction scheme is more complex and not clear yet.

\subsection{Conclusions}

Over-stoichiometric oxygen was the only active species in LNV-10, responsible for formation of $\mathrm{CO}_{2}, \mathrm{C}_{3} \mathrm{H}_{6}, \mathrm{C}_{2} \mathrm{H}_{4}$ and $\mathrm{CH}_{4}$ during pulse tests at all investigated temperatures. Contrary, in the case of $\mathrm{LN}$, the reactive species changed from overstoichiometric oxygen only at $450{ }^{\circ} \mathrm{C}$, to both over-stoichiometric and lattice oxygen at $550{ }^{\circ} \mathrm{C}$, to lattice oxygen only at $650{ }^{\circ} \mathrm{C}$. The activation of lattice oxygen and the consequent formation of $\mathrm{Ni}$ metal were detrimental for selectivity to propylene as formation of $\mathrm{CO}_{\mathrm{x}}, \mathrm{CH}_{4}$ and coke mainly occurred and no olefins were formed. Additionally, it was shown that the composition of $\mathrm{La}_{2} \mathrm{Ni}_{1-\mathrm{x}} \mathrm{V}_{\mathrm{x}} \mathrm{O}_{4+1.5 \mathrm{x}+\delta}$ strongly depended on the pre-treatment condition as the removal of oxygen from the catalyst occurs from $200{ }^{\circ} \mathrm{C}$ onwards in inert atmosphere. The role of vanadium was crucial to stabilize both over-stoichiometric and lattice oxygen, retarding the oxygen loss and preventing the consequent formation of $\mathrm{Ni}$ metal, in the temperature range $450-650^{\circ} \mathrm{C}$.

We conclude therefore that the presence of vanadium in the catalyst was crucial to preserve over-stoichiometric oxygen, which is the reactive specie responsible for propylene formation.

\section{Acknowledgements}

The author would like to thank Dr. C. Trionfetti for inspiring discussions related to this chapter. We thank ACTS/NWO, The Netherlands for financial support (project number 053.62.004).

\section{References}

[1] J. Plotkin and E. Glatzer, Eur. Chem. News, 82 (2005) 20

[2] N. Alperowicz, Chem. Week, 169 (2007) 27 
[3] N. Alperowicz, Chem. Week, 168 (2006) 17

[4] C. Sumner, PTC/US2004/038213

[5] R. K. Grasselli, D. L. Stern and J. G. Tsikoyiannis, Appl. Catal. A: Gen., 189 (1999) 1-8

[6] T.A. Nijhuis, S.J. Tinnemans, T. Visser and B.M. Weckhuysen, Chem. Eng. Sci., 59 (2004) 5487

[7] F. Cavani, N. Ballarini and A. Cericola, Cat. Today 127 (2007) 113-131

[8] S.B. Wang and Z.H. Zhu, Energy \& Fuel, 18 (2004) 1126-1139

[9] E.N. Naumovich, M.V. Patrakeev, V.V. Kharton, A.A. Yaremchenko, D.I. Logvinovich and F.M.B. Marques, Solid State Sci., 7 (2005) 1353-1362

[10] M. Burriel, G. Garcia, J. Santiso, J.A. Kilner, R.J. Chater and S.J. Skinner, J. Mater. Chem., 18 (2008) 416-422

[11] A.L. Shaula, E.N. Naumovich, A.P. Viskup, V.V. Pankov, A.V. Kovalevsky and V.V. Kharton, Solid State Ion., 180 (2009) 812-816

[12] R. Merkle and J. Maier, Top. Catal., 38 (2006) 141-145

[13] J. C. Conesa, Catal. Today, 143 (2009) 315-325

[14] C. Trionfetti, I. V. Babich, K. Seshan and L. Lefferts, Top. Catal., 39 (2006) 191-197

[15] S. Crapanzano, I.V. Babich and L. Lefferts, Appl. Catal. A, submitted

[16] A.A. Yaremchenko, V.V. Kharton, E.N. Naumovich, D.I. Shestakov, V.F. Chukharev, A.V. Kovalevsky, A.L. Shaula, M.V. Patrakeev, J.R. Frade and F.M.B. Marques, Solid State Ion., 177 (2006) 549-558

[17] V.V. Kharton, E.V. Tsipis, E.N. Naumovich, A. Thursfield, M.V. Patrakeev, V.A. Kolotygin, J.C. Waerenborgh and I.S. Metcalfe, J. Solid State Chem., 181 (2008) $1425-1433$

[18] S. Crapanzano, I.V. Babich and L. Lefferts, Langmuir, submitted

[19] R.H.E. van Doorn, H. Kruidhof, A. Nijmeijer, L. Winnubst and A.J. Burggraaf, J. Mater. Chem., 1998, 8(9), 2109-2112

[20] B. Zhao, R. Wang, W. Yao, X. Yang and B. Zhou, Catal. Lett., 132 (2009) 4149

[21] B.S. Liu and C.T. Au, Appl. Catal. A: Gen., 244 (2003) 181-195

[22] B.S. Liu and C.T. Au, Catal. Lett., Vol. 85, Nos 3-4 (2003) 165-169

[23] G. S. Gallego, F. Mondragon, J. Barrault, J.M. Tatibouet and C. BatiotDupeyrat, Appl. Catal. A: Gen., 311 (2006) 164-171

[24] L. Leveles, K. Seshan, J.A. Lercher and L. Lefferts, J. Catal., 218 (2003) 296306

[25] K.P. De Jong and J.W. Geus, Catal. Rev. Sci. Eng., 42 (2000) 481-510

[26] G. Sierra Gallego, F. Mondragon, J.M. Tatibouet, J. Barrault, C. BatiotDupeyrat, Catal. Today 133 (2008) 200-209 



\section{6}

\section{The influence of over-stoichiometry in $\mathrm{La}_{2} \mathrm{Ni}_{0.9} \mathrm{~V}_{0.1} \mathrm{O}_{4.15+\delta}$ on selective oxidative dehydrogenation of propane}

In this chapter, the non-stoichiometric redox compound $\mathrm{La}_{2} \mathrm{Ni}_{0.9} \mathrm{~V}_{0.1} \mathrm{O}_{4.15+\delta}$ has been tested as an oxidant in selective oxidation of propane in pulse experiments. The extent of over-stoichiometry $(\delta)$ was varied via both removing oxygen with propane, as well as partial re-oxidation with oxygen. The optimal degree of overstoichiometry $(\delta)$ has been precisely quantified; olefins are formed whereas formation of $\mathrm{CO}_{2}$ is prevented provided that $\delta$ is below 0.03. Additionally, the structural stability of the material was tested with in-situ X-ray diffraction in $\mathrm{H}_{2}$ $\left(\mathrm{H}_{2}-\mathrm{XRD}\right)$, temperature programmed reduction (TPR), thermo-gravimetric analysis (TGA), propane-pulse-experiments and re-oxidation cycles. $\mathrm{La}_{2} \mathrm{Ni}_{0.9} \mathrm{~V}_{0.1} \mathrm{O}_{4.15+\delta}$ has demonstrated structure stability and reversibility during oxidation-reduction cycles at $550{ }^{\circ} \mathrm{C}$ and therefore considered suitable for catalytic dense membrane reactor provided that the degree of over-stoichiometry is limited to 0.03 at the surface exposed to propane. 



\subsection{Introduction}

The demand of propylene is expected to increase in the future because it is a crucial intermediate for many industrial processes [1]. The simplest and most direct way to obtain propylene is dehydrogenation of propane, as shown in Eq. 6.1.

$$
\mathrm{C}_{3} \mathrm{H}_{8} \leftrightarrows \mathrm{C}_{3} \mathrm{H}_{6}+\mathrm{H}_{2} \quad \Delta \mathrm{H}=+156 \mathrm{KJ} / \mathrm{mol}
$$

Catalytic dehydrogenation of propane using Cr- and Pt- supported catalysts was extensively studied in the past and several processes such as Catofin (from Houdry, United Catalyst Inc., ABB Lummus Crest), Oleflex (from UOP), Star (from Phillips Petroleum), FDB (from Snamprogetti) and PDH (from Linde-BASF) were commercialized [2]. Due to the high endothermicity of the reaction, high temperature is often required to increase the olefin yield. Unfortunately, operation at high temperature induces undesired cracking reactions, coke formation and consequent catalyst deactivation.

An alternative way for propylene production is oxidative dehydrogenation (ODH) of propane [3], as illustrated in Eq. 6.2.

$$
\mathrm{C}_{3} \mathrm{H}_{8}+\mathrm{O}_{2} \leftrightarrows \mathrm{C}_{3} \mathrm{H}_{6}+\mathrm{H}_{2} \mathrm{O} \quad \Delta \mathrm{H}=-86 \mathrm{KJ} / \mathrm{mol}
$$

The high quantity of heat generated by water formation turns the overall ODH of propane into an exothermic reaction, which overcomes the thermodynamic limitation. On the other hand, deep oxidation of propane to $\mathrm{CO}_{2}$ is drastically decreasing the selectivity to olefins, due to the fact that highly reactive oxygen- and propyl-radicals are involved $[4,5]$.

Many alternative oxidative agents were investigated (i.e. $\mathrm{N}_{2} \mathrm{O}, \mathrm{H}_{2} \mathrm{O}_{2}$ and $\mathrm{CO}_{2}$ ) to accomplish less severe oxidative conditions, aiming at increasing the yield. It was shown [6] that replacing pure $\mathrm{O}_{2}$ with $\mathrm{N}_{2} \mathrm{O} / \mathrm{O}_{2}$ mixture in ammoxidation of propane over Fe-silicalite resulted in significant higher selectivity to acrylonitrile. Oxidation of propylene with $\mathrm{H}_{2} \mathrm{O}_{2}$ resulted in high selectivity to propylene oxide [7, 8] and the same oxidative agent was also employed in selective oxidation of styrene to benzaldehyde [9]. $\mathrm{CO}_{2}$ was also used as alternative oxidative agent on many reactions, i.e., ethylene production from ethane [10] and selective oxidation of ethylbenzene to styrene [11].

Another option to improve the selectivity is to use solid oxides as oxidant. Obviously, the oxide will be reduced when exposed to the hydrocarbons and the 


\section{Chapter 6}

reactivity of the lattice oxygen depends on composition and structure of the oxide. After exposure to hydrocarbon, the oxide needs to be regenerated via oxidation. This scheme is rather similar to the classical Mars - Van Krevelen mechanism, with the difference that, in this case, the oxidation and reduction steps are separated. This separation can be made in time, by using either moving bed technology or by switching between exposure to alkane and oxygen, respectively. This is the case of phthalic anhydride production from o-xylene, using $\mathrm{VO}_{\mathrm{x}} / \mathrm{TiO}_{2}$ catalyst $[12,13]$ or maleic anhydride production from n-butane over VPO catalyst $[14,15]$ in which double bed technology is required [16].

Another option is to separate the two steps in space by using a catalytic dense membrane reactor (CDMR). The membrane is exposed on one side to hydrocarbon and, on the other side, to molecular oxygen, generating oxygen lattice ions which permeate through the mixed conducting dense membrane. When arriving at the other side of the membrane, oxygen lattice ions are converted and removed by reaction with the alkane. By matching the oxygen permeability rate with the rate of conversion, oxygen recombination at alkane side can be prevented. Consequently, oxygen and alkane are strictly separated at two side of membrane and conversion of alkane can proceed via oxygen lattice ions exclusively.

In this study, such concept will be followed and $\mathrm{La}_{2} \mathrm{Ni}_{0.9} \mathrm{~V}_{0.1} \mathrm{O}_{4.15+\delta}$ oxide will be employed as catalyst which is also permeable to oxygen ions [17-18]. $\mathrm{La}_{2} \mathrm{Ni}_{0.9} \mathrm{~V}_{0.1} \mathrm{O}_{4.15+\delta}$ presents a $\mathrm{K}_{2} \mathrm{NiF}_{4}$-structure (perovskite-like structure) with a double layer arrangement: $\mathrm{Ni}$ and $\mathrm{V}$, octahedrally coordinated, are present in the perovskite layer and $\mathrm{La}$, tetragonally coordinated, is present in a rock-salt layer, as shown in fig.6.1.

Due to the specific crystallographic arrangement of this oxide and the redox nature of $\mathrm{Ni}$ and $\mathrm{V}$, the catalyst possesses two types of structural defects: vacancies and interstitial oxygen (indicated with $\delta$ in the catalyst nominal composition). Vacancies are lacking oxygen-ions in lattice position, like in many redox $[19,20]$ and defective [21] compounds. Interstitial oxygen, typical for $\mathrm{K}_{2} \mathrm{NiF}_{4}$-structure materials, is due to presence of over-stoichiometric oxygen which is located in between of perovskite and rock-salt layer, hence called interstitial oxygen (not shown in fig. 6.1) [22]. As result, $\mathrm{La}_{2} \mathrm{Ni}_{0.9} \mathrm{~V}_{0.1} \mathrm{O}_{4.15+\delta}$ contains two crystallographic types of oxygen ions (lattice and interstitial), possibly having different reactivity. 


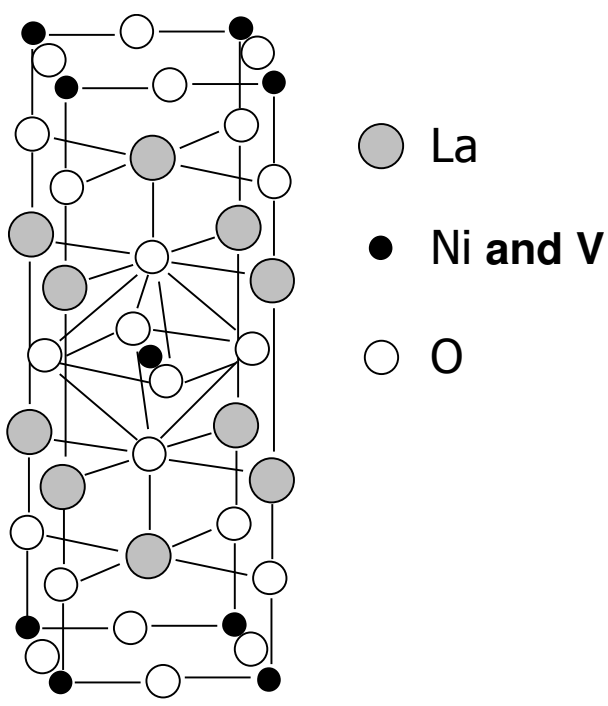

Fig. 6.1: Schematic representation of $\mathrm{K}_{2} \mathrm{NiF}_{4}$-structure related to $\mathrm{La}_{2} \mathrm{Ni}_{0.9} \mathrm{~V}_{0.1} \mathrm{O}_{4.15+\delta}$ catalyst.

In chapter 4 [23] the role of over-stoichiometric oxygen as reactive species in selective oxidative dehydrogenation of propane over $\mathrm{La}_{2} \mathrm{NiO}_{4+\delta}$ and $\mathrm{La}_{2} \mathrm{Ni}_{0.9} \mathrm{~V}_{0.1} \mathrm{O}_{4.15+\delta}$ was demonstrated via propane pulse experiments at $550{ }^{\circ} \mathrm{C}$. It was shown that the depletion of oxygen and consequent decrease of catalyst reactivity affected the dominant reaction pathway. Slightly reduced catalyst showed significant propylene formation, while $\mathrm{CO}_{2}$ was the main product over oxidized catalyst. Additionally, we reported that vanadium stabilizes the active oxygen active species, decreasing reactivity and enhancing the selectivity to propylene.

The goal of this chapter is to determine the quantitative relationship between the oxygen content of $\mathrm{La}_{2} \mathrm{Ni}_{0.9} \mathrm{~V}_{0.1} \mathrm{O}_{4.15+\delta}$, i.e. the value of $\delta$, with the performance in the conversion of propane. Additionally, the structural stability of the material, the reactivity and the amount of over-stoichiometric oxygen when removing and reabsorbing those species, will be investigated. 


\subsection{Experimental}

\subsubsection{Catalyst preparation}

The catalyst was prepared via sol-gel method using EDTA as chelating agent [24]. The appropriate amount of $\mathrm{V}_{2} \mathrm{O}_{5}$ (Merck) was dissolved in diluted $\mathrm{HNO}_{3}$ (Merck) at $80{ }^{\circ} \mathrm{C}$ under stirring for $1 \mathrm{~h}$. A stoichiometric amount of $\mathrm{La}\left(\mathrm{NO}_{3}\right)_{3} * 6 \mathrm{H}_{2} \mathrm{O}$ (Merck), $\mathrm{Ni}\left(\mathrm{NO}_{3}\right)_{2} * 6 \mathrm{H}_{2} \mathrm{O}$ (Merck), EDTA and $\mathrm{NH}_{4} \mathrm{OH}$ solutions were added and the obtained solution was heated for 2 hours under stirring.

After drying at $230{ }^{\circ} \mathrm{C}$, foam-type material was formed and pyrolysis took place after spontaneous ignition. The resulting solid mixed metal oxide was milled and calcined in air, slowly increasing temperature $\left(1^{\circ} \mathrm{C} / \mathrm{min}\right)$ up to $1050{ }^{\circ} \mathrm{C}$ to obtain pure phase materials. The resulting material was ball milled in acetone for $5 \mathrm{~h}$ and dried at $80{ }^{\circ} \mathrm{C}$. The material was sieved and particles size of $0.1-0.3 \mathrm{~mm}\left(2.0 \mathrm{~m}^{2} / \mathrm{g}\right)$ was used for all experiments.

\subsubsection{Characterization}

The crystal structure of fresh $\sim 0.5 \mathrm{~mm}$ thick pellet was determined with X-ray diffraction (XRD) using a Philips (X'Pert-MPD Pro) diffractometer with $\mathrm{Cu} \mathrm{K}_{\alpha}$ radiation $(\lambda=0.15406 \mathrm{~nm})$. The pellet was fixed on the Pt sample holder by means of Ag-based glue. Data were collected varying $2 \theta$ between 20 and $80^{\circ}$ with a step size of $0.01^{\circ}$ and a step time of $10 \mathrm{~s}$.

The XRD patterns of reduced sample were obtained after in-situ reduction in $\mathrm{H}_{2}$ in a high temperature chamber (Anton Paar HTK16). The temperature was increased up to $500{ }^{\circ} \mathrm{C}$ and $750{ }^{\circ} \mathrm{C}$ respectively, in $4 \% \mathrm{H}_{2} / \mathrm{Ar}$ atmosphere and kept at those specific temperatures for $1 \mathrm{~h}$. Subsequently, the samples were cooled down to room temperature under the same atmosphere and the XRD pattern was measured.

Temperature programmed reduction (TPR) was carried out with a home-built setup, equipped with a TCD detector. First, $40 \mathrm{mg}$ of sample mixed with $40 \mathrm{mg}$ quartz particles were placed into a $4 \mathrm{~mm}$ inner diameter reactor, heated up to $500{ }^{\circ} \mathrm{C}(10$ ${ }^{\circ} \mathrm{C} / \mathrm{min}$ ), kept at $500{ }^{\circ} \mathrm{C}$ for $1 \mathrm{~h}$ in a $20 \mathrm{ml} / \mathrm{min}$ flow of $5 \% \mathrm{O}_{2}$ in $\mathrm{He}$ and then the sample was cooled down to room temperature in the same atmosphere, as schematically presented in fig. 6.2. At room temperature the flow was changed to $5 \% \mathrm{H}_{2}$ in $\mathrm{Ar}$ and the TPR was carried out at $5{ }^{\circ} \mathrm{C} / \mathrm{min}$ up to $450{ }^{\circ} \mathrm{C}$. Subsequently, after flushing the reactor with pure $\mathrm{He}$ for $15 \mathrm{~min}$, the flow was changed to $5 \% \mathrm{O}_{2}$ in $\mathrm{He}$ and the catalyst was re-oxidized for $1 \mathrm{~h}$ at $450{ }^{\circ} \mathrm{C}$. The system was cooled down to room temperature under the same atmosphere and flushed with pure He for 15 
min. Afterwards, the flow was changed to $5 \% \mathrm{H}_{2}$ in $\mathrm{Ar}$ and temperature was increased up to $450{ }^{\circ} \mathrm{C}$ and the reduction profile over re-oxidized sample was measured. The TCD was calibrated via reduction of $\mathrm{NiO}$.

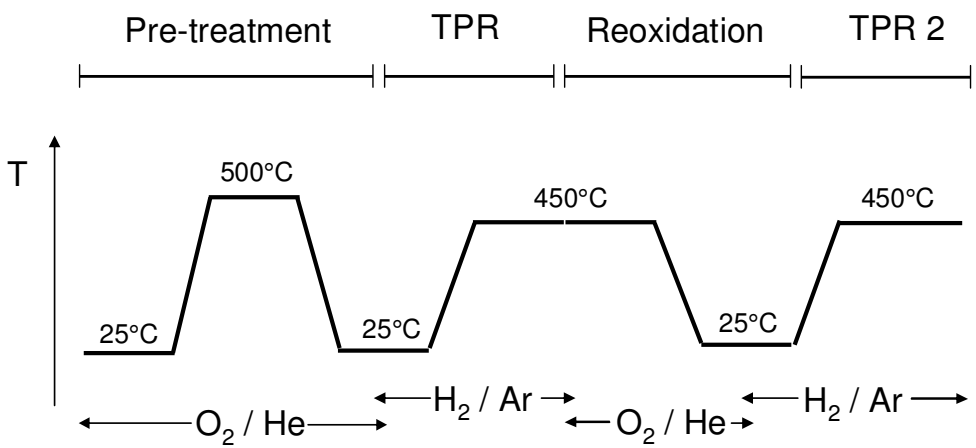

Fig. 6.2: Experimental mode scheme of sample pre-treatment and temperature programmed reduction in $\mathrm{H}_{2}\left(R T-450{ }^{\circ} \mathrm{C}\right)$.

Thermal gravimetric analysis (TGA) was carried out using a Mettler-Toledo TGASDTA 851 unit. The sample (around $55 \mathrm{mg}$ ) was placed in a TGA cup and kept at $140{ }^{\circ} \mathrm{C}$ for $8 \mathrm{~h}$ to remove $\mathrm{H}_{2} \mathrm{O}$ and any organic volatile compound adsorbed on the surface. Than the catalyst was heated up to $550^{\circ} \mathrm{C}$ with rate of $10^{\circ} \mathrm{C} / \mathrm{min}$ in $\mathrm{Ar}$ flow of $40 \mathrm{ml} / \mathrm{min}$. The weight loss was considered after $30 \mathrm{~min}$ of isothermal treatment at $550{ }^{\circ} \mathrm{C}$, mimicking the pre-treatment of pulse experiment. To check the sample stability, the compound was kept at $550{ }^{\circ} \mathrm{C}$ for $14 \mathrm{~h}$ and the weight loss was considered. Experimental results were corrected for the buoyancy effect using a cup filled with quartz particles with similar volume.

\subsubsection{Pulse experiment}

Pulse experiments were carried out in a fix-bed reactor (quartz tube, length 400 $\mathrm{mm}$, internal diameter $2 \mathrm{~mm})$ at $550{ }^{\circ} \mathrm{C}$. The catalyst particles $(\sim 35 \mathrm{mg})$ were sieved (particle size $0.1-0.3 \mathrm{~mm}$ ) and packed between two quartz-wool plugs (length approximately $10 \mathrm{~mm}$ each). The remaining volume of the reactor was filled up with quartz particles, in order to reduce the void space and minimize gas phase reactions. Before each titration test, the catalysts were pre-treated in $10 \%$ of $\mathrm{O}_{2}$ in He flow $\left(20 \mathrm{ml} / \mathrm{min}, 30 \mathrm{~min}\right.$.) at $720{ }^{\circ} \mathrm{C}$ in order to remove any trace of water or inorganic compounds physisorbed on surface and keep the catalyst oxygen level as 


\section{Chapter 6}

high as possible. The samples were cooled down to reaction temperature under the same atmosphere, whereafter the gas flow was changed to $\mathrm{He}(3 \mathrm{ml} / \mathrm{min})$. After flowing pure $\mathrm{He}$ for $15 \mathrm{~min}$, pulses of $300 \mu \mathrm{l}$ at atmospheric pressure containing $10 \% \mathrm{C}_{3} \mathrm{H}_{8}$ in $\mathrm{He}$ were introduced, whereas pulses containing $10 \% \mathrm{O}_{2}$ in $\mathrm{He}$ were used to re-oxidize the catalyst, after exposure to $\mathrm{C}_{3} \mathrm{H}_{8}$ pulses.

Products distributions were monitored by sampling on-line to a quadrupole mass spectrometer (Pfeiffer AG Balzers, OmniStar) equipped with Channeltron and Faraday detectors (2-200 amu). Prior to each experiment, the fragment pattern of fresh propane and fresh oxygen were recorder allowing quantitative determination of propane and oxygen with an experimental error of about 5\%. Water, propane and oxygen were identified monitoring $\mathrm{m} / \mathrm{z}=18,29$ and 32 , respectively, since no other products contribute significantly to these $\mathrm{m} / \mathrm{z}$ signals. The concentration of methane, ethane, ethylene, propylene and carbon mono- and di-oxide were calculated semi-quantitatively with a matrix calculation in order to account for cross-contamination effects; calibration for these compounds was not available.

Apparent selectivities were calculated based on the integrated area of peaks of the corresponding $\mathrm{m} / \mathrm{z}$ signals of each compound divided by total integrated areas of the peaks of all carbon containing products (e.g. for methane: $\mathrm{A}\left(\mathrm{m}_{/} \mathrm{Z}_{\mathrm{CH} 4}\right) / \mathrm{A}\left(\mathrm{m}_{/} \mathrm{Z}_{\mathrm{CH} 4}\right)$ $\left.+\mathrm{A}\left(\mathrm{m}_{/} \mathrm{Z}_{\mathrm{C} 2 \mathrm{H} 6}\right)+\mathrm{A}\left(\mathrm{m}_{/} \mathrm{Z}_{\mathrm{C} 2 \mathrm{H} 4}\right)+\mathrm{A}\left(\mathrm{m}_{/} \mathrm{Z}_{\mathrm{C} 3 \mathrm{H} 6}\right)+\mathrm{A}\left(\mathrm{m}_{/} \mathrm{Z}_{\mathrm{CO}}\right)+\mathrm{A}\left(\mathrm{m}_{/} \mathrm{Z}_{\mathrm{CO} 2}\right)\right)$. The conversion of propane was below the detection limit when pulsing propane to the reactor filled with quartz particle exclusively and therefore we exclude gas phase initiation during the pulse tests. The amount of oxygen removed from the fresh catalyst during propane pulsing was quantified with help of back-titration with $\mathrm{O}_{2}$.

In a second series of experiments, the oxidation state of the catalysts was manipulated by reoxidizing the catalyst partly, varying the number of $\mathrm{O}_{2}$ pulses. Subsequently, propane pulse experiments were performed and the product distributions were compared.

\subsection{Results}

\subsubsection{Characterization}

Fig. 6.3 shows the influence of reduction in $\mathrm{H}_{2}$ at $500{ }^{\circ} \mathrm{C}$ and at $750{ }^{\circ} \mathrm{C}$ on the XRD pattern of $\mathrm{La}_{2} \mathrm{Ni}_{0.9} \mathrm{~V}_{0.1} \mathrm{O}_{4.15+\delta}$.

The fresh sample (fig. 6.3a) possesses very good cristallinity and all peaks can be assigned to the $\mathrm{K}_{2} \mathrm{NiF}_{4}$ tetragonal structure, typical for these type materials [25-28]. After reduction in $\mathrm{H}_{2}$ at $500{ }^{\circ} \mathrm{C}$ (fig. $6.3 \mathrm{~b}$ ), the intensity of most peaks decreases without changes in peak positions. Additionally, the two patterns clearly show different ratios in peak intensities in the range $31^{\circ}<2 \theta<33^{\circ}$ as well as $42^{\circ}<2 \theta<48^{\circ}$. 
Contrary, after reduction at $750{ }^{\circ} \mathrm{C}$ in $\mathrm{H}_{2}$ the pattern changes completely (fig. $6.3 \mathrm{c}$ ), denoting the disappearance of the $\mathrm{K}_{2} \mathrm{NiF}_{4}$-type structure. All peaks observed in the new diffraction pattern can be assigned to $\mathrm{La}_{2} \mathrm{O}_{3}$ and Ni-metal. No peaks related to vanadium oxides were observed.

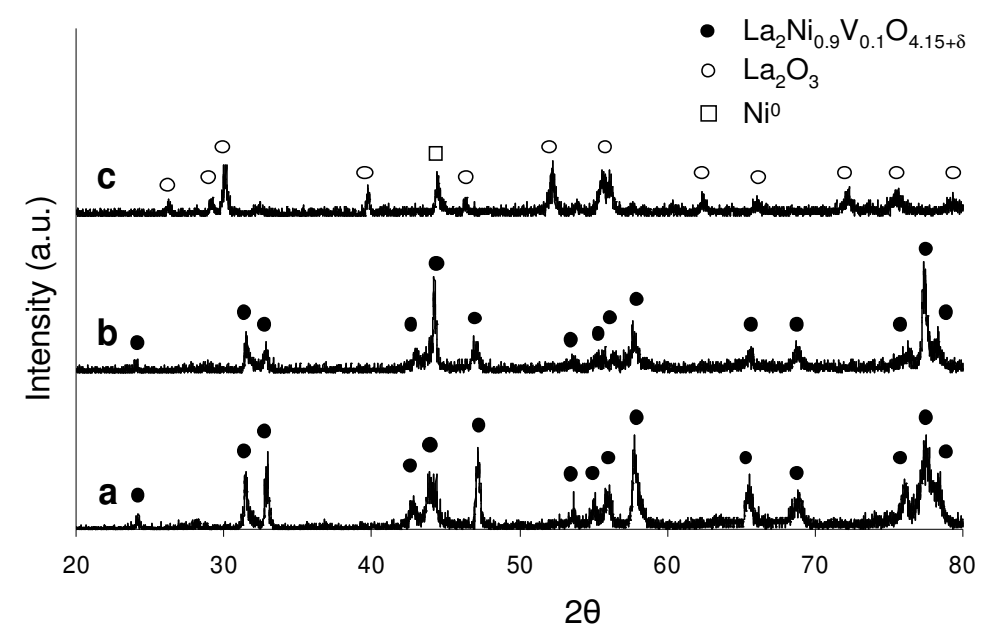

Fig. 6.3: In-situ XRD pattern of fresh $\mathrm{La}_{2} \mathrm{Ni}_{0.9} \mathrm{~V}_{0.1} \mathrm{O}_{4+\delta}(a), \mathrm{La}_{2} \mathrm{Ni}_{0.9} \mathrm{~V}_{0.1} \mathrm{O}_{4+\delta}$ reduced in $\mathrm{H}_{2}$ at $500{ }^{\circ} \mathrm{C}\left(\right.$ b) and $\mathrm{La}_{2} \mathrm{Ni}_{0.9} \mathrm{~V}_{0.1} \mathrm{O}_{4+\delta}$ reduced in $\mathrm{H}_{2}$ at $750{ }^{\circ} \mathrm{C}$ (c).

Temperature programmed reduction of fresh sample (fig. 6.4a) resulted in one single peak with a maximum rate of $\mathrm{H}_{2}$ consumption around $390{ }^{\circ} \mathrm{C}$, which is typical for $\mathrm{K}_{2} \mathrm{NiF}_{4}$-type of materials $[26,27]$. The observed reduction step corresponded to removal of $0.42 \pm 0.02 \mathrm{mmol} \mathrm{O} / \mathrm{g}$ of catalyst. Fig. $6.4 \mathrm{~b}$ confirms that re-oxidation of reduced catalyst completely recovers the TPR profile.

Fig. 6.5 shows the thermogravimetric analysis of fresh $\mathrm{La}_{2} \mathrm{Ni}_{0.9} \mathrm{~V}_{0.1} \mathrm{O}_{4.15+\delta}$, resulting in weight loss of $0.231 \mathrm{mg}$ between 200 and $550{ }^{\circ} \mathrm{C}$, which corresponds to 0.26 mmol oxygen per gram of catalyst. The weight loss is associated to partial removal of over-stoichiometric oxygen as already reported in chapter 4 and in literature for $\mathrm{La}_{2} \mathrm{NiO}_{4+\delta}[23,29]$. The equilibration of catalyst weight at $550{ }^{\circ} \mathrm{C}$ occurred within 20-30 min. Moreover, subsequent isothermal treatment of $14 \mathrm{~h}$ at $550{ }^{\circ} \mathrm{C}$ caused an additional weight decrease equal to only $0.009 \mathrm{mg}$, i.e. less then $5 \%$ of the weight loss observed during the first $30 \mathrm{~min}$. 


\section{Chapter 6}

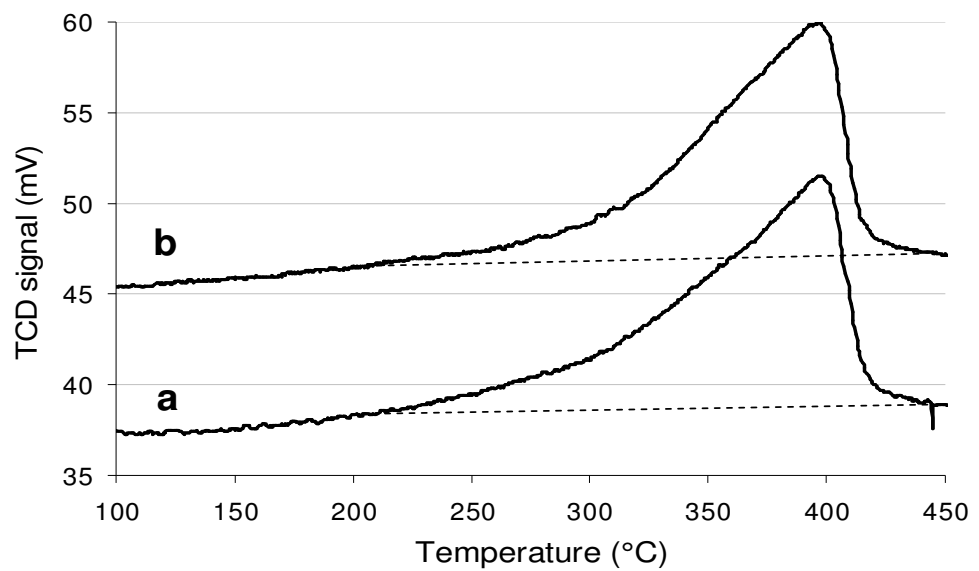

Fig 6.4: Two consecutive temperature programmed reduction on fresh $\mathrm{La}_{2} \mathrm{Ni}_{0.9} \mathrm{~V}_{0.1} \mathrm{O}_{4+\delta}(a)$ and on re-oxidized sample at $450{ }^{\circ} \mathrm{C}(b)$.

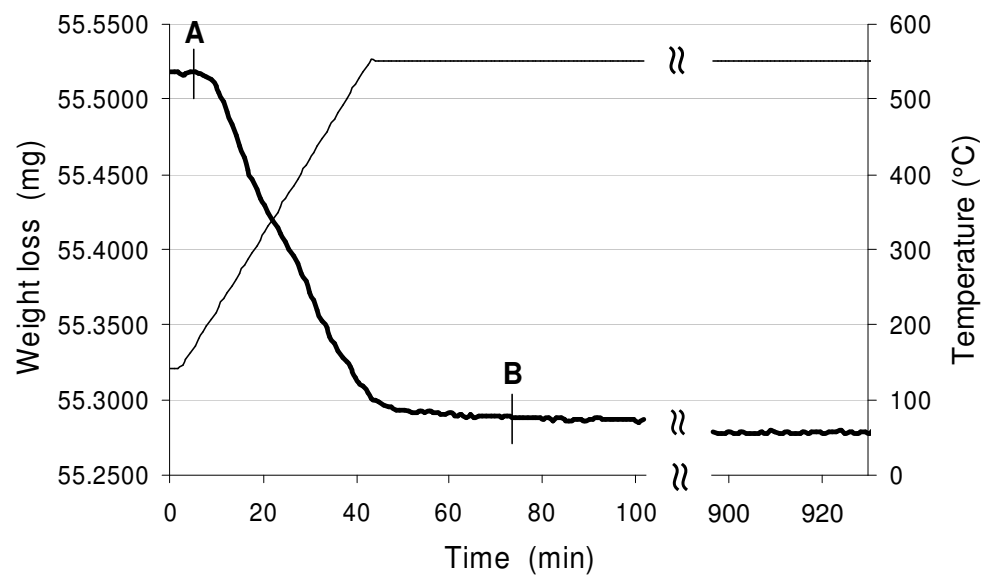

Fig 6.5: Ar-TGA on fresh $\mathrm{La}_{2} \mathrm{Ni}_{0.9} \mathrm{~V}_{0.1} \mathrm{O}_{4+\delta}$ at $550{ }^{\circ} \mathrm{C}$. 


\subsubsection{Quantification of removed oxygen}

The propane pulse test over fresh $\mathrm{La}_{2} \mathrm{Ni}_{0.9} \mathrm{~V}_{0.1} \mathrm{O}_{4.15+\delta}$ at $550^{\circ} \mathrm{C}$ was reported in chapter 4 [23] and therefore the results are not repeated here. The quantification of removed oxygen during the above mentioned pulse experiment is shown in fig. 6.6. Fig. 6.6 shows that the amount of removed oxygen, quantified with seven different back titrations with $\mathrm{O}_{2}$, increases with the number of pulses; whereas the amount that is removed per pulse obviously decreases with decreasing oxygen content. After 45 pulses, $0.144 \mathrm{mmol}$ oxygen per gram of catalyst was removed and the catalyst remained active ( $\sim 5 \%$ conversion).

Complete removal of the reactive oxygen was achieved by heating the catalyst in pure $\mathrm{He}$ from 25 to $550{ }^{\circ} \mathrm{C}$ and keeping the catalyst at $550{ }^{\circ} \mathrm{C}$ under diluted $\mathrm{C}_{3} \mathrm{H}_{8}$ atmosphere for $30 \mathrm{~min}$, which resulted in subsequent zero $\mathrm{C}_{3} \mathrm{H}_{8}$ conversion. The back titration of removed oxygen at $550{ }^{\circ} \mathrm{C}$ resulted in $0.180 \mathrm{mmol} / \mathrm{g}$ in $\mathrm{He}$ atmosphere.

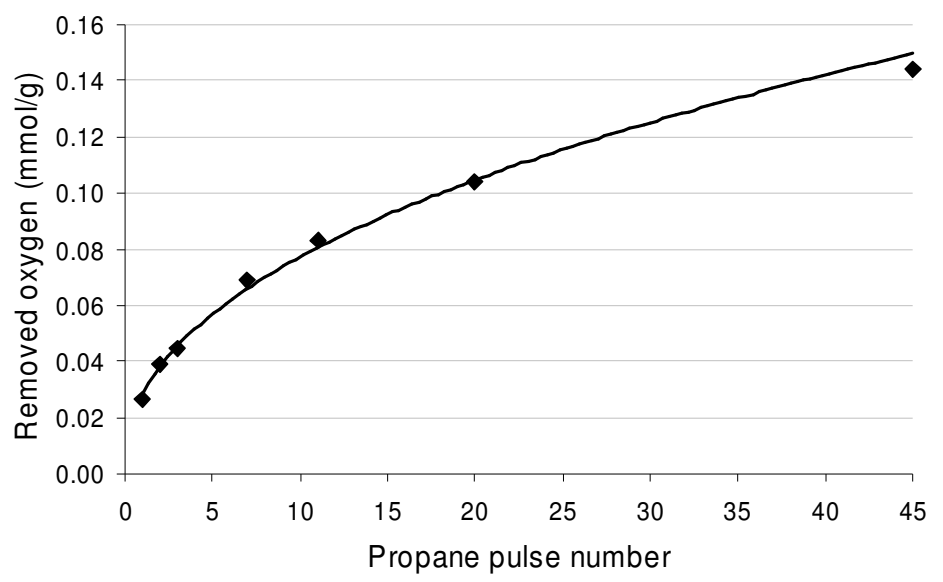

Fig. 6.6: Quantification of removed oxygen with back titration with $\mathrm{O}_{2}$ after 1,2,3,7,12,20 and 45 propane pulses along the pulse test on $\mathrm{La}_{2} \mathrm{Ni}_{0.9} \mathrm{~V}_{0.1} \mathrm{O}_{4+\delta}$ at $550^{\circ} \mathrm{C}$. 


\subsubsection{Products distribution of totally and partially oxidized catalysts}

Fig. 6.7 shows the product distribution during pulse experiments at $550{ }^{\circ} \mathrm{C}$ of totally re-oxidized $\mathrm{La}_{2} \mathrm{Ni}_{0.9} \mathrm{~V}_{0.1} \mathrm{O}_{4.15+\delta}$ which resulted in $\mathrm{CO}_{2}$ and $\mathrm{H}_{2} \mathrm{O}$ as the main products, decreasing throughout the experiment, similarly to what was observed in chapter 4 on fresh catalyst [23]. After pulse $10, \mathrm{CO}_{2}$ formation decreased below the MS detection threshold and the formation of $\mathrm{C}_{3} \mathrm{H}_{6}, \mathrm{C}_{2} \mathrm{H}_{4}$ and $\mathrm{CH}_{4}$ remains constant. Although $\mathrm{CO}_{2}$ is no longer produced after pulse 10 , slightly reducing the sample, it is important to stress that $\mathrm{H}_{2} \mathrm{O}$ is formed during the whole experiment.

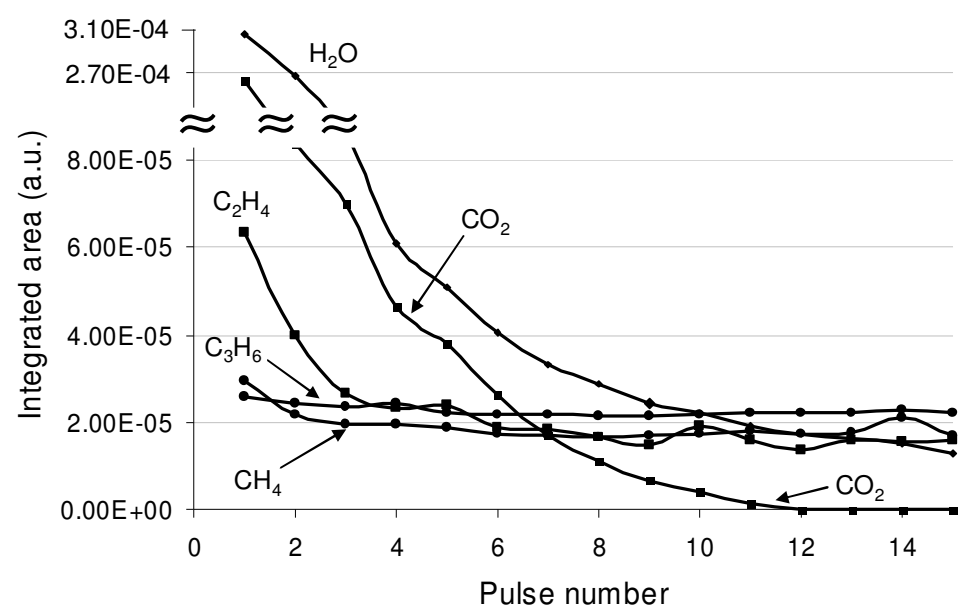

Fig. 6.7: Products distribution during pulse experiment at $550{ }^{\circ} \mathrm{C}$ (15 pulses) of totally re-oxidized $\mathrm{La}_{2} \mathrm{Ni}_{0.9} \mathrm{~V}_{0.1} \mathrm{O}_{4+\delta}$.

The scenario is different in the case of a partially re-oxidized sample (one $\mathrm{O}_{2}$ pulse only), shown in fig. 6.8. The $\mathrm{CO}_{2}$ formation was below the MS detection threshold already for the first propane pulse and a constant production level of exclusively $\mathrm{C}_{2} \mathrm{H}_{4}, \mathrm{CH}_{4}$ (main products) and $\mathrm{C}_{3} \mathrm{H}_{6}$ (minor product) was detected. $\mathrm{H}_{2} \mathrm{O}$ formation continuously decreased during the experiment. It should be noted that the y-axis scale is different in fig. 6.7 and 6.8 . 


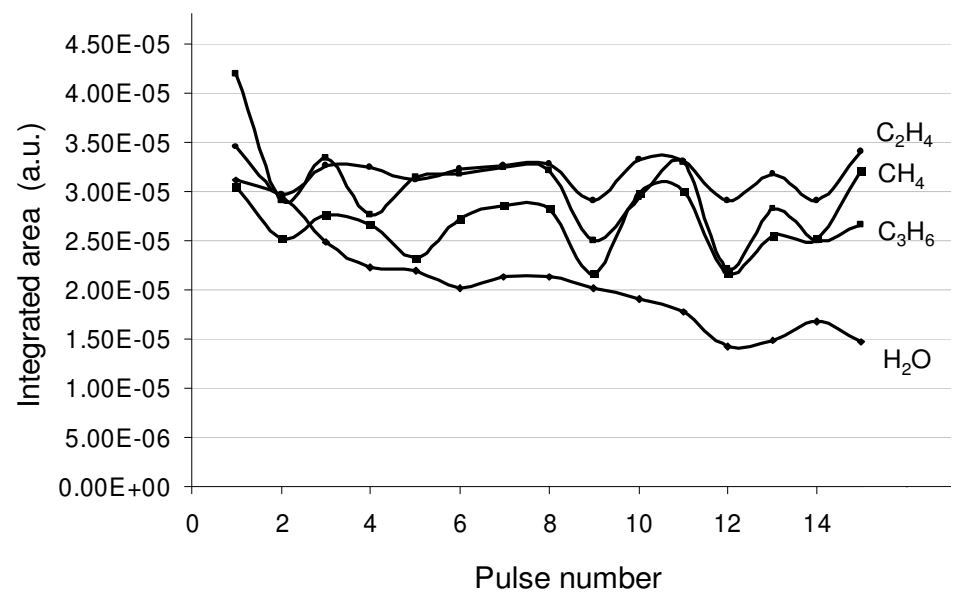

Fig. 6.8: Products distribution during pulse experiment (15 pulses) of partially reoxidized $\mathrm{La}_{2} \mathrm{Ni}_{0.9} V_{0.1} \mathrm{O}_{4+\delta}$ with one $\mathrm{O}_{2}$ pulse only at $550{ }^{\circ} \mathrm{C}$.

\subsection{Discussion}

In chapter 4 we have proven that by pulsing propane, the amount of overstoichiometric oxygen in the catalyst is depleted and, consecutively, the oxygen reactivity is reduced. At that stage, constant selectivity to olefins and inhibition of $\mathrm{CO}_{2}$ formation is accomplished while deep oxidation products were the main compounds at the beginning of the test, with a more oxidized sample [23].

In this chapter, the structural stability of the material when removing and reabsorbing oxygen, was investigated. Complete reversibility of removal / absorption of over-stoichiometric oxygen is demonstrated by oxidation-reduction cycles at 450 ${ }^{\circ} \mathrm{C}$ (fig. 6.4), resulting in identical peak areas (amount of removed oxygen) and peak shapes (stability). Moreover, no structural change was observed under reducing atmosphere up to $500{ }^{\circ} \mathrm{C}$, when all over-stoichiometric oxygen was removed (fig. 6.3b). Compared to XRD on fresh material, the only difference observed was changes in the ratio of peak-intensity in the ranges between 31 and 33 degrees as well as 42 and 48 degrees. This is very similar to the effect of $\mathrm{Cu}$ or $\mathrm{V}$ addition to $\operatorname{LN}[23,28]$. The cause of this effect is not known but we suggest that it might be due to structural distortion (or stress), caused by removing overstoichiometric oxygen. Decomposition of $\mathrm{La}_{2} \mathrm{Ni}_{0.9} \mathrm{~V}_{0.1} \mathrm{O}_{4.15+\delta}$ catalyst in $\mathrm{La}_{2} \mathrm{O}_{3}$ and $\mathrm{Ni}^{0}$ took place at $750{ }^{\circ} \mathrm{C}$ (fig. 6.3c); such high temperature was therefore not used in the pulse experiments presented here, circumventing any phase-changes. No peaks 


\section{Chapter 6}

related to $\mathrm{V}$ were observed, which is probably due to the low amount in the sample ( $1.2 \%$ by weight).

As the material showed reversibility while varying the over-stoichiometry level, the attention was focused on quantification of over-stoichiometric oxygen during pulse experiments. However, over-stoichiometry in $\mathrm{La}_{2} \mathrm{Ni}_{0.9} \mathrm{~V}_{0.1} \mathrm{O}_{4.15+\delta}$ appears extremely sensitive to the experimental conditions. The exact pre-treatment prior to the propane pulse test, is therefore influencing the oxygen content in the catalyst and, consecutively, its reactivity. As was shown with TG analysis (fig. 6.5), $0.26 \mathrm{mmol}$ of oxygen per gram of catalyst were removed when pretreating in $\mathrm{He}$ at $550{ }^{\circ} \mathrm{C}$ for 30 min. Knowing that the total amount of over-stoichiometric oxygen in the fresh sample equals to $0.42 \pm 0.02 \mathrm{mmol} / \mathrm{g}$ (fig. 6.4), the corresponding $\delta$ value changes from 0.170 at room temperature, to 0.066 at $550{ }^{\circ} \mathrm{C}$. Consequently, the catalyst composition changed from $\mathrm{La}_{2} \mathrm{Ni}_{0.9} \mathrm{~V}_{0.1} \mathrm{O}_{4.320}$ at room temperature to $\mathrm{La}_{2} \mathrm{Ni}_{0.9} \mathrm{~V}_{0.1} \mathrm{O}_{4.216}$ at $550{ }^{\circ} \mathrm{C}$.

Isothermal treatment at $550{ }^{\circ} \mathrm{C}$ for $14 \mathrm{~h}$ caused oxygen loss equal to $0.27 \mathrm{mmol} / \mathrm{g}$, which is very similar (within $4 \%$ ) to the effect of a treatment during 30 minutes. This is probably due to relatively fast equilibration, although it should be mentioned that the equilibrium might be influenced by traces of $\mathrm{O}_{2}(<2 \mathrm{ppm})$ present in He. It is evident that the catalyst also released oxygen during the pre-treatments before starting propane pulse experiments. The similarity in the numbers after 30 minutes and $14 \mathrm{~h}$ in TGA clearly show that the data can be safely used to estimate the oxygen content after pretreating in the pulse equipment. Thus, the decrease of $\delta$ during the pulse experiments at $550{ }^{\circ} \mathrm{C}$ was calculated, based on (i) the initial value of $\delta$ equal to 0.066 (fig. 6.5) and (ii) the amount of removed oxygen obtained with back titration with $\mathrm{O}_{2}$ pulses (fig. 6.6). Fig. 6.9 shows the resulting values of $\delta$ as a function of the pulse number.

As expected, the value of $\delta$ decreased with the number of pulses, resulting in a $\delta$ value of 0.008 after 45 pulses. Clearly, over-stoichiometric oxygen is the active species for propane selective oxidation throughout the whole experiment. In a separate experiment not shown here, the over-stoichiometric oxygen was completely removed via pre-treatment in $\mathrm{He}$ up to $550{ }^{\circ} \mathrm{C}$ and switching to $\mathrm{C}_{3} \mathrm{H}_{8}$ flow for $30 \mathrm{~min}$ at same temperature. The complete oxygen removal was proved by means of back titration with oxygen pulses in $\mathrm{He}$ atmosphere. The amount of previously removed oxygen by $30 \mathrm{~min}_{3} \mathrm{C}_{8}$ flow was quantified as $0.18 \mathrm{mmol} / \mathrm{g}$ which perfectly matched with the residual over-stoichiometric oxygen at $550{ }^{\circ} \mathrm{C}$ in $\mathrm{He}$ atmosphere. This is the amount of over-stoichiometric oxygen remained in the sample at $550{ }^{\circ} \mathrm{C}$ in inert atmosphere (before to switch to $\mathrm{C}_{3} \mathrm{H}_{8}$ flow), which is equal to the amount of reactive oxygen available during pulse experiment at same temperature, responsible for product distribution described in chapter 4 [23]. Subsequent propane pulses, prior the back titration with oxygen, resulted in zero conversion, demonstrating that the catalyst is not active when over-stoichiometric oxygen is removed completely. It is interesting to notice that the amount of oxygen 
removed during the pretreatment in inert from 25 to $550{ }^{\circ} \mathrm{C}(0.26 \mathrm{mmol} / \mathrm{g}$, according to TGA), added to the amount of oxygen removed during the pretreatment in $\mathrm{C}_{3} \mathrm{H}_{8}$ at $550{ }^{\circ} \mathrm{C}(0.18 \mathrm{mmol} / \mathrm{g})$, is in very good agreement with the total amount of over-stoichiometric oxygen removed by $\mathrm{H}_{2}-\mathrm{TPR}(0.42 \pm 0.02 \mathrm{mmol} / \mathrm{g})$ at same temperature.

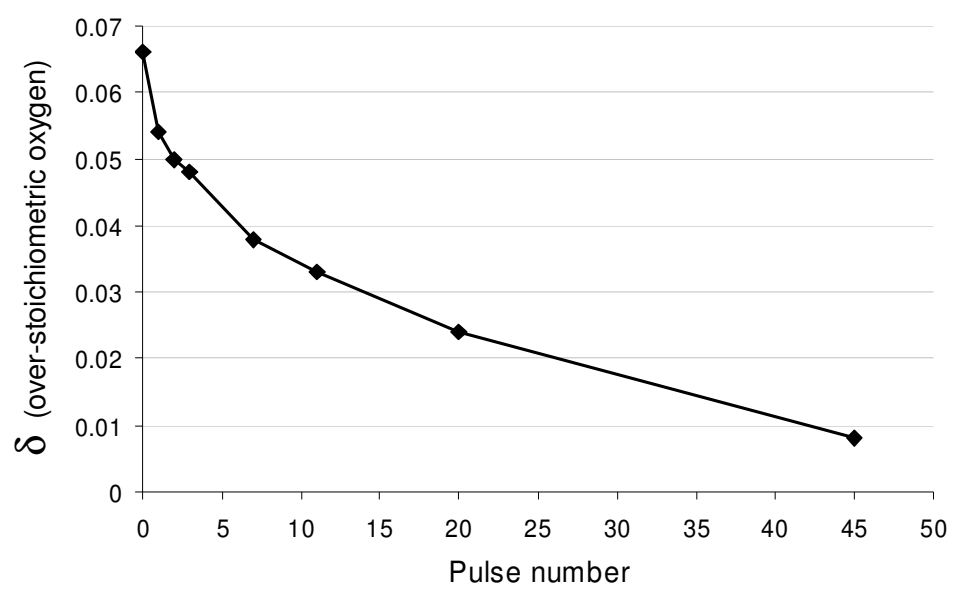

Fig. 6.9: Variation of $\delta$ during pulse test on $\mathrm{La}_{2} \mathrm{Ni}_{0.9} \mathrm{~V}_{0.1} \mathrm{O}_{4+\delta}$ at $550^{\circ} \mathrm{C}$.

In chapter 4 [23], we have reported that the product distribution changes throughout the pulse experiment. Now, it is possible to relate the selectivity change to the variation in $\delta$, as shown in fig 6.10 (full symbols). The two sets of open symbols in the same figure represent the apparent selectivity of completely and partially reoxidized catalysts. Initially, the activity of oxygen is too high, resulting in mainly deep oxidation products. Decreasing the amount of over-stoichiometric oxygen, the formation $\mathrm{CO}_{2}$ decreases and the apparent selectivity towards olefins increases. The $\mathrm{CO}_{2}$ level is below the MS detection limit for values of $\delta$ below 0.030 (catalyst composition $\mathrm{La}_{2} \mathrm{Ni}_{0.9} \mathrm{~V}_{0.1} \mathrm{O}_{4.18}$ ) resulting in maximal selectivity towards olefins.

Instead of varying $\delta$ via removing oxygen by pulsing with propane, the $\delta$ value can also be modified by partial, instead of complete, re-oxidation after pulsing propane. The open symbols in fig. 6.10 present the results. First, complete re-oxidation restores the performance of the material completely, as also reported in chapter 4 [23]. Partial oxidation, restoring $\delta$ to 0.028 , results in a similar result as compared to the same $\delta$ value achieved via propane pulsing, in the sense that in both cases $\mathrm{CO}_{2}$ formation is below the detection limit whereas ethylene, propylene and methane are being formed. However, the ratio of these products is quite different, indicating that partial re-oxidation does not result in the same thermodynamically equilibrated material, resulting from pulsing propane. We suggest that O- 


\section{Chapter 6}

concentration gradients, and thus $\delta$ gradients, result from partial re-oxidation, either along the reactor axis or within the solid oxide due to bulk diffusion.

Anyhow, the results clearly show that good selectivity to olefins can be expected using $\mathrm{La}_{2} \mathrm{Ni}_{0.9} \mathrm{~V}_{0.1} \mathrm{O}_{4.15+\delta}$ as catalytic dense membrane, when the over-stoichiometry at the surface exposed to the alkane is maintained in the range $0.00<\delta<0.03$. This can in principle be achieved via correctly balancing the rate of diffusion of oxygen ions though the membrane with the rate of oxygen consumption at the interface exposed to alkane.

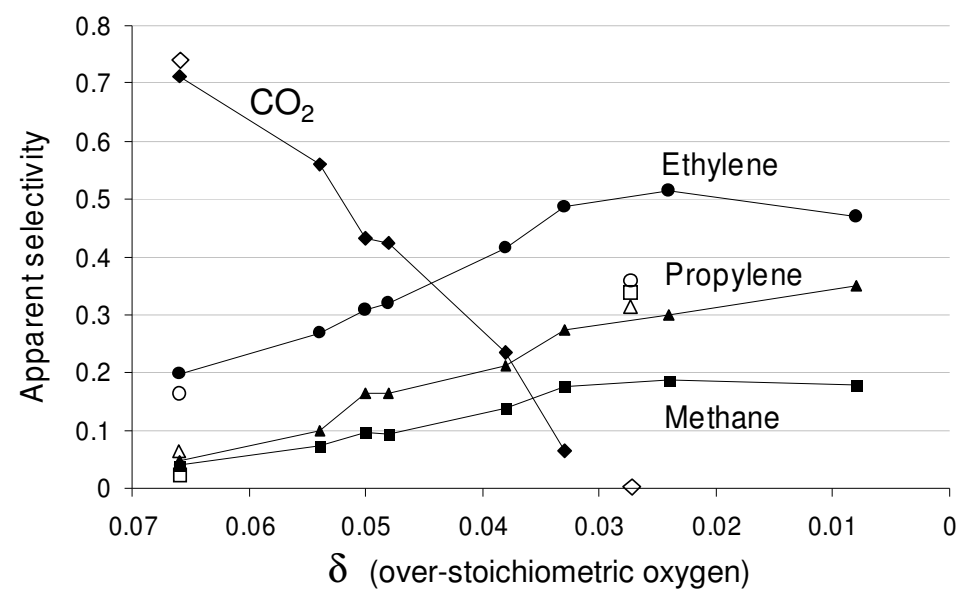

Fig. 6.10: Apparent selectivities of methane $(\boldsymbol{\square}, \square)$, ethylene $(\boldsymbol{\bullet}, O)$, propylene $(\boldsymbol{\Lambda}$ $\triangle$ ) and $\mathrm{CO}_{2}(\diamond, \diamond)$ during the pulse test at $550{ }^{\circ} \mathrm{C}$ on fresh $\mathrm{La}_{2} \mathrm{Ni}_{0.9} \mathrm{~V}_{0.1} \mathrm{O}_{4.15+\delta}$ (full symbols), and on re-oxidized $\mathrm{La}_{2} \mathrm{Ni}_{0.9} V_{0.1} \mathrm{O}_{4.15+\delta}$ (open symbols). The two sets of open symbols represent apparent selectivity of totally $(\delta=0.066)$ and partially $(\delta=0.028)$ re-oxidized catalyst.

\subsection{Conclusions}

The reactivity of $\mathrm{La}_{2} \mathrm{Ni}_{0.9} \mathrm{~V}_{0.1} \mathrm{O}_{4.15+\delta}$ with propane at $550{ }^{\circ} \mathrm{C}$ strongly depends on $\delta$. When $\delta>0.03$ the main product is $\mathrm{CO}_{2}$, whereas selective conversion to propylene, ethylene and methane is achieved when $0.00<\delta<0.03$. Furthermore, oxidationreduction cycles in propane and oxygen at $550{ }^{\circ} \mathrm{C}$ are reversible and the material is stable. Therefore, $\mathrm{La}_{2} \mathrm{Ni}_{0.9} \mathrm{~V}_{0.1} \mathrm{O}_{4.15+\delta}$ is suitable for constructing a catalytic dense membrane reactor, under the condition that oxygen conversion and oxygen 
diffusion are tuned to maintain a $\delta$ value between 0.00 and 0.030 at the propane interface.

\section{Acknowledgements}

The author would like to thank Dr. C. Trionfetti for inspiring discussions about pulse experiment and Dr. G. Van Hummel for technical assistance during in-situ XRD analysis. We thank ACTS/NWO, The Netherlands for financial support (project number 053.62.004).

\section{References}

[1] J. F. Brazdil, Top. Catal. 38 (2006) 289

[2] R. K. Grasselli, D. L. Stern, J. G. Tsikoyiannis, Appl. Catal. A 189 (1999) 1

[3] F. Cavani, N. Ballarini, A. Cericola, Catal. Today 127 (2007) 113

[4] E. V. Kondratenko, M. Y. Sinev, Appl. Catal. A 325 (2007) 353

[5] L. Leveles, K. Seshan, J.A. Lercher, L. Lefferts, J. Catal. 218 (2003) 307

[6] J. Perez-Ramirez, N. Blangenois, P. Ruiz, Catal. Lett. 104 (2005) 163

[7] J. R. Monnier, Appl. Catal. A 221 (2001) 73

[8] M. G. Clerici, G. Bellussi, U. Romano, J. Catal. 129 (1991) 159

[9] J. Hu, K. Li, W. Li, F. Ma, Y. Guo, Appl. Catal. A 364 (2009) 211

[10] V. Cortes Corberan, Catal. Today 99 (2005) 33

[11] K.N. Rao, B.M. Reddy, B. Abhishek, Y.H. Seo, N. Jiang, S. Park, Appl. Catal. B 91 (2009) 649

[12] G. C. Bond, J. Catal. 116 (1989) 531

[13] F. Cavani, N. Ballarini, S. Luciani, Top. Catal. 52 (2009) 935

[14] Y. Zhang-Lin, M. Forissier, J. C. Vedrine, J. C. Volta, J. Catal. 145 (1994) 267

[15] E. V. Cheburakova, A. Zazighalov, Kinet. Catal. 49 (2008) 552

[16] R.M. Contractor, H.E. Bergna, H.S. Horowitz, C.M. Blackstone, B. Malone,

C.C. Torardi, B. Griffeths, U. Chowdhry, A.W. Sleight, Catal. Today 1 (1987) 49

[17] E.N. Naumovich, M.V. Patrakeev, V.V. Kharton, A.A. Yaremchenko, D.I. Logvinovich, F.M.B. Marques, Solid State Sci. 7 (2005) 1353

[18 ] M. Burriel, G. Garcia, J. Santiso, J.A. Kilner, R.J. Chater, S.J. Skinner, J. Mater. Chem. 18 (2008) 416

[19] R. Merkle, J. Maier, Top. Catal. 38 (2006) 141

[20] J. C. Conesa, Catal. Today 143 (2009) 315

[21] C. Trionfetti, I. V. Babich, K. Seshan, L. Lefferts, Top. Catal. 39 (2006) 191 


\section{Chapter 6}

[22] L. Minervini, R. W. Grimes, J. A. Kilner, K. E. Sickafus, J. Mater. Chem. 10 (2000) 2349

[23] S. Crapanzano, I.V. Babich, L. Lefferts, Appl. Catal. A submitted

[24] R.H.E. van Doorn, H. Kruidhof, A. Nijmeijer, L. Winnubst, A.J. Burggraaf, J. Mater. Chem. 8 (1998) 2109

[25] D.E. Rice, D.J. Buttrey, J. Solid State Chem. 105 (1993) 197

[26] B.S. Liu, C.T. Au, Catal. Lett. 85 (2003) 165

[27] G. S. Gallego, F. Mondragon, J. Barrault, J.M. Tatibouet, C. Batiot-Dupeyrat, Appl. Catal. A 311 (2006) 164

[28] T.C. Vaimakis, Thermochim. Acta 206 (1002) 219

[29] R. Saez Puche, J.L. Rodriguez, F. Fernandez, Inorg. Chem. Acta 140 (1987)

$151-153$ 


\section{7}

\section{Selective oxidative dehydrogenation of propane over dense membrane}

In this chapter, $\operatorname{PrBaCo}_{2} \mathrm{O}_{5+\delta}(\mathrm{PBC}), \mathrm{Ba}_{0.5} \mathrm{Sr}_{0.5} \mathrm{Co}_{0.8} \mathrm{Fe}_{0.2} \mathrm{O}_{3-\delta}$ (BSCF), $\mathrm{La}_{2} \mathrm{NiO}_{4+\delta}$ (LN) and $\mathrm{La}_{2} \mathrm{Ni}_{0.9} \mathrm{~V}_{0.1} \mathrm{O}_{4.15+\delta}$ (LNV-10) dense membranes have been tested as oxygen supplier in selective oxidative dehydrogenation of propane. Unfortunately, as the permeation rate was higher than the reaction rate in the case of $\mathrm{LN}, \mathrm{BSCF}$ and PBC, it is reasonable to assume that intermediate adsorbed oxygen species $\left(\mathrm{O}_{2}{ }^{-}\right.$, $\mathrm{O}_{2}{ }^{2-}$, and $\mathrm{O}^{-}$), which subsequently formed molecular $\mathrm{O}_{2}$, were present and possibly responsible for $\mathrm{CO}_{2}$ formation, decreasing the selectivity. In the case of LNV-10, no unconverted molecular $\mathrm{O}_{2}$ was detected in the product mixture, suggesting that exclusively active $\mathrm{O}^{2-}$ lattice oxygen was present as oxidant. Unfortunately, the contribution of the LNV-10 membrane on converting propane was very small although it showed higher yield to olefins at $550{ }^{\circ} \mathrm{C}$. Interestingly, BSCF enhanced the selectivity to $\mathrm{C}_{2} \mathrm{H}_{4}$ and $\mathrm{CH}_{4}$, as compared to operation in gas phase. Increasing the temperature, the contribution of the membranes to the reaction progressively decreased and the gas phase reaction gradually dominated. 



\subsection{Introduction}

The demand of propylene is expected to increase in the future because it is a crucial building block for the petrochemical industry [1]. The simplest and most direct way to obtain propylene is the dehydrogenation of propane, as shown in Eq. 7.1.

$$
\mathrm{C}_{3} \mathrm{H}_{8} \leftrightarrows \mathrm{C}_{3} \mathrm{H}_{6}+\mathrm{H}_{2} \quad \Delta \mathrm{H}=+156 \mathrm{KJ} / \mathrm{mol}
$$

Catalytic dehydrogenation of propane using $\mathrm{Cr}$ - and Pt- supported catalysts was extensively studied in the past [2]. Due to the high endothermicity of the reaction, high temperature is required to increase the olefin yield. Unfortunately, operation at high temperature causes high energy consumption and induces undesired cracking reactions, coke formation and consequent catalyst deactivation.

An alternative way for propylene production is oxidative dehydrogenation (ODH) of propane [3], as illustrated in Eq. 7.2.

$$
\mathrm{C}_{3} \mathrm{H}_{8}+\mathrm{O}_{2} \leftrightarrows \mathrm{C}_{3} \mathrm{H}_{6}+\mathrm{H}_{2} \mathrm{O} \quad \Delta \mathrm{H}=-86 \mathrm{KJ} / \mathrm{mol}
$$

The high quantity of heat generated by water formation turns the overall ODH of propane into an exothermic reaction, which overcomes the thermodynamic limitation. On the other hand, deep oxidation of highly reactive olefins to $\mathrm{CO}_{\mathrm{x}}$ can also take place. In fact, oxygen ions adsorbed on the catalyst can further react with propylene, which is more reactive than propane, drastically decreasing the selectivity to olefins $[4,5]$.

Many alternative oxidative agents were investigated (i.e. $\mathrm{N}_{2} \mathrm{O}, \mathrm{H}_{2} \mathrm{O}_{2}$ and $\mathrm{CO}_{2}$ ) to accomplish less severe oxidative conditions, aiming at increasing the yield [6 - 8]. Additionally, solid oxides were used as oxidant to improve the selectivity $[9,10]$. Obviously, the oxide will be reduced when exposed to the hydrocarbons and the reactivity of the lattice oxygen depends on composition and structure of the oxide. After exposure to hydrocarbon, the oxide needs to be regenerated via oxidation. This scheme is rather similar to the classical Mars - Van Krevelen mechanism, with the difference that, in this case, the oxidation and reduction steps are separated. This separation can be made in time, by using either moving bed technology or by switching between exposure to alkane and oxygen, respectively [11].

Another option is to separate the two steps in space by using a catalytic dense membrane reactor (CDMR). The membrane is exposed on one side to hydrocarbon and, on the other side, to molecular oxygen, generating oxygen lattice ions which 
permeate through the mixed conducting dense membrane. When arriving at the other side of the membrane, oxygen lattice ions are converted and removed by reaction with the alkane. By matching the oxygen permeability rate with the rate of conversion, oxygen recombination at the alkane side can be prevented. Consequently, oxygen and alkane are strictly separated at the two sides of membrane and conversion of alkane can proceed via oxygen lattice ions exclusively. Additionally, a steady-state process via reduction of the membrane during reaction with hydrocarbons and simultaneous regeneration by permeated oxygen ions can be obtained, in principle.

This approach was already studied for many reactions in catalysis, i.e. methane coupling to ethane and ethylene using $\mathrm{Ba}-\mathrm{Sr}-\mathrm{Co}-\mathrm{Fe}$ oxide $[12,13]$, partial oxidation of methane to syngas $[13,14]$ and oxidative dehydrogenation of light alkanes to olefins $[15,16]$ using Bi-Me-V oxides, in which $\mathrm{Me}=\mathrm{Cu}, \mathrm{Co}, \mathrm{Fe}, \mathrm{Ta}$ and $\mathrm{Ni}$.

In this study the concept of CDMR as oxygen supplier in selective oxidative dehydrogenation of propane is investigated using as $\mathrm{PrBaCo}_{2} \mathrm{O}_{5+\delta}$ (PBC), $\mathrm{Ba}_{0.5} \mathrm{Sr}_{0.5} \mathrm{Co}_{0.8} \mathrm{Fe}_{0.2} \mathrm{O}_{3-\delta}$ (BSCF), $\mathrm{La}_{2} \mathrm{NiO}_{4+\delta}$ (LN) and $\mathrm{La}_{2} \mathrm{Ni}_{0.9} \mathrm{~V}_{0.1} \mathrm{O}_{4+\delta}$ (LNV-10) dense membranes. These materials have been selected because of clear differences in ion permeability $[17,18]$ and lattice oxygen reactivity $[19,20]$, despite their similar perovskite-like structures as discussed in chapter 3 [21]. In the case of redox metals such as $\mathrm{Co}, \mathrm{Fe}$ and $\mathrm{Ni}$, the oxidation states can easily vary, inducing over- or under-stoichiometry in the samples, which is indicated by $\delta$ in the nominal composition of the materials. In this chapter, the propane conversion and the selectivity in the temperature range between 550 and $650{ }^{\circ} \mathrm{C}$ will be considered and suggestions about optimum operation temperature will be provided in correlation with oxygen permeability, membrane reactivity and reaction in the gas phase.

\subsection{Experimental}

\subsubsection{Catalyst preparation}

$\mathrm{PrBaCO}_{2} \mathrm{O}_{5+\delta} \quad(\mathrm{PBC}), \quad \mathrm{Ba}_{0.5} \mathrm{Sr}_{0.5} \mathrm{Co}_{0.8} \mathrm{Fe}_{0.2} \mathrm{O}_{3-\delta} \quad(\mathrm{BSCF}), \quad \mathrm{La}_{2} \mathrm{NiO}_{4+\delta} \quad(\mathrm{LN}) \quad$ and $\mathrm{La}_{2} \mathrm{Ni}_{0.9} \mathrm{~V}_{0.1} \mathrm{O}_{4.15+\delta}$ (LNV-10) catalysts were prepared via sol-gel method using EDTA as chelating agent [25]. Solutions of metal- hydrated nitrates (Merck), EDTA and $\mathrm{NH}_{4} \mathrm{OH}$ were mixed in the appropriate amounts. The obtained solutions were heated for 2 hours under stirring. During drying at $230{ }^{\circ} \mathrm{C}$, pyrolysis took place after spontaneous ignition and foam-type material was formed. The resulting solid mixed metal oxides were milled and calcined in air, slowly increasing 
temperature $\left(1{ }^{\circ} \mathrm{C} / \mathrm{min}\right)$ up to $900-1050{ }^{\circ} \mathrm{C}$ to obtain single phase materials. The resulting materials were ball milled in acetone for $5 \mathrm{~h}$, dried at $80^{\circ} \mathrm{C}$. Subsequently, the dry materials were isostatically pressed at 4000 bar and sintered at appropriate temperatures $\left(1200,1100,1370\right.$ and $1420{ }^{\circ} \mathrm{C}$ for PBC, BSCF, LN and LNV-10, respectively) in air for $10 \mathrm{~h}$, obtaining bulk densities $>95 \%$.

\subsubsection{Characterization}

XRD, BET and TPR analysis of the investigated materials were already presented in chapter 3 and will not be repeated here. The oxygen permeability experiments were performed in a vertical high-temperature gas permeation system schematically illustrated in fig. 7.1.

A ceramic glass ring was used for sealing $1 \mathrm{~mm}$ tick membrane disk on a quartz tube reactor. Permeation studies were performed at temperatures between 500 and $700{ }^{\circ} \mathrm{C}$. On the oxygen side of the membrane, a constant flow of $100 \mathrm{ml} / \mathrm{min}$ of technical air was employed while on the sweep side $100 \mathrm{ml} / \mathrm{min}$ of high purity $\mathrm{He}$ $\left(\mathrm{O}_{2}<2 \mathrm{ppm}\right)$ was used. A CP-4900 micro gas chromatograph equipped with Poraplot Q and 5Asil columns was connected to the outlet of the sweep side. The oxygen permeability was calculated based on (i) the amount of molecular oxygen present on the sweep side, (ii) the sweep gas flow rate and (iii) the membrane surface area. Nitrogen was not detected in the sweep gas, demonstrating that leakage of $\mathrm{N}_{2}$ or $\mathrm{O}_{2}$ through pores or cracks did not occur.

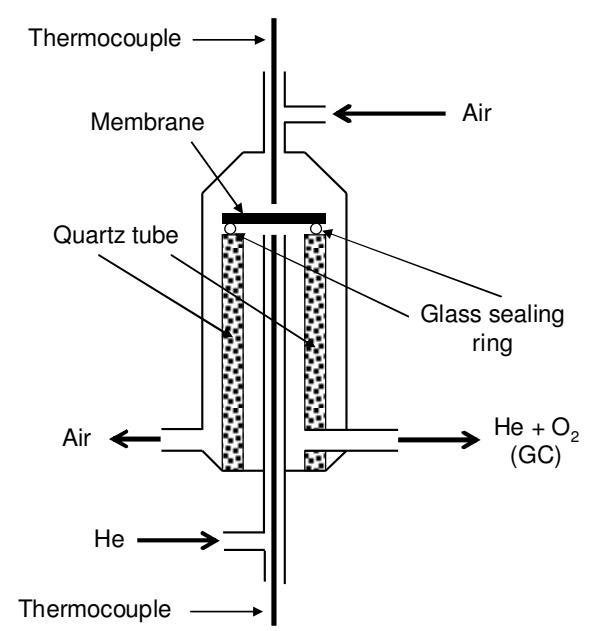

Fig. 7.1: Schematic representation of experimental set-up for permeability measurement and catalytic test of disk dense membrane reactor. 


\subsubsection{Catalytic test}

Catalytic tests were conducted using the equipment described above (fig. 7.1); however $10 \mathrm{ml} / \mathrm{min}$ flow of $10 \% \mathrm{C}_{3} \mathrm{H}_{8}$ in $\mathrm{He}$ was used instead of pure He. Propane conversion and product distribution were calculated using data from the micro chromatograph described above. The feed was measured before and after each catalytic test thus allowing calculation of propane conversion. The propane conversion in the gas phase was measured by replacing the membrane with an inert quartz disk (blank experiment). The product distributions were considered after 14 $\mathrm{h}$ of time on stream and the selectivities were calculated based on the carbon containing products only $\left(\mathrm{CO}, \mathrm{CO}_{2}, \mathrm{C}_{3} \mathrm{H}_{6}, \mathrm{C}_{2} \mathrm{H}_{6}, \mathrm{C}_{2} \mathrm{H}_{4}\right.$ and $\left.\mathrm{CH}_{4}\right)$. The carbon balance was higher that $99 \%$ in all catalytic tests.

\subsection{Results}

\subsubsection{Characterization}

Oxygen permeation measurements showed an increase of the oxygen permeability with temperature for all four samples, as illustrated in fig. 7.2.

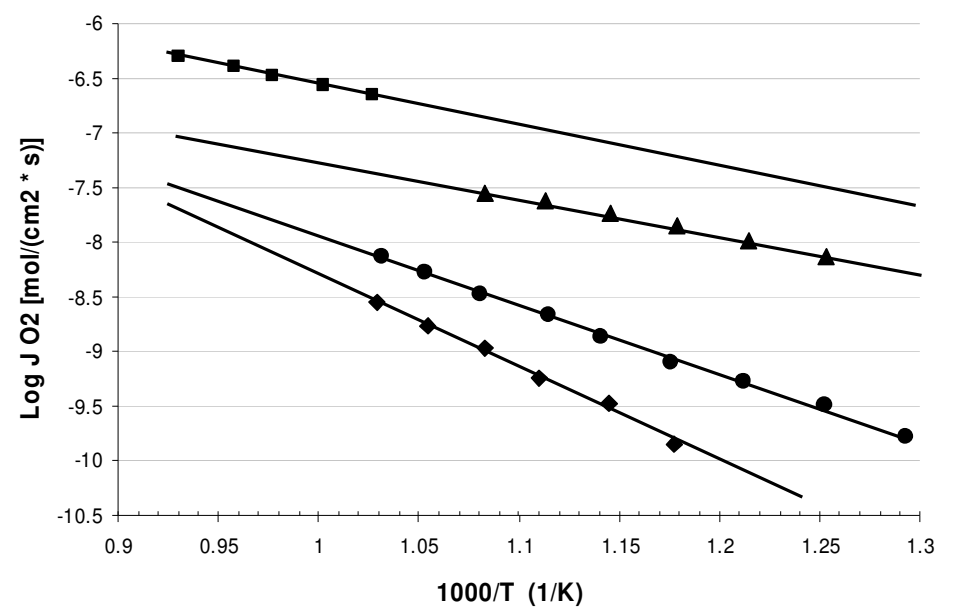

Fig. 7.2: Oxygen permeation fluxes through $L N V-10(\bullet), L N(\bullet), P B C(\bullet)$ and BSCF (-) membranes. BSCF data are extrapolated from high temperature measurements $(0.93<1000 / T<1.027)$ published in literature [26]. 
BSCF data are taken from literature $(0.93<1000 / \mathrm{T}<1.027)$ [26] and a linear extrapolation at lower temperature is considered to compare this material with $\mathrm{PBC}$, LN and LNV-10. The permeability within the four material differs approximately by one order of magnitude, decreasing in the sequence $\mathrm{BSCF}>\mathrm{PBC}>\mathrm{LN}>\mathrm{LNV}$ 10 , as earlier reported in chapter 3 for BSCF, PBC and LN.

\subsubsection{Catalytic test}

The propane conversion over PBC, BSCF, LN and LNV-10 after $14 \mathrm{~h}$ on time on stream during catalytic tests at 550,600 and $650{ }^{\circ} \mathrm{C}$ were compared to the gas phase reaction (blank) in fig. 7.3, showing decreasing activity in the order $\mathrm{PBC}>\mathrm{BSCF}>$ $\mathrm{LN}>\mathrm{LNV}-10>$ blank, at $550{ }^{\circ} \mathrm{C}$. Catalytic tests over LN and LNV-10 at $600{ }^{\circ} \mathrm{C}$ showed similar propane conversion while both catalysts showed identical conversion compared to the gas phase reaction when testing at $650{ }^{\circ} \mathrm{C}$ (fig. 7.3).

Additionally, comparing the selectivities of LN, LNV-10 and in the gas phase at 600 and $650{ }^{\circ} \mathrm{C}$, no significant variations were observed (not shown). Exclusively at $550{ }^{\circ} \mathrm{C}$, LN catalyst showed minor formation of $\mathrm{CO}_{2}$ which was not detected for both LNV-10 and in the blank experiment, as shown in fig. 7.4.

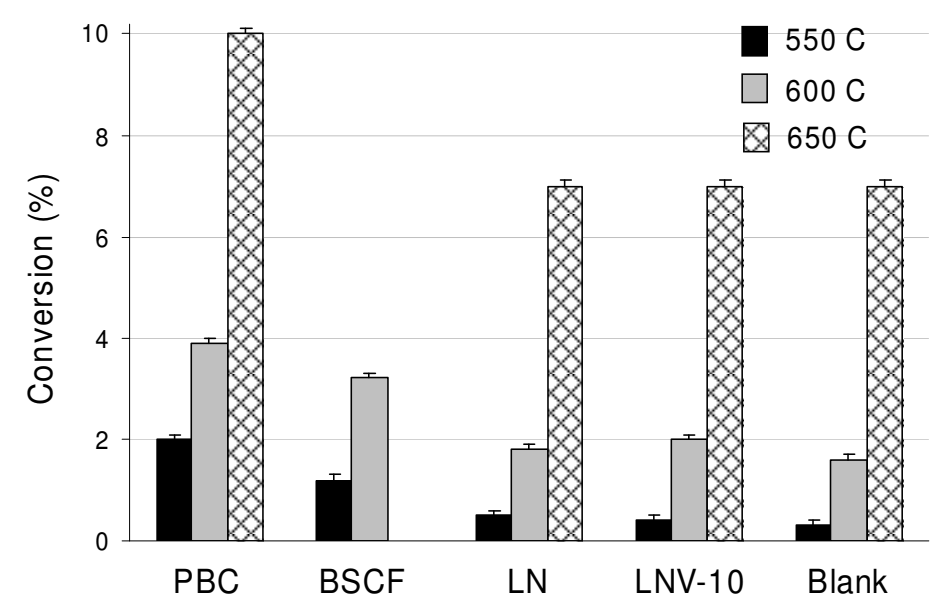

Fig. 7.3: Propane conversion during catalytic tests at 550, 600 and $650{ }^{\circ} \mathrm{C}$ after $14 \mathrm{~h}$ on time on stream on PBC, BSCF, LN, LNV-10 and in gas phase (blank). 


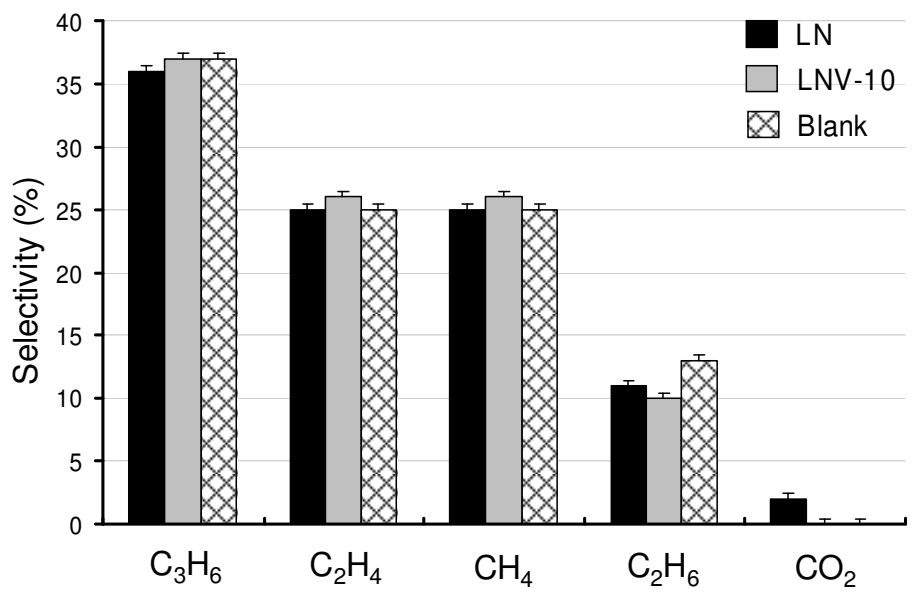

Fig. 7.4: Selectivities of formed products after $14 \mathrm{~h}$ on time on stream during catalytic tests at $550{ }^{\circ} \mathrm{C}$ over LN, LNV-10 and on gas phase (blank).

Catalytic test at $550{ }^{\circ} \mathrm{C}$ for BSCF showed $\mathrm{C}_{3} \mathrm{H}_{6}$ as main product with selectivity of $34 \%$ and significant amounts of $\mathrm{C}_{3} \mathrm{H}_{6}, \mathrm{C}_{2} \mathrm{H}_{4}$ and $\mathrm{CH}_{4}$, as shown in fig. 7.5. Selectivities to $\mathrm{C}_{2} \mathrm{H}_{4}$ and $\mathrm{CH}_{4}$ were similar and slightly higher than in the gas phase. Selectivity to $\mathrm{CO}_{2}$ was $11 \%$ and small amounts of $\mathrm{C}_{2} \mathrm{H}_{6}$ and $\mathrm{CO}$ were also detected. It should be mentioned that the selectivity to $\mathrm{C}_{3} \mathrm{H}_{6}$ was lower than in the gas phase.

Increasing the temperature to $600{ }^{\circ} \mathrm{C}$, the catalytic test resulted in a slight decrease of selectivity to $\mathrm{C}_{3} \mathrm{H}_{6}$ and a small increase in selectivities to $\mathrm{C}_{2} \mathrm{H}_{4}$ and $\mathrm{CH}_{4}$ (fig. 7.5). Interestingly, the selectivity to $\mathrm{CO}_{2}$ decreased. Note that the selectivities to $\mathrm{C}_{3} \mathrm{H}_{6}$, $\mathrm{C}_{2} \mathrm{H}_{4}, \mathrm{CH}_{4}$ and $\mathrm{C}_{2} \mathrm{H}_{6}$ were lower than the corresponding selectivities in gas phase at $600{ }^{\circ} \mathrm{C}$. Exclusively the selectivities to $\mathrm{CO}$ and $\mathrm{CO}_{2}$ were higher than those in the gas phase in which formation of $\mathrm{CO}_{\mathrm{x}}$ was not observed. 


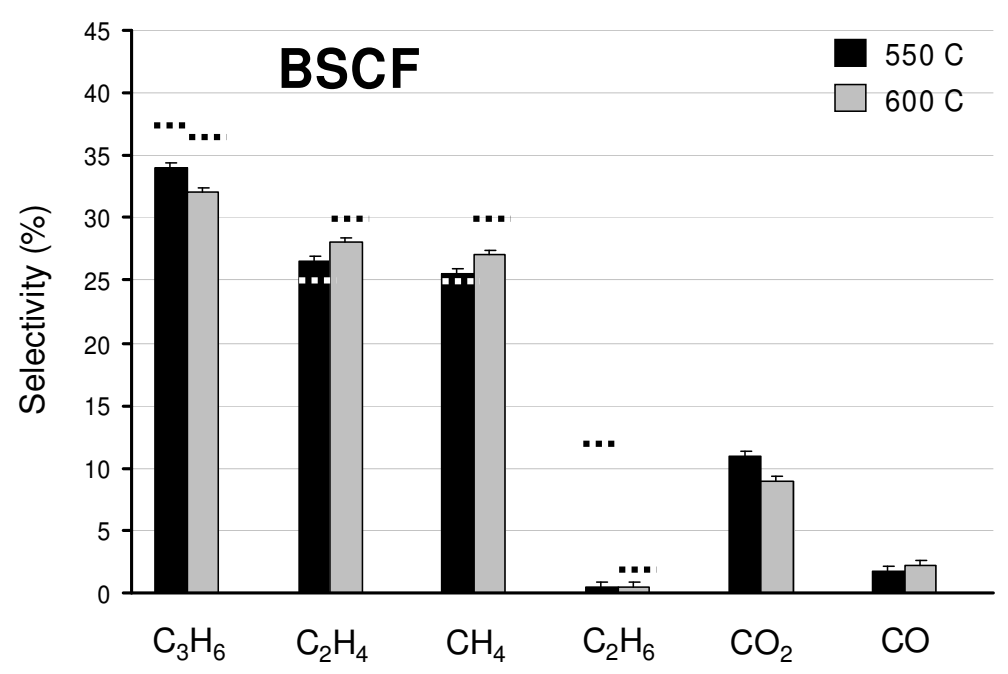

Fig. 7.5: Selectivities of carbon containing products after $14 \mathrm{~h}$ on time on stream during catalytic tests at 550 and $600{ }^{\circ} \mathrm{C}$ over BSCF. The dotted lines above most of the bars indicate the selectivities obtained in the gas phase.

Catalytic test at $550{ }^{\circ} \mathrm{C}$ over $\mathrm{PBC}$ resulted in $\mathrm{CO}_{2}$ as main product with selectivity of $43 \%$ and significant amounts of $\mathrm{C}_{3} \mathrm{H}_{6}, \mathrm{C}_{2} \mathrm{H}_{4}$ and $\mathrm{CH}_{4}$, as shown in fig. 7.6. Selectivities to $\mathrm{C}_{2} \mathrm{H}_{4}$ and $\mathrm{CH}_{4}$ were similar. Additionally, small amounts of $\mathrm{C}_{2} \mathrm{H}_{6}$ and $\mathrm{CO}$ were detected.

Increasing the temperature to 600 and $650{ }^{\circ} \mathrm{C}$, the catalytic test resulted in significantly increasing selectivities towards $\mathrm{C}_{3} \mathrm{H}_{6}, \mathrm{C}_{2} \mathrm{H}_{4}$ and $\mathrm{CH}_{4}$ (fig. 7.6). Interestingly, the selectivity to $\mathrm{CO}_{2}$ drastically decreased while the selectivity to $\mathrm{C}_{2} \mathrm{H}_{6}$ and $\mathrm{CO}$ slightly increased. Note that the selectivities towards $\mathrm{C}_{3} \mathrm{H}_{6}, \mathrm{C}_{2} \mathrm{H}_{4}, \mathrm{CH}_{4}$ and $\mathrm{C}_{3} \mathrm{H}_{6}$ were lower than the same selectivities obtained in gas phase at all investigated temperatures. Exclusively the selectivity to $\mathrm{CO}$ and $\mathrm{CO}_{2}$ were higher than in gas phase in which formation of $\mathrm{CO}_{\mathrm{x}}$ was not observed. 


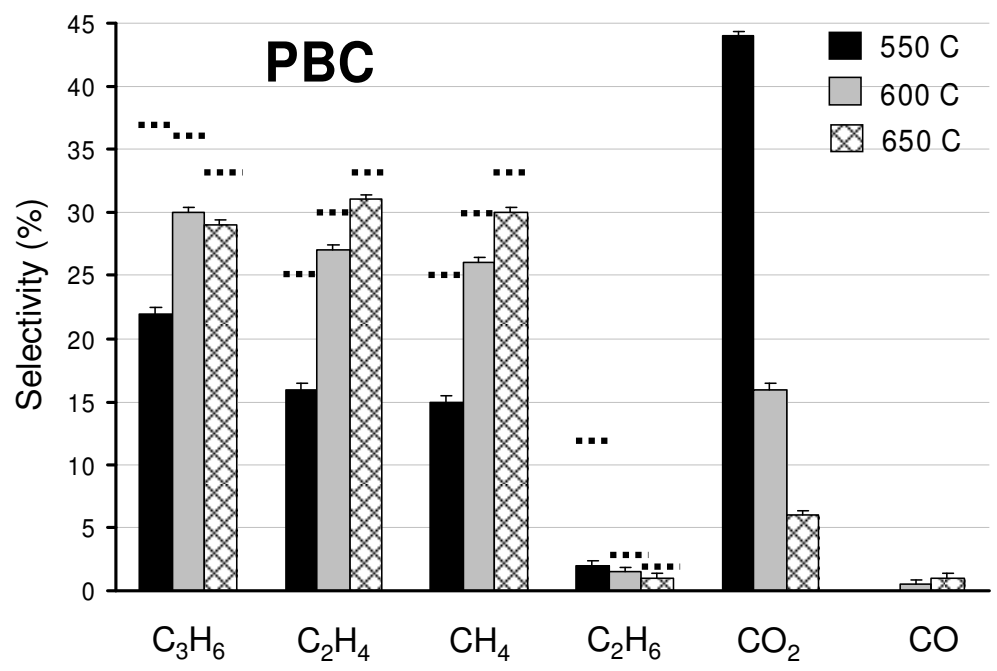

Fig. 7.6: Selectivities of carbon containing products after $14 \mathrm{~h}$ on time on stream during catalytic tests at 550, 600 and $650{ }^{\circ} \mathrm{C}$ over PBC. The dotted lines above most of the bars indicate the selectivities obtained in the gas phase.

The conversions and the selectivities obtained with LN, LNV-10 and BSCF were constant with time on stream at all investigated temperatures, therefore the selectivities vs time on stream are not shown. Contrary, the selectivities with PBC varied with time on stream, as shown in fig. 7.7. The selectivity to $\mathrm{CO}_{2}$ at $550{ }^{\circ} \mathrm{C}$ varied from 51 to $46 \%$ during $14 \mathrm{~h}$ time on stream and consequently selectivities to $\mathrm{C}_{3} \mathrm{H}_{6}, \mathrm{C}_{2} \mathrm{H}_{4}$ and $\mathrm{CH}_{4}$ increased slightly (fig. 7.7a). Similar variations of selectivities with time on stream were observed at higher temperatures (fig $7.7 \mathrm{~b}$ and $7.7 \mathrm{c}$ ). Please note that the higher the reaction temperature, the lower the selectivity to $\mathrm{CO}_{2}$, in agreement with the data in fig. 7.6. 

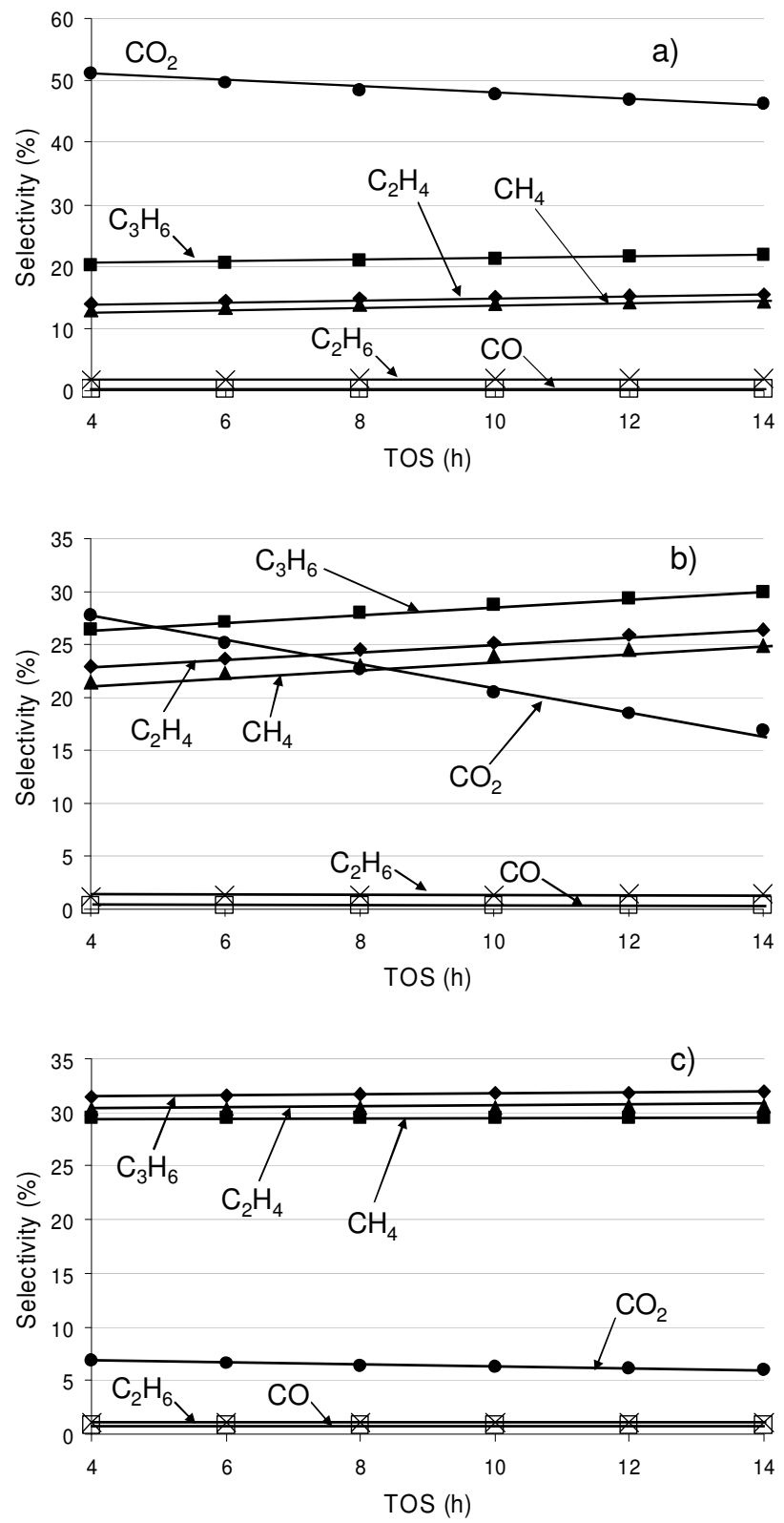

Fig. 7.7: Selectivities to $\mathrm{C}_{3} \mathrm{H}_{6}(\bullet), \mathrm{C}_{2} \mathrm{H}_{4}(\bullet), \mathrm{CH}_{4}(\bullet), \mathrm{C}_{2} \mathrm{H}_{6}(\times), \mathrm{CO}(\square)$ and $\mathrm{CO}_{2}(\bullet)$ vs time on stream during catalytic tests with propane over PBC at $550($ a), $600($ b) and $650{ }^{\circ} \mathrm{C}(\mathrm{c})$. 
Additionally to the carbon containing products, molecular $\mathrm{O}_{2}$ was also detected in the product mixture during the catalytic tests over $\mathrm{LN}, \mathrm{PBC}$ and BSCF. The molecular $\mathrm{O}_{2}$ was below the detection limit of the $\mathrm{GC}\left(\log \mathrm{J}\left(\mathrm{O}_{2}\right)<-10.5\right.$, corresponding to $5 \bullet 10^{-11} \mathrm{~mol}$ of $\mathrm{O}_{2} \bullet \mathrm{s}^{-1}$ ) in case of LNV-10 at all temperatures. The oxygen permeation rates $\left(\mathrm{mol} \mathrm{O}_{2} \bullet \mathrm{cm}^{-2} \bullet \mathrm{s}^{-1}\right)$, calculated based on (i) the amount of molecular $\mathrm{O}_{2}$ detected in the product mixture, (ii) the surface area of the membrane and (iii) the propane flow rate, are reported in table 7.1.

Table 7.1: Oxygen permeation rates of BSCF, $P B C, L N$ and $L N V-10$ membranes in $\mathrm{C}_{3} \mathrm{H}_{8}$ atmosphere based on the molecular $\mathrm{O}_{2}$ detected in the product mixture exclusively.

\begin{tabular}{|cccc|}
\hline \multirow{2}{*}{ Membrane } & \multicolumn{3}{c|}{ Oxygen permeation rates $\left(\log \left(\mathrm{J}\left(\mathrm{O}_{2}\right)\right)\right.$} \\
& $550{ }^{\circ} \mathrm{C}$ & $600{ }^{\circ} \mathrm{C}$ & $650{ }^{\circ} \mathrm{C}$ \\
\cline { 2 - 4 } & -8.58 & -7.77 & \\
\hline BSCF & -8.60 & -7.86 & -7.32 \\
\hline PBC & -9.35 & -8.95 & -8.90 \\
\hline LN & $<-10.5$ & $<-10.5$ & $<-10.5$ \\
\hline LNV-10 & $\left.\left.<-1 \mathrm{cmol}^{-2} \bullet \mathrm{s}^{-1}\right)\right]$ \\
\hline
\end{tabular}

Note that the oxygen permeation rates reported in table 7.1 corresponds to absolute amount of $\mathrm{O}_{2}\left(\mathrm{~mol} \bullet \mathrm{s}^{-1}\right)$ which varies between 1 and $7 \%$ as compared to total amount of carbon containing products.

\subsection{Discussion}

Selective / oxidative dehydrogenation of propane proceeds via activation of propane on the surface of the catalyst and consequent formation of propyl-radicals which (i) can further react on the surface of the catalyst or (ii) can be released to the gas phase, followed by the formation of the products [4, 27, 28]. Generally, conventional catalytic tests operate with a mixture of hydrocarbon and oxygen as feed which, on one hand, is beneficial for the catalyst regeneration but, on the other hand, easily causes consecutive oxidation of the products to $\mathrm{CO}_{\mathrm{x}}$. Note that at high temperature, the contribution of the catalyst to the formation of radicals is apparently minimal and the reaction takes place most importantly in gas phase.

In this paragraph, we will discuss the role of dense membranes as catalysts, comparing the propane conversion and selectivities of the products in the presence 
of the membrane with conversion and selectivities observed in the blank experiment, in which exclusively gas phase reactions can contribute.

\subsubsection{LN and LNV-10}

The reactivity of LN and LNV-10 catalysts on the oxidative dehydrogenation of propane was compared with the gas phase reaction at different temperature (fig. 7.3). Both catalysts showed activity in converting propane at temperature as high as $600{ }^{\circ} \mathrm{C}$, testified by the fact that the propane conversion was slightly higher in the presence of the catalysts than in the gas phase. Further increasing the temperature to $650{ }^{\circ} \mathrm{C}$, the gas phase conversion dominates as the propane conversion in presence of the catalysts and in blank experiment was identical. Additionally, both catalysts showed very similar selectivity compared to the gas phase at all temperatures. Therefore, the presence of the membrane increased the yield to propylene at $550{ }^{\circ} \mathrm{C}$. We suggest that propyl-radicals are formed on the catalyst surface, whereas further conversion takes place in gas phase because of the similarity in the formation of products and their selectivities, similar to suggestions in literature $[4,27,28]$. This explains (i) the higher conversion in presence of the catalyst and (ii) the similar selectivity with and without catalyst. Clearly, increasing the temperature, the thermal activation of propane in gas phase is more significant than the catalytic activation of propane on the catalyst surface.

Remarkably, in the case of $\mathrm{LN}$, molecular $\mathrm{O}_{2}$ was detected in the product mixture (table 7.1). This means that the oxygen permeability was faster than rate of conversion of oxygen, suggesting (i) the presence of adsorbed oxygen ions $\left(\mathrm{O}_{2}{ }^{-}\right.$, $\mathrm{O}_{2}^{2-}$, and $\mathrm{O}^{-}$) on the surface and (ii) the further recombination to $\mathrm{O}_{2}$ at the reaction side of the membrane. Therefore adsorbed, lattice and molecular oxygen possibly contributed to the conversion of propane. Based on table 7.1 and fig. 7.4, we suggest that $\mathrm{CO}_{2}$ is formed on the surface of the catalyst at $550{ }^{\circ} \mathrm{C}$, via adsorbed $\left(\mathrm{O}_{2}^{-}, \mathrm{O}_{2}^{2-}\right.$, and $\left.\mathrm{O}^{-}\right)$and $/$or lattice $\left(\mathrm{O}^{2-}\right)$ oxygen, rather than in gas phase. The formation of $\mathrm{CO}_{2}$ in gas phase can be excluded considering that (i) $\mathrm{CO}_{2}$ is formed at $550{ }^{\circ} \mathrm{C}$ exclusively and that (ii) the amount of molecular $\mathrm{O}_{2}$ in the product mixture increases with temperature. Increasing the temperature to $600{ }^{\circ} \mathrm{C}$, the reactivity of the membrane surface significantly decreases and the formation of $\mathrm{CO}_{2}$ is inhibited, as mentioned in the section 7.3.2. Remarkably, we can therefore conclude that the presence of $\mathrm{O}_{2}$ in gas phase is not responsible for formation of $\mathrm{CO}_{2}$ which must predominantly proceed on the membrane surface.

Contrary, in the case of LNV-10, no molecular oxygen was detected in the product mixture, suggesting the absence of adsorbed oxygen ions $\left(\mathrm{O}_{2}^{-}, \mathrm{O}_{2}{ }^{2-}\right.$, and $\left.\mathrm{O}^{-}\right)$on the surface and therefore, the presence of $\mathrm{O}^{2-}$ lattice oxygen as oxidant, exclusively. The adsorbed oxygen ions are considered to be formed during oxidation of $\mathrm{O}^{2-}$ 
lattice ions to form molecular $\mathrm{O}_{2}$. This explains why no $\mathrm{CO}_{2}$ is formed at any investigated temperature, also resulting in slightly higher selectivities to $\mathrm{C}_{3} \mathrm{H}_{6}, \mathrm{C}_{2} \mathrm{H}_{4}$ and $\mathrm{CH}_{4}$ as compared to $\mathrm{LN}$.

In chapter 6 the change of product distribution with variation of over-stoichiometry ( $\delta$ ) of LNV-10 catalyst was investigated in propane pulse experiment at $550{ }^{\circ} \mathrm{C}$ [29]. It was shown that for $\delta>0.03, \mathrm{CO}_{2}$ was the main product while for $\delta \leq 0.03$ olefins were mainly produced and $\mathrm{CO}_{2}$ formation was below the MS detection limit. Therefore, based on qualitative comparison between the apparent selectivities during pulse experiments and the selectivities during the catalytic tests (fig. 7.4), we suggest that the membrane surface was operating at $\delta \leq 0.03$ during the catalytic tests at temperatures between 550 and $650{ }^{\circ} \mathrm{C}$, as $\mathrm{CO}_{2}$ was not formed at the investigated temperatures.

\subsubsection{PBC}

The reactivity of PBC membrane in the oxidative dehydrogenation of propane was compared with the gas phase reaction at temperatures between 550 and $650{ }^{\circ} \mathrm{C}$ (fig. 7.6). The activity of the catalyst is testified by the fact that the conversions were significantly higher than in gas phase (fig. 7.3). Also in the case of PBC, molecular $\mathrm{O}_{2}$ was detected in the product mixture (table 7.1), suggesting the presence of adsorbed oxygen ions $\left(\mathrm{O}_{2}^{-}, \mathrm{O}_{2}{ }^{2-}\right.$, and $\left.\mathrm{O}^{-}\right)$on the surface and (ii) the further recombination to $\mathrm{O}_{2}$ at the reaction side of the membrane. The fact that the amount of molecular $\mathrm{O}_{2}$ detected in the product mixture increases with temperature (table 7.1) while the formation of $\mathrm{CO}_{2}$ decreases with temperature, suggests that $\mathrm{CO}_{2}$ is formed on the surface of the catalyst rather than in gas phase, similarly to LN, as described in the previous paragraph.

Comparing the propane conversions and selectivities in presence of the catalyst with the blank experiment, it is clear that the gas phase contribution increases with increasing temperature (fig. 7.3 and 7.6). Consequently, the activation of propane on the membrane surface diminishes relatively when increasing temperature, thus lowering deep oxidation of $\mathrm{C}_{3} \mathrm{H}_{8}$ to $\mathrm{CO}_{2}$ (fig 7.6). Therefore, at high temperature the selectivity pattern resembles operation in gas phase, similarly to LN.

The fact that selectivity to $\mathrm{CO}_{2}$ slightly decreased and selectivities to $\mathrm{C}_{3} \mathrm{H}_{6}, \mathrm{C}_{2} \mathrm{H}_{4}$ and $\mathrm{CH}_{4}$ increased with time on stream (fig. 7.7), suggests that the reactivity of the catalyst changes during the catalytic test. The reason for this remains unclear at this point and would require additional research. It might be speculated that the (surface) structure of PBC changes with time on stream. 


\subsubsection{BSCF}

In contrast to $\mathrm{PBC}$ and $\mathrm{LN}, \mathrm{BSCF}$ showed higher selectivities to $\mathrm{C}_{2} \mathrm{H}_{4}$ and $\mathrm{CH}_{4}$ at $550{ }^{\circ} \mathrm{C}$ as compared to operation in gas phase (fig. 7.5). This suggests that $\mathrm{C}_{2} \mathrm{H}_{4}$ and $\mathrm{CH}_{4}$ are formed both in gas phase as well as on the surface of the membrane at 550 ${ }^{\circ} \mathrm{C}$. Similarly to $\mathrm{LN}$ and $\mathrm{PBC}, \mathrm{CO}_{2}$ is formed on the BSCF membrane in contrast to the gas phase reaction and the selectivity to $\mathrm{CO}_{2}$ decreases with temperature. Considering that the amount of molecular $\mathrm{O}_{2}$ detected in the product mixture increases with temperature (table 7.1), we can conclude that $\mathrm{CO}_{2}$ was formed on catalyst surface rather than in gas phase, similarly to $\mathrm{LN}$ at $550{ }^{\circ} \mathrm{C}$ and for $\mathrm{PBC}$ at all investigated temperatures.

At $600{ }^{\circ} \mathrm{C}$, all selectivities except for $\mathrm{CO}_{\mathrm{x}}$ drop below the level of the blank experiment, indicating that the role of the membrane surface is limited to (i) generating propyl radicals, increasing the conversion level (fig. 7.3) and (ii) forming $\mathrm{CO}_{\mathrm{x}}$ thereby slightly decreasing the selectivities to hydrocarbons.

The oxygen permeability of BSCF membrane is known to deteriorate with time on stream due to (i) a cubic-to-hexagonal phase transition when operated at temperature below $800{ }^{\circ} \mathrm{C}$, and/or (ii) $\mathrm{Ba}$ - and Sr-based carbonate formation in the presence of $\mathrm{CO}_{2}$ [30]. These factors did not influence the catalytic activity and the product distribution of BSCF as the performance of the membrane was stable with time on stream, showing carbon balance of $99 \%$. Probably, $14 \mathrm{~h}$ time on stream is simply too short as compared to $100 \mathrm{~h}$ time on stream in literature [30].

\subsubsection{Comparison of oxygen fluxes in $\mathrm{C}_{3} \mathrm{H}_{8}$ and $\mathrm{He}$ atmospheres}

The reactivity of $\mathrm{C}_{3} \mathrm{H}_{8}$, removing oxygen ions from the membrane surface, affects the gradient of oxygen partial pressure over the membrane $\left(\Delta \mathrm{pO}_{2}\right)$. At the same time, variation of $\Delta \mathrm{pO}_{2}$ affects the oxygen flux through the membrane. Therefore, varying the atmosphere from $\mathrm{He}$ to $\mathrm{C}_{3} \mathrm{H}_{8}$, the oxygen flux is expected to increase. Oxygen fluxes in propane atmosphere for PBC, BSCF and LN membranes at 550 ${ }^{\circ} \mathrm{C}$ were calculated and compared with oxygen permeability in $\mathrm{He}$, as shown in table 7.2. Oxygen fluxes were calculated based on the amount of oxygen consumed during the catalytic tests, considering (i) the propane flow rate, (ii) the propane conversion, (iii) the membrane surface area, and assuming that $\mathrm{CO}_{2}$ is formed according to the eq. 7.3. 
Table 7.2: Oxygen permeation rates of BSCF, $P B C$ and $L N$ membranes in He atmosphere (experimental values, fig. 7.2) and oxygen fluxes in $\mathrm{C}_{3} \mathrm{H}_{8}$ atmosphere (calculated values, based on catalytic tests) at $550{ }^{\circ} \mathrm{C}$.

\begin{tabular}{|ccc|}
\hline Membrane & $\begin{array}{c}\log \mathrm{J}\left(\mathrm{O}_{2}\right) \\
\text { in } \mathrm{He} \text { at } 550{ }^{\circ} \mathrm{C} \\
{\left[\left(\log \left(\mathrm{mol} \mathrm{O}_{2} \bullet \mathrm{cm}^{-2} \bullet \mathrm{s}^{-1}\right)\right]\right.}\end{array}$ & $\begin{array}{c}\log \mathrm{J}\left(\mathrm{O}_{2}\right) \\
\text { in } \mathrm{C}_{3} \mathrm{H}_{8} \text { at } 550{ }^{\circ} \mathrm{C} \\
{\left[\left(\log \left(\mathrm{mol} \mathrm{O}_{2} \bullet \mathrm{cm}^{-2} \bullet \mathrm{s}^{-1}\right)\right]\right.}\end{array}$ \\
\hline BSCF & -7.38 & -7.20 \\
\hline PBC & -7.98 & -6.65 \\
\hline LN & -9.27 & -8.73 \\
\hline LNV-10 & -10.05 & n.d. (a) \\
\hline
\end{tabular}

(a) Not determined

$\mathrm{C}_{3} \mathrm{H}_{8}+10 \mathrm{O} \rightarrow 3 \mathrm{CO}_{2}+4 \mathrm{H}_{2} \mathrm{O}$

The oxygen flux through LNV-10 membrane was not determined as during the catalytic test no $\mathrm{CO}_{2}$ was formed and no molecular $\mathrm{O}_{2}$ was detected in the product mixture, suggesting that permeated oxygen formed $\mathrm{H}_{2} \mathrm{O}$ exclusively (not monitored with GC). Apparently, permeated oxygen is converted to $\mathrm{H}_{2} \mathrm{O}$, slightly increasing the propane conversion level as compared to the gas phase contribution (fig. 7.3). The permeation of oxygen is at least equal to the permeation observed in $\mathrm{He}$, however our data do not allow to conclude whether it increased when operating in propane.

As expected, all membranes in table 7.2 showed higher oxygen fluxes in propane atmosphere than in He. It is remarkable to notice that in the case of PBC, the oxygen flux in propane is more than one order of magnitude higher than in $\mathrm{He}$ ($6.65 \mathrm{vs}-7.98 \log \left(\mathrm{J}\left(\mathrm{O}_{2}\right)\right)$, respectively) while the variation for BSCF is much smaller (- 7.20 vs $-7.38 \log \left(\mathrm{J}\left(\mathrm{O}_{2}\right)\right)$, respectively). $\mathrm{LN}$ showed a significant increase of oxygen permeation rate in propane than in $\mathrm{He}$, similarly to $\mathrm{PBC}$, but the permeation rate remained much lower as compared to $\mathrm{PBC}$ and $\mathrm{BSCF}$ in propane, as also observed in He (fig. 7.2). Additionally, $\mathrm{PBC}$ showed higher oxygen flux than BSCF when flowing $\mathrm{C}_{3} \mathrm{H}_{8}$, while the trend is the opposite when flowing pure $\mathrm{He}$, as shown in table 7.2.

This is in line with the higher reactivity of $\mathrm{PBC}$ as compared to BSCF during catalytic tests (fig. 7.3) as well as during pulse experiments, discussed on chapter 3. The large effect for PBC is also in line with the very high selectivity to $\mathrm{CO}_{2}$, resulting in poor selectivity in the catalytic test (fig. 7.6) as well as in the pulse experiment (chapter 3 ). 
Comparing the results at $550{ }^{\circ} \mathrm{C}$ in tables 7.1 and 7.2 , reveals that the unconverted permeated oxygen, detected as molecular $\mathrm{O}_{2}$ in the product mixture was $1,2.5$ and $16 \%$ as compared to the amount of reactive oxygen consumed to form $\mathrm{CO}_{2}$, in case of $\mathrm{PBC}$, BSCF and LN, respectively. Clearly, the higher is the reactivity of $\mathrm{O}^{2-}$ lattice oxygen in propane ( $\mathrm{PBC}>\mathrm{BSCF}>\mathrm{LN}$, table 7.2), the lower is the relative amount of unconverted permeated oxygen $(\mathrm{LN}>\mathrm{BSCF}>\mathrm{PBC})$. Note that in case of $\mathrm{PBC}$, too reactive $\mathrm{O}^{2-}$ lattice oxygen resulted in significant propane conversion to $\mathrm{CO}_{2}$ mainly, thus decreasing the selectivities to olefins as compared to operation in gas phase. Contrary, in the case of $\mathrm{LN}$ and LNV-10, less reactive $\mathrm{O}^{2-}$ lattice oxygen resulted in lower propane conversion but higher yield to olefins as compared to operation in gas phase. This means that reactivity of $\mathrm{O}^{2-}$ lattice oxygen is a crucial parameter to balance significant propane conversion, promising selectivities to olefins and amount of unconverted permeated oxygen.

\subsection{Conclusions}

In this chapter it was shown that dense membranes can operate as oxygen supplier for catalytic reactions. Unfortunately, as the permeation rate was higher than the reaction rate in the case of $\mathrm{LN}, \mathrm{BSCF}$ and $\mathrm{PBC}$, we have not yet been able to balance the oxygen flux and the oxygen conversion rate. Therefore, it is reasonable to assume that intermediate adsorbed oxygen species in the formation of $\mathrm{O}_{2}$ molecules $\left(\mathrm{O}_{2}{ }^{-}, \mathrm{O}_{2}^{2-}\right.$, and $\left.\mathrm{O}^{-}\right)$were present and possibly responsible for $\mathrm{CO}_{2}$ formation, decreasing the selectivity. Please note that in the case of LNV-10, no unconverted molecular $\mathrm{O}_{2}$ was detected in the product mixture, suggesting that exclusively active $\mathrm{O}^{2-}$ lattice oxygen was present as oxidant. Unfortunately, the contribution of the LNV-10 membrane on converting propane was very small although it showed higher yield to olefins at $550{ }^{\circ} \mathrm{C}$, as also observed for $\mathrm{LN}$. Interestingly, BSCF enhanced the selectivity to $\mathrm{C}_{2} \mathrm{H}_{4}$ and $\mathrm{CH}_{4}$, as compared to operation in gas phase. Increasing the temperature, the contribution of both membranes to the reaction progressively decreased and the gas phase reaction gradually dominated. Contrary, using PBC as membrane, the selectivities to olefins and $\mathrm{CH}_{4}$ were always lower than in gas phase due to high formation of $\mathrm{CO}_{2}$.

\section{Acknowledgements}

The author would like to thank Ir. C. Song for the catalytic tests and the oxygen permeability tests in He, Dr. H.J.M Bouwmeester for inspiring discussions, Ir. B. Geerdink for technical support during catalytic tests and the ASPECT programme 
of ACTS/NWO, The Netherlands for financial support (project number 053.62.004)

\section{References}

[1] J. F. Brazdil, Top. Catal. 38 (2006) 289

[2] R. K. Grasselli, D. L. Stern, J. G. Tsikoyiannis, Appl. Catal. A 189 (1999) 1

[3] F. Cavani, N. Ballarini, A. Cericola, Catal. Today 127 (2007) 113

[4] E. V. Kondratenko, M. Y. Sinev, Appl. Catal. A 325 (2007) 353

[5] L. Leveles, K. Seshan, J.A. Lercher, L. Lefferts, J. Catal. 218 (2003) 307

[6] J. Perez-Ramirez, N. Blangenois, P. Ruiz, Catal. Lett. 104 (2005) 163

[7] J. R. Monnier, Appl. Catal. A 221 (2001) 73

[8] K.N. Rao, B.M. Reddy, B. Abhishek, Y.H. Seo, N. Jiang, S. Park, Appl. Catal. B 91 (2009) 649

[9] G. C. Bond, J. Catal. 116 (1989) 531

[10] Y. Zhang-Lin, M. Forissier, J. C. Vedrine, J. C. Volta, J. Catal. 145 (1994) 267

[11] R.M. Contractor, H.E. Bergna, H.S. Horowitz, C.M. Blackstone, B. Malone,

C.C. Torardi, B. Griffeths, U. Chowdhry, A.W. Sleight, Catal. Today 1 (1987) 49

[12] L. Oliver, S. Haag, C. Mirodatos, A.C. van Veen, Catal. Today142 (2009) 3441

[13] P.J. Gellings, H.J.M. Bouwmeester, Catal. Today 58 (2000) 1-53

[14] C. Pirovano, A. Lofberg, H. Bodet, E. Bordes-Richard, M.C. Steil, R.N. Vannier, Solid State Ionics 177 (2006) 2241-2244

[15] A.A. Dalmon, A. Cruz-lopez, D. Farrusseng, N. Guilhaume, E. Iojoiu, J.C. Jalibert, S. Miachon, C. Mirodatos, A. Pantazidis, M. Rebeilleau-Dassonneville, Y. Schuurman, A. van Veen, Appl. Catal. A 325 (2007) 198-204

[16] A. Lofberg, H. Bodet, C. Pirovano, M.C. Steil, R.N. Vannier, E. BordesRichard, Catal. Today 117 (2006) 168-173

[17] H. Wang, W.S. Yang, Y. Cong, X. Zhu, Y.S. Lin, J. Memb. Science 224 (2003) 107-115

[18] A.L. Shaula, E.N. Naumovich, A.P. Viskup, V.V. Pankov, A.V. Kovalevsky, V.V. Kharton, Solid State Ionics 180 (2009) 812-816

[19] W,L. Chu, J.H. Tong, W.S. Yang, L. W. Lin, Chinese Chemical Letters 12 (2001) 975-978

[20] C. Guo, J. Zhang, X. Zhang, React. Kinet. Catal. Lett., 95 (2008) 89-97

[21] S. Crapanzano, I.V. Babich, L. Lefferts, Appl. Catal A Special Edition, in press [22] G. Kim, S. Wang, A.J. Jacobson, L. Reimus, P. Brodersen, C.A. Mims, J. Mater. Chem. 17 (2007) 2500-2505

[23] C. Frontera, A. Caneiro, A.E. Carrillo, J. Oro-Sole, J.L. Garcia-Munoz, Chem. Mater. 17 
[24] L. Minervini, R.W. Grimes, J.A. Kilner, K.E. Sickafus, J. Mater. Chem. 10 (2000), 2349-2354

[25] R.H.E. van Doorn, H. Kruidhof, A. Nijmeijer, L. Winnubst and A.J. Burggraaf, J. Mater. Chem., 1998, 8(9), 2109-2112

[26] H. Wang, W.S. Yang, Y. Cong, X. Zhu, Y.S. Lin, J. Memb. Science 224 (2003) $107-115$

[27] M. Xu, T.H. Ballinger, J.H. Lunsford, J. Phys. Chem. 99 (1995) 14494

[28] C. Trionfetti, PhD Thesis, 2008, University of Twente (NL)

[29] S. Crapanzano, I.V. Babich, L. Lefferts, Langmuir, submitted

[30] Z. Shao, G. Xiong, H. Dong, W. Yang, L. Lin, Sep. Purif. Technol. 25 (2001) $97-116$ 



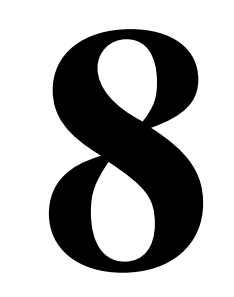

Conclusions and recommendations 



\subsection{Conclusions}

Selective oxidative dehydrogenation of propane proceeds via activation of propane on the surface of the catalyst with consequent formation of propyl-radicals, which (i) can further react on the surface of the catalyst or (ii) can be released in gas phase, before the formation of the products [3 - 5]. Generally, the feed is a mixture of hydrocarbon and oxygen which, on one hand, is beneficial for the catalyst regeneration but, on the other hand, can further oxidize the products to $\mathrm{CO}_{\mathrm{x}}$. For this reason many alternative oxidative agents have been investigated (i.e. $\mathrm{N}_{2} \mathrm{O}$, $\mathrm{H}_{2} \mathrm{O}_{2}$ and $\mathrm{CO}_{2}$ ) to accomplish less severe oxidative conditions, aiming to increase the yield. Another option to improve the selectivity is to use solid oxides as oxidant and promising results were achieved over V-based catalyst, i.e. $\mathrm{VPO}$ and $\mathrm{VO}_{\mathrm{x}} / \mathrm{TiO}_{2}$ catalysts. Clearly, the oxide is reduced when exposed to the hydrocarbons and the reactivity of the lattice oxygen varies with the change of composition and structure of the oxide. After exposure to hydrocarbon, the oxide needs to be regenerated via oxidation. This scheme is rather similar to the classical Mars - Van Krevelen mechanism, with the difference that, in this case, the oxidation and reduction steps are separated. This separation can be made in time, by using either moving bed technology or by switching between exposure to alkane and oxygen, respectively.

Another option is to separate the two steps in space by using a catalytic dense membrane reactor (CDMR). The membrane is exposed on one side to hydrocarbon and, on the other side, to molecular oxygen, generating oxygen lattice ions which permeate through the mixed conducting dense membrane. When arriving at the other side of the membrane, oxygen lattice ions are converted and removed by reaction with the alkane. By matching the oxygen permeability rate with the rate of conversion, oxygen recombination at the alkane side can be prevented. Consequently, oxygen and alkane are strictly separated at the two sides of membrane and conversion of alkane can proceed via oxygen lattice ions exclusively.

In this thesis the effect of the oxidation state of the catalyst, i.e. the oxygen content, on both reactivity of propane as well as the product slate, was studied by gradually removing oxygen, i.e. reducing the catalyst, by providing small propane pulses. By pulsing propane exclusively, lattice oxygen in the catalyst was the only oxidant present for the oxidative dehydrogenation, excluding the presence of adsorbed oxygen on the surface $\left(\mathrm{O}^{-}\right.$and $\left.\mathrm{O}_{2}{ }^{-}\right)$as well as gas phase oxygen $\left(\mathrm{O}_{2}\right)$.

It was shown in Chapter 3 that pulse experiments can be used as method to select materials for operation of catalytic dense membrane reactors for selective oxidation of propane, provided that $\mathrm{CO}_{2}$ formed is not adsorbed on the surface of the catalyst. Pulse experiments reveal the intrinsic activity and selectivity of lattice oxygen-ions 
in the mixed oxides. Within three model compounds chosen, which are $\mathrm{Ba}_{0.5} \mathrm{Sr}_{0.5} \mathrm{Co}_{0.8} \mathrm{Fe}_{0.2} \mathrm{O}_{3-\delta}(\mathrm{BSCF}), \mathrm{La}_{2} \mathrm{NiO}_{4+\delta}(\mathrm{LN})$ and $\mathrm{PrBaCo}_{2} \mathrm{O}_{5+\delta}(\mathrm{PBC}), \mathrm{LN}$ is the most promising material for membrane application, provided that it is operated in the right window of reduction degree, to ensure high selectivity towards $\mathrm{C}_{3} \mathrm{H}_{6}$. According to the pulse experiments $\mathrm{PBC}$ is not suitable, showing low selectivity to $\mathrm{C}_{3} \mathrm{H}_{6}$ due to significant formation of $\mathrm{CO}_{2}$, independently of the oxidation degree of the material. BSCF appears to adsorb $\mathrm{CO}_{2}$, forming carbonates. Therefore, pulse experiments fail to give reliable data on selectivity of BSCF in propane pulse experiments. However, pulse experiments revealed the remarkable stability of BSCF catalyst towards $\mathrm{CO}_{2}$. Despite the presence of carbonate, the material preserved the ability to act as an oxygen source for propane and can be completely regenerated via oxidation. Additionally, the reactivity of lattice oxygen ions (with propane) in the three materials clearly correlates with the onset temperature in TPR. It is recommended to investigate the tendency of $\mathrm{LN}$ and $\mathrm{PBC}$ to adsorb $\mathrm{CO}_{2}$ by forming carbonates, as reported for BSCF. TPD analysis on spent LN and PBC, following the possible release of $\mathrm{CO}_{2}$, can provide further information about possible adsorption of $\mathrm{CO}_{2}$, as no data are available in literature. Additionally, it is recommended to further investigate the variation of catalyst performance as function of carbonate accumulation on catalyst surface.

In the chapter 4 , reactivity and product distribution over $\mathrm{La}_{2} \mathrm{NiO}_{4+\delta}$ catalyst (LN) were compared with $\mathrm{La}_{2} \mathrm{Ni}_{0.9} \mathrm{~V}_{0.1} \mathrm{O}_{4.15+\delta}$ catalyst (LNV-10). It was shown that over the oxidized materials, too high activity of oxygen species was responsible for formation of deep oxidation products $\left(\mathrm{CO}_{2}\right.$ and $\left.\mathrm{H}_{2} \mathrm{O}\right)$ for both doped and un-doped materials, as also described in chapter 3 in case of LN. The scenario changed after partial removal of oxygen and consequent decrease of reactivity of the remaining oxygen species: $\mathrm{C}_{3} \mathrm{H}_{6}, \mathrm{C}_{2} \mathrm{H}_{4}, \mathrm{CH}_{4}$ and $\mathrm{H}_{2} \mathrm{O}$ were the only products detected with beneficial effect on selectivity to olefins. The presence of vanadium as dopant in $\mathrm{LN}$ enhances the material stability towards reduction in $\mathrm{H}_{2}$. The stabilization of over-stoichiometric oxygen positively affected the product distribution in pulse experiment, as less $\mathrm{CO}_{2}$ was produced (and less oxygen consumed), over preoxidized catalyst. Also the stability of lattice oxygen, bonded to $\mathrm{Ni}$ atoms, was influenced by the dopant. It was shown that the presence of $\mathrm{V}$ prevented the probable release of lattice oxygen and the consequent formation on $\mathrm{Ni}^{0}$. The formation on $\mathrm{Ni}^{0}$ is responsible for drastic detrimental change in product patterns ( $\mathrm{CO}, \mathrm{CH}_{4}$ and coke as products). Therefore, the $\mathrm{V}$-doped catalyst showed a much larger window (more than 30 propane pulses wide) in which the selectivity towards propylene was constant and promising, contrary to un-doped catalyst.

The effect of $\mathrm{V}$ on stabilizing the oxygen species was further described in chapter 5 at variable temperatures between 450 to $650{ }^{\circ} \mathrm{C}$. It was shown that overstoichiometric oxygen was the only active species in LNV-10, responsible for formation of $\mathrm{CO}_{2}, \mathrm{C}_{3} \mathrm{H}_{6}, \mathrm{C}_{2} \mathrm{H}_{4}$ and $\mathrm{CH}_{4}$ during pulse tests at all investigated 
temperatures. Contrary, in the case of $\mathrm{LN}$, the reactive species changed from overstoichiometric oxygen only at $450{ }^{\circ} \mathrm{C}$, to both over-stoichiometric and lattice oxygen at $550{ }^{\circ} \mathrm{C}$, in agreement with chapter 4 , to lattice oxygen only at $650{ }^{\circ} \mathrm{C}$. The activation of lattice oxygen and the consequent formation of $\mathrm{Ni}$ metal were detrimental for selectivity to propylene as formation of $\mathrm{CO}_{\mathrm{x}}, \mathrm{CH}_{4}$ and coke mainly occurred and no olefins were formed. Additionally, it was shown that the composition of both catalysts strongly depended on the pre-treatment condition as the removal of oxygen from the catalyst occurs from $200{ }^{\circ} \mathrm{C}$ onwards in inert atmosphere. The role of vanadium was crucial to stabilize both over-stoichiometric and lattice oxygen, retarding the oxygen loss and preventing the consequent formation of $\mathrm{Ni}$ metal, in the temperature range $450-650{ }^{\circ} \mathrm{C}$. We concluded therefore that the presence of vanadium in the catalyst was crucial to preserve overstoichiometric oxygen, which is the reactive specie responsible for propylene formation.

It is recommended to further characterize the spent catalyst, particularly $\mathrm{LN}$, in order to obtain additional evidence for $\mathrm{Ni}^{0}$ formation. In situ-XPS, Raman and IR spectroscopy will certainly help to further clarify the formation of $\mathrm{Ni}$ metal.

In chapter 6 the over-stoichiometry $(\delta)$ of LNV-10 at $550{ }^{\circ} \mathrm{C}$ was quantified and correlated to the catalyst performance. It was shown that when $\delta>0.03$ the main product is $\mathrm{CO}_{2}$, whereas selective conversion to propylene, ethylene and methane is achieved when $0.00<\delta<0.03$. Furthermore, oxidation-reduction cycles in propane and oxygen at $550{ }^{\circ} \mathrm{C}$ were reversible and the material was stable. Therefore, $\mathrm{La}_{2} \mathrm{Ni}_{0.9} \mathrm{~V}_{0.1} \mathrm{O}_{4.15+\delta}$ is in principle suitable for constructing a catalytic dense membrane reactor, under the condition that oxygen conversion and oxygen diffusion are tuned to maintain a $\delta$ value between 0.00 and 0.030 at the propane interface.

It is recommended to investigate the variation of over-stoichiometry of LNV-10 catalyst at temperatures between 450 and $650{ }^{\circ} \mathrm{C}$. In this way, an optimum operation temperature can be found based on (i) the catalyst performances described on chapter 5 and (ii) amount of reactive over-stoichiometric oxygen available in the catalyst at different temperatures.

In chapter 7, LN, LNV-10, $\mathrm{PBC}$ and $\mathrm{BSCF}$ were tested as catalytic dense membrane reactors for selective / oxidative dehydrogenation of propane in the temperature between 550 and $650{ }^{\circ} \mathrm{C}$. Despite a moderate conversion for most of them, it was shown that catalytic dense membrane should be operated at moderate temperature. In fact, a compromise between relatively high temperature, required to achieve significant oxygen permeability through the membrane and relatively low temperature, required to avoid that gas phase reaction dominates the overall conversion, should be found. Clearly, the optimum temperature varies from membrane type to membrane type. Additionally, it was suggested that it is crucial to 
match the oxygen ion permeation rate with the reaction rate to achieve steady-state operation.

It is recommended to perform a catalytic test over BSCF longer than $14 \mathrm{~h}$, in order to check the variation of the membrane performance due to formation of carbonates.

\subsection{General recommendations}

In this study it was shown that dense membranes can operate as oxygen suppliers for catalytic reactions. Unfortunately, we have not yet been able to balance the oxygen flux and the oxygen conversion rate because the permeation rate was higher than the reaction rate for most of the investigated membranes, Therefore, it is reasonable to assume that intermediate adsorbed oxygen species $\left(\mathrm{O}_{2}^{-}, \mathrm{O}_{2}{ }^{2-}\right.$, and $\left.\mathrm{O}^{-}\right)$ in the formation of $\mathrm{O}_{2}$ molecules were present and possibly responsible for $\mathrm{CO}_{2}$ formation, decreasing the selectivity. The fact that unconverted molecular $\mathrm{O}_{2}$ was detected in the product mixture in many cases, suggests that the reactivity of the membrane surface was not sufficient. Therefore we recommend to vary the composition of the membrane, in order to tune the reactivity and permeability of the membrane, aiming to increase the rate of propane conversion to olefins. In addition, as formation of explosive mixtures between $\mathrm{O}_{2}$ and hydrocarbons can occur, it is furthermore recommended to avoid the recombination of oxygen ions to molecular $\mathrm{O}_{2}$ in the reaction side.

It is recommended to study the membrane geometry as, in the case of the disc membrane described in this work, the contact between propane and membrane surface might not be optimal. In fact, it is possible that part of the feed was not converted simply because it did not interact with the membrane surface. We suggest that using a tubular membrane reactor, tuning length and the internal diameter, might be useful to increasing the contact time, i.e. increasing the propane conversion.

Different oxygen species showed different selectivities as propane conversion due to over-stoichiometric oxygen resulted in formation of $\mathrm{C}_{3} \mathrm{H}_{6}, \mathrm{C}_{2} \mathrm{H}_{4}$ and $\mathrm{CH}_{4}$ while reaction due to lattice oxygen resulted in formation of $\mathrm{CO}$ and $\mathrm{CH}_{4}$. An important issue regarding the over-stoichiometric oxygen is the ease of the removability at high temperature even during the pre-treatment in inert atmosphere, as shown for $\mathrm{LN}$ catalyst. Therefore it is recommended to use for CDMR application, $\mathrm{K}_{2} \mathrm{NiF}_{4}-$ type materials, similar to LNV-10, which possesses significant amount of overstoichiometric oxygen which are not removed during the pre-tretment. Furthermore, we recommend investigating the possibility to increase as much as possible the amount of over-stoichiometric oxygen in the membrane, since it has shown 
promising selectivity towards olefins. This can be achieved increasing the amount of vanadium as dopant and changing the composition of the membrane.

The reaction temperature is another important issue for CDMR application. Based on work presented in this thesis, we recommend operating CDMR at moderate temperature (suggested temperature between 500 and $600{ }^{\circ} \mathrm{C}$ ). In fact, it is common knowledge that oxygen ion permeation through dense membrane, using $\mathrm{He}$ as sweep gas, does not occur at temperature lower that $500^{\circ} \mathrm{C}$. On the other hand, high temperature which would enhance the oxygen permeability through the membrane, also enhances the reactivity of alkanes in gas phase rather than on the membrane surface, thus diminishing the contribution of the membrane to the selectivity. Clearly, a moderate reaction temperature is required to balance permeability and reactivity of the membrane. It should be note that using propane as reactant at the sweep side increases the gradient of oxygen partial pressure over the membrane $\left(\Delta \mathrm{pO}_{2}\right)$, thus, in principle, allowing oxygen permeation at temperatures lower than $500{ }^{\circ} \mathrm{C}$. Thus, we suggest that the membrane can operate at temperatures lower than $500{ }^{\circ} \mathrm{C}$ with beneficial effects on selectivity. 



\section{Summary}

The demand of propylene is expected to increase in the future because it is a crucial intermediate for many industrial processes. The simplest and most direct way to obtain propylene is dehydrogenation of propane, as shown in Eq. 1.

$\mathrm{C}_{3} \mathrm{H}_{8} \leftrightarrows \mathrm{C}_{3} \mathrm{H}_{6}+\mathrm{H}_{2}$

$$
\Delta \mathrm{H}=+156 \mathrm{KJ} / \mathrm{mol}
$$

Eq. 1

Catalytic dehydrogenation of propane using Cr- and Pt- supported catalysts was extensively studied in the past and several processes were commercialized by numerous companies such as Houdry, United Catalyst Inc., ABB Lummus Crest, UOP, Phillips Petroleum, Snamprogetti and Linde-BASF. Due to the high endothermicity of the reaction, high temperature is often required to increase the olefin yield. Unfortunately, operation at high temperature induces undesired cracking reactions, coke formation and consequent catalyst deactivation.

An alternative way for propylene production is oxidative dehydrogenation (ODH) of propane, as illustrated in Eq. 2.

$\mathrm{C}_{3} \mathrm{H}_{8}+\mathrm{O}_{2} \leftrightarrows \mathrm{C}_{3} \mathrm{H}_{6}+\mathrm{H}_{2} \mathrm{O} \quad \Delta \mathrm{H}=-86 \mathrm{KJ} / \mathrm{mol}$

Eq. 2

The high quantity of heat generated by water formation turns the overall ODH of propane into an exothermic reaction, which overcomes the thermodynamic limitation. On the other hand, deep oxidation of propane to $\mathrm{CO}_{2}$ is drastically decreasing the selectivity to olefins, due to the fact that olefins are more reactive than alkanes.

Many alternative oxidative agents were investigated (i.e. $\mathrm{N}_{2} \mathrm{O}, \mathrm{H}_{2} \mathrm{O}_{2}$ and $\mathrm{CO}_{2}$ ) to accomplish less severe oxidative conditions, aiming at increasing the yield. It was shown in literature that replacing pure $\mathrm{O}_{2}$ with $\mathrm{N}_{2} \mathrm{O} / \mathrm{O}_{2}$ mixture or $\mathrm{H}_{2} \mathrm{O}_{2}$ or $\mathrm{CO}_{2}$, higher selectivity to the desired products can be achieved in selective oxidation of propane.

Another option to improve the selectivity is to use solid oxides as oxidant. In this case, the reactivity of lattice oxygen can be tuned varying the catalyst composition, possibly affecting the product distribution. Consequently, the extent of deep oxidation can be limited with beneficial effect to olefins yield. Obviously, the oxide will be reduced when exposed to the hydrocarbons therefore, the material needs subsequently to be regenerated via oxidation. This scheme is rather similar to the classical Mars - Van Krevelen mechanism, with the difference that, in this case, the oxidation and reduction steps are separated. This separation can be made in time, by 
using either moving bed technology or by switching between exposure to alkane and oxygen, respectively. This is the case of phthalic anhydride production from oxylene, using $\mathrm{VO}_{\mathrm{x}} / \mathrm{TiO}_{2}$ catalyst or maleic anhydride production from n-butane over VPO catalyst in which double bed technology is required.

Another option is to separate the two steps in space by using a catalytic dense membrane reactor (CDMR). The membrane is exposed on one side to hydrocarbon and, on the other side, to molecular oxygen, generating oxygen lattice ions which permeate through the mixed conducting dense membrane. When arriving at the other side of the membrane, oxygen lattice ions are converted and removed by reaction with the alkane. By matching the oxygen permeability rate with the rate of conversion, oxygen recombination at the alkane side can be prevented. Consequently, oxygen and alkane are strictly separated at the two sides of membrane and conversion of alkane can proceed via oxygen lattice ions exclusively.

In this thesis the effect of the oxidation state of the catalyst, i.e. the oxygen content, on both reactivity of propane as well as the product slate, was studied by gradually removing oxygen, i.e. reducing the catalyst, by providing small propane pulses. By pulsing propane exclusively, lattice oxygen in the catalyst was the only oxidant present for the oxidative dehydrogenation, excluding the presence of adsorbed oxygen on the surface $\left(\mathrm{O}^{-}\right.$and $\left.\mathrm{O}_{2}{ }^{-}\right)$as well as gas phase oxygen $\left(\mathrm{O}_{2}\right)$.

In chapter 3, propane pulse experiments at $550{ }^{\circ} \mathrm{C}$ are used as a method to select suitable oxides for operation of catalytic dense membrane reactor (CDMR) for selective oxidation of propane. $\mathrm{Ba}_{0.5} \mathrm{Sr}_{0.5} \mathrm{Co}_{0.8} \mathrm{Fe}_{0.2} \mathrm{O}_{3-\delta}(\mathrm{BSCF}), \mathrm{La}_{2} \mathrm{NiO}_{4+\delta}(\mathrm{LN})$ and $\mathrm{PrBaCo}_{2} \mathrm{O}_{5+\delta}(\mathrm{PBC})$ powders were used as model catalysts to explore the catalytic properties of membrane surfaces in terms of activity and selectivity. Furthermore, as propane pulses induce variation of the oxidation degree by slowly reducing the oxide, crucial information on the effect of variation of the oxygen content (i.e. the oxidation degree) in the samples on reactivity and selectivity is obtained. It was shown that $\mathrm{LN}$ is the most promising material for membrane application, provided that it is operated in the optimal window of reduction degree, to ensure high selectivity towards $\mathrm{C}_{3} \mathrm{H}_{6}$. Contrary, $\mathrm{PBC}$ and $\mathrm{BSCF}$ are not suitable for CDMR. In fact, $\mathrm{PBC}$ showed low selectivity to $\mathrm{C}_{3} \mathrm{H}_{6}$ due to significant formation of $\mathrm{CO}_{2}$, independently of the oxidation degree of the material and BSCF appears to adsorb $\mathrm{CO}_{2}$ by forming carbonates, which might be detrimental for long term operation. However, pulse experiments revealed the remarkable stability of BSCF catalyst towards $\mathrm{CO}_{2}$. Despite the presence of carbonate, the material preserved the ability to act as an oxygen source for propane and can be completely regenerated via oxidation. Additionally, the onset temperature in TPR appears to correlate well with the reactivity of lattice oxygen ions with propane, for the three materials studied.

In chapter 4, non-stoichiometric redox compounds such as $\mathrm{La}_{2} \mathrm{NiO}_{4+\delta}$, $\mathrm{La}_{2} \mathrm{Ni}_{0.95} \mathrm{~V}_{0.05} \mathrm{O}_{4.07+\delta}$ and $\mathrm{La}_{2} \mathrm{Ni}_{0.9} \mathrm{~V}_{0.1} \mathrm{O}_{4.15+\delta}$ have been tested as oxidants in selective 
oxidation of propane, in order to judge the suitability of these materials for a densemembrane reactor for selective propane oxidation. Reducibility of the samples has been investigated using temperature programmed reduction in $\mathrm{H}_{2} / \mathrm{Ar}$ flow. The catalysts' activity and selectivity at $550{ }^{\circ} \mathrm{C}$ have been investigated employing sequential pulses of diluted propane over the oxides.

Pulsing with propane induces step-by-step reduction of the oxide; consequently, the activity of remaining oxygen decreases with the number of pulses, affecting the products distribution. It is observed that at $550{ }^{\circ} \mathrm{C}$ on oxidized catalysts $\mathrm{CO}_{2}$ and $\mathrm{H}_{2} \mathrm{O}$ are the main products and the selectivity towards propylene is very low. At a certain reduction level, obtained after pulse 8 in our experiments, the production of $\mathrm{CO}_{2}$ stopped without changing the amount of $\mathrm{C}_{3} \mathrm{H}_{6}$ produced. At this stage, also $\mathrm{CH}_{4}$ and $\mathrm{C}_{2} \mathrm{H}_{4}$ are being formed. V-doped catalysts have shown a constant level of $\mathrm{C}_{3} \mathrm{H}_{6}$ production within a broad window of oxidation degree, while the performance of $\mathrm{La}_{2} \mathrm{NiO}_{4+\delta}$, catalyst deteriorated drastically after just a few pulses. $\mathrm{CO}, \mathrm{CH}_{4}$ and coke deposits are formed with $\mathrm{La}_{2} \mathrm{NiO}_{4+\delta}$, caused by the formation of metallic $\mathrm{Ni}$. Vanadium is able to prevent this phenomenon, thus drastically broadening the window of selective oxidation of propane.

In chapter 5, $\mathrm{La}_{2} \mathrm{NiO}_{4+\delta}$ and $\mathrm{La}_{2} \mathrm{Ni}_{0.9} \mathrm{~V}_{0.1} \mathrm{O}_{4.15+\delta}$ have been tested in pulse experiments at temperatures between 450 and $650{ }^{\circ} \mathrm{C}$. The oxygen contents in the samples before and after pulsing propane at different temperatures were calculated based on TGA analysis and back titration with $\mathrm{O}_{2}$, respectively. In the case of $\mathrm{La}_{2} \mathrm{Ni}_{0.9} \mathrm{~V}_{0.1} \mathrm{O}_{4.15+\delta}$ over-stoichiometric oxygen was the only active species, responsible for formation of $\mathrm{CO}_{2}, \mathrm{C}_{3} \mathrm{H}_{6}, \mathrm{C}_{2} \mathrm{H}_{4}$ and $\mathrm{CH}_{4}$ while pulsing propane at all investigated temperatures. Contrary, the reactive species in $\mathrm{La}_{2} \mathrm{NiO}_{4+\delta}$ changed from over-stoichiometric oxygen only at $450{ }^{\circ} \mathrm{C}$, to both over-stoichiometric and lattice oxygen at $550{ }^{\circ} \mathrm{C}$, to lattice oxygen only at $650{ }^{\circ} \mathrm{C}$. The activation of lattice oxygen and the consequent formation of Ni metal were detrimental for selectivity to propylene as formation of $\mathrm{CO}_{\mathrm{x}}, \mathrm{CH}_{4}$ and coke mainly occurred and no olefins were formed.

In chapter $6, \mathrm{La}_{2} \mathrm{Ni}_{0.9} \mathrm{~V}_{0.1} \mathrm{O}_{4.15+\delta}$ has been tested as an oxidant in selective oxidation of propane in pulse experiments and the over-stoichiometric oxygen content was precisely quantified while pulsing propane. The extent of over-stoichiometry $(\delta)$ was varied via both removing oxygen with propane, as well as partial re-oxidation with oxygen. It was shown that olefins are formed whereas formation of $\mathrm{CO}_{2}$ is prevented provided that $\delta$ is below 0.03 . Additionally, the structural stability of the material was tested with in-situ X-ray diffraction in $\mathrm{H}_{2}\left(\mathrm{H}_{2}-\mathrm{XRD}\right)$, temperature programmed reduction (TPR), thermo-gravimetric analysis (TGA), propane-pulseexperiments and re-oxidation cycles. $\mathrm{La}_{2} \mathrm{Ni}_{0.9} \mathrm{~V}_{0.1} \mathrm{O}_{4.15+\delta}$ has demonstrated structure stability and reversibility during oxidation-reduction cycles at $550{ }^{\circ} \mathrm{C}$ and therefore 
considered suitable for catalytic dense membrane reactor provided that the degree of over-stoichiometry is limited to 0.03 at the surface exposed to propane.

In chapter $7, \quad \mathrm{PrBaCo}_{2} \mathrm{O}_{5+\delta}, \quad \mathrm{Ba}_{0.5} \mathrm{Sr}_{0.5} \mathrm{Co}_{0.8} \mathrm{Fe}_{0.2} \mathrm{O}_{3-\delta}, \quad \mathrm{La}_{2} \mathrm{NiO}_{4+\delta} \quad$ and $\mathrm{La}_{2} \mathrm{Ni}_{0.9} \mathrm{~V}_{0.1} \mathrm{O}_{4.15+\delta}$ dense membranes have been tested as oxygen supplier in selective oxidative dehydrogenation of propane. Unfortunately, as the permeation rate was higher than the reaction rate in the case of LN, BSCF and PBC, it was reasonable to assume that intermediate adsorbed oxygen species $\left(\mathrm{O}_{2}{ }^{-}, \mathrm{O}_{2}{ }^{2-}\right.$, and $\left.\mathrm{O}^{-}\right)$, which subsequently formed molecular $\mathrm{O}_{2}$, were present and possibly responsible for $\mathrm{CO}_{2}$ formation, decreasing the selectivity. In the case of LNV-10, no unconverted molecular $\mathrm{O}_{2}$ was detected in the product mixture, suggesting that exclusively active $\mathrm{O}^{2-}$ lattice oxygen was present as oxidant. Unfortunately, the contribution of the LNV-10 membrane on converting propane was very small although it showed higher yield to olefins at $550{ }^{\circ} \mathrm{C}$. Interestingly, BSCF enhanced the selectivity to $\mathrm{C}_{2} \mathrm{H}_{4}$ and $\mathrm{CH}_{4}$, as compared to operation in gas phase. Increasing the temperature, the contribution of the membranes to the reaction progressively decreased and the gas phase reaction gradually dominated. 


\section{Samenvatting}

Naar verwachting zal de vraag naar propyleen in de toekomst toenemen, omdat het een belangrijk intermediair is in veel industriële processen. De dehydrogenering van propaan is de meest eenvoudige en directe manier om propyleen te maken:
$\mathrm{C}_{3} \mathrm{H}_{8} \leftrightarrows \mathrm{C}_{3} \mathrm{H}_{6}+\mathrm{H}_{2}$
$\Delta \mathrm{H}=+156 \mathrm{KJ} / \mathrm{mol}$

De katalytische dehydrogenering van propaan met behulp van gedragen Cr- en Ptkatalysatoren is in het verleden uitgebreid bestudeerd en verscheidene processen zijn gecommercialiseerd door bedrijven als Houdry, United Catalyst Inc., ABB Lummus Crest, UOP, Phillips Petroleum, Snamprogetti and Linde-BASF. Omdat de reactie sterk endotherm is, zijn hoge temperaturen nodig om de propyleenopbrengst te verhogen. Door de hoge procestemperatuur treden echter ongewenste kraakreacties op, waardoor koolvorming ontstaat en de katalysator deactiveert.

Een alternatieve manier om propyleen te maken is de oxidatieve dehydrogenering $(\mathrm{ODH})$ van propaan:

$$
\mathrm{C}_{3} \mathrm{H}_{8}+\mathrm{O}_{2} \leftrightarrows \mathrm{C}_{3} \mathrm{H}_{6}+\mathrm{H}_{2} \mathrm{O} \quad \Delta \mathrm{H}=-86 \mathrm{KJ} / \mathrm{mol}
$$

De vorming van water bij deze reactie genereert zoveel warmte dat de overall ODH van propaan exotherm is, waarmee de thermodynamische barrière verdwijnt. Maar aangezien olefines reactiever voor $\mathrm{O}_{2}$ zijn dan alkanen, verlaagt dooroxidatie naar $\mathrm{CO}_{2}$ drastisch de opbrengst van olefines. Verschillende oxidatoren zijn onderzocht (i.e. $\mathrm{N}_{2} \mathrm{O}, \mathrm{H}_{2} \mathrm{O}_{2}$ and $\mathrm{CO}_{2}$ ) om hogere productopbrengsten te krijgen bij minder sterke oxidatieve condities. $\mathrm{Zo}$ is er in de literatuur gerapporteerd dat het vervangen van pure $\mathrm{O}_{2}$ door een mengsel van $\mathrm{N}_{2} \mathrm{O} / \mathrm{O}_{2}$ of $\mathrm{H}_{2} \mathrm{O}_{2}$ of $\mathrm{CO}_{2}$ de selectiviteit naar het gewenste product verhoogt in het geval van de selectieve oxidatie van propaan.

Een andere manier om de selectiviteit te verbeteren is het gebruik van vaste oxidische materialen als oxidant. Bij deze materialen kan de reactiviteit van het roosterzuurstof aangepast worden door de katalysatorsamenstelling te variëren, waarmee de productverdeling van de oxidatiereactie beïnvloed zou kunnen worden. Als gevolg hiervan kan de dooroxidatie beperkt worden met een positief effect op de olefineopbrengst. Natuurlijk wordt het oxidische materiaal gereduceerd wanneer het blootgesteld wordt aan koolwaterstoffen en het zal dus geregenereerd moeten worden door middel van oxidatie. Deze reactiestappen lijken op het klassieke Mars - Van Krevelen mechanisme met het verschil dat de oxidatie en reductiestappen gescheiden zijn. De scheiding kan in de tijd uitgevoerd worden door de zogeheten 
moving-bed-technologie of door te schakelen tussen koolwaterstof en zuurstof. Dit is bijvoorbeeld het geval bij de productie van phtaalzuuranhydride uit o-xyleen met behulp van een $\mathrm{VO}_{\mathrm{x}} / \mathrm{TiO}_{2}$ katalysator en bij de productie van maleïnezuuranhydride uit n-butaan met behulp van een VPO katalysator, waarbij gebruik wordt gemaakt van de zogeheten double-bed-technologie.

Een andere mogelijkheid voor het scheiden van de oxidatie- en reductiestap is het gebruik van een dicht-katalytisch-membraan-reactor (Catalytic dense membrane reactor - CDMR). Het membraan wordt aan de ene kant blootgesteld aan de koolwaterstof, terwijl gelijkertijd aan de andere kant $\mathrm{O}_{2}$ wordt gegeven waarmee roosterzuurstofionen worden gegenereerd die diffunderen door het zuurstofiongeleidende dichte membraan. Aan de koolwaterstofkant worden de zuurstofionen verwijderd door reactie met de koolwaterstof. Door de zuurstofion-diffusiesnelheid aan te passen aan de omzettingsnelheid kan zuurstofrecombinatie (resulterend in $\mathrm{O}_{2}$ ) aan de koolwaterstofkant voorkomen worden. Op deze manier zijn zuurstof en koolwaterstof strikt gescheiden door het membraan en vindt omzetting van het alkaan alleen plaats via de aanvoer van roosterzuurstofionen.

In dit proefschrift is het effect onderzocht van de oxidatietoestand van de katalysator, i.e. de hoeveelheid roosterzuurstof, op de reactiviteit van propaan en de productverdeling door het geleidelijk verwijderen van zuurstof, i.e. reductie van de katalysator, met kleine propaanpulsen. Hierbij wordt de aanwezigheid van geadsorbeerd zuurstof op het oppervlak $\left(\mathrm{O}^{-}\right.$en $\left.\mathrm{O}_{2}{ }^{-}\right)$en gasfase zuurstof $\left(\mathrm{O}_{2}\right)$ uitgesloten, waardoor alleen de aanwezige roosterzuurstof als oxidant kan fungeren in de reactie.

In hoofdstuk 3 worden de resultaten beschreven van propaanpulsexperimenten bij $550^{\circ} \mathrm{C}$ als methode voor het selecteren van geschikte oxidische materialen voor de selectieve oxidatie van propaan in CDMR. $\mathrm{Ba}_{0.5} \mathrm{Sr}_{0.5} \mathrm{Co}_{0.8} \mathrm{Fe}_{0.2} \mathrm{O}_{3-\delta}$ (BSCF), $\mathrm{La}_{2} \mathrm{NiO}_{4+\delta}$ (LN) en $\mathrm{PrBaCo}_{2} \mathrm{O}_{5+\delta}$ (PBC) poeders zijn als modelkatalysatoren gebruikt om de katalytische activiteit en selectiviteit van membraanoppervlakken te onderzoeken. Aangezien de propaanpulsen een variatie in oxidatiegraad veroorzaken door de geleidelijke reductie van het oxide wordt ook belangrijke informatie verkregen over het effect van het zuurstofgehalte (i.e. oxidatiegraad) van het materiaal op de reactiviteit en selectiviteit. Uit de experimenten is gebleken dat $\mathrm{LN}$ het meest veelbelovende materiaal is om toegepast te worden als membraan voor hoge selectiviteit naar propyleen, mits de reactie uitgevoerd wordt in het optimale venster van oxidatiegraad.

Er is echter ook gebleken dat PBC en BSCF niet geschikt zijn voor CDMR. PBC gaf een lage selectiviteit naar propyleen door significante $\mathrm{CO}_{2}$ productie onafhankelijk van de oxidatiegraad van het materiaal. BSCF bleek $\mathrm{CO}_{2}$ te adsorberen in de vorm van carbonaten wat voor het membraan bij langdurige continue operatie schadelijk zal zijn. Onder pulscondities bleek echter een opmerkelijke stabiliteit van de $\mathrm{BSCF}$ katalysator voor $\mathrm{CO}_{2}$. Ondanks de 
aanwezigheid van carbonaten bleef het materiaal actief als zuurstofbron voor propaanoxidatie en kon het compleet geregenereerd worden.

Als laatste is gebleken dat de on-set temperatuur in temperatuur-geprogrammeerdereductie experimenten in $\mathrm{H}_{2} / \mathrm{Ar}$ (Temperature Programmed Reduction - TPR) goed correleerde met de reactiviteit van het roosterzuurstof met propaan voor alle drie de bestudeerde materialen.

In hoofdstuk 4 worden de experimenten beschreven aan niet-stoichiometrische redoxmaterialen zoals $\mathrm{La}_{2} \mathrm{NiO}_{4+\delta}, \mathrm{La}_{2} \mathrm{Ni}_{0.95} \mathrm{~V}_{0.05} \mathrm{O}_{4.07+\delta}$ en $\mathrm{La}_{2} \mathrm{Ni}_{0.9} \mathrm{~V}_{0.1} \mathrm{O}_{4.15+\delta}$. Deze materialen zijn getest als oxidator in de selectieve oxidatie van propaan om te bepalen of ze toepasbaar zijn in CDMR. De reduceerbaarheid van de materialen is onderzocht met TPR. De katalytische activiteit van de oxides is onderzocht met propaan pulsexperimenten bij $550^{\circ} \mathrm{C}$. Bij $550^{\circ} \mathrm{C}$ produceerden de geoxideerde materialen voornamelijk $\mathrm{CO}_{2}$ en $\mathrm{H}_{2} \mathrm{O}$ en de selectiviteit naar propyleen was erg laag. De $\mathrm{CO}_{2}$ productie stopte echter bij een bepaalde reductiegraad, in onze experimenten na puls 8 , zonder de propyleenproductie te beïnvloeden; tegelijkertijd werden ook $\mathrm{CH}_{4}$ en $\mathrm{C}_{2} \mathrm{H}_{4}$ gevormd. De V-gemodificeerde katalysatoren toonden een constante productie van propyleen in een breed venster van reductiegraad, terwijl $\mathrm{La}_{2} \mathrm{NiO}_{4+\delta}$ na enkele pulsen al dramatisch slechter werd. De vorming van metallisch $\mathrm{Ni}$ veroorzaakte de productie van $\mathrm{CO}, \mathrm{CH}_{4}$ en koolstof op $\mathrm{La}_{2} \mathrm{NiO}_{4+\delta}$. Vanadium bleekt dit fenomeen te voorkomen, daarmee het venster van selectieve oxidatie van propaan sterk verbredend.

In hoofdstuk 5 zijn $\mathrm{La}_{2} \mathrm{NiO}_{4+\delta}$ and $\mathrm{La}_{2} \mathrm{Ni}_{0.9} \mathrm{~V}_{0.1} \mathrm{O}_{4.15+\delta}$ getest met pulsexperimenten tussen $450^{\circ} \mathrm{C}$ en $650^{\circ} \mathrm{C}$. De zuurstofgehaltes van de materialen is bepaald voor en na de propaanpulsen bij verschillende temperaturen gebaseerd op respectievelijk thermogravische analyse (TGA) en terugtitratie met $\mathrm{O}_{2}$. Voor $\mathrm{La}_{2} \mathrm{Ni}_{0.9} \mathrm{~V}_{0.1} \mathrm{O}_{4.15+\delta}$ bleek alleen de over-stoichiometrische zuurstof $(\delta)$ actief te zijn en werden $\mathrm{CO}_{2}$, $\mathrm{C}_{3} \mathrm{H}_{6}, \mathrm{C}_{2} \mathrm{H}_{4}$ en $\mathrm{CH}_{4}$ gevormd tijdens de propaanpulsen bij alle temperaturen. In $\mathrm{La}_{2} \mathrm{NiO}_{4+\delta}$ daarentegen, veranderde de reactieve zuurstof van enkel overstoichiometrisch bij $450^{\circ} \mathrm{C}$, via zowel over-stoichiometrisch als roosterzuurstof bij $550^{\circ} \mathrm{C}$, naar enkel roosterzuurstof bij $650^{\circ} \mathrm{C}$. De activering van roosterzuurstof en de Ni-vorming die daaruit volgde, verlaagde de selectiviteit naar propyleen dramatisch, omdat alleen nog $\mathrm{CO}_{\mathrm{x}}, \mathrm{CH}_{4}$ en koolstof werden geproduceerd.

In Hoofdstuk 6 is $\mathrm{La}_{2} \mathrm{Ni}_{0.9} \mathrm{~V}_{0.1} \mathrm{O}_{4.15+\delta}$ als oxidant onderzocht en de hoeveelheid overstoichiometrisch zuurstof is precies bepaald tijdens de propaanpulsexperimenten. De hoeveelheid over-stoichiometrisch zuurstof $(\delta)$ werd gevarieerd door zowel zuurstof te verwijderen met propaan als ook door gedeeltelijk re-oxidatie met zuurstof. Het bleek dat olefines vormden en $\mathrm{CO}_{2}$ werd voorkomen zolang $\delta$ kleiner was dan 0.03 . Verder is de stabiliteit van de kristalstructuur van het materiaal onderzocht met in-situ röntgen diffractie in $\mathrm{H}_{2}$, TPR, TGA, 
propaanpulsexperimenten en re-oxidatie cycli. $\mathrm{La}_{2} \mathrm{Ni}_{0.9} \mathrm{~V}_{0.1} \mathrm{O}_{4.15+\delta}$ bleek stabiel te zijn en reversibele redoxeigenschappen te hebben tijdens oxidatie-reductie cycli bij $550{ }^{\circ} \mathrm{C}$ en wordt daarom beschouwd als geschikt materiaal voor CDMR mits $\delta$ kleiner is dan 0.03 op het oppervlak dat wordt blootgesteld aan propaan.

In hoofdstuk 7 zijn $\mathrm{PrBaCo}_{2} \mathrm{O}_{5+\delta}(\mathrm{PBC}), \mathrm{Ba}_{0.5} \mathrm{Sr}_{0.5} \mathrm{Co}_{0.8} \mathrm{Fe}_{0.2} \mathrm{O}_{3-\delta}(\mathrm{BSCF}), \mathrm{La}_{2} \mathrm{NiO}_{4+\delta}$ (LN) en $\mathrm{La}_{2} \mathrm{Ni}_{0.9} \mathrm{~V}_{0.1} \mathrm{O}_{4.15+\delta}$ (LNV-10) dichte membranen getest als zuurstofbron voor de selectieve oxidatie van propaan. In het geval van LN, BSCF en PBC was de zuurstofiondiffusiesnelheid hoger dan de reactiesnelheid, wat tot de conclusie leidde dat zuurstofionen als $\mathrm{O}_{2}^{-}, \mathrm{O}_{2}{ }^{2-}$, en $\mathrm{O}^{-}$op het oppervlak recombineerden naar waargenomen $\mathrm{O}_{2}$, dat leidde tot de productie van $\mathrm{CO}_{2}$ en dus een lagere selectiviteit naar olefine.

Voor LNV-10 werd geen moleculair $\mathrm{O}_{2}$ aangetroffen in het productmengsel, suggererend dat alleen $\mathrm{O}^{2-}$ roosterzuurstof actief was als oxidator. Helaas was de conversie van propaan over LNV-10 erg laag, terwijl het materiaal een hogere olefineopbrengst gaf bij $550{ }^{\circ} \mathrm{C}$. Interessant was de waarneming dat BSCF een verhoogde selectiviteit naar $\mathrm{C}_{2} \mathrm{H}_{4}$ en $\mathrm{CH}_{4}$ gaf vergeleken met de gasfasereactie. Met toenemende temperatuur nam de bijdrage van de membranen aan de reactie steeds meer af en domineerde de gasfasereactie uiteindelijk. 


\section{Riassunto}

La richiesta di propilene è in continuo aumento dal momento che e' un componente primario in parecchi processi industriali. La maniera più semplice e diretta di ottenere il propilene è la deidrogenazione del propano, come mostrato dall'Eq. 1 .
$\mathrm{C}_{3} \mathrm{H}_{8} \leftrightarrows \mathrm{C}_{3} \mathrm{H}_{6}+\mathrm{H}_{2}$
$\Delta \mathrm{H}=+156 \mathrm{KJ} / \mathrm{mol}$
Eq. 1

La deidrogenazione catalitica del propano utilizzando catalizzatori supportati a base di $\mathrm{Cr}$ e Pt è stata ampiamente studiata in passato e molti processi sono stati commercializzati da numerose compagnie petrol-chimiche quali la Houdry, la United Catalyst Inc., la ABB Lummus Crest, la UOP, la Phillips Petroleum, la Snamprogetti e la Linde-BASF. A causa dell'elevata endotermicità del processo, alte temperature di reazione sono spesso necessarie per aumentare la produzione di olefine. Purtroppo, i processi ad alta temperatura inducono reazioni secondarie non desiderate quali cracking e formazione di coke, provocando una conseguente disattivazione del catalizzatore.

Una maniera alternativa di produrre propilene è la deidrogenazione ossidativa (ODH) del propano, come mostrato nell'Eq. 2.

$\mathrm{C}_{3} \mathrm{H}_{8}+\mathrm{O}_{2} \leftrightarrows \mathrm{C}_{3} \mathrm{H}_{6}+\mathrm{H}_{2} \mathrm{O} \quad \Delta \mathrm{H}=-86 \mathrm{KJ} / \mathrm{mol}$

Eq. 2

La grande quantità di calore generata dalla formazione di acqua rende la reazione esotermica, eliminando di conseguenza le limitazioni termodinamiche del processo. Contrariamente, la completa ossidazione del propano a $\mathrm{CO}_{2}$ diminuisce drasticamente la selettività a olefine, a causa della maggior reattività di queste ultime rispetto alle paraffine, delle quali il propano fa parte.

Agenti ossidanti quali, per esempio, $\mathrm{N}_{2} \mathrm{O}, \mathrm{H}_{2} \mathrm{O}_{2}$ e $\mathrm{CO}_{2}$, sono stati studiati come alternative all'ossigeno molecolare $\left(\mathrm{O}_{2}\right)$ puntando ad ottenere condizioni ossidative meno severe, con lo scopo di aumentare la produzione di olefine. In alcuni casi, l'efficacia di tali ossidanti alternativi è stata dimostrata in letteratura.

Un'altra possibilità per migliorare la selettività del processo è l'utilizzo di ossidi solidi come ossidanti. In questo caso, la reattività dell'ossigeno reticolare può essere modificata variando la composizione del catalizzatore, influenzando di conseguenza la distribuzione dei prodotti. In aggiunta, l'ossidazione completa del propano a $\mathrm{CO}_{2}$ è così limitata, influenzando positivamente la formazione di olefine. Ovviamente l'ossido andrà in contro ad un processo di riduzione a causa dell'esposizione agli idrocarburi, e di conseguenza, il materiale avrà bisogno di essere rigenerato tramite susseguente ossidazione. Questo schema è parecchio simile al classico meccanismo 
di Mars - Van Krevelen, con la differenza che, in questo caso, l'ossidazione e la riduzione non sono simultanee, ma avvengono in due fasi separate. Le due fasi del processo vengono eseguite all'interno di reattori a letto mobile o tramite esposizione variabile del catalizzatore ad atmosfere ossidative (ossigeno) o riduttive (idrocarburi). Questo è il caso della produzione dell' anidride ftalica partendo dall'oxylene, utilizzando $\mathrm{VO}_{\mathrm{x}} / \mathrm{TiO}_{2}$ come catalizzatore oppure il caso della produzione di anidride maleica partendo dal n-butano, utilizzando VPO come catalizzatore.

Un'ulteriore possibilità è quella di separare fisicamente le due fasi (ossidazione e riduzione), utilizzando una membrana catalitica densa (catalytic dense membrane reactor, CDMR). La membrana è esposta da un lato agli idrocarburi e dall' altro lato ad ossigeno molecolare. L'interazione tra l'ossigeno molecolare e la membrana genera ioni, i quali permeano attraverso la membrana densa che così agisce da conduttore ionico. Una volta giunti sul lato opposto della membrana, gli ioni ossigeno possono interagire con il propano e venir convertiti. Uguagliando la velocità di permeazione degli ioni ossigeno con la velocità di reazione, responsabile della loro estrazione dalla membrana, la ricombinazione degli ioni a ossigeno molecolare può essere evitata. Di conseguenza, l'ossigeno molecolare e il propano non vengono mai a contatto, essendo rigorosamente confinati ai due lati della membrana, e la conversione dell'idrocarburo è dovuta esclusivamente ad ossigeno ionico (ossigeno reticolare).

In questa tesi si analizza l'effetto della variazione dello stato di ossidazione del catalizzatore sulla reattività del propano e sulla conseguente distribuzione dei prodotti. Lo stato di ossidazione, leggisi il contenuto di ossigeno nel catalizzatore, viene variato gradualmente pulsando minime quantità di propano, responsabili della progressiva rimozione di ossigeno. Pulsando esclusivamente propano, si garantisce l'unicità dell'ossigeno reticolare come specie ossidante, escludendo così la presenza di specie adsorbite sulla superficie quali $\mathrm{O}^{-}$e $\mathrm{O}_{2}^{-}$, o la presenza di ossigeno molecolare in fase gassosa $\left(\mathrm{O}_{2}\right)$.

Nel Capitolo 3 esperimenti in cui il propano viene pulsato alla temperature di 550 ${ }^{\circ} \mathrm{C}$ sono utilizzati per testare e selezionare differenti ossidi metallici, adatti ad essere utilizzati come membrane catalitiche dense. $\mathrm{Ba}_{0.5} \mathrm{Sr}_{0.5} \mathrm{Co}_{0.8} \mathrm{Fe}_{0.2} \mathrm{O}_{3-\delta}$ (BSCF), $\mathrm{La}_{2} \mathrm{NiO}_{4+\delta}(\mathrm{LN})$ e $\mathrm{PrBaCo}_{2} \mathrm{O}_{5+\delta}$ (PBC) sono utilizzati come modelli per esplorare le proprietà catalitiche della superficie della membrana, in termini di attività e selettività. In aggiunta, questo capitolo fornisce informazioni fondamentali sul cambiamento della reattività e della selettività di tali materiali in funzione della variazione del contenuto di ossigeno al loro interno (stato di ossidazione). Nel capitolo 3 viene mostrato che LN può essere utilizzato come membrana catalitica (CDMR) purché operi all'interno di una specifica finestra di riduzione al fine di garantire un'elevata selettività verso il $\mathrm{C}_{3} \mathrm{H}_{6}$. $\mathrm{Al}$ contrario, $\mathrm{PBC}$ e BSCF non sono adatti ad essere utilizzati come CDMR. Infatti, (i) $\mathrm{PBC}$ mostra una bassa selettività verso il $\mathrm{C}_{3} \mathrm{H}_{6}$, dovuta alla elevata formazione di $\mathrm{CO}_{2}$, indipendentemente dal livello di riduzione del materiale, e (ii) $\mathrm{BSCF}$ sembrerebbe interagire con la $\mathrm{CO}_{2}$ prodotta, 
formando carbonati sulla superficie, i quali si potrebbero rivelare, a lungo termine, dannosi per il processo in modalità "steady-state". Tuttavia, gli esperimenti di "pulse" rivelano la notevole stabilità di BSCF nei confronti della $\mathrm{CO}_{2}$ : nonostante la formazione di carbonati in superficie, il materiale (i) mantiene l'abilita' di agire come fonte di ossigeno per la reazione e (ii) mostra reversibilità verso la rigenerazione ossidativa dei siti attivi. In aggiunta, la temperatura iniziale di riduzione nell'analisi in rampa di temperatura (temperature programmed reduction, TPR) per tutti e tre i materiali studiati è univocamente correlata alla reattività degli ossigeni reticolari.

Nel Capitolo 4, composti redox non stechiometrici quali $\mathrm{La}_{2} \mathrm{NiO}_{4+\delta}$ (LN), $\mathrm{La}_{2} \mathrm{Ni}_{0.95} \mathrm{~V}_{0.05} \mathrm{O}_{4.07+\delta}(\mathrm{LNV}-05)$ e $\mathrm{La}_{2} \mathrm{Ni}_{0.9} \mathrm{~V}_{0.1} \mathrm{O}_{4.15+\delta}(\mathrm{LNV}-10)$ sono studiati come ossidanti nell'ossidazione selettiva del propano. In aggiunta, anche in questo caso, viene valutata l'applicabilità dei suddetti materiali come membrane catalitiche dense. La riducibilità dei campioni è studiata utilizzando l'analisi TPR a $800{ }^{\circ} \mathrm{C}$, flussando una miscela di $\mathrm{H}_{2} \mathrm{e} \mathrm{Ar}$ mentre l'attività e la selettività sono analizzate tramite "pulse" sequenziali di propano diluito a $550{ }^{\circ} \mathrm{C}$. Tali "pulse" provocano una graduale riduzione dell'ossido e, di conseguenza, l'attività' degli ossigeni reticolari rimasti all'interno del materiale decresce progressivamente, influenzando la distribuzione dei prodotti. In questo capitolo viene riportato che $\mathrm{CO}_{2}$ e $\mathrm{H}_{2} \mathrm{O}$ sono $\mathrm{i}$ principali prodotti quando il catalizzatore è ossidato, con conseguente bassa selettività verso il propilene. Ad uno specifico grado di riduzione del materiale, ottenuto, nel nostro esperimento, dopo l'ottavo "pulse", la produzione di $\mathrm{CO}_{2}$ cessa mentre la formazione di $\mathrm{C}_{3} \mathrm{H}_{6}$ rimane costante. In questa fase si formano anche $\mathrm{CH}_{4}$ $\mathrm{e}_{2} \mathrm{H}_{4}$. I catalizzatori dopati con il vanadio mostrano una produzione costante di $\mathrm{C}_{3} \mathrm{H}_{6}$ all'interno di un' ampia finestra di riduzione mentre la formazione di $\mathrm{C}_{3} \mathrm{H}_{6}$ nel caso di $\mathrm{La}_{2} \mathrm{NiO}_{4+\delta}$ diminuisce drasticamente dopo pochi "pulse". In seguito, $\mathrm{CO}$, $\mathrm{CH}_{4}$ e coke (differenti specie carboniose) vengono rilevati come principali prodotti, probabilmente a causa della formazione di Ni metallico sulla superficie dell'ossido $\mathrm{La}_{2} \mathrm{NiO}_{4+\delta}$. In conclusione, si afferma che il vanadio è in grado di prevenire tale fenomeno, allargando di conseguenza la finestra di riducibilità all'interno della quale il materiale si dimostra selettivo verso il propilene.

Nel Capitolo 5, i catalizzatori $\mathrm{La}_{2} \mathrm{NiO}_{4+\delta}$ e $\mathrm{La}_{2} \mathrm{Ni}_{0.9} \mathrm{~V}_{0.1} \mathrm{O}_{4.15+\delta}$ sono testati tramite esperimenti di "pulse" di propano a temperatura variabile tra 450 e $650{ }^{\circ} \mathrm{C}$. Il contenuto di ossigeno all'interno dei catalizzatori è calcolato tramite analisi termogravimetriche (thermo-gravimetric analysis, TGA) e tramite titolazione ossidativa, prima e dopo gli esperimenti di "pulse". Nel caso del catalizzatore $\mathrm{La}_{2} \mathrm{Ni}_{0.9} \mathrm{~V}_{0.1} \mathrm{O}_{4.15+\delta}$, l'ossigeno non-stechiometrico $(\delta)$ e' l'unica specie attiva, responsabile della formazione di $\mathrm{CO}_{2}, \mathrm{C}_{3} \mathrm{H}_{6}, \mathrm{C}_{2} \mathrm{H}_{4}$ e $\mathrm{CH}_{4}$, all'interno dell'intero intervallo di temperatura. $\mathrm{Al}$ contrario, nel caso del catalizzatore $\mathrm{La}_{2} \mathrm{NiO}_{4+\delta}$, le specie attive cambiano con la temperatura. L'ossigeno over-stechiometrico è l'unica 
specie attiva esclusivamente a $450{ }^{\circ} \mathrm{C}$ mentre l'ossigeno reticolare è l'unica specie attiva a $650{ }^{\circ} \mathrm{C}$. Alla temperatura intermedia di $550{ }^{\circ} \mathrm{C}$, entrambe le specie contribuiscono al processo. Viene dimostrato che l'attivazione dell'ossigeno reticolare, e la conseguente formazione di Ni metallico, è dannosa per la selettività a propilene, dal momento che tale specie metallica induce esclusivamente la formazione di $\mathrm{CO}_{\mathrm{x}}, \mathrm{CH}_{4}$ e coke, azzerando la produzione di olefine.

Nel capitolo 6, la variazione dell' ossigeno non-stechiometrico $(\delta)$ del catalizzatore $\mathrm{La}_{2} \mathrm{Ni}_{0.9} \mathrm{~V}_{0.1} \mathrm{O}_{4.15+\delta}$ durante gli esperimenti di "pulse" di propano è stata accuratamente quantificata. La quantità di ossigeno non-stechiometrico viene variata in due modi: (i) pulsando minime quantità di propano e (ii) ri-ossidando parzialmente con ossigeno il catalizzatore ridotto. In questo capitolo si dimostra che le olefine sono prodotte senza alcuna formazione di $\mathrm{CO}_{2}$ esclusivamente per valori di $\delta$ inferiori a 0.03 . In aggiunta, è provata la stabilità strutturale e la reversibilità verso cicli di ossidazione - riduzione del catalizzatore tramite: (i) diffrazione di raggi $\mathrm{X}$ in-situ in atmosfera di $\mathrm{H}_{2}$ (X-ray diffraction in $\mathrm{H}_{2}, \mathrm{H}_{2}-\mathrm{XRD}$ ), (ii) TPR, (iii) TGA, (iv) esperimenti di pulse di propano e (v) cicli di ossidazione - riduzione. Di conseguenza, il catalizzatore è considerato adatto ad essere utilizzato come membrana catalitica densa purché il valore di ossigeno non-stechiometrico sia inferiore a 0.03 .

Nel capitolo 7, vengono effettuati test catalitici in modalità "steady-state" su membrane dense quali $\mathrm{PrBaCo}_{2} \mathrm{O}_{5+\delta}$ (PBC), $\mathrm{Ba}_{0.5} \mathrm{Sr}_{0.5} \mathrm{Co}_{0.8} \mathrm{Fe}_{0.2} \mathrm{O}_{3-\delta}$ (BSCF), $\mathrm{La}_{2} \mathrm{NiO}_{4+\delta}(\mathrm{LN})$ e $\mathrm{La}_{2} \mathrm{Ni}_{0.9} \mathrm{~V}_{0.1} \mathrm{O}_{4.15+\delta}$ (LNV-10) e tali materiali sono testati quali fonti di ossigeno nella deidrogenazione ossidativa del propano. Nel caso di LN, $\mathrm{BSCF}$ e $\mathrm{PBC}$, è riscontrato che la velocità di permeazione degli ioni ossigeno attraverso la membrana è maggiore della velocità di reazione con il propano, poiché ossigeno molecolare $\left(\mathrm{O}_{2}\right)$ è presente tra i prodotti di reazione. Di conseguenza, è ragionevole assumere che specie intermedie di ossigeno adsorbite sulla superficie $\left(\mathrm{O}_{2}^{-}, \mathrm{O}_{2}{ }^{2-}, \mathrm{e} \mathrm{O}^{-}\right)$, precursori della formazione di ossigeno molecolare, possano essere responsabili della produzione di $\mathrm{CO}_{2}$, con conseguente diminuzione della selettività ad olefine. Al contrario, nel caso della membrana LNV-10, l'ossigeno molecolare non è rilevato tra i prodotti di reazione, suggerendo che l'unica specie ossidante presente sia l'ossigeno reticolare $\left(\mathrm{O}^{2-}\right)$. Purtroppo, il contributo della membrana LNV-10 alla conversione del propano è minimo, benché la quantità di olefine prodotte a $550^{\circ} \mathrm{C}$ è molto alta. $\mathrm{E}$ ' interessante notare che, nel caso della membrana BSCF, la selettività verso $\mathrm{C}_{2} \mathrm{H}_{4}$ e $\mathrm{CH}_{4}$ è maggiore rispetto alla selettività in fase gassosa. Aumentando la temperatura, il contributo della membrana diminuisce progressivamente e la reazione in fase gassosa gradualmente diventa predominante. 


\section{Publications}

Effect of $\mathrm{V}$ in $\mathrm{La}_{2} \mathrm{Ni}_{X} \mathrm{~V}_{l_{-X}} \mathrm{O}_{4+\delta}$ on selective oxidative dehydrogenation of propane S. Crapanzano, I.V. Babich and L. Lefferts

Applied Catalysis A: Gen., 378 (2010) 144-150

Li ion incorporation in $\mathrm{MgO}$ for oxidative dehydrogenation / cracking of propane: Active site characterization and mechanism of regeneration C. Trionfetti, S. Crapanzano, I.V. Babich, K. Seshan and L. Lefferts

Catalysis Today 145 (2009) 19-26

Selection of mixed conducting oxides for selective oxidation of propane with dense membrane

S. Crapanzano, I.V. Babich and L. Lefferts,

Applied Catalysis A: Gen, in press

Effect of $V$ in $L a_{2} \mathrm{Ni}_{X} V_{1-X} \mathrm{O}_{4+\delta}$ on selective oxidative dehydrogenation of propane: stabilization of lattice oxygen

S. Crapanzano, I.V. Babich and L. Lefferts

Applied Catalysis A: Gen., in press

The influence of $\mathrm{La}_{2} \mathrm{Ni}_{0.9} \mathrm{~V}_{0.1} \mathrm{O}_{4.15+\delta}$ over-stoichiometry variation on selective oxidative dehydrogenation of propane

S. Crapanzano, I.V. Babich, and L. Lefferts

Langmuir, submitted

Structure and performance of $\mathrm{Li}-\mathrm{MgO}$ supported molybdenum oxide for the oxidative cracking of hexane

C. Boyadjian, S. Crapanzano, I.V. Babich, B.L. Mojet, L Lefferts and K. Seshan

Journal of Catalysis, submitted 



\section{Acknowledgements and ringraziamenti}

The end has come for this intriguing, challenging and worthwhile experience called "PhD". This gives me the opportunity to thank many people who were either fundamental for my scientific education, or crucial in cheering up my daily life with their joy, happiness and friendship. Now it is finally the moment to express my gratitude to all of them.

First of all, I would like to thank my friend, mentor, buddy, supervisor, teacher, benchmark, reference point (... and much more) Cristiano, who was the first person to acquaint me with the idea of doing the $\mathrm{PhD}$ in Enschede, who showed me an outstanding daily friendship since my beginning here, who was always available to help me and to answer any question I had, who showed me what it means to be and to act as a scientist. "Who finds a friend, finds a treasure", I found a fortune impossible to describe in words!

Together with Francesca, Vittorio and Elena, you have been my Italian family in Enschede which I will keep in my heart forever.

A special thank you goes to the people who have directly contributed to the scientific development of my project:

Leon, the promoter; your way of teaching science to me was unique and unexpected, but, in the end, it was effective and appreciated: thank you for that, for your criticism and for your challenging attitude which forced me to go beyond what I though was my scientific limit.

Igor, the supervisor; the fact that firstly you were my friend and then my supervisor helped me a lot in expressing myself as a scientist. Thank you for your friendly approach to each and every meeting we had, especially on Friday afternoons after $5 \mathrm{pm}$.

Barbara, the early supervisor; although our collaboration was quite short, you found the way to teach me how to be critical and to develop my own scientific ideas. Thank you for that and for calling me "Maestro": it is always gratifying.

Prof. Seshan and Jan; although you were not directly involved in my project, you were always available to give scientific suggestions and to have discussions. However, what I appreciated the most is your availability to talk about various topics, from football to diving, from news to politics, and much more. 
Prof. H. Bouwmeester and Ir. C. Song; thank you for your scientific help as project partners which helped me to be introduced to the field of dense membranes.

Very warm thanks go to all my colleagues who, above all else, showed their friendship to me:

Bert aka Bertolino, the paranimf; besides the help you gave to me in the lab, I really appreciate your friendship which you showed outside it, while helping me with my bike, the chandelier in my apartment, with the drilling machine and, the most humorous, fixing my broken bed. Thanks a lot for that and for the many funny moments on Friday afternoons, evenings, nights.

Berta, la chica latina; you have been one of the best friends I had in Enschede. We have shared unforgettable moments, we have been very important one another, always supporting each other, and we had a lot of fun dancing and sharing our passion for football. Forever in my heart.

Kumar, the most European Indian,; we started our PhDs at the same time, and we will finish at the same time: in between, thousands of awesome memories and joyful experiences. You have been an excellent friend to me.

Dejan aka Dejo, the man of nicknames; it was a pleasure to meet you, to become friends, to be called Davidenko and to follow your advice about life. I think I have learnt a lot from you, definitely not only about science. Thank you for caring about me.

Sune, the big Dane; since I joined the group you have been a pivotal person for my introduction to the "new society". I will never forget all the dinners and parties at your place and all "the pleas... favours you did to me".

Gacia, the belly dancer; we spent a long time together in Enschede, sharing the good and bad feelings that this experience reserved for us. Thank you for the friendship that you and Bedo (...it was an honor to be called "capitano"!) have always shown to me.

Gemma, the sweet Catalan girl; we started as colleagues who share science, then you became one of the most important people of my experience in Enschede. I will never forget you and the time we spent together in Enschede, Barcelona, Turin, and in Utrecht which was really special.

Iris, the capoeira girl; I had the chance to spend time with you outside the University, discovering your vitality and internal energy. I really enjoyed your 
company very much and your way of thinking. I will never forget the "Pinkpop" festival that we attended together, it was very funny, an explosion of positive energy.

Joao, the house-mate; it was a remarkable experience to share the apartment with you. I really enjoyed chatting with you (well, $90 \%$ listening and 10\% talking), mainly about our common passion, that sport called football, but not exclusively. I am really thankful to you for your huge contribution in improving my English and for your relaxed attitude at home. You have been a very good house-mate and a pleasant friend.

Johannes, the "399 friend"; we have been living in the same student house for one year and we built up a solid friendship. In the rare bad moments, you showed to me your loyalty and friendship and in the good moments you have been a wonderful buddy. I will never forget you, and all our "399 friends" Hasan, Pavlina, Salvo, Dimitri, Karolina, Silvie, Laura, Ruben, Gracia, Maher, Manuela, Fabrizio, Nico, Jordi, Hilal, Georgos, Bro, Ivo, Simao and many many more.

Karin, the very friendly technician; thank you for your availability in the lab and for being so delightful during coffee breaks at UT and dinners all around Enschede.

Lianne, the "friendly smile" lady; you were the first CPM staff member who interacted with me and I immediately saw that you were a great person. I really enjoy your positive attitude to life and your daily smiling to me.

Jeroen, the "tsjonge jonge jonge" guy; it was very nice to be in the lab with you, always available to talk with me about everything, mainly football, but not science. I really enjoy your Italian way to welcome me in the lab everyday ("Buongiornooooo....") and your very funny and loud exclamation: "tsjonge jonge jonge!"

Željko, the "always available friend"; since you joined the group I had the chance to know you better and to enjoy your presence in the office, which was very valuable to me. You have been always immediately available for any question I had, always eager to share your enormous knowledge with me and you have lightened my time in the office with funny discussions and sense of humor. You are a very good friend.

Vijay, the office-mate; we have shared the office for years, which have meant to share the joys and the bad feelings regarding the work. Thank you for your loyalty, dependability and your constant support to pursue the final goal, the $\mathrm{PhD}$ degree. 
Marijana, aka "Maya with y"; we have spent a lot of time together, sharing science in the lab and at meetings, but, at the same time, a lot of fun and laughing during parties and daily life. I really enjoyed your company and I hope that one day I will have the honor to dance with you.

Chris, the "youdontknownoootthing" guy; many funny moments to remember, especially joking about the Italian way to speak English (Valentino Rossi rules) and the hilarious discussions during the Friday drinks. I am really glad that you joined the group, bringing a bit of "freshness" to it.

Tom, the singer; our friendship started from the first moment you joined the group, sharing your big knowledge and our big passion for Rock music. I really enjoyed our daily conversations, filled with your good humor. I leave you the honor of being "The President of the Borrel", being sure that you will do a great job.

Son, the sport-mate; it was enjoyable to play tennis with you, and excellent to weekly play football as well. You are a nice person, with a unique sense of humor.

Inga, the Russian from Mexico; it was excellent to meet you, to share many parties and to learn your different perceptions of life.

Shilpa, the "aayiii - aayiaaa" girl; we had not the chance to share a long time in Enschede but anyhow I have seen the beauty, the vitality and the joy which are inside you, and I have enjoyed them. Thank you for your cheery company, especially during the Friday drinks.

Ruben, the "always available" technician; thank you for being always available for any technical help, from computer to equipment, from bicycle to whatever else. It was nice to do sports with you (playing football weekly and sometimes tennis) and to talk about FC Twente and Juventus every Monday.

Arturo, el mexicano; it was short but anyhow I had the chance to know you a bit, to enjoy your cheery manner and to share with you a bit of Italian-Spanish language, which is always welcome.

Masoud, the traveller; we had very short time to know each other but I really appreciate your constant smiling and your polite way to greet me every day. Thank you for that and good luck with the CPM football team.

Hrudya, the Indian girl; thank you for being always an honest and reliable person with me. It was brilliant to learn from you about your culture and your special diet. 
Dennis, "Don Pilot"; it was amusing to joke with you about the "sicilyanity" of my surname and thank you for helping me with pictures, poster and light.

Arie, the new staff member; thank you for your precious suggestions about $\mathrm{PhD}$ life.

Sabine, the new secretary; thank you for your diligence at work and for the time we shared during lunch.

Lastly a big thank you to all of those people I have not mentioned but probably should have: you have all contributed to my life in Enschede with your friendship and happiness...

...because, first of all it was an outstanding human- and life- experience which I will take with me wherever I will go, forever and ever, and afterwards, it was a valuable scientific and professional education.

Un grandissimo e sentito ringraziamento va a tutti coloro i quali mi hanno supportato ed incitato dall' Italia: benché molto distanti il vostro calore non é mai mancato.

Un grazie particolare a:

mamma e papà; per aver sopportato, a malincuore, la mia lontananza, sicuri della validità e dell'importanza della mia scelta, benché, in certe occasioni, fossi io quello a metterne in dubbio il valore. Il vostro è stato un aiuto molto prezioso.

Marta, mia sorella; per essere stata sempre al mio fianco, periodicamente presente ad Enschede, allietando così le mie giornate con la tua presenza. Le tue parole d'incoraggiamento e la tua visione della situazione sempre lucida ed attenta, mi hanno aiutato e guidato nelle varie scelte e decisioni. Grazie.

Il Mone, "l'artista di vita"; per aver sempre creduto in me e per avermi sempre spronato a perseverare verso l'obiettivo finale, mai dubbioso della felice conclusione. La tua voce al telefono e quella impressa su cd mi hanno dato una carica difficile da descrivere con le parole... "Perché ci sono viaggiatori che si bruciano presto, che non chiedono il resto e a volte muoiono presto..." (cit.): beh, direi che noi siamo sopravissuti alla grande! 
Darione e Manu, "quel qualcosa in più"; per il vostro calore e la vostra vicinanza dimostrati soprattutto nei momenti difficili, con i fatti piuttosto che con le parole... perché, in certe occasioni, una visita inaspettata oppure un piatto di gnocchi al pomodoro ed una cotoletta alla milanese valgono più di mille parole. Grazie di cuore.

Orla, Chicco, Pozza e Luca, gli "amici del viale"; per i vostri sms, e-mail, chat su internet che mi hanno rallegrato le serate e fatto sentire meno solo. Il vostro affetto e la vostra amicizia sono doni preziosi, che custodisco gelosamente.

Fab, Edo, Ale e Cizzo, gli "amici di tante avventure"; per aver condiviso con me tutto ciò che vi succedeva intorno, come se io non fossi mai partito, ansiosi di un mio parere o consiglio. Nel Bene (Alice e Tommasino, due di noi!) e nel Male siamo sempre stati, siamo, e saremo una squadra... vincente!

Ire, Dona e Fra, gli "amici dell'università"; benché la distanza abbia limitato le nostre serate, risate ed i nostri momenti "pignotici", ogni qualvolta tornassi a Torino siete sempre stati presenti e desiderosi di trascorrere del tempo in mia compagnia. L'ho apprezzato molto, come apprezzo l'amicizia che mi avete sempre dimostrato. 